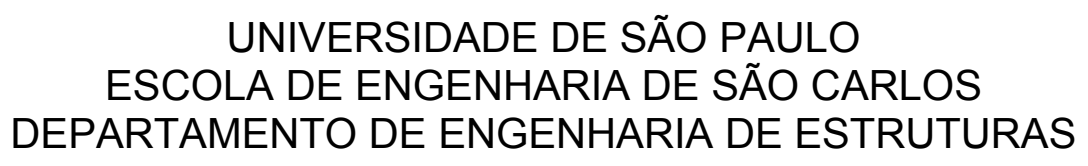

\title{
ANÁLISE TEÓRICA-EXPERIMENTAL DE PERFIS DE AÇO FORMADOS A FRIO DEVIDO À INSTABILIDADE POR DISTORÇÃO NA FLEXÃO
}

Julio Cesar Martins da Silva

Dissertação apresentada à Escola de Engenharia de São Carlos da Universidade de São Paulo, como parte dos requisitos para obtenção do título de "Mestre em Engenharia de Estruturas".

Orientador: Prof. Dr. Roberto M. Gonçalves 
Dedico este trabalho a Deus, à minha mãe (Dna. Teresinha Lima) e às memórias de meu avô Antônio Joaquim e do amigo de graduação e pósgraduação Wellington Yamamoto. 


\section{AGRADECIMENTOS}

À minha família por ser a base de minha formação e o grande motivador de minhas atitudes.

Ao professor Roberto Martins Gonçalves pela orientação, compreensão e apoio desempenhado na realização deste trabalho.

Aos professores Maximiliano Malite e Sérgio Proença pela colaboração no desenvolvimento do trabalho.

Ao professor Carlos Eduardo Javaroni da Universidade Estadual Paulista, Campus de Bauru, pela colaboração na realização deste trabalho e ao apoio produzido no desenvolvimento experimental do projeto.

À Adriana Barticioti pela motivação, paciência e compreensão durante $o$ andamento do trabalho.

Ao Conselho Nacional de Desenvolvimento Científico e Tecnológico (CNPq) e a Fundação de Amparo a Pesquisa do Estado de São Paulo (FAPESP) pelo auxílio financeiro.

Agradeço ao apoio dos amigos, colegas, professores e funcionários do Departamento de Estruturas da EESC que colaboraram de forma direta e indireta para a realização deste trabalho. 


\section{SUMÁRIO}

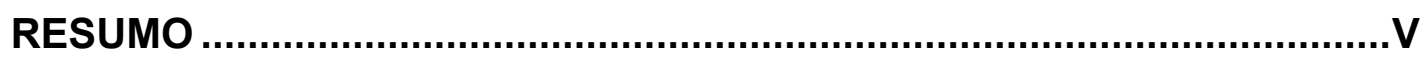

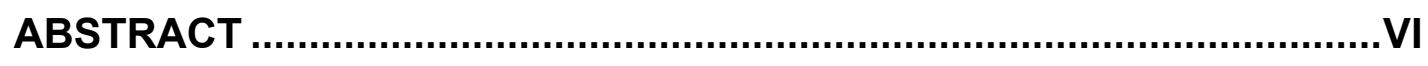

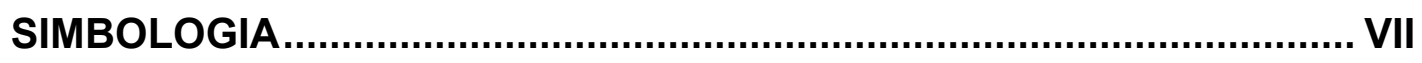

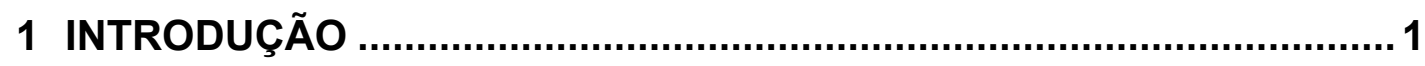

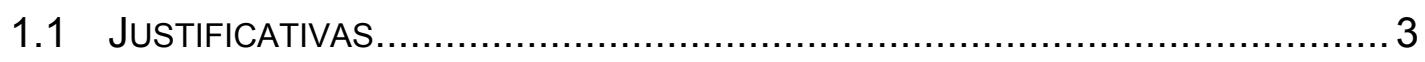

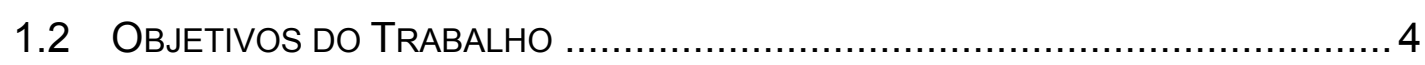

2 PERFIS FORMADOS A FRIO

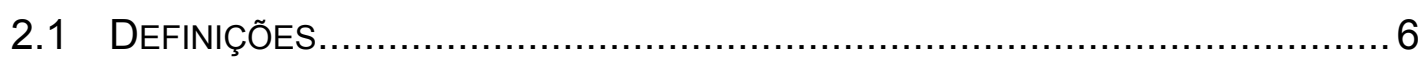

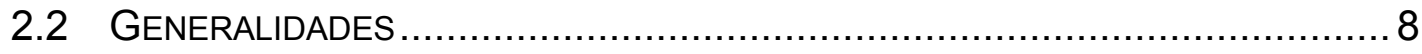

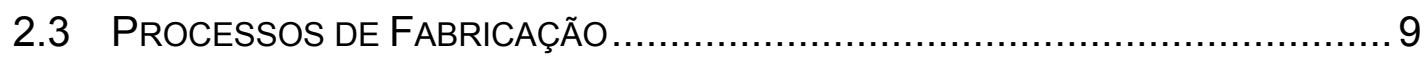

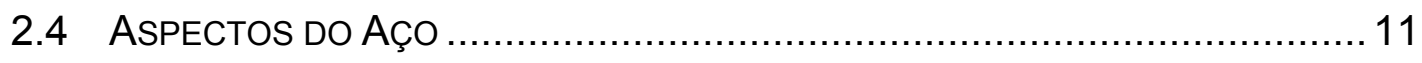

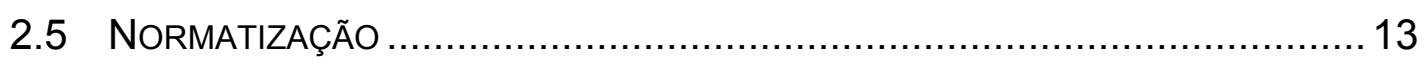

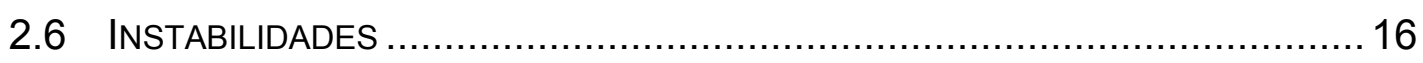

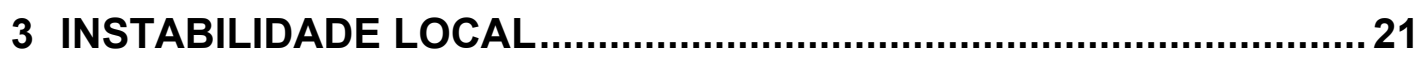

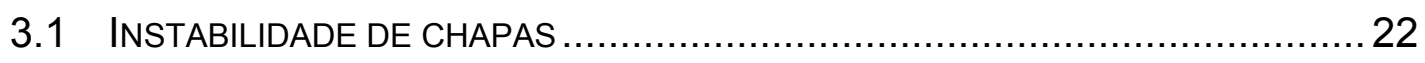

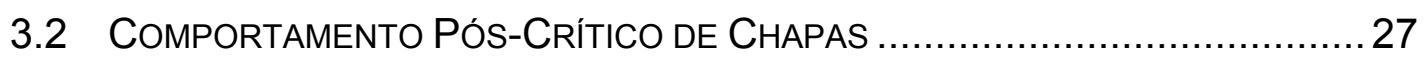

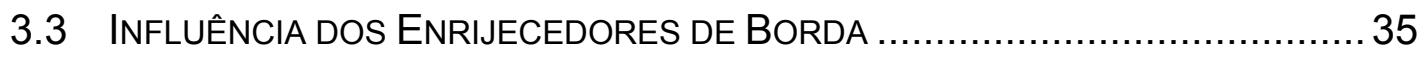

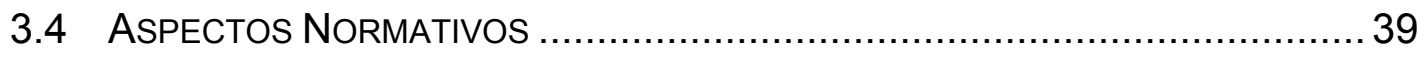

4 INSTABILIDADE DISTORCIONAL ....................................................... 41

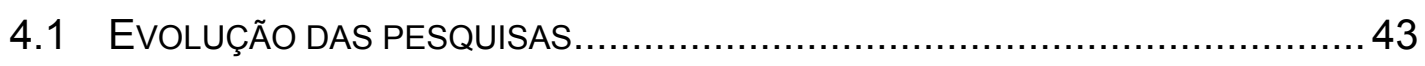

4.2 Modelo de Lau \& Hancock Para Perfis Submetidos À Compressão 47

4.2.1 Hipóteses de Cálculo ........................................................ 49

4.2.2 Formulação Analítica - Perfil Submetido à Compressão......... 49

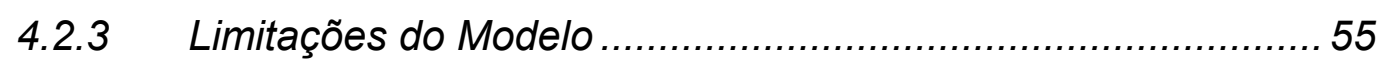

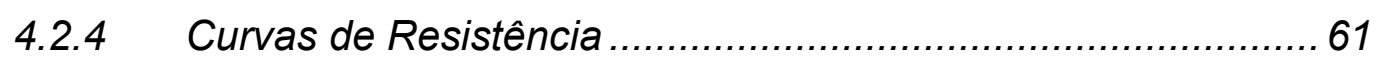

4.2.5 Modelo de Lau \& Hancock para perfis submetidos à Flexão ... 65 
4.2.6 Formulação Analítica - Perfil Submetido à Flexão ..................67 67

4.2.7 Modelo de Sharp........................................................... 71

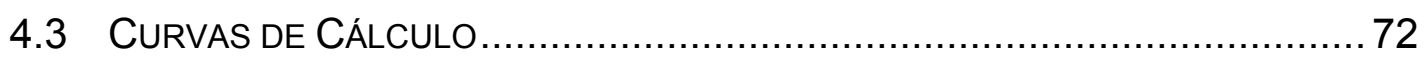

4.4 SimplificAÇÃO do MOdELO DistorcionAl DE HANCOCK PARA PERFIS

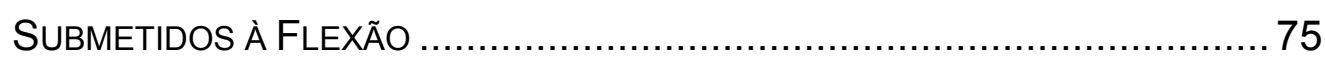

4.5 INFLUÊNCIA DE TRAVAMENTOS NOS MODOS DE INSTABILIDADE ESTRUTURAL 76

4.6 Modelo de Peköz \& Soroushian Para Perfis Conectados a PainéIS

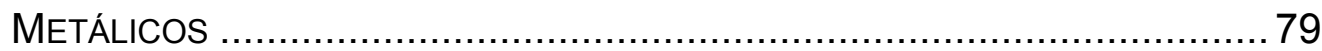

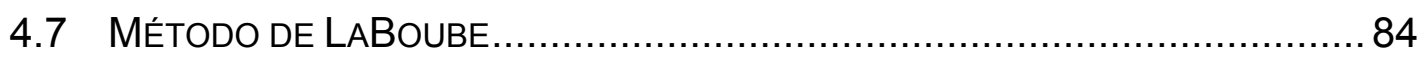

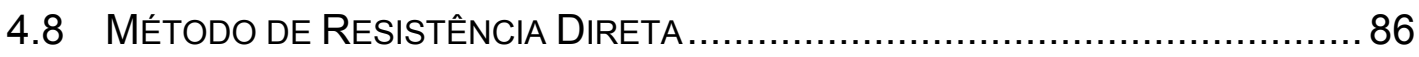

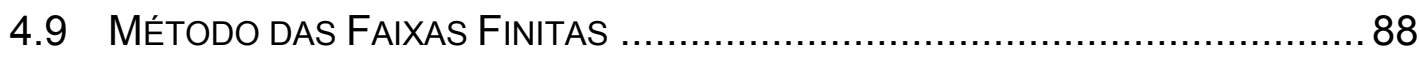

4.10 CURVAS DE INSTABILIDADE PARA MRD ........................................ 91

4.10.1 Instabilidade Local ......................................................... 92

4.10.2 Instabilidade Distorcional .............................................. 93

4.10.3 Instabilidade Global ................................................... 95

4.10.4 Interação entre os Modos de Instabilidade ......................... 97

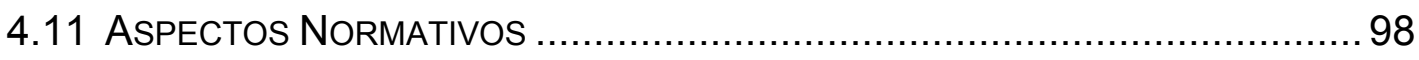

4.11.1 Perfis fletidos Isolados .................................................... 98

4.11.2 Perfis fletidos conectados a painel..................................... 99

5 PROGRAMA EXPERIMENTAL ................................................... 100

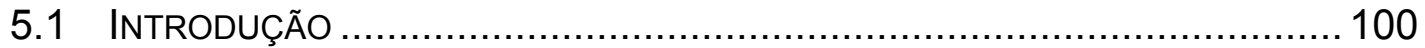

5.2 Propriedades Geométricas dos Perfis ...................................... 100

5.3 PROPRIEDAdES MECÂNICAS DO AÇO ........................................ 102

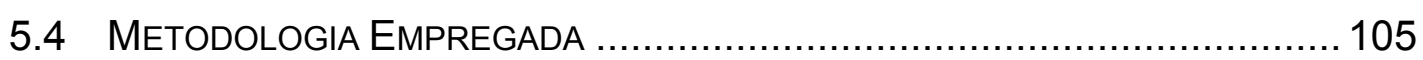

5.5 ModELOS ENSAIAdOS ......................................................... 109

5.6 ApRESENTAÇÃO E ANÁLISE dos Resultados ................................. 112

5.6.1 Análise de Instabilidade via Método das faixas finitas ........... 126

6 CONCLUSÕES .......................................................................... 131

6.1 SugESTÕES PARA TRABALHOS FutUROS ..................................... 132

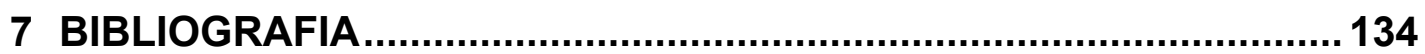


ANEXO I - GRÁFICOS: FORÇA X DESLOCAMENTOS 139

ANEXO II - GRÁFICOS: GIROS DAS MESAS DOS PERFIS. 147

ANEXO III - GRÁFICOS DE GIRO DOS PERFIS. 154

ANEXO IV - GRÁFICOS FORÇA X DEFORMAÇÃO 162 ANEXO V - ANÁLISE DE INSTABILIDADE VIA MÉTODO DAS FAIXAS FINITAS 170 


\section{RESUMO}

SILVA, J.C.M. Análise teórica-experimental de perfis de aço formados a frio devido à instabilidade por distorção na flexão, 2004. Dissertação (Mestrado) - Escola de Engenharia de São Carlos, Universidade de São Paulo.

Apresenta-se neste trabalho um estudo teórico-experimental sobre a instabilidade distorcional de perfis formados a frio submetidos à flexão. A instabilidade distorcional se faz comum na presença de tensões de compressão atuando sobre perfis enrijecidos e fabricados com aços de elevada resistência mecânica.

A parte teórica abrange os métodos de cálculo analíticos e numéricos para a análise de instabilidade distorcional de perfis de seção aberta formados a frio. Na parte experimental inclui-se o estudo de perfis formados a frio com seções do tipo $U$ enrijecidos submetidos aos ensaios à flexão. Nestes ensaios variou-se a altura de alma e espessura de chapa procurando-se abranger maior número de condições geométricas para análise da estabilidade distorcional. Inclui-se também a análise de instabilidade numérica dos perfis do programa experimental através do Método de Resistência Direta via Método das Faixas Finitas.

Com base nos resultados experimentais, numéricos e na análise teórica do problema, verificou-se o procedimento adotado pela NBR14762/2001 e efetuou-se comparação entre curvas de resistência propostas para o dimensionamento de perfis formados a frio à flexão.

Foi verificado que o fenômeno de instabilidade distorcional pode ser o estado limite último crítico para o dimensionamento dos perfis formados a frio.

Palavras-chave: Estruturas metálicas; perfis formados a frio; instabilidade distorcional; Métodos das Faixas Finitas. 


\section{ABSTRACT}

SILVA, J.C.M. Theoretical-experimental analysis of cold-formed steel for distortional buckling in flexural members, 2004. Dissertação (Mestrado) - Escola de Engenharia de São Carlos, Universidade de São Paulo.

This work present a study theoretical-experimental about the distortional buckling of cold-formed steel members under bending. The distortional buckling is common for members with edge-stiffened sections and manufactured with steel of high strength.

The theorical part present the analitic and numerical methods for stability analysis by distortional buckling. The experimental part included the study of cold-formed with sections channel altering flange width and thickness by proof in flexural members. Included too the numerical analysis by Direct Strength Method in Finite Strip Method on members with the same configurations of experimental investigation.

Based on the experimental measurements, numerical analysis and in the theorical analysis of work, verified the procedures adopted in Brazilian code NBR 14762/2001 and compared with others distorional curve proposed for to design of cold-formed members under bending.

Verified that the distortional buckling may control the design being the critical mode for the ultimate limit state.

Key-words: Steel structures; cold-formed members; distortional buckling; Finite Strip Method. 


\section{SIMBOLOGIA}

\section{Letras romanas maiúsculas}

A área bruta da seção transversal da barra;

$\mathrm{A}_{\text {ef }} \quad$ área efetiva da seção transversal da barra;

$\mathrm{C}_{\mathrm{w}} \quad$ constante de empenamento da seção

D largura nominal do enrijecedor de borda

E módulo de elasticidade do aço (205 $000 \mathrm{MPa}$ )

$\mathrm{F}_{\mathrm{Rd}} \quad$ força resistente de cálculo, em geral

$\mathrm{F}_{\mathrm{Sd}} \quad$ força solicitante de cálculo, em geral

$\mathrm{F}_{\mathrm{X}} \quad$ força transversal ao elemento sujeito à flambagem por distorção

G módulo de elasticidade transversal do aço $(0,385 \mathrm{E}=78925 \mathrm{MPa})$

$\mathrm{I}_{\mathrm{x}} ; \mathrm{I}_{\mathrm{y}} \quad$ momentos de inércia da seção bruta em relação aos eixos principais $x$ e $y$, respectivamente

$I_{x y}$ produto de inércia da seção em relação ao sistema de coordenadas $x y$

$\mathrm{I}_{\mathrm{t}} \quad$ momento de inércia à torção uniforme

$K_{x} L_{x} \quad$ comprimento efetivo de flambagem da barra em relação ao eixo $x$

$\mathrm{K}_{\mathrm{y}} \mathrm{L}_{\mathrm{y}} \quad$ comprimento efetivo de flambagem da barra em relação ao eixo y

$\mathrm{K}_{\mathrm{t}} \mathrm{L}_{\mathrm{t}} \quad$ comprimento efetivo de flambagem da barra por torção

comprimento de barra, no geral

L comprimento sem contenção transversal do elemento sujeito à distorção

$L_{d} \quad$ comprimento da meia onda longitudinal associada à tensão convencional de flambagem elástica por distorção

$\mathrm{L}_{0} \quad$ comprimento de referência empregado no cálculo da tensão convencional de flambagem elástica por distorção

M momento fletor solicitante

$M_{\text {dist }} \quad$ momento fletor de flambagem por distorção

$\mathrm{M}_{\mathrm{Rd}} \quad$ momento fletor resistente de cálculo

$M_{S d} \quad$ momento fletor solicitante de cálculo

$\mathrm{N}_{\mathrm{c}, \mathrm{Rd}}$ força normal de compressão resistente de cálculo 


\begin{tabular}{|c|c|}
\hline $\mathrm{N}_{\mathrm{c}, \mathrm{Sd}}$ & força normal de compressão solicitante de cálculo \\
\hline $\mathrm{N}_{\mathrm{cr}}$ & força normal crítica de flambagem elástica por distorção \\
\hline $\mathrm{N}_{\mathrm{e}}$ & $\begin{array}{l}\text { força normal de flambagem elástica } \\
\text { força normal empregada no cálculo da tensão convencional de } \\
\text { flambagem elástica por distorção }\end{array}$ \\
\hline $\mathrm{N}_{\mathrm{s}, \mathrm{Rd}}$ & $\begin{array}{l}\text { força normal de compressão resistente de cálculo do enrijecedor } \\
\text { de alma }\end{array}$ \\
\hline $\mathrm{V}_{\mathrm{Rd}}$ & força cortante resistente de cálculo \\
\hline $\mathrm{V}_{\mathrm{Sd}}$ & força cortante solicitante de cálculo \\
\hline $\mathrm{W}_{\mathrm{c}}$ & $\begin{array}{l}\text { módulo de resistência elástico da seção bruta em relação à fibra } \\
\text { comprimida }\end{array}$ \\
\hline $\mathrm{W}_{\text {ef }}$ & $\begin{array}{l}\text { módulo de resistência elástico da seção efetiva referente ao início } \\
\text { de escoamento da seção efetiva }\end{array}$ \\
\hline
\end{tabular}

\section{Letras romanas minúsculas}

b

$b_{c}$

$b_{\text {ef }}$

$b_{w}$

C

d

$f_{u}$

$f_{y}$

h

$h_{x} ; h_{y}$

$\mathrm{k}$

$\mathrm{k}_{\mathrm{x}}$

$\mathrm{k}_{\phi}$

largura do elemento, é a dimensão plana do elemento sem incluir dobras

largura do trecho comprimido de elementos sob gradiente de tensões normais

largura efetiva

largura nominal da alma

comprimento, na direção longitudinal da barra, de atuação da força aplicada

largura do enrijecedor de borda altura da seção

resistência à ruptura do aço na tração

resistência ao escoamento do aço

largura da alma (altura da parte plana da alma)

coordenadas $x$ e $y$, respectivamente, do apoio da seção constituída pela mesa e enrijecedor de borda em relação ao seu centróide

coeficiente de flambagem local

constante de rigidez à flexão do elemento sujeito à distorção

constante de rigidez à rotação empregada no cálculo da tensão convencional de flambagem elástica por distorção 
q força uniformemente distribuída de referência

r raio de giração da seção bruta

raio de giração polar da seção bruta em relação ao centro de torção

$r_{x} \quad$ raio de giração da seção bruta em relação ao eixo principal $x$

$r_{y} \quad$ raio de giração da seção bruta em relação ao eixo principal y

t $\quad$ espessura da chapa ou do elemento

$x_{0} \quad$ coordenada do centro de torção, na direção do eixo $x$, em relação ao centróide

distância entre o eixo neutro da seção bruta e o centróide da barra

$\mathrm{y}_{\mathrm{c}} \quad$ comprimida equivalente

yo coordenada do centro de torção, na direção do eixo $y$, em relação ao centróide

\section{Letras gregas minúsculas}

$\alpha_{1} a \alpha_{3} \quad$ parâmetros empregados no cálculo da tensão convencional de flambagem elástica por distorção

$\beta_{1}$ a $\beta_{4} \quad$ parâmetros empregados no cálculo da tensão convencional de flambagem elástica por distorção

parâmetro empregado no cálculo da tensão convencional de

$\eta \quad$ flambagem elástica por distorção

$\lambda_{\text {dist }} \quad$ índice de esbeltez reduzido referente à flambagem por distorção

$\lambda_{\mathrm{p}} \quad$ índice de esbeltez reduzido do elemento

$\lambda_{\mathrm{pd}} \quad$ índice de esbeltez reduzido do elemento calculado com a tensão $\sigma_{\mathrm{n}}$

$\mu ; \mu_{0} \quad$ parâmetros empregados no cálculo de $\mathrm{N}_{\mathrm{cr}}$

$v \quad$ coeficiente de Poisson do aço, adotado igual a 0,3

$\theta \quad$ ângulo entre o plano da mesa e o plano do enrijecedor de borda simples

$\rho$ fator de redução associado à flambagem da barra

$\sigma \quad$ tensão normal, em geral

$\sigma_{\text {dist }} \quad$ tensão convencional de flambagem elástica por distorção 


\section{INTRODUÇÃO}

No dimensionamento de estruturas metálicas, o problema da instabilidade de perfis formados a frio possui maior complexidade em comparação aos perfis laminados/soldados. A principal causa dessa complexidade está diretamente ligada à elevada esbeltez dos perfis. Por essa razão, os perfis formados possuem alta sensibilidade aos problemas de instabilidade.

Atualmente, a aplicabilidade e a liquidez no consumo dos perfis formados estruturais transformaram este tipo de perfil em uma importante classe dentro da construção metálica brasileira. Entretanto, o aumento do consumo de perfis formados impulsionou o desenvolvimento tecnológico tanto da fabricação de aços estruturais de elevada resistência mecânica quanto da melhoria dos processos de produção. Esses rumos permitiram simultâneo avanço científico no domínio do comportamento estrutural dos mesmos. Conseqüentemente, promoveu-se economia no consumo de aço estrutural através da redução das espessuras de chapa e do maior enrijecimento de formas das seções transversais. Em razão disso, ocorreu o surgimento do fenômeno de instabilidade distorcional.

A instabilidade distorcional é um fenômeno recente de estudos e caracteriza-se como um modo local de instabilidade. A distorção do perfil consiste na alteração da geometria original da seção transversal pela rotação e translação dos elementos submetidos à tensão de compressão. Este modo de instabilidade se faz comum na presença de enrijecedores que geram vinculação na direção longitudinal a elementos planos constituintes de perfil de seção aberta. Assim, o modo de instabilidade distorcional pode 
ser um estado crítico no dimensionamento de estruturas metálicas constituídas de perfis formados a frio.

O modo de instabilidade distorcional para os perfis formados foi profundamente estudado no início da década de 80 pelo professor Hancock da Universidade de Sydney, Austrália. Hancock propôs um modelo de cálculo analítico baseado no conceito de instabilidade por flexo-torção de coluna apoiada elasticamente, objetivando o cálculo da tensão crítica de instabilidade por distorção.

A importância do modelo de Hancock está na maior cobertura dos casos de instabilidade distorcional, não verificada nas principais normas específicas. O procedimento de Hancock permite o dimensionamento desse estado limite último para perfis formados submetidos tanto à flexão e quanto à compressão. Esse procedimento de cálculo tem o reconhecimento internacional e integra a NBR $14762 / 2001^{1}$ da ASSOCIAÇÃO BRASILEIRA DE NORMAS TÉCNICAS (ABNT). A Escola de Engenharia de São Carlos (EESC) da Universidade de São Paulo (USP), Departamento de Engenharia de Estruturas (SET), através da representação do prof. Dr. Maximiliano Malite, teve importante colaboração no desenvolvimento da NBR14762.

O presente trabalho está inserido no conjunto de estudos da Área de Estruturas Metálicas do SET e possui o fomento financeiro da Fundação de Amparo à Pesquisa do Estado de São Paulo (FAPESP) e do Conselho Nacional de Desenvolvimento Científico e Tecnológico (CNPq).

Nesse trabalho foram analisados os aspectos teóricos e experimentais relativos aos perfis de aço formados a frio submetidos à flexão, especificamente ao estado limite último caracterizado pela flambagem por distorção.

Em outra situação pode ser encontrada a ocorrência do fenômeno distorcional de perfis formados a frio, como é o caso de terça conectada a painéis metálicos. O modelo analítico de Peköz \& Soroushian e o modelo empírico de LaBoube são os modelos que estudam tal situação. Os métodos analíticos para o cálculo da resistência de perfis formados estão sendo 
questionados na atualidade pelo conservadorismo das curvas de resistência devido à análise isolada dos componentes formadores da seção transversal. Com isso, métodos de resistência direta que analisam a seção transversal como um todo, vêem sendo propostos. Existe uma tendência futura para a substituição dos métodos analíticos pelos métodos de resistência direta em razão das vantagens oferecidas. Os métodos de resistência direta oferecem maior flexibilidade, praticidade e rapidez na determinação das tensões críticas para todos os modos de instabilidade dos perfis formados.

Além do aspecto teórico-experimental, foi também desenvolvido um estudo em simulação numérica pelo cálculo da resistência direta através do método das faixas finitas. Observa-se que o programa utilizado foi desenvolvido por Ben Schafer, professor da Universidade Johns Hopkins, Estados Unidos.

Os perfis analisados foram de seção transversal do tipo $U$ enrijecido, com características geométricas escolhidas de tal forma a proporcionar o modo de instabilidade desejado.

O desenvolvimento experimental foi realizado na Faculdade de Engenharia de Bauru (FEB) da Universidade Estadual Paulista (Unesp) em parceria com o prof. Dr. Carlos Eduardo Javaroni. No desenvolvimento experimental, foram ensaiados 24 conjuntos de perfis formados solicitados à flexão, com variação de espessura de chapa e altura de alma. Cada conjunto de viga caracteriza-se pela união de dois perfis unidos costa-àcosta e montagem em dispositivo distanciador/fixador.

\subsection{Justificativas}

Os principais estudos e análises experimentais utilizando-se perfis formados a frio são os realizados na América do Norte (Estados Unidos), Oceania (Austrália) e Europa (Inglaterra).

No Brasil, os programas de ensaios com os perfis de aço formados a frio ainda são pouco numerosos e existe a necessidade em se dispor de resultados experimentais que reflitam a realidade brasileira, possibilitando comparação entre os trabalhos desenvolvidos em outros países. 
Esta análise teórica e experimental tem como justificativa o estudo dos perfis do tipo $U$ enrijecido verificando a confiabilidade das prescrições contidas na NBR14762. Desse modo, contribuindo para um maior conhecimento sobre o comportamento à flexão dos perfis nacionais e evidenciando o uso racional dos mesmos nas edificações brasileiras.

Justifica-se também o presente trabalho, ao grande número de edificações residenciais, comerciais e industriais, de pequeno e médio porte, que vem sendo construídas no Brasil em estruturas de aço, utilizando esse tipo de perfil.

O estudo do fenômeno da distorção na flexão para os perfis formados ainda é recente no Brasil, mesmo em outros países. Por isso, o trabalho de pesquisa pretende contribuir com informações ao tema e, também, consolidar o grupo de pesquisa da Área de Estruturas Metálicas do SET. O aprofundamento no desenvolvimento da pesquisa permitirá avanços efetivos no conhecimento do fenômeno distorcional aplicado aos perfis formados. Dessa maneira, o trabalho estará gerando novos conhecimentos específicos para a formação qualificada e aplicação desses no ensino de graduação e pós-graduação.

\subsection{Objetivos do Trabalho}

A pesquisa proposta tem como objetivo principal a analise teóricaexperimental do comportamento estrutural de perfis formados a frio de seção aberta submetidos à flexão quanto ao modo de instabilidade distorcional.

Quanto ao comportamento estrutural pretende-se verificar a influência da instabilidade distorcional na forma isolada e na interação com os demais modos de instabilidade.

Os objetivos teóricos foram levantar o maior número de informações científicas sobre o estado limite último caracterizado pela flambagem distorcional de perfis formados solicitados à flexão e à compressão. $\mathrm{Na}$ análise do material obtido, pretendeu-se chegar ao limite do conhecimento do assunto enfocado. 
A parte experimental objetivou ensaiar um conjunto de perfis do tipo $U$ enrijecido submetidos à flexão. Desses ensaios, foram recolhidas informações técnicas sobre o comportamento estrutural e foram comparados em relação aos dados teóricos. Essa comparação teve a finalidade de se obter uma melhor avaliação do momento crítico para os perfis analisados segundo os critérios de projeto adotado na NBR14762.

Javaroni (1999) realizou uma série de ensaios à flexão cujos estudos analisaram os diversos modos de instabilidade para as seções tipo $U$, tipo $U$ enrijecido e tipo $Z$ enrijecido, sob 3 diferentes condições de carregamento e com dois vãos distintos, em um total de 64 perfis ensaiados.

Soma-se a esse conjunto a etapa de análise experimental desse projeto, onde foram ensaiados 48 perfis do tipo $U$ enrijecido para a análise da flambagem por distorção. Nessa etapa, o objetivo principal foi a caracterização do fenômeno da instabilidade por distorção.

Adiciona-se ainda o trabalho realizado por Chodraui (2003) para a análise de instabilidade distorcional, teórica e numérica, de perfis submetidos à flexão e à compressão. Nessa análise Chodraui comparou os resultados obtidos pelo procedimento da norma brasileira, pela análise elástica via método das faixas finitas e pela análise via métodos dos elementos finitos. 


\section{PERFIS FORMADOS A FRIO}

O objetivo do capítulo é apresentar alguns tópicos com caráter geral para o esclarecimento do trabalho.

Neste capítulo serão abordados assuntos básicos relevantes ao estudo de perfis formados a frio a fim de culminar ao problema de instabilidade enfocado, instabilidade distorcional na flexão.

\subsection{Definições}

As seguintes definições serão de grande valia para o entendimento dos procedimentos de cálculo, conceitos e generalidades quanto ao estudo dos perfis formados a frio. As definições foram extraídas diretamente da NBR14762.

Aço virgem: Aço recebido do produtor ou distribuidor antes das operações de formação a frio.

Aço com qualificação estrutural: Aço produzido com base em especificação que o classifica como estrutural e estabelece a composição química e as propriedades mecânicas.

Aço sem qualificação estrutural: Aço produzido com base em especificação que estabelece apenas a composição química.

Perfil estrutural de aço formado a frio: Perfil obtido por dobramento, em prensa dobradeira, de lâminas recortadas de chapas ou tiras, ou por perfilagem, em mesa de roletes, a partir de bobinas laminadas a frio ou a quente, sendo ambas as operações realizadas com o aço em temperatura ambiente. 
Elemento: Parte constituinte de um perfil formado a frio: mesa, alma, enrijecedor, etc.

Elemento com bordas vinculadas [elemento AA]: Elemento plano com as duas bordas vinculadas a outros elementos na direção longitudinal do perfil (Figura 1).

Elemento com borda livre [elemento $A L$ ]: Elemento plano vinculado a outro elemento em apenas uma borda na direção longitudinal do perfil (Figura 1).

Enrijecedor de borda simples: enrijecedor de borda constituído por um único elemento plano (Figura 1).

Elemento com enrijecedor(es) intermediário(s): Elemento enrijecido entre as bordas longitudinais por meio de enrijecedor(es) intermediário(s) paralelo(s) à direção longitudinal do perfil (Figura 1).

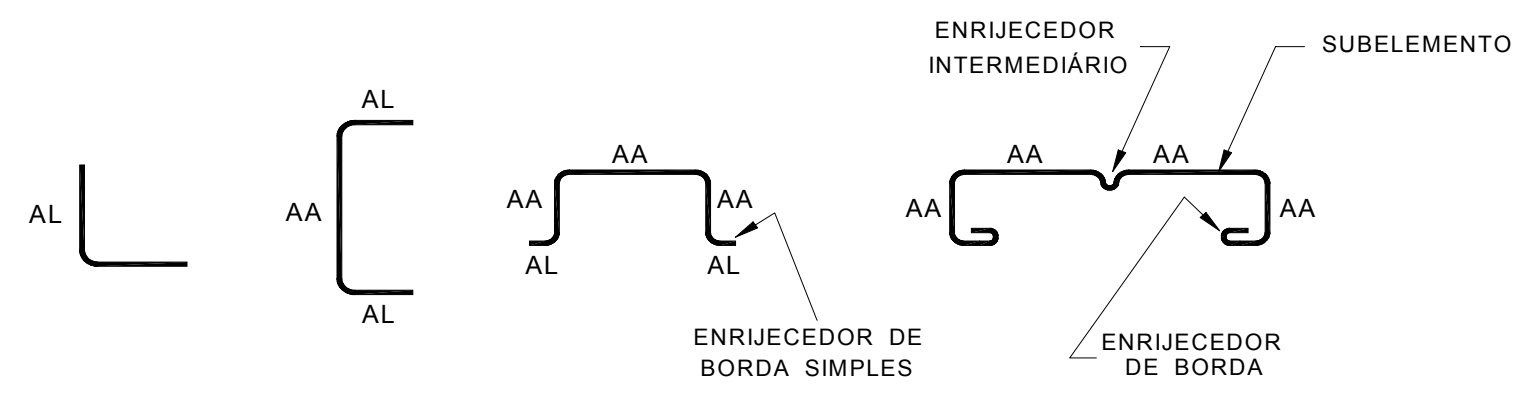

AA - ELEMENTO COM BORDAS VINCULADAS

AL - ELEMENTO COM BORDA LIVRE

Figura 1 llustração dos tipos de elementos componentes de perfis formados a frio. (Fonte: NBR 14762)

Espessura: Espessura da chapa de aço, excluindo revestimentos.

Largura nominal do elemento: Largura total do elemento incluindo as regiões de dobra, medida no plano da seção transversal e empregada para designação do perfil.

Largura do elemento [largura]: Largura da parte plana de um elemento, medida no plano da seção transversal. 
Largura efetiva: Largura de um elemento reduzida para efeito de projeto, devida à instabilidade local.

Relação largura-espessura: Relação entre a parte plana de um elemento e sua espessura.

\subsection{Generalidades}

Na construção metálica em aço de edificações comuns são utilizados para a composição estrutural dos elementos os perfis do tipo laminado, soldado e formado a frio. Estes perfis são normalmente divididos em duas classes em razão da natureza de normalização, responsáveis quanto ao dimensionamento.

Os perfis laminados do tipo americano e os perfis constituídos por chapas planas e soldadas constituem uma classe e são dimensionados pela NBR8800/1986 ${ }^{1}$. Os perfis formados a frio representam a outra classe e são dimensionados pela NBR14762. Os perfis laminados do tipo americano eram utilizados extensivamente na construção metálica brasileira, mas, atualmente nota-se um movimento de substituição por alternativas mais econômicas através de perfis soldados e formados a frio. Ambos fornecem inúmeras vantagens à construção civil e são hoje opções competitivas no mercado frente a outros tipos de materiais. As principais vantagens da construção metálica são as reduções das cargas às fundações, rapidez e praticidade de execução, organização, etc. Entretanto, cada classe pode responder de maneira mais eficiente e econômica de acordo com as necessidades de projeto.

A classe dos perfis formados a frio em relação aos laminados/soldados possui certas vantagens em algumas condições. Para obras de grande porte, onde existe a predominância de carregamentos de elevada intensidade, as melhores soluções para a constituição da estrutura principal são os perfis laminados/soldados. Porém, em elementos secundários, tais como: terças, longarinas, etc, os perfis formados a frio fornecem melhores

1 - NBR 8800/1986: Projeto e Execução de Estruturas de Aço de Edifícios. Observa-se que a NBR8800 está em processo de revisão. 
alternativas. Já em obras de pequeno porte, numa situação a qual encontramos pequena intensidade de carregamentos dificilmente os perfis formados a frio perdem espaço de aplicação. As principais vantagens em relação aos laminados/soldados são:

$\checkmark \quad$ Seções esbeltas - Os perfis formados a frio possuem elevadas relações inércia/massa numa mesma condição geométrica nominal, o que acarreta em uma maior economia do consumo de aço;

$\checkmark \quad$ Flexibilidade geométrica - Devido ao maior número de opções de configuração de seções, os projetistas podem trabalhar com maior liberdade no dimensionamento.

A difusão da utilização dos perfis formados a frio deve-se ao acelerado desenvolvimento do número de aplicações, proporcionando cada vez mais estruturas esbeltas e econômicas. Outro motivo que pode justificar esta difusão está na facilidade de se encontrar o produto no mercado. Facilidade esta não encontrada nos perfis laminados/soldados por que, muitas vezes, o custo é elevado, existe a indisponibilidade de material, os prazos de entrega são extensos ou inadequados, etc.

Os perfis formados a frio vêm conquistando esse mercado e as principais aplicações encontram-se na engenharia civil em construções de edificações, galpões industriais, fôrmas de concretagem, lajes incorporadas, andaimes, escoramentos, etc. Em outras áreas também podemos observar a aplicação desses elementos na elaboração de armários industriais para estocagem (normalmente chamados de "racks"), guarda-corpo para proteção em estradas, sinalização rodoviária, partes componentes de veículos (párachoques de caminhões, por exemplo) e entre outras aplicações. Não podemos esquecer que além de aplicações diretas de seções simples ainda existe a possibilidade da combinação desses perfis para a obtenção das mais variadas formas. Essa combinação pode ser obtida através de ligações soldadas ou parafusadas.

\subsection{Processos de Fabricação}


A obtenção dos perfis formados a frio é dividida basicamente em dois tipos de processos de fabricação:

$\checkmark$ Perfilação;

$\checkmark$ Dobramento.

Os processos de fabricação dos perfis conceitualmente não diferem um do outro. O conceito está na preparação da chapa seguida da conformação mecânica, com as características pré-definidas. Na preparação busca-se obter lâminas (tiras) de aço nas larguras correspondentes aos desenvolvimentos das características dos perfis desejados. A obtenção da tira é realizada no corte de produtos planos (chapas de aço virgem laminados a quente ou a frio) em guilhotinas. No processo por dobramento utilizam-se tiras de aço e no processo por perfilação bobinas ou tiras de aço, conforme o comprimento do perfil especificado.

Hoje em dia existem empresas no mercado com capacidade de produção de perfis com excelente qualidade e com sistemas totalmente automatizados. Esses sistemas são controlados via comando numérico e permite interação entre os equipamentos, com o mínimo contato humano durante o processo. Assim, obtendo produtos com elevada produtividade. $\mathrm{O}$ avanço tecnológico possibilitou maior flexibilidade nas formas da seção transversal com maior capacidade de enrijecimento das mesmas (Figura 2), o uso de ligas de aço com alto grau de qualidade e resistência mecânica e o incremento no desenvolvimento de sistemas construtivos. Em razão disso, a pesquisa científica foi impulsionada na busca de soluções e metodologias de cálculo para o domínio do conhecimento e do comportamento estrutural desses perfis.

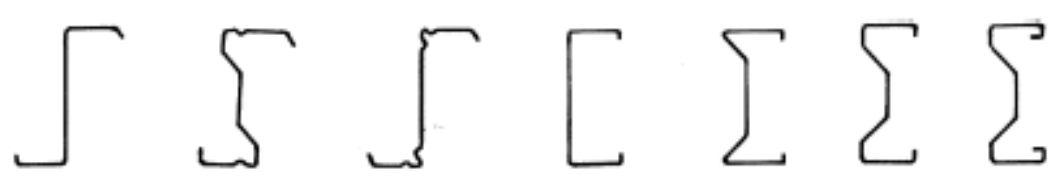

Figura 2 Exemplos de seções de perfis formados a frio, Davies (2000). 
Os processos de fabricação estão evoluindo rapidamente nos últimos anos, mas, no todo, a realidade nacional é bem diferente e os processos manuais em série perduram pelas fábricas.

O processo manual que se destaca na fabricação de perfis é o processo por dobramento pelo uso do equipamento denominado dobradeira. As dobradeiras são prensas hidráulicas que realizam a conformação a frio das tiras em perfis nas mais variadas formas de seção transversal. $O$ comprimento dos perfis é geralmente de 3 ou 6 metros. Após o corte, cada tira é submetida ao processo de conformação dobra-à-dobra das arestas, o que interfere na produtividade do processo (descontínuo).

$\mathrm{Na}$ fabricação de perfis via processo de perfilação, o trabalho é contínuo e a operação é realizada em mesa de roletes por meio de estágios de conformação. Por isso, permite-se maior liberdade nos comprimentos dos perfis e maior capacidade de produção, em comparação com o processo por dobramento. Além da fabricação de perfis, o processo por perfilação é muito empregado na fabricação de telhas metálicas. Verifica-se que na fabricação de perfis para os formatos comuns têm-se restrições quanto à espessura de chapa devido aos equipamentos disponíveis no mercado nacional.

As seções transversais mais comuns dos perfis de aço formado a frio empregadas em projeto de estruturas metálicas são os do tipo $U, U$ enrijecido, cartola, $Z$ e $Z$ enrijecido, respectivamente ilustrados na Figura 3.a à Figura 3.e.

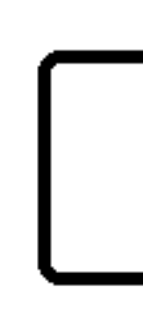

(a)

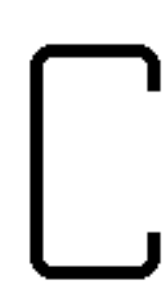

(b)

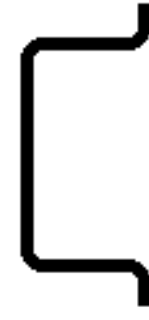

(c) (d)

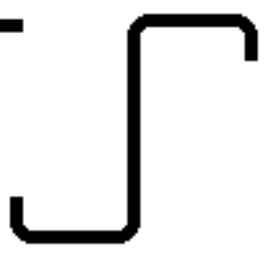

(e)

Figura 3 Seções transversais comuns de perfis formados a frio.

\subsection{Aspectos do Aço}


Os tipos de aços empregados na construção de perfis são os aços com qualificação estrutural indicados nas principais normas mundiais. Os aços mais utilizados são: aço carbono, aço de baixa liga com alta resistência mecânica e o aço de baixa liga com alta resistência mecânica e a corrosão atmosférica.

No mercado brasileiro, vê-se a utilização para a confecção de perfis formados a frio o uso de aços não estruturais, originalmente empregados da indústria mecânica. Esses são controlados somente na composição química e as normas recomendam reduções nos limites de resistência, devido a grande variabilidade desses limites. Hoje no mercado brasileiro encontra-se com certa facilidade perfis de aço com qualificação estrutural na ordem de 300 MPa de resistência mínima ao escoamento. A operação de conformação a frio altera as propriedades mecânicas do aço. O principal efeito do trabalho a frio está na elevação da tensão limite de escoamento e na redução da ductilidade nas regiões das dobras.

O ganho de resistência pode ser utilizado no dimensionamento de perfis segundo o item 6.5.b da NBR14762. Entretanto, pode-se utilizar o aumento da resistência ao escoamento devido ao trabalho a frio desde que não ocorra instabilidade local nos elementos constituintes da seção do perfil.

O aumento do limite de resistência ao escoamento nas regiões conformadas induz os problemas de instabilidade local de chapa e o início de escoamento da seção para as regiões menos influenciadas pelo trabalho a frio, regiões de aço virgem. Hancock (1987) afirma que para aços de elevada resistência ao escoamento (da ordem de $500 \mathrm{MPa}$ ) o efeito do trabalho a frio é eliminado. 


\subsection{Normatização}

O uso de perfis formados a frio na construção metálica se iniciou nos Estados Unidos e na Inglaterra por volta de 1850. Durante o período de 1850 a 1940, a utilização deste tipo de perfil foi pouco expressiva e houve a carência de informações tecnológicas. Tanto as limitações no dimensionamento quanto o real comportamento estrutural culminaram com a necessidade da elaboração de procedimentos técnicos para o auxílio dos projetistas.

Nesse contexto, segundo $\mathrm{Yu}(2000)$ as primeiras pesquisas sobre o comportamento estrutural com ênfase aos perfis formados a frio foram realizadas nos Estados Unidos em 1939 através do patrocínio do AMERICAN IRON AND STEEL INSTITUTE (AISI). A coordenação deste estudo ficou a cargo do professor George Winter, da Universidade de Cornell. Anos depois, com base nas pesquisas do prof. Winter e na experiência prática acumulada, o AISI publicou em 1946 a primeira especificação de projeto para perfis estruturais em aço formado a frio. Desde então, muitos trabalhos de pesquisa e o desenvolvimento de aplicações práticas contribuíram para a formulação das novas edições desta respeitada norma mundial.

O primeiro critério de segurança adotado nas principais normas para o dimensionamento de perfis formados a frio foi o Método das Tensões Admissíveis. Esse tradicional critério de dimensionamento foi usado durante algumas décadas, mas, devido às falhas inerentes, encontra-se hoje em desuso sendo constantemente substituído pelo Método dos Estados Limites. O Método dos Estados Limites envolve todos os aspectos na análise estrutural e inclui a especificação de ações e a análise de segurança. A primeira norma específica a utilizar esse método foi a canadense no ano de 1984 através do CANADIAN STANDARDS ASSOCIATION (CSA). Essa publicação, segundo Javaroni (1993), foi fruto de pesquisas próprias sendo que, na edição anterior de 1974, já se disponibilizava a opção do Método dos Estados Limites. 
No ano de 2001, as entidades normalizadoras da América do Norte uniram-se para a elaboração do North American Specification for the Design of Cold-Formed Steel Structural Members (Especificação Norte Americana para o Dimensionamento Estrutural de Elementos de Aço Formado a Frio). Constitui-se, assim, uma especificação única e válida como referência para os três países: Estados Unidos, Canadá e México. A norma americana do AISI foi o texto base desta união, com contribuições dos demais órgãos dos respectivos países. Observa-se que cada país mantém a sua atual norma específica.

Em nosso país, o emprego estrutural de perfis formados a frio se desencadeou na década de 60. Devido à necessidade, foi publicada em 1967 pela ABNT a NB-143 (Cálculo de Estruturas de Aço Constituídas por Perfis Leves). Esta norma foi elaborada com base na edição da norma americana de 1962. Anos seguintes, a ABNT publicou a NBR6355/1980 (Perfis Estruturais de Aço Formados a Frio) e teve como objetivo a padronização dos aspectos relevantes da fabricação dos perfis de chapa dobrada, nomenclatura utilizada na época. Ambas as normas sofreram o processo de obsolência devido à falta de divulgação e, também, pela estaticidade em razão da falta de revisão. Esses fatos obrigavam os profissionais envolvidos em projetos no país a adoção de normas estrangeiras, o que pode ter gerado algumas distorções quanto à compatibilidade entre especificações. Estas incompatibilidades extendem-se desde diferenças entre coeficientes de segurança até mesmo ao tipo de critério de segurança adotado.

Desse modo, a NBR14762 foi publicada em 2001 e veio de encontro a essa necessidade. O papel importante dessa norma é o de promover a compatibilidade entre as normas brasileiras, uniformizar os critérios de segurança (Método dos Estados Limites) e agregar o conhecimento atual dentro de uma realidade nacional. $\mathrm{O}$ aumento no consumo de perfis de aço formados a frio, a divulgação e a criação de cadeiras específicas nos cursos de graduação, contribuirão para o desenvolvimento da NBR14762 e, 
conseqüentemente, ao avanço científico na área. Por essa razão, o objetivo do trabalho é dar a sua parcela de contribuição ao avanço científico brasileiro ao estudo da instabilidade dos perfis formados a frio. $O$ fenômeno distorcional em perfis formados a frio foi inserido pela primeira vez como especificação de norma pelo AISI. O procedimento de cálculo foi baseado no modelo proposto por Douty em 1962 a qual se analisa a instabilidade distorcional para perfis fletidos em relação ao eixo paralelo à alma com enrijecedores de borda comprimidos, conforme a Figura 4 ilustra.

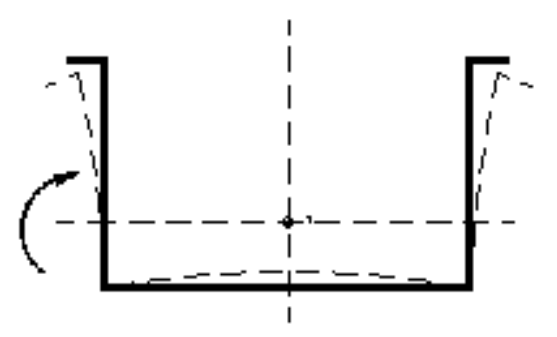

Figura 4 Modelo de Douty para perfil tipo cartola.

Para o caso de perfis fletidos em relação ao eixo paralelo a mesa com enrijecedores de borda a padronização através de procedimento de cálculo foi implantada pela norma australiana/neozelandesa no ano de 1996, AS/NZS $4600^{1}$. Este procedimento foi baseado no modelo de cálculo analítico de Hancock (1987). Hancock provou que, sob certas condições, o fenômeno distorcional poderia ser um estado limite último no dimensionamento de perfis, contradizendo a tradicional norma do AISI.

A NBR14762 agregou estes modelos de cálculo para o dimensionamento estrutural nas respectivas situações. Desta forma, o trabalho reduz esta carência de pesquisa sobre o tema, verificando o comportamento de uma gama de perfis nacionais submetidos à flexão.

1 - AS/NZS 4600: Australian/New Zealand Standard. Cold Formed Steel Strucutres, 1996. 


\subsection{Instabilidades}

A análise do comportamento estrutural de perfis formados a frio é complexa e requer cuidados especiais no tratamento dos fenômenos de instabilidade. Nessa análise, os tradicionais conceitos de equilíbrio entre esforços não mais favorecem a este estudo. Por isso, utilizamos os conceitos da Teoria da Estabilidade Elástica para a análise do comportamento estrutural.

Nesse conceito, a análise por critérios de energia total do sistema permite identificar o tipo de equilíbrio da estrutura. De modo geral, o equilíbrio estrutural classifica-se em estável ou instável.

A ação de carregamentos sobre a estrutura conduz a efeitos de segunda ordem principalmente ligados às não-linearidades geométricas. Os deslocamentos e as deformações da estrutura permitem analisar a estabilidade do equilíbrio. A perturbação do sistema estrutural em decorrência de uma ação externa indica a passagem do tipo de equilíbrio e a mudança de configuração da estrutura. Alteração geralmente ocorrida via ponto de bifurcação.

Segundo Proença (2001), ponto de bifurcação é o ponto a partir do qual as soluções equilibradas deixam de ser únicas, dividindo-se, a partir dele, entre soluções estáveis e instáveis. O ponto de bifurcação corresponde à chamada carga/tensão crítica de flambagem e o modo de instabilidade.

Os fenômenos de instabilidade de barra, em geral, levam ao ganho de rigidez para grandes deslocamentos, não-linearidade geométrica. Dessa maneira, atingi-se cargas/tensões superiores à carga/tensão crítica de instabilidade (Euler). Assim, verifica-se o conceito de resistência pós-crítica, ou seja, a capacidade estrutural de ultrapassar o limite da carga crítica.

As reduzidas espessuras das chapas resultam em elevada esbeltez dos elementos constituintes dos perfis formados a frio. Assim, promovem perdas de estabilidade normalmente com carregamentos bem inferiores àqueles correspondentes a plastificação total ou parcial da sua seção transversal. 
A instabilidade de um perfil é classificada como sendo do tipo local ou global, podendo ocorrer a interação entre os tipos. Os modos locais de instabilidade estão diretamente ligados a flambagem de chapa dos elementos da seção transversal do perfil. Os modos globais referem-se aos problemas de instabilidade do perfil como um todo. A ocorrência da instabilidade de um perfil está condicionada às características geométricas da seção transversal, às condições de vinculação e de carregamentos e ao tipo de solicitação.

O desenvolvimento das aplicações práticas, o emprego de aços com elevada resistência mecânica e o conseqüente aumento da relação largura/espessura dos elementos dos perfis (esbeltez) contribuíram para elevar o grau de complexidade desse estudo. Conseqüentemente, maiores cuidados no tratamento dos fenômenos da instabilidade devem ser adotados.

Anteriormente a estes fatos, o problema da instabilidade local de perfis formados a frio se resumia à instabilidade de chapas constituintes da seção transversal. Dessa forma, surgiu um novo modo de instabilidade local denominado de instabilidade distorcional.

Algumas características diferem os modos de instabilidade local. $\mathrm{Na}$ instabilidade local de chapa caracteriza-se o desenvolvimento de grandes deformações fora do plano sem o deslocamento relativo das arestas (bordas de apoio). Essa característica limita os comprimentos de flambagem às dimensões dos próprios elementos constituintes. A título de ilustração, apresentam-se na Figura 5 o fenômeno da instabilidade local de chapa (elemento com borda livre - tipo $A L$ ) de um perfil tipo $U$ sujeito à flexão e de um tubo quadrado submetido a compressão (elementos com borda vinculada - tipo AA). Como pode ser visto na Figura 5, os comprimentos de flambagem estão limitados à largura dos elementos. Esse fenômeno possui natureza estabilizante e oferece grande capacidade de reserva pós-crítica. 


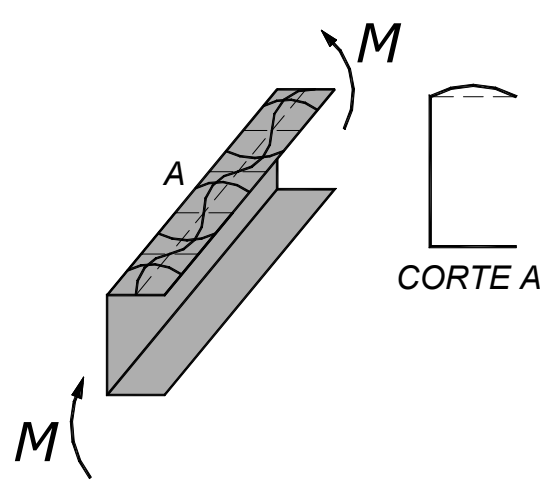

a - VIGA

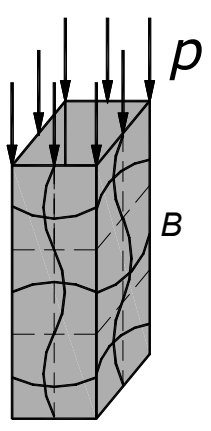

b - PILAR

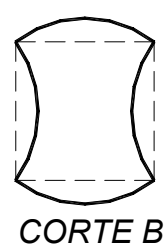

CORTE B

Figura 5 Instabilidade local em perfis submetidos à flexão e à compressão.

$\mathrm{Na}$ instabilidade distorcional observa-se alteração da forma original da seção transversal do perfil com a rotação e a translação de elementos componentes, sem a ocorrência da distorção dos mesmos. Ao contrário da instabilidade local de chapa, na instabilidade distorcional observa-se o movimento de bordas de apoio. O comprimento de instabilidade nesse caso é muitas vezes superior ao da instabilidade local de chapa e verifica-se pequena reserva de resistência pós-crítica.

$\mathrm{Na}$ Figura 6 apresenta-se o fenômeno de instabilidade distorcional de um perfil $U$ enrijecido (elemento com bordas vinculadas - tipo AA) submetido à flexão. Como pode ser visto na Figura 6.a, o comprimento de flambagem distorcional do conjunto mesa superior/enrijecedor de borda é algumas vezes superior à largura da mesa rotacionada.

Para efeito de nomenclatura da NBR14762 e para que não haja confusão de fenômenos de instabilidade, desse ponto em diante a instabilidade local de chapa será denominada de instabilidade local e a instabilidade local distorcional apenas de instabilidade distorcional. 


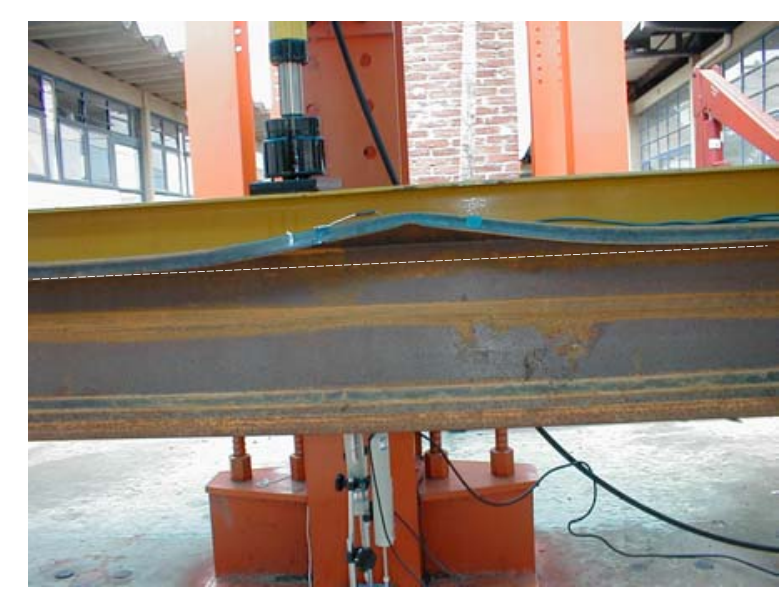

a - Vista lateral

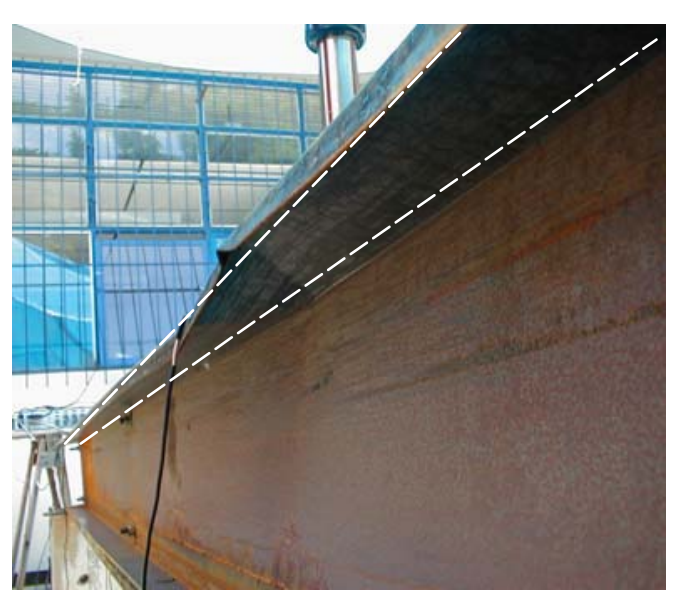

b - Vista longitudinal

Figura 6 Instabilidade distorcional da mesa do perfil $U$ enrijecido. Ensaio à flexão simples realizado na Unesp, campus de Bauru, SP.

A instabilidade global de um perfil formado a frio pode ocorrer basicamente em três formas: instabilidade por flexão, por torção e a combinação dos dois casos. A instabilidade por flexão compreende na instabilidade em torno do eixo de menor inércia, com deslocamentos laterais. A instabilidade por torção pura consiste na rotação da seção transversal em torno de um eixo longitudinal. No terceiro caso, de maior complexidade, aplica-se o conceito em dois tipos de elementos. Para vigas, a ausência de contenção lateral na flexão caracteriza a instabilidade lateral com torção, Figura 7. Para pilares, a compressão desse elemento pode caracterizar a instabilidade por flexo-torção. Em todos os casos de instabilidade global, nos deslocamentos dos perfis são apenas verificados movimentos de corpo rígido, isto é, não existe alteração da geometria da seção transversal, conforme pode ser verificado na Figura 7.

Em comparação com os casos de instabilidade local, na instabilidade global nota-se uma inexistência de reserva de resistência pós-crítica e os comprimentos de flambagem são muitas vezes superiores a instabilidade distorcional. Segundo Fruchtengarten (1995), ao contrário do que ocorre na instabilidade local, a reserva de resistência pós-crítica é muito baixa ou, quando é elevada, corresponde a deslocamentos incompatíveis com a utilização normal da estrutura, não sendo por isso considerada em projeto. 


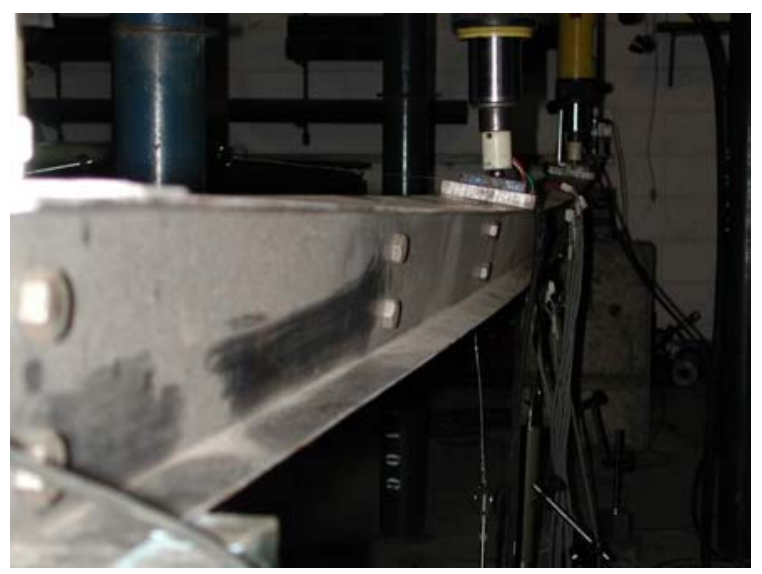

Figura 7 Flambagem lateral com torção de viga I. Ensaio realizado durante a disciplina de Análise Experimental de Estruturas, EESC, 2001.

O estudo da instabilidade lateral com torção não faz parte diretamente do trabalho. Assim, as equações de norma são utilizadas diretamente para as verificações. Preveniu-se o aparecimento desse estado limite último para que o estudo fosse centralizado no fenômeno de instabilidade distorcional na flexão e, secundariamente, no fenômeno de instabilidade local. 


\section{INSTABILIDADE LOCAL}

A instabilidade local é um estado limite último de fundamental importância e está diretamente ligado à ocorrência do fenômeno de flambagem de chapa em elementos isolados da seção transversal. Esse tipo de instabilidade pode ocorrer sob tensão inferior em relação ao surgimento do escoamento total da seção, à instabilidade distorcional ou à instabilidade global do perfil.

Acreditava-se que com o uso de enrijecedores de borda o problema de instabilidade local fosse solucionado considerando-se somente o cálculo da instabilidade global. Entretanto, sabe-se hoje em dia que esse fato também pode gerar a instabilidade do perfil segundo o modo distorcional.

O comportamento pós-crítico de chapa é caracterizado por graduais deslocamentos normais ao plano, simultaneamente ocorrendo redistribuição das tensões. Essa capacidade portante pode exceder a tensão crítica de instabilidade, apresentando elevada reserva de resistência.

A análise do comportamento pós-crítico de chapa foi iniciada com os estudos teóricos do fenômeno segundo a teoria das chapas de grandes deslocamentos. Von Karman foi o primeiro pesquisador a realizar esse estudo através da análise de chapas perfeitas e imperfeitas.

A complexidade do fenômeno de instabilidade de chapa conduziu ao estudo de expressões simplificadas. As várias normas específicas apresentam estas expressões simplificadas para o cálculo de perfis formados de modo a considerar o comportamento não-linear do material, imperfeições de chapa e tensões residuais. 
O fenômeno de instabilidade local pode ocorrer nos perfis formados a frio submetidos à compressão axial, à compressão por flexão e ao cisalhamento.

O modo de instabilidade local interage com os outros modos, em particular interesse com o modo distorcional. Assim, não temos como discutir o tema sem apresentarmos as bases desse assunto a qual possui um século de estudos.

\subsection{Instabilidade de chapas}

A chapa perfeita sob a ação do carregamento uniformemente distribuído e unidirecional apresenta-se com as seguintes características, conforme a Figura 8:

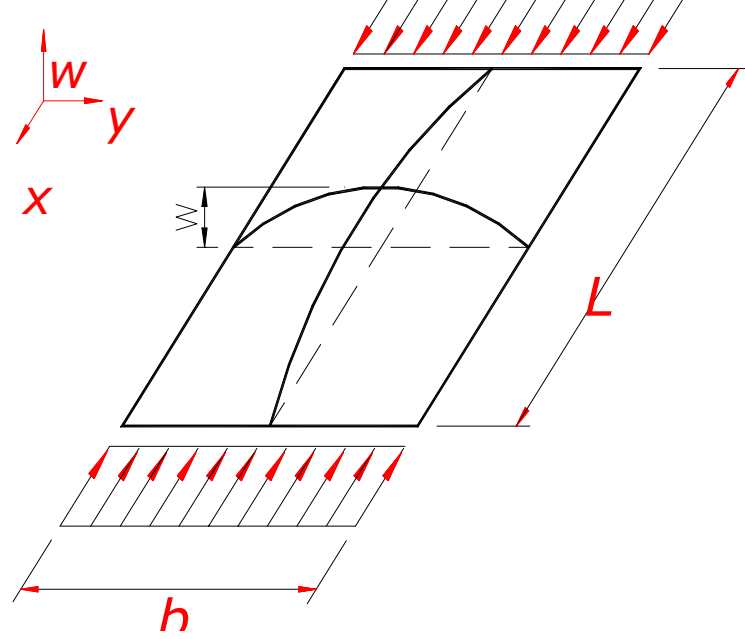

Figura 8 Modo de instabilidade local de chapa perfeita;

Onde:

$\checkmark \quad b$ é a largura da chapa;

$\checkmark \quad L$ é o comprimento da chapa;

$\checkmark$ Vinculação dos bordos: simplesmente apoiada;

$\checkmark$ Deslocamentos $\mathrm{u}, \mathrm{v}$ e w nas respectivas direções dos eixos $\mathrm{x}, \mathrm{y}$ e z;

$\checkmark$ Relação b/L aproximadamente igual a 1. 
A chapa sob essas condições apresenta à instabilidade com deslocamentos $w$ fora do plano caracterizado por curvatura simples.

Para o caso da chapa perfeita o comportamento estrutural corresponde ao gráfico da Figura 9, problema típico de instabilidade por ponto de bifurcação.

Como podemos analisar no gráfico da Figura 9, o trecho $A B$ corresponde ao campo de equilíbrio estável da chapa. Condição de equilíbrio esta com energia potencial estacionária mínima. Ao ponto $B$ denomina-se ponto de bifurcação onde, por definição, as soluções estáveis deixam de serem únicas. $\mathrm{O}$ trecho $\mathrm{BC}$ apresenta a faixa de equilíbrio instável da estrutura. $\mathrm{O}$ ponto $\mathrm{C}$ indica que a estrutura está com energia potencial estacionária máxima e que houve uma perturbação externa causando a mudança de configuração do sistema estrutural, ponto D. Os níveis de energia potencial estacionária podem ser observados na Figura 10.

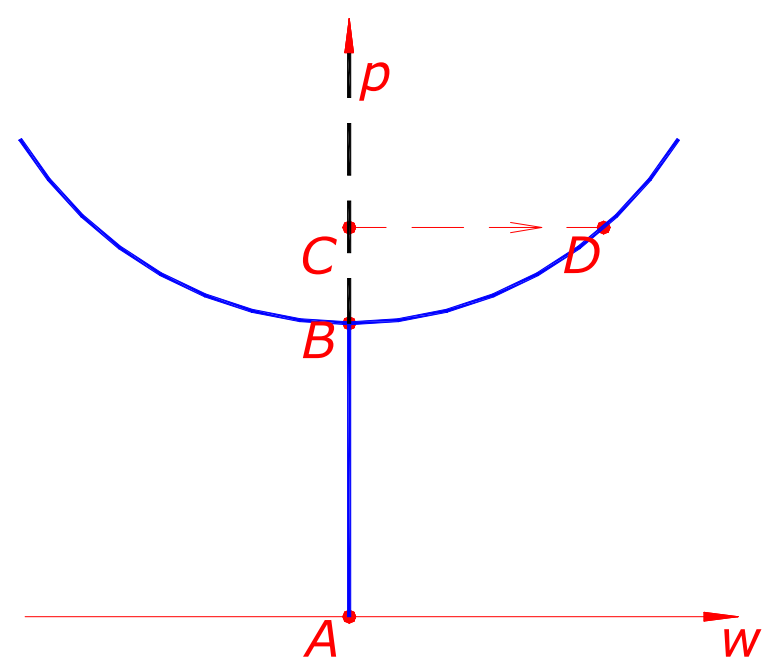

Figura 9 Gráfico de equilíbrio de chapas ideais.

Os pontos A, B, C e D na Figura 10 correspondem ao nível de energia mínimo (equilíbrio estável) e ao ponto $\mathrm{E}$ o nível de energia máximo (equilíbrio instável). 


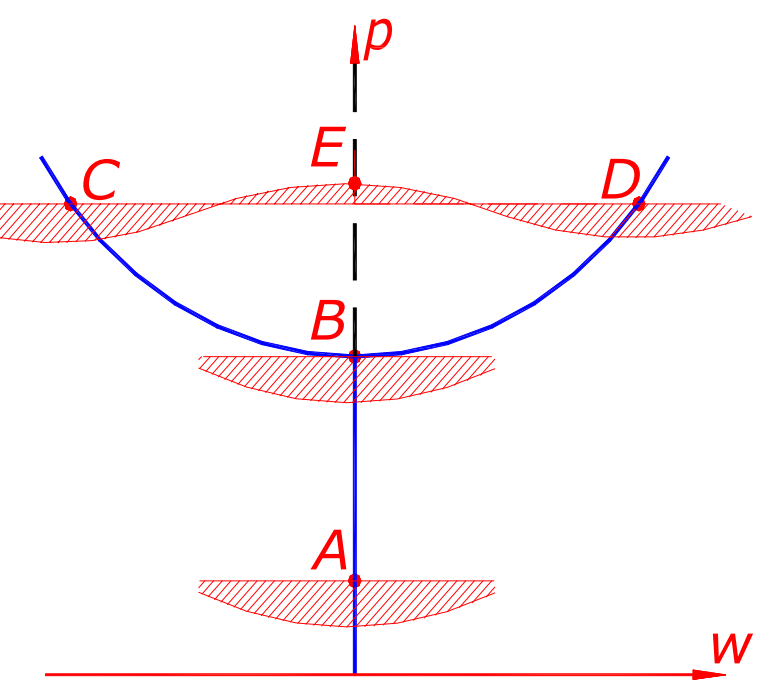

Figura 10 Níveis de energia nas faixas de equilíbrio.

Entretanto, o comportamento ideal de uma chapa serve apenas de base para o estudo das chapas reais (imperfeitas). Conforme podemos observar no gráfico da Figura 11, a sensibilidade às imperfeições de uma chapa comporta-se de modo assíntoto à chapa ideal.

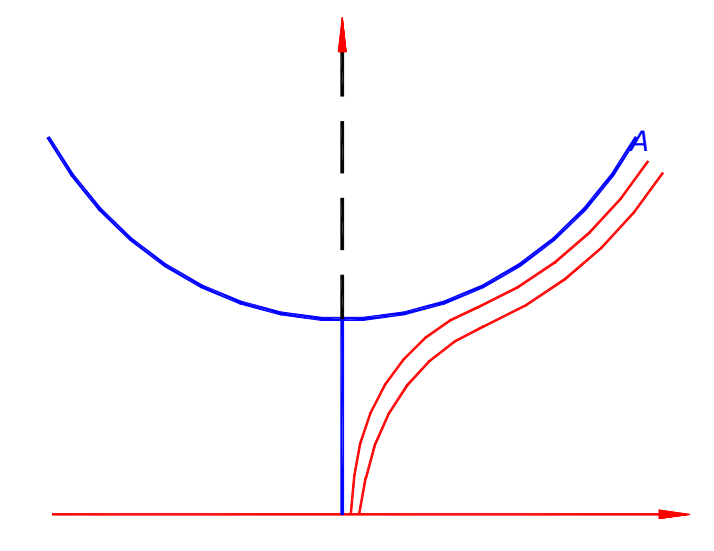

A - Comportamento de chapa perfeita

Figura 11 Estabilidade de chapas perfeitas e imperfeitas.

Segundo Batista (2001), quanto mais "perfeita" a chapa, mais brusca será a passagem do regime pré-crítico para o regime pós-crítico. Portanto, as imperfeições são responsáveis quanto ao desenvolvimento do comportamento de instabilidade da chapa. 
Para efeito de engenharia, as relações entre comprimento e largura (L/b) de chapa influem no comportamento através da alteração do coeficiente de flambagem $\mathrm{k}$ de chapa.

A relação $L / b \geq 4$ representa com fidelidade a maioria dos casos práticos de elementos que constituem partes planas da seção transversal de perfis.

Assim, adotando-se a chapa com relação referencial $L / b=4$, carregamento de compressão unidirecional e uniformemente distribuído, vinculação apoiada no quatro bordos e espessura t, conforme a Figura 12.

Nessas condições, pode-se determinar a tensão crítica de instabildade de chapa através da equação diferencial (3.1).

$$
\frac{\partial^{4} w}{\partial x^{4}}+2 \cdot \frac{\partial^{4} w}{\partial x^{2} \partial y^{2}}+\frac{\partial^{4} w}{\partial y^{4}}+\frac{\sigma_{x} \cdot t}{D} \cdot \frac{\partial^{2} w}{\partial x^{2}}=0
$$

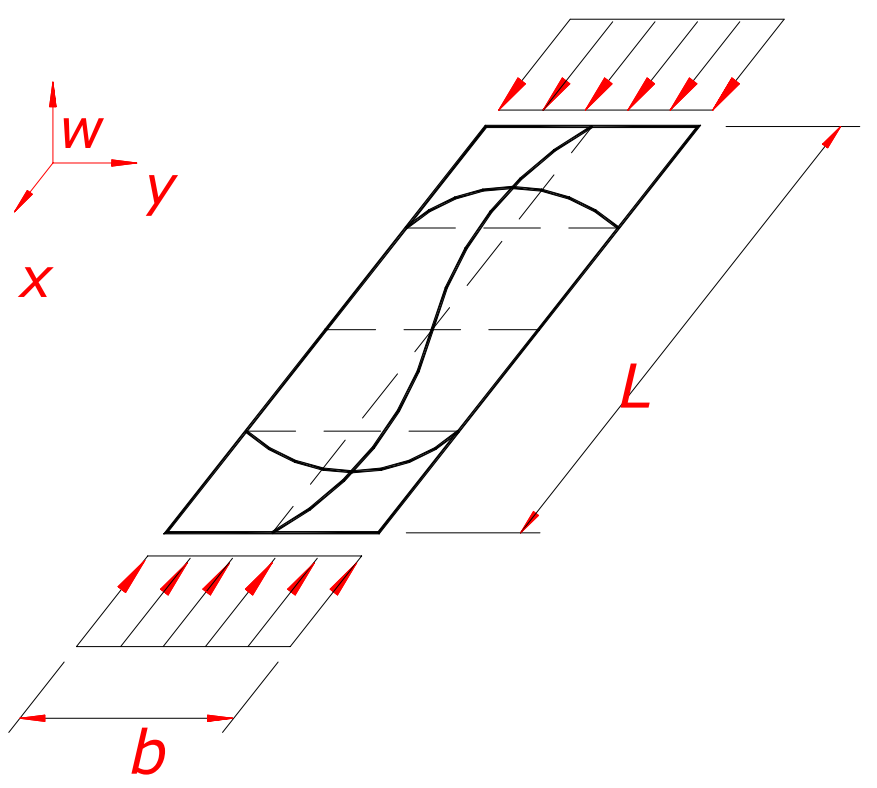

Figura 12 Instabilidade de chapa com relação $L / b \geq 4$.

Sendo:

$$
D=\frac{E \cdot t^{3}}{12 \cdot\left(1-v^{2}\right)}
$$

Onde:

D Módulo de rigidez a flexão unitária; 
E Módulo de elasticidade longitudinal do material;

$v \quad$ Coeficiente de Poisson;

w Deslocamento da chapa normal ao plano da superfície;

$\sigma_{\mathrm{x}} \quad$ Tensão normal de compressão na direção x.

Os deslocamentos w de flexão fora do plano da chapa em regime póscrítico podem ser representados pela série dupla senoidal nas direções dos eixos x e y, conforme a equação (3.3).

$\omega=\sum_{m=1}^{\infty} \sum_{n=1}^{\infty} A_{m n} \operatorname{sen}\left(\frac{m \pi x}{L}\right) \cos \left(\frac{n \pi y}{b}\right)$

Onde:

m Representa o número de meias ondas senoidais na direção $\mathrm{x}$;

n Representa o número de meias ondas senoidais na direção y;

A escolha dessas funções permite satisfazer as condições de contorno adotadas pelo problema.

Derivando-se a equação (3.1) e utilizando-se das funções senoidais da equação (3.3) determinamos a tensão crítica de instabildade elástica da chapa perfeita, equação (3.4).

$$
\sigma_{c r}=\frac{D \cdot \pi^{2}}{t \cdot b^{2}} \quad\left[m\left(\frac{b}{L}\right)+\frac{n^{2}}{m}\left(\frac{L}{b}\right)\right]^{2}
$$

A tensão crítica mínima na chapa ocorre com o modo de estabilidade correspondente a uma semi-onda senoidal na direção y.

Assim, para $\mathrm{n}=1$, temos:

$$
\sigma_{c r}=\frac{D \cdot \pi^{2}}{t \cdot b^{2}} \cdot k
$$

Onde: 


$$
k=\left[m\left(\frac{b}{L}\right)+\frac{1}{m}\left(\frac{L}{b}\right)\right]^{2}
$$

Substituindo-se a equação (3.2) em (3.5), determina-se o valor da tensão crítica de instabilidade elástica paras chapas através da equação (3.7) sob a condição imposta.

$$
\sigma_{c r}=\frac{\pi^{2} E}{12\left(1-v^{2}\right)(b / t)^{2}} \cdot k
$$

Como podemos observar na equação (3.7) o valor do coeficiente de flambagem é diretamente proporcional a tensão crítica de instabilidade elástica da chapa. Dessa forma, as condições de contorno e o tipo de solicitação podem afetar no valor da tensão crítica da chapa em razão da influência no valor de $\mathrm{k}$.

\subsection{Comportamento Pós-Crítico de Chapas}

As chapas ao atingirem tensões pós-críticas apresentam 0 comportamento não-linear. Por ser um processo de instabilidade estável, verifica-se o incremento de solicitação à chapa por ocorrência simultânea de redistribuição de tensões para as regiões dos apoios.

Este fenômeno foi primeiramente observado por Von Karman (1910). O autor desenvolveu matematicamente o fenômeno através da equação (3.8) onde pode caracterizar o comportamento pós-crítico de chapas considerando os grandes deslocamentos envolvidos.

$$
\frac{\partial^{4} w}{\partial x^{4}}+2 \cdot \frac{\partial^{4} w}{\partial x^{2} \partial y^{2}}+\frac{\partial^{4} w}{\partial y^{4}}=\frac{t}{D} \cdot\left(\frac{\partial^{2} F}{\partial y^{2}} \cdot \frac{\partial^{2} w}{\partial x^{2}}-2 \cdot \frac{\partial^{2} F}{\partial y \cdot \partial x} \cdot \frac{\partial^{2} w}{\partial y \cdot \partial x}+\frac{\partial^{2} F}{\partial x^{2}} \cdot \frac{\partial^{2} w}{\partial y^{2}}\right)=0
$$

Sendo:

F $\quad$ Função de tensão para a fibra média da chapa. 
Deste modo a tensões na direção dos eixos x e y são:

$$
\sigma_{x}=\frac{\partial^{2} F}{\partial y^{2}} ; \quad \sigma_{y}=\frac{\partial^{2} F}{\partial x^{2}} ; \quad \tau_{x y}=-\frac{\partial^{2} F}{\partial x \partial y}
$$

Tomando-se como exemplo o elemento do tipo AA da Figura 13, podemos demonstrar o mecanismo de redistribuição de tensões do fenômeno de flambagem de chapa.

$\mathrm{Na}$ Figura 13.a o primeiro estágio do processo apresenta-se com tensão uniforme em toda extensão do elemento. A tensão atual é inferior à tensão crítica de instabilidade da chapa.

Ao atingir a tensão crítica, inicia-se propriamente o processo de redistribuição das tensões para as regiões mais "rígidas", Figura 13.b. Os acréscimos de tensão submetidos à chapa são transferidos para as regiões de periferia até o limite de tensão máxima, tensão de início de escoamento. Na Figura 13.c apresenta-se o final do processo com a borda do elemento atingindo a tensão de escoamento do material, definindo o colapso da chapa. Observa-se que para o caso de perfis formados a frio a tensão de escoamento das regiões conformadas é elevada pelo efeito de trabalho a frio. Constituindo, dessa maneira, um ponto favorável para o aumento da resistência no processo e a exclusão das bordas no cálculo da largura efetiva.

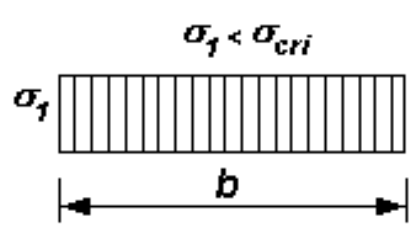

(a)

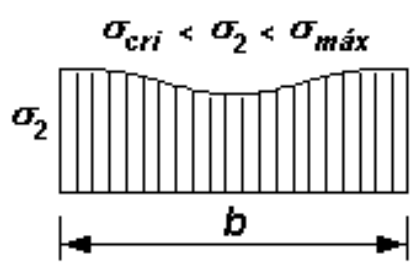

(b)

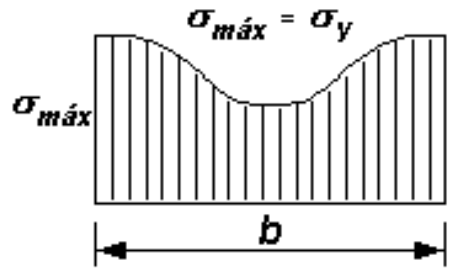

(c)

Figura 13 Distribuição de tensões para elementos enrijecidos.

Para outros tipos de elementos, conforme a vinculação de borda, a redistribuição possui características diferentes. Como podemos notar na 
Figura 14 a distribuição das tensões é alterada pelo tipo de vinculação. Para o elemento tipo AA a distribuição é simétrica com valor de $\mathrm{k}$ igual a 4. Para o elemento tipo AL só ocorre distribuição de tensões obviamente para a borda apoiada, $k=0,43$. O elemento $A A$ com vinculação de enrijecedor de borda é o caso intermediário em relação aos anteriores. A distribuição de tensões é mais acentuada para o apoio (por exemplo, mesa de um perfil conectada a alma) e em menor grau de distribuição para o lado do enrijecedor (apoio elástico). O coeficiente de flambagem deste elemento varia entre os dois casos anteriores, isto é, entre 0,43 e 4. O valor desse coeficiente dependerá da eficiência do enrijecedor em gerar o apoio ao elemento.

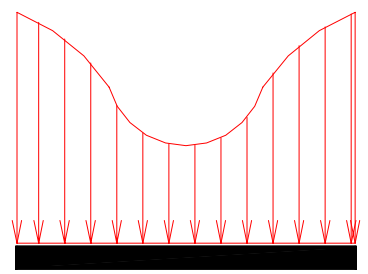

Elemento $A A$

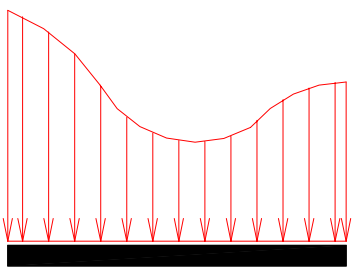

Elemento $A A$ Enrijecido de Borda

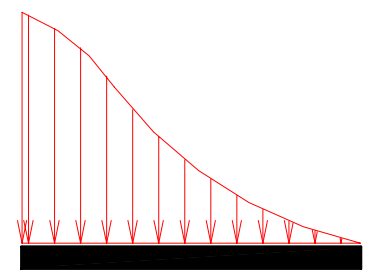

Elemento $A L$

Figura 14 Distribuição de tensão nos elementos.

Segundo Winter (1959), o mecanismo de flambagem de chapa pode ser ilustrado por meio do modelo de grelha da Figura 15. Conforme pode ser visto na Figura 15, a tendência das "colunas longitudinais" de flambarem é impedida pelas "cabos transversais". Os cabos transversais atuam contrariamente a flexão das colunas esbeltez, estabilizando o sistema. Esse modelo reproduz de modo simplificado o comportamento pós-crítico de chapa. 


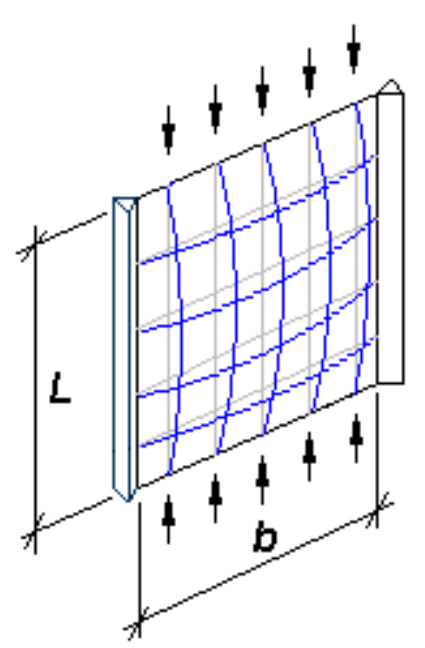

Figura 15 Modelo de grelha para a resistência pós-flambagem de chapas

Para chapas, esse comportamento pós-crítico é relevante por causa dos acréscimos de tensão obtidos acima da tensão crítica de flambagem, não tendo a mesma importância para barras.

O estudo da equação diferencial (3.8) de Von Karman possui certa dificuldade e, por essa razão, um modelo simplificado de análise do comportamento pós-crítico foi desenvolvido pelo autor em 1932, o Método da Largura Efetiva.

O Método da Largura Efetiva objetiva a redução da rigidez da chapa em regime pós-crítico pela redução da largura dos elementos constituintes da seção transversal. Desse modo, obtém-se a redução simplificada das propriedades geométricas da seção transversal.

A distribuição não uniforme de tensões foi substituída por uma distribuição uniforme com valor igual à tensão das bordas, atuando sobre uma largura efetiva fictícia, conforme Figura 16. 


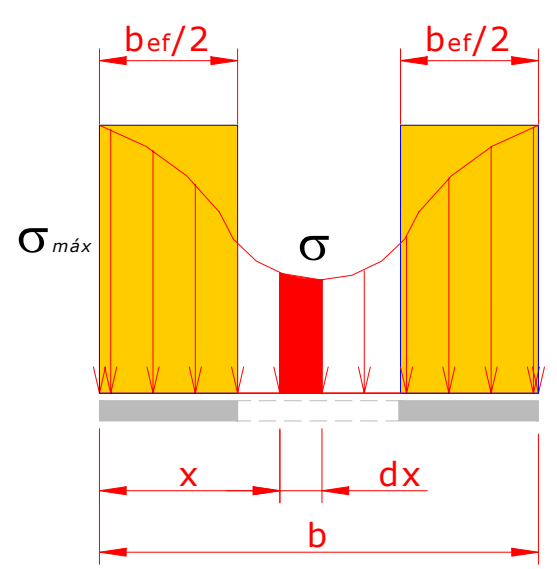

Figura 16 Largura efetiva de um elemento tipo AA.

A determinação da largura efetiva fictícia foi obtida através do equilíbrio entre as resultantes das duas distribuições de tensões, sendo:

$$
\int_{0}^{b} \sigma d x=b_{e f} \cdot \sigma_{\text {máx }}
$$

Para se determinar a largura efetiva de uma chapa de aço, limita-se a tensão de compressão à tensão de início de escoamento $\left(\sigma_{\mathrm{y}}\right)$.

$$
\begin{aligned}
& \text { Assim: } \sigma_{c r i}=\sigma_{y}=\frac{\pi^{2} \cdot E}{3 \cdot\left(1-v^{2}\right) \cdot\left(\frac{b}{t}\right)^{2}} \\
& b_{\text {ef }}=\text { c.t. } \sqrt{\frac{E}{\sigma_{y}}}=1,9 . t \cdot \sqrt{\frac{E}{\sigma_{y}}}
\end{aligned}
$$

Onde:

$\sigma_{y}$ Tensão limite de escoamento do aço;

$v \quad$ Coeficiente de Poisson, $v_{\text {aço }}=0,3$. 
Sendo: $\quad c=\frac{\pi}{\sqrt{3 \cdot\left(1-v^{2}\right)}}=1,9$

Winter aplicou a equação (3.9) de Von Karman aos casos de elementos aos quais possuíam tensão máxima inferior a tensão limite de escoamento, considerando os problemas de imperfeição de chapa. Através de trabalhos experimentais com perfis formados a frio, Winter mostrou que a equação (3.9) se aplica a tais elementos e que o termo "c" tem dependência com o parâmetro adimensional $\left(\sqrt{E / \sigma_{\text {máx }}} \cdot(t / b)\right)$.

Sendo:

$$
c=1,9 .\left(1-0,475 \cdot\left(\frac{t}{b}\right) \cdot \sqrt{\frac{E}{\sigma_{\text {máx }}}}\right)
$$

Como conclusão dessas pesquisas, Winter apud Javaroni (1999), apresentou em 1946 a expressão modificada para o cálculo da largura efetiva de um elemento enrijecido comprimido:

$$
b_{e f}=1,9 \cdot t \sqrt{\frac{E}{\sigma_{\text {máx }}}} \cdot\left(1-0,475 \cdot\left(\frac{t}{b}\right) \cdot \sqrt{\frac{E}{\sigma_{\text {máx }}}}\right)
$$

Em 1968, o prof. Winter propôs a substituição da equação (3.10) pela equação (3.11), a qual apresenta resultados mais próximos dos observados em ensaios.

$$
b_{e f}=1,9 \cdot t \sqrt{\frac{E}{\sigma_{\text {máx }}}} \cdot\left(1-0,415 \cdot\left(\frac{t}{b}\right) \cdot \sqrt{\frac{E}{\sigma_{\text {máx }}}}\right)
$$

A equação (3.11) pode ser generalizada para a determinação da largura efetiva de elementos enrijecidos à compressão sob diferentes condições de contorno: 


$$
b_{e f}=0,95 \cdot t \sqrt{\frac{k \cdot E}{\sigma_{\text {máx }}}} \cdot\left(1-0,208 \cdot\left(\frac{t}{b}\right) \cdot \sqrt{\frac{k \cdot E}{\sigma_{\text {máx }}}}\right)
$$

Onde:

k Coeficiente de flambagem de chapa.

Igualando-se a largura efetiva à largura real do elemento na equação (3.12), tem-se:

$$
\rho=\left(1-\frac{0,22}{\lambda}\right) / \lambda
$$

Sendo:

$$
\lambda=\frac{1,052}{\sqrt{k}} \cdot\left(\frac{b}{t}\right) \cdot \sqrt{\frac{\sigma_{\text {máx }}}{k \cdot E}}
$$

Em termos de esbeltez reduzida do elemento, isto é, comparando a tensão crítica em relação com a tensão de escoamento podemos verificar a influência das imperfeições de chapa através do gráfico da Figura 17.

Sendo:

$$
\lambda_{p}=\sqrt{\frac{\sigma_{y}}{\sigma_{c r}}}
$$

Da equação (3.7) desenvolvida por Von Karman para chapas perfeitas com bef=b para tensão crítica igual a tensão de escoamento, temos:

$$
\frac{b_{e f}}{b}=\frac{1}{\lambda_{p}}
$$

Do mesmo modo, da equação (3.14) tem-se a equação parametrizada de Winter em termos de esbeltez relativa.

$$
\frac{b_{e f}}{b}=\left(1-\frac{0,22}{\lambda_{p}}\right) / \lambda_{p}
$$


O termo $0,22 / \lambda_{p}^{2}$ na equação (3.14) representa na prática os problemas de imperfeição de chapa. O termo $1 / \lambda_{p}$ na mesma equação é a manutenção do problema de bifurcação de Von Karman.

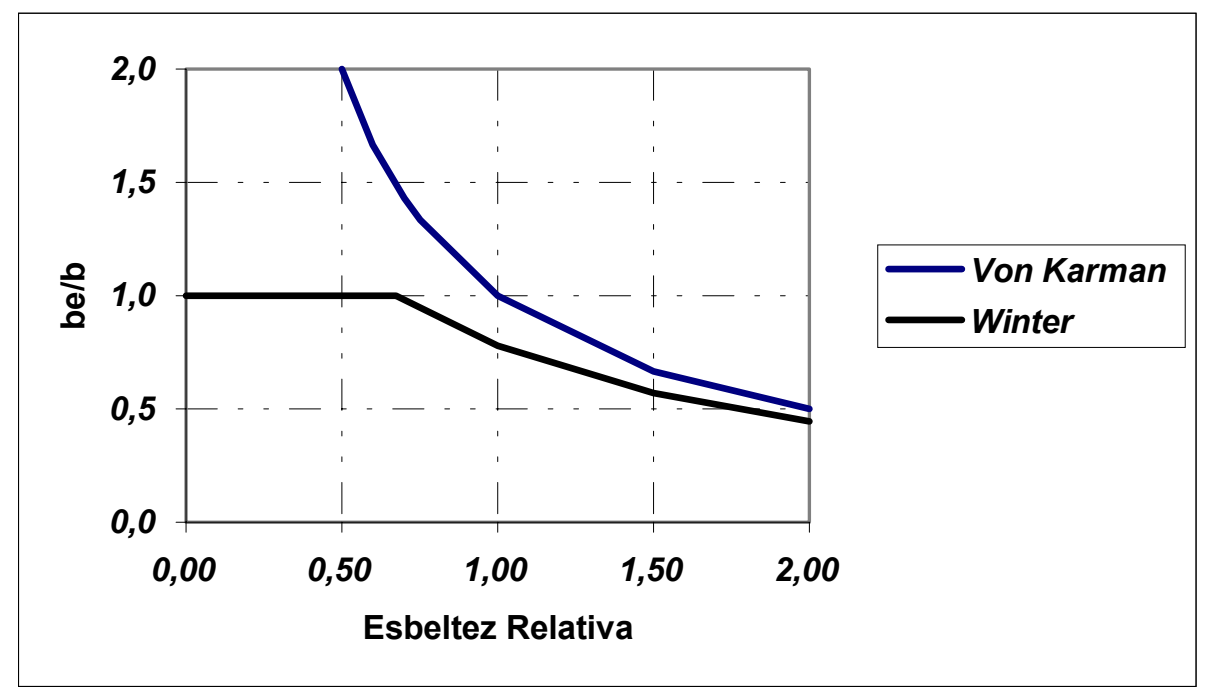

Figura 17 Curva de Winter x Von Karman

Observando o gráfico da Figura 17, quanto maior a esbeltez relativa menor é a influência das imperfeições da chapa na redução da resistência do elemento. Porém, em contrapartida, a resistência da chapa é reduzida significativamente. Para o valor de esbeltez relativa igual 1 , a chapa imperfeita possui a eficiência de $78 \%$ em relação à perfeita. Os valores de esbeltez relativa inferiores a 1 na curva de Von Karman não tem sentido físico.

Na curva de Winter do gráfico da Figura 17 para valores de $\lambda_{p} \leq 0,673$, 0 elemento enrijecido à compressão é totalmente efetivo. Dessa maneira, não existe a ocorrência do fenômeno de flambagem de chapa. Assim, o elemento submetido à compressão entra em colapso através do escoamento do material com tensão uniforme. Para valores de $\lambda_{p}>0,673$, o elemento sofre a redução da largura bruta.

Kalyanaraman et. Al. (1977) verificaram a confiabilidade da equação (3.12) de Winter. A verificação dos resultados obtidos representou um 
satisfatório indicador da capacidade resistente do elemento, empregando-se o coeficiente de flambagem $\mathrm{k}$ adequado.

Observa-se que no cálculo das larguras efetivas dos elementos constituintes da seção (equação de Winter) não estão representados os efeitos da interação entre os elementos, produzindo-se, assim, resultados mais conservativos. Um processo de cálculo que abrange tal situação é o método das faixas finitas, o qual será exposto adiante.

\subsection{Influência dos Enrijecedores de Borda}

Como foi observado na Figura 14 a presença de enrijecedores de borda alteram o perfil de distribuição de tensões do elemento enrijecido. Esse fato promove o aumento de resistência do perfil quanto à instabilidade local do elemento.

A adição de enrijecedores de borda longitudinal é a solução mais prática e econômica para se elevar a resistência dos perfis formados a frio. O termo longitudinal refere-se ao posicionamento paralelo do enrijecedor em relação à direção do plano de tensão de compressão atuante no elemento enrijecido.

As seções transversais dos perfis formados a frio são constituídas de elementos enrijecidos e não-enrijecidos. Devido a falta de apoio longitudinal a uma das bordas do elemento não-enrijecido, sua tensão crítica de flambagem e resistência última são consideravelmente reduzidas em relação a um elemento enrijecido com similares características geométricas e físicas. Assim, segundo Desmond et. al. (1981) o emprego de enrijecedores longitudinais torna-se lucrativo na forma de linhas retas através do simples dobramento a $90^{\circ}$ ou em forma de $\mathrm{L}$ para a borda livre do elemento nãoenrijecido.

Segundo Hancock (1998) a adição de enrijecedores de borda longitudinais em forma de $L$ (classificado pelo autor como enrijecedores de retorno) podem, dependendo da configuração geométrica, gerar o modo de instabilidade do conjunto mesa/enrijecedor através do modo distorcional. 
Yu (2000) afirma que a instabilidade distorcional pode ocorrer simultaneamente com a instabilidade local em perfis formados a frio constituído de elementos com a presença de enrijecedores de borda.

Desmond et. al. (1981) classifica dois modos de instabilidade interrelacionados inerentes ao comportamento de elementos enrijecidos de borda. O primeiro é o modo de instabilidade do enrijecedor, onde a instabilidade é iniciada pela flambagem do enrijecedor perpendicular ao plano do elemento ao qual deveria constituir um apoio contínuo. Nesse caso, o enrijecedor induz, simultaneamente, a instabilidade local do elemento. Esse modo de instabilidade é similar ao modo de instabilidade distorcional de Hancock. O segundo modo é caracterizado pela instabilidade local do elemento enrijecido. Observa-se que nesse modo, o enrijecedor possui propriedades ideais para gerar apoio longitudinal ao elemento plano.

O comportamento do enrijecedor de borda em relação à largura do elemento que o mesmo esta enrijecendo pode ser melhor avaliado pela obtenção do parâmetro “ $\boldsymbol{k}$ ”, apresentado no gráfico da Figura 18.

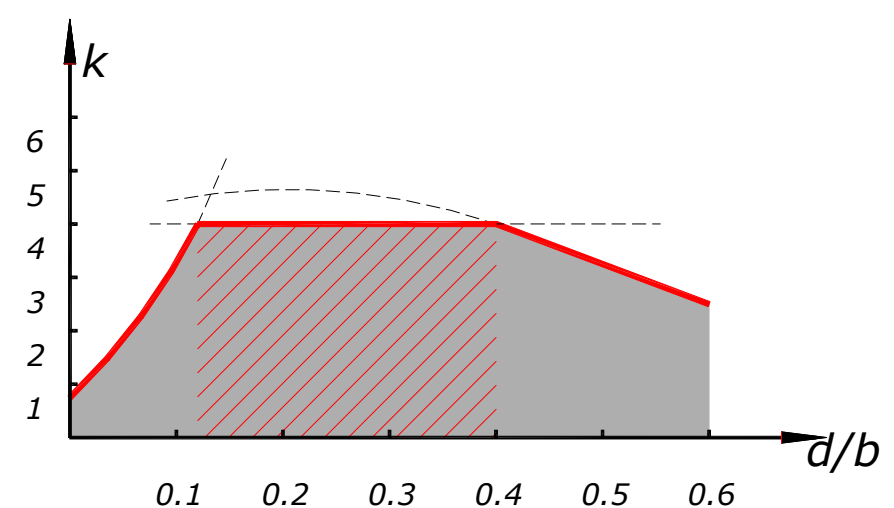

Figura 18 Variação do parâmetro $k$ do elemento enrijecido em função do enrijecedor de borda. Desmond et. al., 1981.

Para relações $d / b<0.12$ a rigidez do enrijecedor é relativamente pequena e a sua presença não é suficiente para caracterizar um apoio contínuo ao elemento plano. Os valores de $k$ são inferiores a 4, caracterizando uma variação da eficiência do enrijecedor ao elemento enrijecido. Os enrijecedores nessa faixa de esbeltez são classificados como parcialmente enrijecidos. 
Para relações $0.12<\mathrm{d} / \mathrm{b}<0.4$, as relações causam a instabilidade simultânea ao enrijecedor e ao elemento enrijecido. $O$ coeficiente de instabilidade é assintoticamente próximo de 4; nessa faixa de esbeltez o enrijecedor é totalmente efetivo e caracteriza-se como um elemento adequadamente enrijecido.

Observa-se que um elemento de chapa é adequadamente enrijecido se o enrijecedor de borda possui características de tal forma que a tensão de instabilidade do elemento enrijecido é simétrica nos apoios do elemento.

Para relações $\mathrm{d} / \mathrm{b}>0.4$, a instabilidade inicia-se pela instabilidade local do elemento enrijecido. A estabilidade local do enrijecedor de borda interage com a do elemento enrijecido e desencadeia-se a instabilidade prematura desse elemento. Entretanto, nota-se que não existem movimentos relativos da junção elemento plano/enrijecedor de borda.

Nota-se que outras formas apropriadas de enrijecedores de borda, ao invés de enrijecedores retos, não são em geral propensos para interagir com a instabilidade local. Para os enrijecedores retos, comprimentos excessivamente extensos não afetam a tensão crítica de instabilidade do conjunto. Esse fato pode ser visto no gráfico da Figura 18 sendo que para esbeltez acima de 0.4 a eficiência é constantemente reduzida.

$\mathrm{Na}$ inexistência de enrijecedor de borda os fenômenos de flambagem de chapa são mais pronunciados e este tipo de elemento pode ser considerado um caso limite particular de elemento parcialmente enrijecido.

O item 7.2.2.2 da NBR 14762 trata do dimensionamento dos elementos uniformemente comprimidos com enrijecedores de borda. Em razão disso, não cabe no presente trabalho a exposição desse assunto com tal profundidade. As exigências geométricas dos enrijecedores de borda quanto aos valores máximos de esbeltez estão prescritos no item 7.1 da mesma norma.

O trabalho teórico-experimental realizado por Desmond et.al. (1981) teve a intenção de avaliar somente a influência do enrijecedor de borda em relação a mesa do perfil submetidos à flexão simples e à compressão centrada. Porém, algumas críticas devem ser comentadas. No modo de 
instabilidade do enrijecedor, nenhuma alusão foi feita ao comprimento de flambagem no sentido longitudinal dos elementos. Este fato poderia gerar alguma contribuição ao estudo da instabilidade distorcional da seção transversal dos perfis. 


\subsection{Aspectos Normativos}

A curva de instabilidade de Winter é o principal procedimento de análise do comportamento estrutural de chapas imperfeitas. A calibração do conceito de larguras efetivas de Von Karman (1932) realizada por Winter em 1947 foi inserida inicialmente como procedimento normativo pelo AISI ${ }^{1}$. Desde a primeira edição até a atual de 2001, pouco foi alterado indicando a elevada confiabilidade no mesmo. Por essa razão a curva de Winter está inserida nas principais normas mundiais para o dimensionamento de estruturas metálicas constituídas por perfis formados a frio.

A equação de Winter original é utilizada para a determinação da resistência de chapas comprimidas em estado limite último. Porém em estado limite de utilização, o EUROCODE $3^{2}$ apresenta uma expressão derivada e calibrada da curva de Winter a qual tem demonstrado satisfatórios resultados experimentais, segundo Batista (2001).

A NBR14762 também adota essas curvas de resistência para a análise de instabilidade local de elementos para os perfis formados. Em conjunto com o método das larguras efetivas, a análise da instabilidade local de elementos planos está inserida sob duas situações de cálculo:

$\checkmark$ Barras submetidas à compressão centrada;

$\checkmark$ Barras submetidas à flexão simples.

O comportamento global da barra sofre a influência da interação com o modo local através das reduções das larguras reais dos elementos que compõem a seção transversal do perfil. A interação conduz a redução da resistência última do perfil. Estes estados limites últimos devem ainda ser comparados com o outro possível estado limite último ligado a instabilidade distorcional da seção transversal, nos respectivos tipos de solicitações. A

2 - EUROCODE 3, Design of Steel Structures; Part 1.3: General Rules, Supplementary Rules for Cold Formed Thin Gauge Members and Sheeting.

1 - AISI, AMERICAN IRON AND STEEL INSTITUTE (1996) Cold Formed Steel Design Manual, Washington, EUA. 
resistência de cálculo do perfil é o menor valor calculado entre os estados limites últimos.

O AISI de certa forma associava o modo de instabilidade distorcional de perfis enrijecidos à ineficiência do enrijecedor, aplicando redução ao coeficiente de flambagem local (k) com valores inferiores a 4 aos elementos planos enrijecidos parcialmente. A redução do coeficiente de flambagem é então usada para computar na largura efetiva do elemento enrijecido parcialmente. Entretanto, Kwon \& Hancock apud Yu (2000) afirmam que, para perfil formado do tipo enrijecido e fabricado com aço de elevada resistência mecânica, a aproximação do AISI é não-conservativa.

Observa-se o seguinte aspecto quanto à forma da tensão atuante nos elementos planos constituintes da seção transversal para o cálculo das propriedades geométricas efetivas do perfil. Para tensões uniformes, ocorrendo ou não reduções nos elementos, procede-se normalmente 0 cálculo das propriedades efetivas. Para tensões gradientes, caso não ocorra redução dos elementos, o cálculo das propriedades efetivas também segue do mesmo modo como o caso anterior, porém, havendo redução na largura bruta de elemento, o cálculo das propriedades geométricas efetivas será realizado por processo iterativo até a convergência do valor. 


\section{INSTABILIDADE DISTORCIONAL}

A pesquisa e o desenvolvimento da engenharia tem alcançado grande avanço no estudo da instabilidade por distorção de perfis de seção transversal aberta. Os avanços iniciais da análise de instabilidade distorcional foram baseados em estudos de modelos analíticos. Segundo Yu (2000), as principais pesquisas sobre o fenômeno distorcional em perfis formados a frio iniciaram com os modelos analíticos propostos por Douty (1962), Peköz \& Soroushian (1982) e Hancock (1987; 1997). Estes modelos estão incorporados nas mais importantes normas mundiais para 0 dimensionamento de perfis formados a frio.

Outra forma de se analisar o fenômeno distorcional é a partir dos Métodos de Resistência Direta (MRD). Os métodos diretos consistem na análise de modelos considerando a seção transversal plena do perfil. Desta maneira, proporcionando interação entre os elementos que compõem a seção transversal.

Como vimos no capítulo anterior, a presença de enrijecedores de borda melhora consideravelmente a resistência do perfil, entretanto, o comportamento estrutural é alterado. Na ausência dos enrijecedores de borda, os modos de instabilidade se resumem ao modo local e ao global. Com o maior enrijecimento das seções transversais e a utilização de aços com elevada resistência mecânica, o modo distorcional pode ocorrer. Dependendo da configuração geométrica da seção transversal do perfil o modo distorcional poderá comandar o dimensionamento com tensões de instabilidade inferiores aos modos local e global. A interação entre o modo 
local e o distorcional pode ocorrer quando a tensão de instabilidade elástica se aproximar da tensão de escoamento do material para o aumento da resistência do perfil. Este aumento está diretamente ligado ao comportamento pós-crítico observado nas pesquisas experimentais.

Segundo Hancock (1987) o modo distorcional de instabilidade de perfis formados a frio monossimétricos envolvem a rotação de corpo rígido do conjunto mesa/enrijecedor sobre a junção alma/mesa do perfil e flexão lateral da seção no plano de simetria. Estes movimentos dependem essencialmente da relação largura da mesa e altura da alma. Para seções com largura de mesa elevada o perfil possui instabilidade pura através do modo rotacional, não existindo flexão lateral. Enquanto, para perfis com mesas mais estreitas o modo de instabilidade lateral é mais preponderante. Para seções com altura de alma com pequena dimensão o modo rotacional é menos efetivo em relação a uma seção com altura de alma "alta". Porém, a mesa pode sofrer distorção.

O modo distorcional foi inicialmente denominado por outras maneiras de classificação. Podemos citar a nomenclatura de Sridharan (1982) que caracterizava o modo distorcional para perfis formados a frio de modo localtorcional, Desmond et. al. (1981) caracterizava o modo distorcional como instabilidade do enrijecedor e Hancock (1985) simplesmente como modo distorcional da seção transversal. A padronização da nomenclatura do modo distorcional evita as confusões quando este modo é relacionado com a instabilidade local do enrijecedor.

Nos perfis formados a frio comprimidos a instabilidade por distorção caracteriza-se por apresentar rotação em direções opostas de cada conjunto mesa/enrijecedor em torno da junção alma/mesa e translação ortogonal à alma, Figura 19.a. Nos perfis formados a frio quando submetidos à flexão, ocorre a instabilidade da parte comprimida da alma juntamente com a mesa envolvendo a flexão transversal da alma com deslocamentos laterais da mesa, como ilustrado na Figura 19.b. Na Figura 19.c apresenta-se a instabilidade distorcional envolvendo a rotação do conjunto mesa/enrijecedor em relação à junção alma/mesa. 


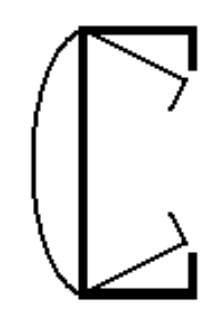

a) Compressão

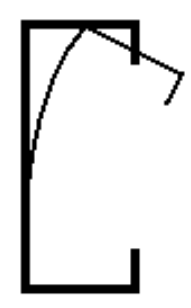

b) Flexão

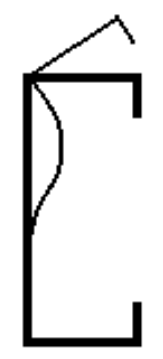

c) Flexão

Figura 19 Formas de instabilidade distorcional em perfis $U$ enrijecido.

Alguns métodos para a análise da instabilidade por distorção têm proposto o tratamento da mesa e enrijecedor como uma coluna sobre base elástica, onde esta base elástica é representada por uma mola, a qual depende da rigidez à flexão das partes adjacentes do elemento plano e das suas condições de contorno.

Dentre esses modelos, o proposto por Hancock tem sido bastante difundido e aplicado em normas técnicas, inclusive na norma brasileira, a NBR 14.762, ABNT (2001). O fato de fornecer expressões analíticas relativamente simples de serem utilizadas para o cálculo manual, torna o modelo de Hancock atraente em situações de projeto. Os modelos de Hancock à flexão e a compressão tem apresentado resultados experimentais satisfatórios para o cálculo da tensão de instabilidade distorcional, desde que sejam respeitados os limites de aplicação dos modelos.

\subsection{Evolução das pesquisas}

Para melhor organizar a ordem dos acontecimentos que contribuíram ao estudo sobre o fenômeno distorcional, pesquisou-se os principais trabalhos relacionados ao tema apresentando-se em ordem cronológica.

Douty (1962) desenvolveu o primeiro modelo para o cálculo do momento crítico de vigas tipo $U$ enrijecido submetidos a momento fletor constante ao longo do vão. O modelo determina a resistência de vigas 
esbeltas elasticamente, considerando a porção comprimida como uma coluna sob fundação elástica.

Haussler (1964) generalizou o modelo de Douty (1962) aplicando a perfis em que as abas comprimidas são enrijecidas por dobras. Yu (2000) afirma que o modelo de Douty em comparação com a simplificação de Haussler pode produzir tensões críticas conservadoras.

Desmond (1981a, 1981b) classificou o modo de instabilidade por distorção em elementos com enrijecedores de borda e com enrijecedores intermediários. O modo de instabilidade por distorção foi chamado de instabilidade do enrijecedor, onde a rigidez deste elemento não é suficiente para servir de 'apoio' à mesa do perfil. Para considerar esse enrijecimento parcial o coeficiente de flambagem de chapa para o elemento enrijecido é inferior a 4. Esse procedimento encontra-se incorporado na norma do AISI (2001).

Peköz \& Soroushian (1982) desenvolveram o modelo analítico de cálculo para perfis conectados a painéis metálicos. O painel metálico sob a ação de vento de sucção promove rigidez rotacional através da interação painel/perfil. A mesa tracionada está conectada ao painel metálico e a mesa comprimida livre sofrendo o fenômeno distorcional simultaneamente com a alma do perfil sob tensão gradiente de compressão.

Ensaios realizados por Hancock (1985) em perfis formados a frio do tipo rack com aço de elevada resistência mecânica verificaram evidências da instabilidade distorcional no comportamento estrutural. Os ensaios foram comparados com análises via método das faixas finitas e os resultados mostraram-se satisfatórios. O estudo revelou que o modo distorcional pode controlar o cálculo dimensional dos perfis tipo rack, não apresentando significante capacidade de reserva pós-crítica. Hancock notou que os perfis formados a frio de seção aberta quando submetidos a tensões de compressão possuíam modo de instabilidade distorcional inferiores aos modos de instabilidade local ou global.

Hancock (1987) desenvolveu o modelo de instabilidade por distorção em colunas. A formulação analítica foi proposta com base na fórmula da 
tensão crítica de placa. Diversos resultados de ensaios experimentais e análises numéricas via método das faixas finitas foram utilizados para a calibração do modelo.

Lau \& Hancock (1988) apud Kwon \& Hancock (1992) apresentaram curva de instabilidade para perfis tipo Rack, $U$ enrijecido e Cartola (enrijecimento no sentido inverso do perfil U enrijecido). Na elaboração desta curva, os ensaios experimentais das seções apresentaram tensão de instabilidade distorcional próxima da tensão de escoamento do material. Dessa maneira, o comportamento inelástico no modo de instabilidade por distorção foi caracterizado tornando-se o limite de resistência para perfis esbeltos.

Kwon \& Hancock (1992) realizaram uma série de ensaios experimentais de perfis $U$ enrijecidos submetidos à compressão em aço de alta resistência mecânica e geometria possibilitando que a carga crítica para que a instabilidade distorcional fosse atingida com tensões significativamente inferiores ao escoamento do material. Com isso, foi verificada elevada capacidade de resistência pós-critica no regime inelástico. A extensão da curva elaborada por Lau \& Hancock (1988) foi finalizada representando a consistente reserva de resistência pós-crítica de seções com elevada esbeltez.

Hancock, Kwon \& Bernard (1994) descrevem propostas de curvas de cálculo para resistência direta em seções delgadas sob instabilidade distorcional. Estas curvas foram baseadas em testes experimentais e simulações numéricas através do método das faixas finitas.

Toma \& Wittemann (1994) realizaram ensaios experimentais em perfis conectados a painéis metálicos sob situação de carregamento gravitacional e carregamento de sucção. Os autores compararam os resultados dos ensaios experimentais com os resultados teóricos obtidos através do modelo de Peköz \& Soroushiam (1982), utilizado pelo Eurocode. O estudo chegou a conclusão que o modelo de Peköz \& Soroushian é conservador. 
Kavanagh \& Ellifritt (1994) verificaram que a presença de pontos de travamento no perfil introduz tensões adicionais, possibilitando a alteração do modo de instabilidade previsto.

Rogers \& Schuster (1997) realizaram análise do modo distorcional comparando alguns modelos de cálculo à flexão em resultados obtidos por vários pesquisadores. Não encontraram grande ocorrência do modo distorcional no volume de ensaios pesquisados.

Hancock (1997) estendeu o modelo de cálculo do modo distorcional à compressão para perfis fletidos. Para tanto, Hancock dobrou o coeficiente de torção da mola em relação ao modelo da compressão, idealizando a alma do perfil restrito nas extremidades e tendo momento fletor atuando somente em uma extremidade.

Peköz \& Schafer (1998) propuseram modificação na curva de instabilidade elástica para o modo distorcional de Hancock em função da análise de dados experimentais provenientes de diversos pesquisadores.

Jönsson (1999) utiliza-se da teoria clássica para vigas de seção aberta e parede fina, Vlassov (1962), introduzindo nesta o modo distorcional através de novas condições de ortogonalidade e modos de deslocamentos relativos à distorção da seção. Pode-se observar através do equacionamento que nem sempre o modo distorcional está desacoplado da torção.

Abu-Sena, Chapman \& Davidson (2001) fazem uma análise detalhada da interação entre a instabilidade por flexo-torção e a distorcional utilizandose do método da energia e, posteriormente, o método dos elementos finitos. Obtém uma redução de até $24 \%$ na carga crítica individual, sem levar em conta essa interação. Esta análise é feita para barras axialmente comprimidas.

Quispe \& Hancock (2002) realizaram um estudo comparativo do método de resistência direta em relação ao método das larguras efetivas (procedimento do AISI) e, também, em relação ao modelo analítico de Hancock. Neste estudo os autores observaram que o método da resistência direta promove resultados próximos aos dois métodos comparados, tendo 
diferenças em média desprezíveis. Os autores ainda destacaram as vantagens do método de resistência direta no sentido de promover maior rapidez através de soluções numéricas e de permitir flexibilidade às seções tornando possível o cálculo de seções complexas.

\subsection{Modelo de Lau \& Hancock para Perfis Submetidos à Compressão}

O modelo analítico de Lau \& Hancock (1987) para perfis formados submetidos à compressão idealiza o conjunto isolado mesa/enrijecedor de perfis tipo Rack como uma barra comprimida, apoiada continuamente e elasticamente pela alma e sujeita à instabilidade por flexo-torção, conforme figura 20. Os perfis do tipo Rack consistem nos perfis do tipo $U$ enrijecido, Rack propriamente e Rack enrijecido, representados na ordem conforme figura 21. Os perfis tipo Rack são perfis enrijecidos e tem emprego constante na indústria para a fabricação de colunas para armários industriais.

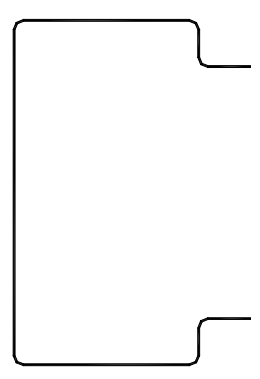

a) Seção transversal

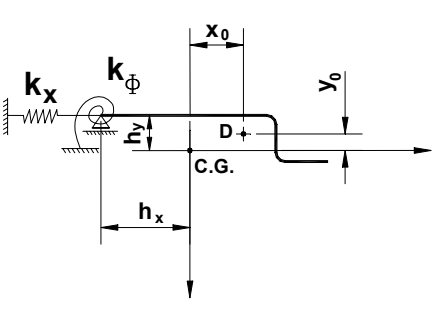

b) Modelo idealizado 


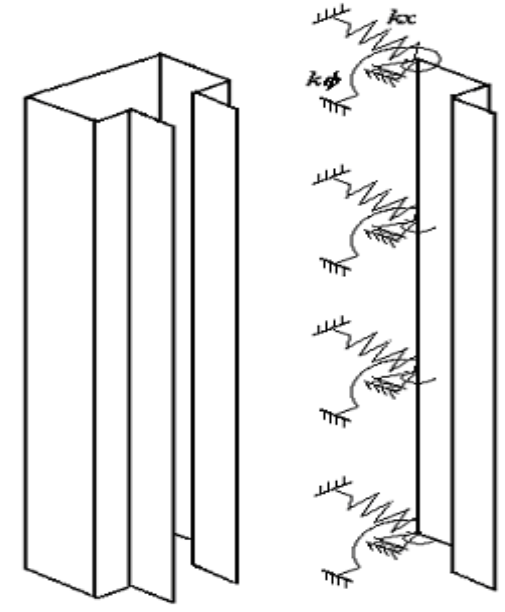

c) Modelo $3 \mathrm{D}$

Figura 20 Modelo de cálculo para instabilidade por distorção.
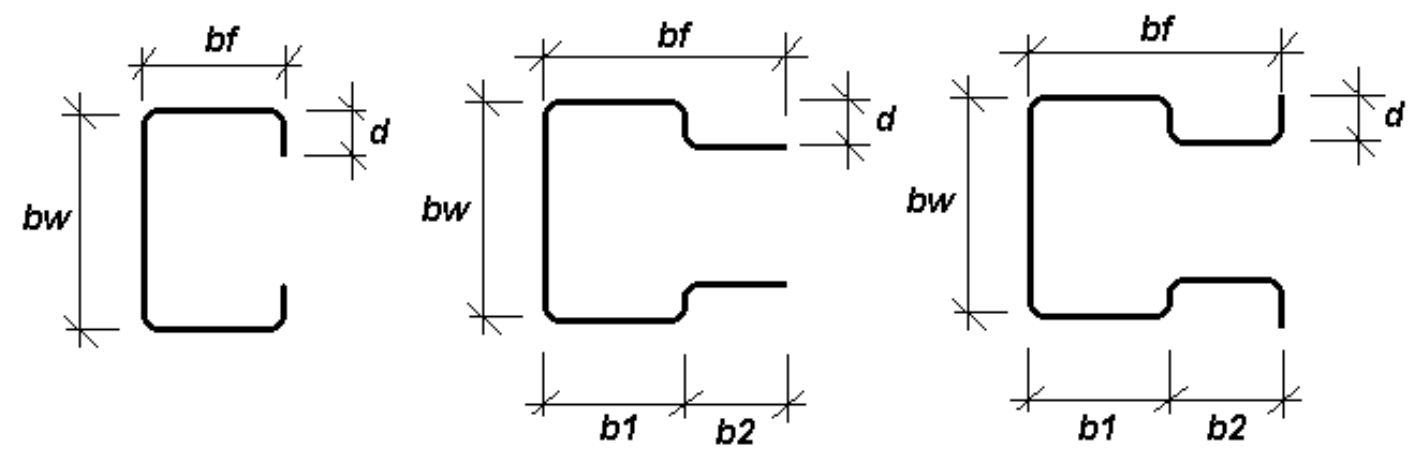

Figura 21 Seções transversais de perfis formadas a frio abrangidas pelo modelo de Lau \& Hancock (1987).

Segundo Hancock (1987) a simplificação adotada no modelo é conseqüência do comportamento de instabilidade distorcional dos perfis. De outra forma, seria complicada a derivação explícita de expressões analíticas para a seção total.

A base para a obtenção da expressão analítica para o cálculo da força crítica de instabilidade distorcional foram as equações formuladas por Vlasov (1961) e por Timoshenko, Gere (1959). Estas equações combinam a instabilidade por flexo-torção de uma barra submetida à compressão com apoios elásticos contínuos sem que haja a distorção da seção transversal. 


\subsubsection{Hipóteses de Cálculo}

As hipóteses de cálculo do modelo de Hancock são:

$\checkmark$ A seção transversal do conjunto mesa/enrijecedor não sofre distorção, isto é, a instabilidade distorcional está associado à instabilidade por flexo-torção do conjunto;

$\checkmark \quad$ Os efeitos da alma são representados pelos apoios elásticos contínuos providos pela mola rotacional $\mathrm{k}_{\phi} \mathrm{e}$ lateral $\mathrm{k}_{\mathrm{x}}$;

$\checkmark \quad$ A carga crítica de compressão atua no centro de gravidade do conjunto mesa/enrijecedor com excentricidade em relação ao centro de torção, o que gera a instabilidade por flexo-torção.

\subsubsection{Formulação Analítica - Perfil Submetido à Compressão}

Seja a seção transversal do perfil tipo Rack, conforme Figura 20.a. Isolando-se a mesa e o enrijecedor da seção, conforme a Figura 20.b, temse as coordenadas do centro de torção $D\left(\mathrm{x}_{0}, \mathrm{y}_{0}\right)$ referidas a um sistema de eixos (xoy). O eixo $x$ é paralelo à mesa, com origem no centro de gravidade da seção idealizada $\left(\mathrm{h}_{\mathrm{x}}, \mathrm{h}_{\mathrm{y}}\right)$. As deflexões em relação ao centro de torção $D$ nas direções $x$ e $y$ são denotadas por $u$ e $v$; a rotação da seção sobre centro de torção é representada por $\phi$.

Considerando o equilíbrio de forças nas direções $x$ e $y$ e o equilíbrio de momentos sobre o centro de torção, a força de compressão $N$ de instabilidade elástica pode ser obtida resolvendo-se o sistema de equações diferenciais:

$$
\begin{aligned}
& E I_{x} v^{i v}+E I_{x y} u^{i v}+N\left(v^{\prime \prime}-x_{0} \phi^{\prime \prime}\right)+Q_{y}=0 \\
& E I_{y} u^{i v}+E I_{x y} v^{i v}+N\left(u^{\prime \prime}+y_{0} \phi^{\prime \prime}\right)+k_{x}\left[u+\left(y_{0}-h_{y}\right) \phi\right]=0 \\
& E C_{\omega} \phi^{i v}-\left(G I_{t}-\frac{I_{0}}{A} N\right) \phi^{\prime \prime}-N\left(x_{0} v^{\prime \prime}-y_{0} u^{\prime \prime}\right)+ \\
& k_{x}\left[u+\left(y_{0}-h_{y}\right) \phi\right]\left(y_{0}-h_{y}\right)-Q_{y}\left(x_{0}-h_{x}\right)+k_{\phi} \phi=0
\end{aligned}
$$


Nas equações (4.1) e (4.2), os primeiros termos representam as derivadas dos termos da flexão da seção sobre os eixos $x$ e $y$, respectivamente. $O$ terceiro termo representa as intensidades de força atuando na mola rotacional durante a ação da força $N$. Os últimos termos representam a intensidade de força de reação lateral atuando ao longo do apoio elástico. Na equação (4.3), os primeiros três termos são as derivadas da torção não uniforme de seções abertas delgadas, enquanto que os últimos três termos são o momento de torção das duas reações laterais e a restrição rotacional do apoio elástico.

Onde:

A Área da seção idealizada;

E, G Módulo de elasticidade longitudinal e transversal do material;

$I_{x}, I_{y}$ Momentos de inércia em relação aos eixos $x$ e $y$;

$I_{x y} \quad$ Produto de inércia;

Io Momento de inércia polar;

$I_{t} \quad$ Momento de inércia à torção;

$C_{\omega} \quad$ Constante de empenamento;

$k_{x} \quad$ Rigidez da mola à translação em $x$;

$k_{\phi} \quad$ Rigidez da mola rotacional;

$Q_{y} \quad$ Reação de apoio na direção $y$.

Adotando-se como soluções das equações anteriores as expressões de forma:

$$
\begin{aligned}
& \phi=A_{1} \operatorname{sen}(\pi z / \lambda) \\
& u=A_{2} \operatorname{sen}(\pi z / \lambda) \\
& v=\left(x_{0}-h_{x}\right) \phi=\left(x_{0}-h_{x}\right) A_{1} \operatorname{sen}(\pi z / \lambda)
\end{aligned}
$$

Sendo:

$A_{1}$ e $A_{2}$ constantes; $\lambda$ o comprimento de uma semi-onda.

Substituindo-se as equações (4.4) a (4.6) nas equações (4.1) a (4.3) e calculando-se o determinante igual a zero, tem-se: 


$$
\begin{aligned}
& {\left[\frac{\pi^{2}}{\lambda^{2}} E I_{x y}\left(x_{0}-h_{x}\right)+\frac{\lambda^{2}}{\pi^{2}} k_{x}\left(y_{0}-h_{y}\right)-N y_{0}\right]^{2}} \\
& -\left(\frac{\pi^{2}}{\lambda^{2}} E I_{y}+\frac{\lambda^{2}}{\pi^{2}} k_{x}-N\right)\left\{\frac{\pi^{2}}{\lambda^{2}}\left[E C_{\omega}+E I_{x}\left(x_{0}-h_{x}\right)^{2}\right]+G I_{t}\right. \\
& \left.-\left(\frac{I_{0}}{A}-x_{0}^{2}+h_{x}^{2}\right) N_{t}+\frac{\lambda^{2}}{\pi^{2}}\left[k_{x}\left(y_{0}-h_{y}\right)^{2}+k_{\phi}\right]\right\}=0
\end{aligned}
$$

A determinação do valor mínimo para a força de compressão $N$ correspondente a um determinado valor de $\lambda$. Através de análises numéricas Hancock (1987) observou que os valores mínimos de tensão de instabilidade distorcional permanecem inalterados com o aumento do número de semiondas senoidais na extensão do comprimento para o conjunto isolado. Conseqüentemente, o aumento do número de semi-ondas senoidais não interfere na aplicabilidade da equação (4.4). O autor ainda observou que se adotando os valores extremos de $k_{x}=0$ e $k_{x}=\infty$ os valores críticos de tensão de instabilidade distorcional são próximos. Por essa razão, Hancock adotou como aproximação o valor de $k_{x}=\infty$ por estar garantido os dois casos.

Segundo Lau \& Hancock (1987), a rigidez rotacional $k_{\phi}$ para uma placa retangular de largura $b$, sujeita à tensão de compressão $\sigma$ e momento fletor distribuído ao longo dessa borda pode ser determinada de acordo com as expressões de (4.8) a (4.11).

$$
\begin{aligned}
& k_{\phi}=\frac{D\left(\alpha^{2}+\beta^{2}\right)}{b}\left(\alpha \tanh \frac{\alpha}{2}+\beta \tan \frac{\beta}{2}\right)^{-1} \\
& \alpha=\pi \sqrt{(b / \lambda)} \sqrt{(b / \lambda+\sqrt{k})} \\
& \beta=\pi \sqrt{(b / \lambda)} \sqrt{(-b / \lambda+\sqrt{k})} \\
& k=\left(b^{2} t / \pi^{2} D\right)
\end{aligned}
$$

Onde:

b Largura da placa; 
$t \quad$ Espessura da placa;

$D \quad$ Rigidez unitária à flexão da placa. $\left[\mathrm{D}=\mathrm{E} \cdot \mathrm{t}^{3} / 12 \cdot\left(1-\mathrm{v}^{2}\right)\right]$

Assim,

$u=-\left(y_{0}-h_{y}\right) \phi=-\left(y_{0}-h_{y}\right) A_{1} \operatorname{sen}(\pi z / \lambda)$

Substituindo-se as equações (4.5), (4.6) e (4.12) nas equações de (4.1) a (4.3), obtém-se a equação (4.13)

$$
\begin{aligned}
& N_{c r}=\frac{\left(\pi^{2} / \lambda^{2}\right) E I_{\omega c}+G I_{t}+\left(\lambda^{2} / \pi^{2}\right) k_{\phi}}{\left(I_{x}+I_{y}\right) / A+h_{x}^{2}+h_{y}^{2}} \\
& I_{\omega c}=C_{\omega}+I_{x}\left(x_{0}-h_{x}\right)^{2}+I_{y}\left(y_{0}-h_{y}\right)^{2}-2 I_{x y}\left(x_{0}-h_{x}\right)\left(y_{0}-h_{y}\right)
\end{aligned}
$$

O valor crítico de $\lambda$ é obtido pela derivada de $N_{c r}$ na equação (4.13) igual a zero. Como $k_{\phi}$ é uma função de $\lambda$ e $N$, então:

$$
k_{\phi}=2 D / b_{w}
$$

A rigidez rotacional $k_{\phi}$ é assintótica a constante $2 D / b$ para longos comprimentos de semi-onda senoidal e pequenos valores de coeficiente de tensão. O uso da equação (4.15) implica que os efeitos da força de compressão sobre a alma do perfil são ignorados e o valor crítico de $\lambda$ é assumido ao longo do conjunto.

Assim,

$$
\lambda_{c r}=\pi\left(E I_{\omega c} b_{w} / 2 D\right)^{0,25}
$$

O uso das equações (4.8) a (4.11) para a determinação do coeficiente rotacional $k_{\phi}$ empregando-se a equação (4.7) é impraticável e o uso de processos iterativos se faz necessário. 
Bleich (1952) apud Lau, Hancock (1987) determinou o coeficiente rotacional $k_{\phi}$ entre os elementos de placa adjacentes para seções transversais do tipo Rack, I e Z para a instabilidade local usando a equação (4.15) com a inserção de um fator de redução para representar a força de compressão atuando na alma do perfil. O fator de redução é a relação entre as tensões de instabilidade local dos elementos de placa adjacentes.

Então:

$$
k_{\phi}=\left[2 D /\left(b_{w}+0.06 \lambda\right)\right] \cdot\left[1-\left(P^{\prime} / A\right) / \sigma_{w}\right]
$$

Onde:

$\sigma_{w} \quad$ Tensão de instabilidade local da alma isolada;

$P^{\prime} / A$ Tensão de instabilidade do conjunto obtida pela equação (4.7) com $\mathrm{k}_{\mathrm{x}}$ e $\mathrm{k}_{\Phi}$ igual a zero.

O fator de redução $\left[1-\left(P^{\prime} / A\right) / \sigma_{w}\right]$ influi no cálculo de $k_{\phi}$. Se as tensões atuantes forem próximas, então o valor da relação tenderá a 1 e $k_{\phi}$ será igual a zero. Se a tensão de instabilidade local da alma for muito maior que em relação ao conjunto, o valor de $k_{\phi}$ será igual a $2 D / b_{w}$.

A equação (4.17) foi aproximada por Lau, Hancock (1987) e ajustada através de resultados de análises numéricas com a inclusão dos efeitos do cisalhamento e distorção na mesa. Estudos paramétricos em seções com enrijecedores perpendiculares à mesa indicaram a adição do termo 0,06 à largura da mesa na equação (4.17).

Adotando-se $k_{x}=0$ na equação (4.7) e calculando-se $\lambda$ e $k_{\phi}$ conforme as equações (4.16) e (4.17), respectivamente, a força de instabilidade distorcional pode ser determinada pela equação (4.18).

$$
N_{c r}=0,5 E\left[\left(\alpha_{1}+\alpha_{2}\right) \pm \sqrt{\left(\alpha_{1}+\alpha_{2}\right)^{2}-4 \alpha_{3}}\right]
$$


Onde:

$$
\begin{aligned}
& \alpha_{1}=\left(\eta / \beta_{1}\right)\left(\beta_{2}+0,039 I_{t} \lambda^{2}\right)+k_{\phi} /\left(\beta_{1} \eta E\right) \\
& \alpha_{2}=\eta\left(I_{y}-2 y_{0} \beta_{3} / \beta_{1}\right) \\
& \alpha_{3}=\eta\left(\alpha_{1} I_{y}-\eta \beta_{3}^{2} / \beta_{1}\right) \\
& \beta_{1}=h_{x}^{2}+\left(I_{x}+I_{y}\right) / A \\
& \beta_{2}=C_{\omega}+I_{x}\left(x_{0}-h_{x}\right)^{2} \\
& \beta_{3}=I_{x y}\left(x_{0}-h_{x}\right) \\
& \beta_{4}=\beta_{2}+\left(y_{0}-h_{y}\right)\left\lfloor I_{y}\left(y_{0}-h_{y}\right)-2 \beta_{3}\right\rfloor \\
& \lambda=4,80\left(\beta_{4} b_{w} / t^{3}\right)^{0,25} \\
& \eta=(\pi / \lambda)^{2} \\
& k_{\phi}=\frac{E t^{3}}{5,46\left(b_{w}+0,06 \lambda\right)}\left[1-\frac{1,11 P^{\prime}}{E A t^{2}}\left(\frac{b_{w}^{2} \lambda}{b_{w}^{2}+\lambda^{2}}\right)^{2}\right]
\end{aligned}
$$

$P^{\prime}$ é obtido a partir da equação (4.17) utilizando-se como primeira aproximação a equação (4.19) com $k_{\phi}=0$.

$$
\alpha_{1}=\left(\eta / \beta_{1}\right)\left(\beta_{2}+0,039 I_{t} \lambda^{2}\right)+k_{\phi} /\left(\beta_{1} \eta E\right)
$$

Como pode ser notado, o modelo analítico de Hancock é a determinação da tensão de instabilidade distorcional simplificada através da combinação dos modos de instabilidade global do elemento isolado com a instabilidade local do elemento adjacente (alma).

A calibração das fórmulas analíticas para o cálculo da tensão de instabilidade distorcional foi realizada através de programa de análise de faixas finitas, desenvolvido por Hancock em 1977. Os resultados se apresentaram conservativos na ordem de $5 \%$ para as seções pesquisadas. 


\subsubsection{Limitações do Modelo}

Caso o enrijecedor do perfil seja relativamente pequeno, problemas de instabilidade local poderão unir-se à instabilidade distorcional, com pequenos comprimentos meias-ondas senoidais. Conseqüentemente, as equações para o cálculo de tensão de instabilidade distorcional poderão ser muito conservativas por que se assumiu nas derivações de cálculo que a junção alma/mesa desloca-se lateralmente devido à flexão. A equação (4.20) demonstra boa estimativa de cálculo para o cálculo da instabilidade distorcional para altura de enrijecedor de borda acima de 4,8t.

$$
d_{\text {min }}=2,8 \cdot t \cdot\left[\left(\frac{b}{t}\right)^{2}-\frac{27600}{F y}\right]^{1 / 6}
$$

Onde:

$F_{y}$ é tensão de escoamento do aço em MPa;

b/t é a relação do comprimento plano e espessura do sub-elemento.

O modelo de Hancock apresenta a limitação para os perfis do tipo $U$ enrijecido com relações entre $0,5 \leq b_{w} / b_{f} \leq 2,5$. Onde: $b_{w}$ é altura da alma e $b_{f}$ é a largura da mesa. Para perfis do tipo Rack: $0,5 \leq b_{2} / b_{1} \leq 1,0$ e $0,75 \leq$ $b_{w} / b_{f} \leq 1,75$. Para perfis do tipo Rack enrijecido: $0,5 \leq b_{2} / b_{1} \leq 1,0$ e $0,5 \leq$ $b_{w} / b_{f} \leq 2,5$.

As seções com relações fora destas faixas, o equacionamento poderá não ser conservativo por causa dos efeitos significativos da flexão lateral ou distorção da mesa.

Batista et. al. (1998) apud Batista et. al. (2000) através de análise de estabilidade numérica via método das faixas finitas de perfis tipo Rack e $U$ enrijecido verificaram distintas possibilidades dos tipos de instabilidade locais em função da geometria da seção transversal do perfil, conforme figura 22. Neste trabalho verificou-se a influência das dimensões nominais dos respectivos tipos de perfis em relação a altura da alma dos mesmos e, também, a influência da esbeltez da alma nos respectivos modos locais de 
instabilidade. Como resumo deste trabalho originou-se a tabela 1, onde a variação das relações geométrica define o modo local preponderante.
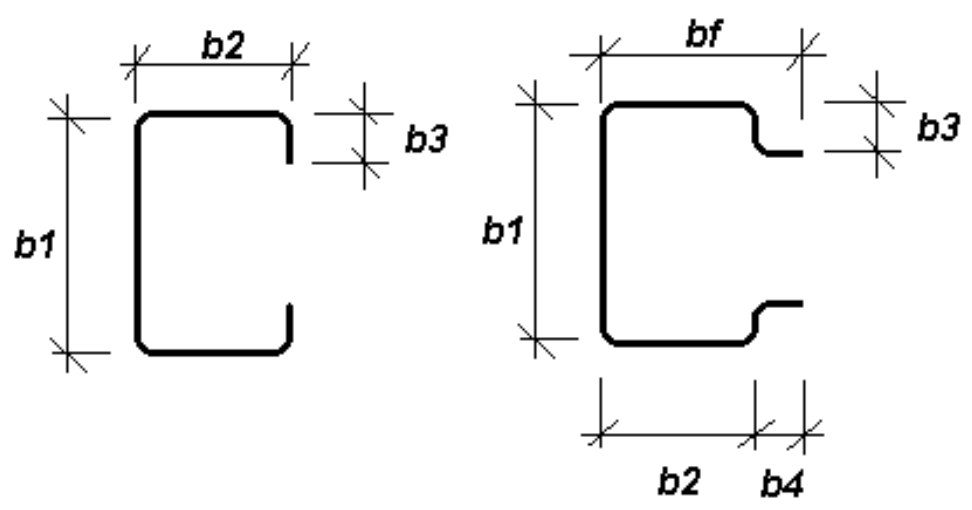

Figura 22 Características geométricas nominais dos perfis do tipo $U$ enrijecido e Rack. Fonte: Batista, 2000.

Tabela 1: Influência da geometria das seções tipo U enrijecido e Rack na definição do modo local crítico:

\begin{tabular}{|c|c|c|}
\hline Quanto Menor & Relação Geométrica & Quanto maior \\
\hline \hline Modo local & $\mathrm{b}_{2} / \mathrm{b}_{1}$ & Modo distorcional \\
\hline Modo distorcional & $\mathrm{b}_{3} / \mathrm{b}_{1}$ & Modo local \\
\hline Modo local & $\mathrm{b}_{4} / \mathrm{b}_{1}$ & Modo distorcional \\
\hline Modo distorcional & $\mathrm{b}_{1} / \mathrm{t}$ & Modo local \\
\hline
\end{tabular}

Como pode ser visto na tabela 1, quanto maior a dimensão da mesa da seção, maior a possibilidade de obtermos o modo distorcional como crítico. De outra forma, quanto menos reduzida a esbeltez da alma do perfil maior a tendência de ocorrer o modo distorcional. Dentro desta análise numérica, Batista et. al. (2000) analisaram os limites geométricos referentes ao modelo de Hancock (1987) e chegaram as seguintes relações:

\footnotetext{
$\checkmark$ Seção tipo U enrijecido: $0,4 \leq b f / b 1 \leq 2,0$

$\checkmark$ Seção tipo Rack: $0,6 \leq b f / b 1 \leq 0,3$

$\checkmark$ Ambos perfis: $0,0 \leq b 3 / b 1 \leq 0,5$ e $25 \leq b 1 / t \leq 400$
} 
Como pode ser observado o perfil do tipo rack possui faixa restrita em comparação ao perfil do tipo $U$ enrijecido. Isto indica a alta sensibilidade ao modo distorcional destes perfis.

Hancock (1985) demonstrou através de estudo numérico-experimental em perfis do tipo rack submetidos à compressão que apresentam elevada sensibilidade ao modo distorcional. A análise numérica desenvolvida pelo autor, através do método das faixas finitas, indicou que o enrijecimento dos perfis do tipo rack com enrijecedores adicionais por virada simples a $90^{\circ}$ permite reduzir a sensibilidade destes ao modo distorcional. Enrijecedores adicionais em perfis do tipo Rack são empregados para aumentar a resistência das mesas posteriores quando estas são extensas. Os perfis Rack são empregados na fabricação de armários industriais com fixação através de parafusos. Porém, a inclusão de enrijecedores adicionais em perfis do tipo Rack influi significativamente na redução da resistência à instabilidade global do perfil. Deste modo o comprimento do perfil será determinante para a definição entre os modos de instabilidade distorcional e global no dimensionamento dos mesmos. Esta redução da resistência à instabilidade global do perfil é causada pelo afastamento do centro de torção em relação ao centro de gravidade da seção transversal.

Batista et. al. (2000) também realizaram um estudo experimental analisando o desempenho do modelo de Hancock (1987) para perfis do tipo rack submetidos à compressão em colunas curtas. Os resultados indicaram o não-conservadorismo do modelo de Hancock para os perfis com esbeltez reduzida de 1,26 e 1,28. Estes valores situam-se no regime inelástico da curva de Hancock, porém, próximos do regime elástico. Nesta faixa de esbeltez reduzida os ensaios não apresentaram resistência pós-crítica. Para valores de esbeltez reduzida entre 1.06 e 1.17 , ensaios realizados anteriormente indicaram reserva de resistência pós-crítica. Os autores afirmam que este fato indica que a esbeltez reduzida está diretamente ligada a capacidade de reserva pós-crítica.

O estudo numérico-experimental de Batista et. al. (2000) indicou que o modelo de Hancock reproduz resultados satisfatórios. Porém, os resultados 
experimentais indicaram uma possível inclusão de um fator de redução da resistência do perfil devido à influência das condições de extremidade. Segundo Hancock (1985) as condições de extremidade não afetam significativamente a carga de instabilidade dos modos local e distorcional de perfis do tipo rack submetidos à compressão por que múltiplas ondas senoidais ocorrem na extensão do perfil e entre os apoios. Entretanto, os ensaios de Batista et. al. (2000) revelam que para colunas curtas engastadas nas extremidades este tipo de influência é significativa com a redução do comprimento do perfil.

Kwon \& Hancock (1992) realizaram análises em perfis formados a frio com seções transversais do tipo $U$ enrijecido e $U$ enrijecido com enrijecedor intermediário na alma submetidos à compressão. Em todos os perfis ensaiados foi encontrado como modo de instabilidade crítico a modo distorcional ou o modo distorcional associado ao modo local. Os perfis possuíam elevada esbeltez e foram produzidos em aço com elevada resistência mecânica. O principal resultado deste trabalho foi a identificação da significante capacidade de reserva pós-crítica do modo distorcional em associação com o modo local ou de forma isolada. A capacidade de reserva pós-crítica foi constatada com a tensão de instabilidade distorcional apresentando reserva de resistência de 1,34-3,3 vezes a tensão máxima suportada pelos perfis nos ensaios. Este comportamento ocorreu com tensão de instabilidade distorcional inferiores a $50 \%$ da tensão de escoamento do material. A relação entre a tensão de instabilidade distorcional experimental e a tensão de instabilidade distorcional teórica (via método das faixas finitas) apresentaram-se na faixa de 0,89-1,12. Estes valores representam um bom indicativo do modelo analítico de Hancock (1987) comparando com os resultados de Hancock (1985). Desta forma, segundo Kwon \& Hancock (1992), a interação entre os modos de instabilidade local e distorcional é plenamente satisfatória para o aumento de resistência do perfil.

No trabalho experimental de Kwon \& Hancock (1992) ainda foram analisados alguns aspectos geométricos no comportamento do modo 
distorcional. Na variação geométrica empregada aos dois tipos de seções transversais foram verificadas as influências no modo distorcional. As influências geométricas foram em relação ao tamanho do enrijecedor de borda, a presença do enrijecedor intermediário na alma e do comprimento do perfil.

A pequena variação no tamanho do enrijecedor ao qual é inadequado para prevenir o movimento normal ao plano da mesa apoiada não reproduz significante redução à tensão de ruína do perfil. Porém, para pequenos decréscimos no tamanho do enrijecedor a tensão de instabilidade distorcional foi significantemente reduzida.

A inclusão do enrijecedor intermediário na alma do perfil $U$ enrijecido eleva as tensões de instabilidade distorcional e de ruína. Este efeito foi gerado pelo aumento da resistência à instabilidade local da alma promovendo aumento na restrição rotacional do conjunto mesa/enrijecedor. Desta forma, a instabilidade local foi direcionada para a mesa do perfil. Assim, a inclusão de enrijecedores intermediários na alma melhora a capacidade de resistência do perfil em relação aos modos de instabilidade distorcional e local.

A influência do comprimento do perfil foi verificada para colunas curtas. Quando o comprimento de flambagem é próximo do comprimento do perfil a tensão de instabilidade distorcional e a tensão de ruína são elevadas proporcionalmente. Porém, comparando as tensões distorcionais experimentais com as tensões teóricas de instabilidade elástica não se verificou qualquer influência das condições de extremidade. O aumento do comprimento com a manutenção das características geométricas da seção transversal não alteram a tensão de instabilidade distorcional. Desta forma, múltiplas ondas senoidais podem desenvolver-se ao longo do comprimento do perfil.

Segundo Kesti \& Davies (1999) as colunas curtas em perfis formados à frio submetidas a tensões de compressão, as condições de extremidade exercem influência significativa na resistência do perfil no modo distorcional. Batista et. al. (2002) confirma este fato sendo que a condição de 
extremidade impedida pode gerar tensões de instabildade elástica distorcionais superiores ao empenamento livre. Desta forma, adotando-se a condição de empenamento livre em situações de projeto pode-se estar reduzindo-se a eficiência da resistência do perfil na prática.

Os dados experimentais de Kwon \& Hancock (1992) verificando a influência do comprimento do perfil são apresentados na tabela 2.

Tabela 2: Resultados experimentais de Kwon \& Hancock (1992).

\begin{tabular}{|c|c|c|c|}
\hline \multirow{2}{*}{ Perfil Ensaiado } & \multicolumn{3}{|c|}{ Resultado } \\
\cline { 2 - 4 } & $\begin{array}{c}\sigma_{\text {dist }} \\
(\mathrm{MPa})\end{array}$ & $\begin{array}{c}\text { Modo de } \\
\text { Instabilidade }\end{array}$ & $\begin{array}{c}\sigma_{\text {Máx }} \\
(\mathrm{MPa})\end{array}$ \\
\hline $\mathrm{CH} 1-7-800$ & 68,6 & $\mathrm{D}(2)+\mathrm{L}(5)$ & 149,5 \\
\hline $\mathrm{CH} 1-7-600$ & 75,8 & $\mathrm{D}(1)+\mathrm{L}(5)$ & 155,7 \\
\hline $\mathrm{CH} 1-7-400$ & 88,8 & $\mathrm{D}(1)+\mathrm{L}(3)$ & 160,0 \\
\hline
\end{tabular}

Na tabela 2, CH1 representa o tipo de seção transversal U enrijecido, 7 o tamanho do enrijecedor de borda em mm, 400-800 os comprimentos dos perfis ensaiados, D o modo distorcional de instabilidade, L o modo local de instabilidade e os valores em parênteses o número de semi-ondas senoidais ocorrido.

Conforme podemos ver na tabela 2, poderia ser analisado a influência do perfil com $1000 \mathrm{~mm}$ verificando-se a tensão distorcional ocorrida e se o número de semi-ondas se manteria ou se elevaria. Assim, teríamos evidências experimentais da influência do aumento do comprimento do perfil na tensão distorcional. É claro que neste ponto talvez teríamos a ocorrência da instabildade global da barra tornando a situação mais complexa.

Utilizando-se das equações para o cálculo da tensão de instabilidade distorcional do anexo D da NBR 14762 verificou-se para a seção transversal ensaiada por Kwon \& Hancock (1992): $b_{w}=120,5$ mm; $b_{f}=89,5$ mm; $t=1,1$ $\mathrm{mm}$ e $\mathrm{d}=7 \mathrm{~mm}$. A tensão de cálculo pelo anexo $D$ da NBR 14762 indicou a tensão de instabilidade distorcional de $56 \mathrm{MPa}$ com comprimento senoidal 
de $471 \mathrm{~mm}$. Desta forma, para o perfil com o comprimento de $1000 \mathrm{~mm}$ a tensão de instabilidade distorcional deverá estar entre os valores extremos da NBR 14762 e o ensaio com o perfil de $800 \mathrm{~mm}$. Assim, também se verifica o conservadorismo do modelo analítico de Hancock empregado na NBR 14762.

\subsubsection{Curvas de Resistência}

A primeira curva de resistência para a determinação da tensão de instabilidade distorcional em perfis submetidos à compressão foi desenvolvido por Lau \& Hancock (1988). Segundo Kwon \& Hancock (1992), esta curva de resistência determina o comportamento inelástico do modo distorcional e teve como filosofia a instabilidade de colunas, baseando-se na parábola de Johnston (1976).

Assim,

$$
\begin{array}{ll}
\sigma_{d i}=F_{y}\left(1-\frac{F_{y}}{4 . \sigma_{d e}}\right) & \sigma_{d e} \geq \frac{F_{y}}{2} \\
\sigma_{d i}=\sigma_{d e} & \sigma_{d e} \leq \frac{F_{y}}{2}
\end{array}
$$

Onde:

$\sigma_{d i} \quad$ Tensão de instabilidade distorcional inelástica;

$\sigma_{d e} \quad$ Tensão de instabilidade distorcional elástica;

$F_{y} \quad$ Tensão de cálculo para o início de escoamento.

A equação da curva (1.a) apresenta a região onde as tensões de instabilidade distorcional experimental são iguais ou superiores às tensões de escoamento do material, trecho inelástico. A equação da curva (1.b) corresponde ao trecho de instabilidade distorcional elástica as quais, na 
época da elaboração da curva, se desconheciam as potencialidades da condição pós-crítica.

Então, Kwon \& Hancock (1992) propuseram a extensão da curva de Lau \& Hancock (1988) por terem verificado experimentalmente considerável reserva de resistência do modo distorcional na forma isolada e em interação com o modo local, para aços de elevada resistência mecânica. Esta forma de interação entre os modos de instabilidade local e distorcional é classificada por Kwon e Hancock (1992) de modo misto. Assim, os autores descreveram melhor a curva (1.b) considerando o comportamento pós-crítico do modo distorcional:

$$
\begin{array}{ll}
\sigma_{\text {máx }}=F_{y}\left(1-\frac{F_{y}}{4 . \sigma_{d e}}\right) & \sigma_{d e} \geq \frac{F_{y}}{2} \\
\sigma_{\text {máx }}=F_{y}\left(0,055\left(\sqrt{\frac{F_{y}}{\sigma_{d e}}}-3,6\right)^{2}+0,237\right) & \frac{F_{y}}{13} \leq \sigma_{d e} \leq \frac{F_{y}}{2}
\end{array}
$$

Onde:

$\sigma_{\text {máx }}$ Tensão de instabilidade distorcional máxima;

$\sigma_{d e} \quad$ Tensão distorcional ou mista de instabilidade elástica;

$F_{y} \quad$ Tensão de escoamento.

A curva 2 apresenta o comportamento pós-crítico do modo distorcional. Na equação da curva (2.a), os perfis de esbeltez menor não apresentam capacidade de reserva pós-crítica significante. Entretanto, a equação da curva (2.b) possui maior capacidade de reserva pós-crítica para perfis de elevada esbeltez. O valor correspondente a $50 \%$ da tensão de escoamento é o limite entre os trechos de instabilidade distorcional elástica e inelástica. Nesse ponto, a capacidade de reserva pós-crítica é nula.

Kwon \& Hancock (1992) proporam alternativamente outra curva de resistência para o cálculo da tensão de instabilidade distorcional. Nesta nova proposta a filosofia utilizada foi a instabilidade de chapas baseando-se na curva de resistência de Winter (1968). Os autores alteraram a tensão de 
instabilidade local limitando aa tensão de instabilidade distorcional ou mista $\left(\sigma_{\mathrm{de}}\right)$.

Assim,

$\frac{b_{e}}{b}=1$

para $\lambda \leq 0,673$

$\frac{b_{e}}{b}=\sqrt{\frac{\sigma_{d e}}{F_{y}}}\left(1-0,22 \sqrt{\frac{\sigma_{d e}}{F_{y}}}\right) \quad$ para $\lambda>0,673$

$\lambda=\sqrt{\frac{F_{y}}{\sigma_{d e}}}$

Onde:

$b_{e} \quad$ Parte efetiva do elemento com da largura $b$;

$\sigma_{d e} \quad$ Tensão distorcional ou mista de instabilidade elástica;

$F_{y} \quad$ Tensão de cálculo para o início de escoamento.

Entretanto, analisando dados experimentais Kwon \& Hancock (1992) verificaram que a curva 3 apresenta alguns casos de ensaios cuja resistência estavam abaixo destas e contra a segurança. Este fato justifica o motivo pelo qual a fórmula de Winter (1968) não responde apropriadamente ao modo distorcional para seções transversais enrijecidas e constituídas de aço de elevada resistência mecânica serem ineficientes. Deste modo, Kwon \& Hancock (1992) proporam modificação na curva 3 para melhor representar os resultados experimentais do modo distorcional.

Então,

$$
\begin{array}{ll}
\frac{b_{e}}{b}=1 & \text { para } \lambda \leq 0,561 \\
\frac{b_{e}}{b}=\left(\frac{\sigma_{d e}}{F_{y}}\right)^{0.6}\left(1-0,25\left(\frac{\sigma_{d e}}{F_{y}}\right)^{0.6}\right) & \text { para } \lambda>0,561 \\
\lambda=\sqrt{\frac{F_{y}}{\sigma_{d e}}} &
\end{array}
$$


As curvas propostas por Hancock para a análise de instabilidade distorcional de perfis formados a frio submetidos à compressão estão apresentadas no gráfico da figura 23.

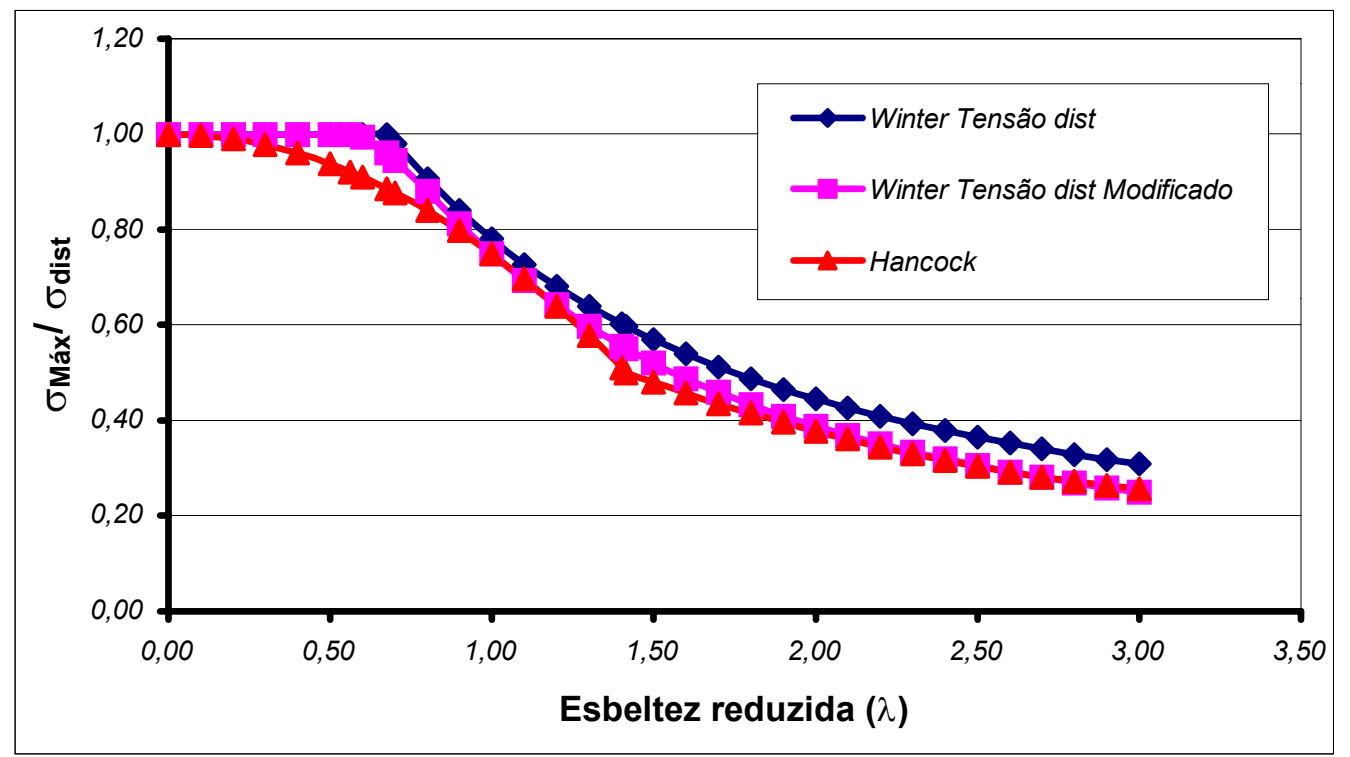

Figura 23 Gráfico de comparação entre as curvas propostas por Kwon \& Hancock (1992) para a análise da instabilidade distorcional.

Observando-se o gráfico da figura 23, comparando-se a curva 2 (filosofia de instabilidade de barra) com as curvas 3 e 4 (filosofia de instabildade de chapa) podemos verificar que a curva 2 cobre todos os casos de instabilidade distorcional gerando resultados mais conservativos. Kwon \& Hancock (1992) transladaram e inclinaram levemente a curva de Winter modificada tangenciando-a com a curva proposta por Hancock em razão de evidências experimentais. Esta modificação foi elaborada através de ajustes dos coeficientes no trecho onde ocorrem as reduções das larguras efetivas dos elementos constituintes da seção transversal.

O trecho de esbeltez reduzida inferior a 1,414 corresponde à instabilidade distorcional inelástica. Neste trecho possui mínima capacidade de reserva pós-crítica havendo a interação entre a tensão de instabilidade elástica com o escoamento do material. No trecho com esbeltez inferior a 0,673 observa-se que não existe redução de largura efetiva de elementos constituintes de perfis. Assim, praticamente não existe o comportamento 
pós-crítico do modo distorcional devido à ausência do fenômeno de instabilidade de chapa. Nesta faixa de esbeltez observou-se experimentalmente que ocorre o início de escoamento da seção transversal anteriormente ao início fenômeno distorcional. Na faixa de esbeltez de 0,673 a 1,414 pode existir a interação entre os modos de instabilidade distorcional e local, porém existindo pequena reserva de resistência pós-crítica.

A instabilidade distorcional elástica corresponde ao trecho com valores de esbeltez reduzida acima de 1,414 e inferiores a 3,6. Como pode ser verificado no gráfico da figura 23 , na interação entre o modo distorcional com o modo local existe extensa capacidade para o comportamento pós-crítico ser desenvolvido. Para valores de esbeltez reduzida acima de 2,0 as curvas propostas tangenciam-se expressando a associação entre os modos de instabilidade local e distorcional. A faixa de esbeltez reduzida entre 1,2 e 2,0 compreende casos de instabilidade puramente distorcional verificados experimental mente em perfis do tipo Rack nos trabalhos de Hancock (1985), Lau \& Hancock (1988), Kwon \& Hancock (1992) e Batista et. al. (2000).

Observa-se que o modo de instabilidade distorcional corresponde ao estado limite último das curvas de resistência apresentadas, independente da interação com o modo local.

\subsubsection{Modelo de Lau \& Hancock para perfis submetidos à Flexão}

A instabilidade distorcional de perfis submetidos à compressão do tipo Rack ou U enrijecido, por exemplo, envolve a rotação em direções opostas dos conjuntos mesa/enrijecedor sob tensões uniformes com centro rotacional nas junções alma/mesa. A rotação do conjunto é simultânea a instabilidade da alma a qual provoca o deslocamento lateral da seção transversal do perfil. Observa-se que a instabilidade da alma é caracterizada por curvatura em semi-onda longitudinal simples, conforme figura 24. 


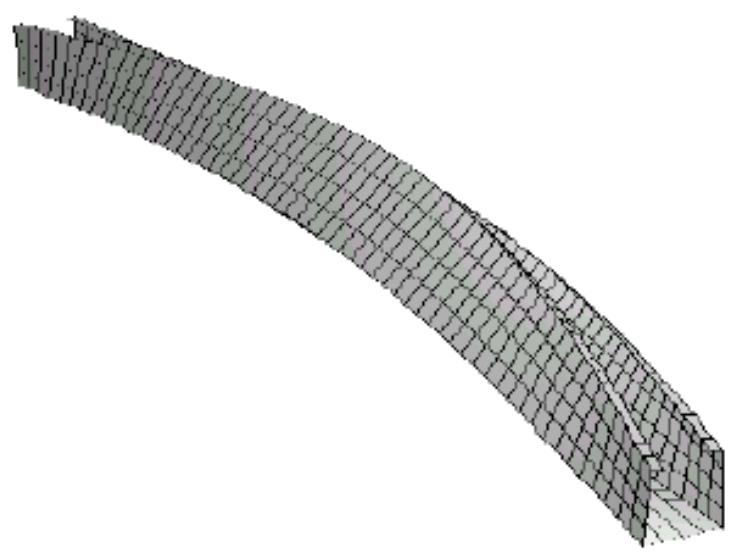

Figura 24 Distorção na compressão com impedimento livre. Fonte: Batista et. al. (2000b).

A instabilidade distorcional de elementos fletidos para perfis de seção transversal do tipo $U$ enrijecido e $Z$ enrijecido, por exemplo, caracteriza-se pelo mesmo movimento rotacional. Entretanto, somente rotaciona o conjunto submetido às tensões de compressão no gradiente de tensão. Deste modo, observa-se que a instabilidade da alma é desenvolvida por curvatura em semi-onda longitudinal dupla. Nota-se que os comprimentos de flambagem distorcional dos elementos mesa e alma do perfil são iguais tanto na compressão quanto na flexão.

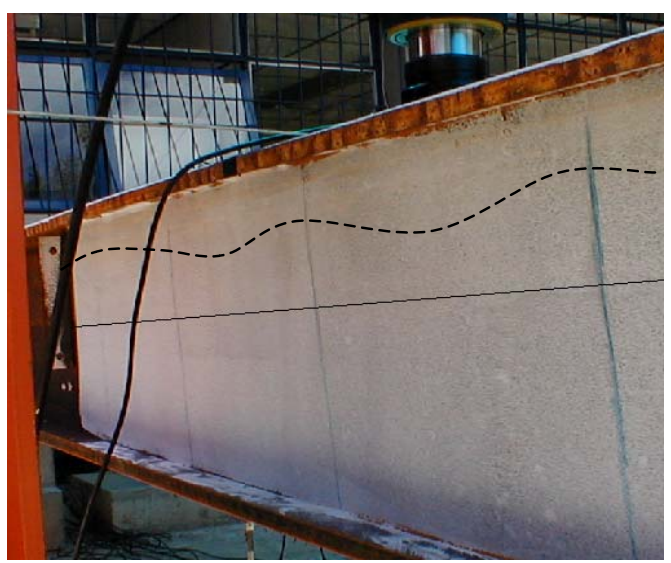

Figura 25 Curvatura dupla longitudinal da alma devido a distorção na flexão de perfil U enrijecido. 


\subsubsection{Formulação Analítica - Perfil Submetido à Flexão}

O modelo analítico de Lau \& Hancock (1997) é uma extensão do modelo de Lau \& Hancock (1987) para perfis submetidos à compressão aos quais objetivam a determinação da tensão de instabilidade distorcional elástica. Algumas características diferem os modelos obviamente em razão do tipo de solicitação.

A formulação do modelo de Lau \& Hancock (1987) para perfis formados a frio submetidos à compressão é baseada no modelo de coluna simples, tratando o conjunto mesa/enrijecedor restringido elasticamente pela alma de forma isolada e sofrendo a instabilidade por flexo-torção. Ao efeito da instabilidade na alma, o modelo de Lau \& Hancock contempla a perda de rigidez através da redução do coeficiente de restrição rotacional $\mathrm{k}_{\phi}$.

Hancock (1997) modificou as equações do modelo a compressão de Lau \& Hancock (1987) para seções submetidas à compressão a fim de que se utilize no modo distorcional a flexão.

Tratando-se a alma do perfil $U$ enrijecido submetida a compressão como uma viga simplesmente apoiada na flexão conforme figura 26 , a rigidez rotacional nas extremidades é definida como $2 \mathrm{EI} / \mathrm{L}$ com valores de momentos iguais e opostos.

Analogamente, o mesmo tipo de perfil submetido à flexão tem-se modificações nas vinculações. Assim, tratando-se a viga como simplesmente apoiada em uma extremidade e engastadas na outra, conforme figura 26, a rigidez rotacional pode ser considerada como 4EI/L. Deste modo, Hancock (1997) conclui que a mudança de vinculação das extremidades da "viga" idealizada do perfil submetido à compressão para a flexão aproximadamente o dobro do valor do coeficiente de rigidez rotacional $\mathrm{k}_{\phi}$. 


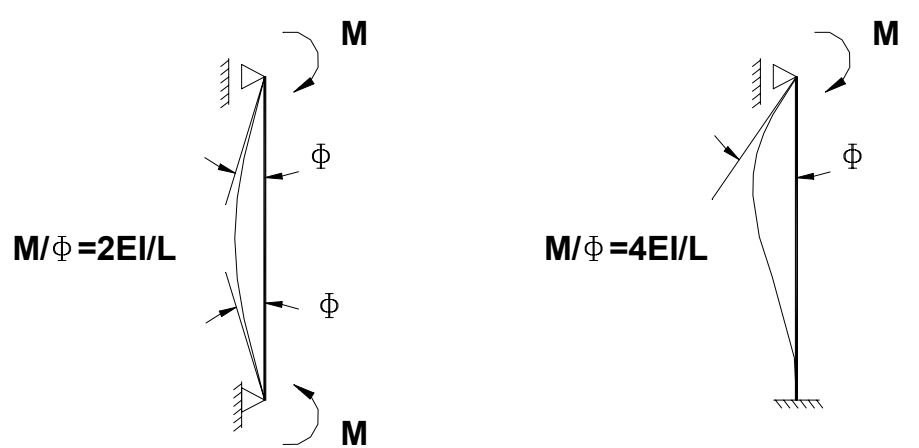

\section{$\begin{array}{ll}\text { a) Compressão } & \text { b) Flexão }\end{array}$}

Figura 26 Vinculações de vigas idealizando as deformações da alma de perfis devido ao efeito distorcional.

Deste modo, para os perfis fletidos o cálculo da carga crítica de instabilidade por distorção é calculado com $k_{\phi}$, conforme a expressão (4.21).

$$
k_{\phi}=\frac{2 . E t^{3}}{5,46\left(b_{w}+0,06 \lambda\right)}\left[1-\frac{1,11 P^{\prime}}{E A t^{2}}\left(\frac{b_{w}^{4} \lambda_{d}^{2}}{2.192 b_{w}^{4}+12.56 \lambda_{d}^{4}+13.39 \lambda_{d}^{2} b_{w}^{2}}\right)\right]
$$

Onde:

$$
\begin{aligned}
& \lambda_{d}=4,80\left(\beta_{4} b_{w} / 2 \cdot t^{3}\right)^{0,25} \\
& \eta=\left(\pi / \lambda_{d}\right)^{2}
\end{aligned}
$$

Observa-se que o efeito do gradiente de tensão do modo distorcional na flexão modifica o fator de redução de rigidez da alma devido à alteração do coeficiente de flambagem de chapa. Hancock (1997) modificou o fator de redução (termo dos colchetes da equação 4.21) através dos valores de $k$ listados por Thimoshenko \& Gere (1961) para casos de elementos submetidos à flexão. Deste modo esta extensão do modelo analítico de Lau \& Hancock (1987) foi nomeada de modelo analítico de Lau \& Hancock à flexão (1997). 
Segundo Hancock (1997), o modelo de Lau \& Hancock (1987) na forma inicial não possuía limitação da configuração reta no enrijecedor. Deste modo, o modelo pode ser utilizado para perfis com enrijecedores de borda inclinados (figura 27.a) ou com enrijecedores de retorno (figura 27.b).

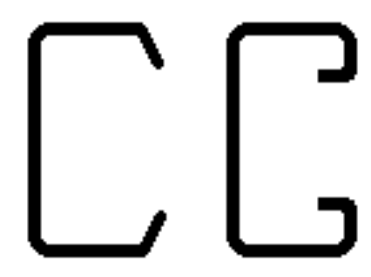

(a)

(b)

Figura 27 Variações do tipo de perfis do tipo $U$ enrijecido: a - Bordas inclinadas; $b$ - Enrijecedores de retorno.

A inclusão de enrijecedores adicionais aos perfis formados já enrijecidos foi uma tentativa de fabricantes de aumentarem a resistência do perfil à instabilidade distorcional e local. Este avanço tecnológico aumentou a complexidade dos enrijecedores o que motivou pesquisas. Neste sentido, Bambach et al. (1998) realizaram um estudo teórico desta situação com o objetivo de utilizarem as equações dos modelos de Lau \& Hancock (1987) para os perfis submetidos à compressão e Lau \& Hancock (1997) para o caso de perfis fletidos. Na determinação da tensão de instabilidade distorcional elástica as definições das propriedades geométricas foram obtidas derivadas para os casos de enrijecedores inclinados e enrijecedores de retorno.

Bambach et al. (1998) verificaram a influência da altura do enrijecedor de borda com a adição de enrijecedores de "retorno" no modo distorcional. Os autores verificaram que para enrijecedores "curtos", isto é, entre a exigência de tamanho mínimo e até um certo limite de início de influência da ordem de $15 \mathrm{~mm}$, não existe modificação no modo de instabilidade distorcional. Entretanto, para o tamanho de enrijecedores de borda a partir de $20 \mathrm{~mm}$ notou-se o surgimento do fenômeno distorcional no conjunto de enrijecedores de borda. A presença do enrijecedor adicional 
causa a distorção do conjunto de enrijecedores comprimidos através da rotação na junção mesa/enrijecedor. Neste modo de instabilidade a alma do perfil sofre flexão e existe distorção da mesa comprimida. Por esse motivo, este modo de instabilidade distorcional é chamado de mesa/enrijecedor. Observa-se que o fato de haver a distorção da mesa fere uma das hipóteses do modelo de Lau \& Hancock.

Para propósitos práticos observa-se que este modo de instabilidade distorcional não é crítico desde que a relação comprimento do enrijecedor/altura da alma seja consideravelmente extensa. Aos perfis comprimidos a relação altura de alma/comprimento da mesa deve ser inferior a 3. Este propósito é de se evitar a ocorrência da instabilidade da mesa em decorrência de valores negativos ou desprezíveis do coeficiente de rigidez rotacional $(\mathrm{k} \phi)$. Aos perfis fletidos, a relação largura da mesa/altura do enrijecedor deve ser maior que 3,3 para se evitar o excessivo conservadorismo das equações para o cálculo da tensão elástica distorcional e deve ser empregado o fator de correção $\left[b_{w} /\left(b_{w}-2 \bar{y}\right)\right]$ para considerar a tensão gradiente no enrijecedor de borda e a tensão uniforme no enrijecedor adicional. Para ambas solicitações, o enrijecedor de borda deve atender a exigência do tamanho mínimo de enrijecedor para se garantir a eficiência do mesmo (equação 4.20).

Como simples comparação, foi realizada uma análise via faixas finitas partindo-se de um perfil padrão $U_{\text {enr }}$ submetido à flexão. $O$ perfil adotado possui as dimensões nominais de $100 \mathrm{~mm}$ de altura de alma $\left(b_{w}\right), 80 \mathrm{~mm}$ de largura de mesa $\left(b_{f}\right), 20 \mathrm{~mm}$ de comprimento do enrijecedor de borda (d), espessura $2 \mathrm{~mm}$ e tensão de escoamento igual $300 \mathrm{MPa}$. Efetuou-se uma análise inicial e verificou-se que o modo distorcional era o modo crítico. Posteriormente, adicionou-se o complemento de $40 \mathrm{~mm}$ no enrijecedor de borda com uma virada a $90^{\circ}$ graus com o intuito de formar um perfil do tipo rack e, numa outra situação, um perfil do tipo com enrijecedor de retorno. Os dados da análise de instabilidade críticos obtidos estão listados na tabela 3 após serem feitas as correções pela parábola de Johnston.

Tabela 3: Análise comparativa de perfis submetidos à flexão. 


\begin{tabular}{|c|c|c|}
\hline Perfil & $\begin{array}{c}\sigma_{\text {Local }} \\
(\mathrm{MPa})\end{array}$ & $\begin{array}{c}\sigma_{\text {Dist }} \\
(\mathrm{MPa})\end{array}$ \\
\hline$U_{\text {enr }}$ & 261 & 255 \\
\hline Rack & 261 & 219 \\
\hline$U_{\text {Retorno }}$ & 261 & 268 \\
\hline
\end{tabular}

Como pode ser observado na tabela 3 , a adição do enrijecedor com virada externa formando o perfil do tipo rack reduziu a tensão crítica distorcional em $14,2 \%$ em relação ao perfil do tipo $U_{\text {enr. }}$. Verifica-se neste exemplo a evidência da alta sensibilidade deste tipo de perfil ao modo distorcional. Esta sensibilidade foi também verificada nos trabalhos de Hancock (1987) e Batista et al (2000). Para o caso da adição de enrijecedor com virada interna ( $\left.\cup_{\text {Retorno }}\right)$ a tensão crítica foi elevada em $5 \%$ em relação ao perfil $U_{\text {enr. }}$. Deste modo, observa-se que a adição de enrijecedores de retorno pode ser favorável ao aumento da resistência crítica do perfil ao modo distorcional. Observa-se que a tensão crítica de instabilidade local permaneceu igual para os três casos representando a instabilidade local da mesa dos perfis.

\subsubsection{Modelo de Sharp}

O modelo de Sharp (1966) é uma formulação para o cálculo de tensão de instabilidade elástica de elementos compridos delgados.

Sendo:

$$
\sigma_{c r}=\left(\frac{2 \sqrt{E I_{x f} b_{f}^{2} k_{\phi}}+\frac{E J_{f}}{2(1+v)}}{\left(I_{x f}+I_{y f}\right)+A_{f}\left(\bar{x}^{2}+\bar{y}^{2}\right)}\right)
$$

Onde:

$\mathrm{A}_{\mathrm{f}} \quad$ Área bruta da seção transversal do conjunto mesa/enrijecedor comprimido; 
$I_{x f}, I_{y f} \quad$ Momento de inércia do conjunto mesa/enrijecedor sobre os eixos $\mathrm{x}$ e $\mathrm{y}$, onde os eixos são colocados no centro de gravidade do conjunto;

$\mathrm{J}_{\mathrm{f}} \quad$ Momento de inércia à torção do conjunto mesa/enrijecedor;

$\bar{x}, \bar{y}$ Distancia da junção mesa/alma ao centro de gravidade do conjunto mesa/enrijecedor.

Segundo Hancock (1997), o modelo se Sharp (1966) não admite redução da rigidez devido à compressão da alma.

Como hipótese o modelo de Sharp (1966) a rigidez de mola à translação $k_{x}$ é assumida com infinita tornando a junção alma/mesa como um ponto fixo com liberdade rotacional. A rigidez rotacional é definida pela equação:

$$
k_{\phi}=\frac{2 \cdot E t^{3}}{5,46\left(b_{w}+\frac{2}{3} b_{f}\right)}
$$

Hancock (1997) realizou comparação numérica avaliando o modelo de Lau \& Hancock com o método das faixas finitas e o modelo de Sharp (1966). Os resultados obtidos por Hancock (1997) foram que o modelo de Lau \& Hancock são satisfatórios, apresentando valores em média 1,8\% inferiores em relação a analise de instabilidade distorcional pelo método das faixas finitas (sem restrição lateral).

\subsection{Curvas de Cálculo}

Curvas de resistência para perfis formados a frio submetidos à flexão foram propostas por Hancock (1997) derivadas dos trabalhos dos trabalhos 
experimentais de Kwon \& Hancock (1992) e Hancock et al. (1994). Essas são baseadas em duas filosofias de cálculo. A curva 4 se baseia na filosofia da instabilidade de barras e a curva 5, alternativamente, se baseia na instabilidade de chapas (Winter). Observa-se que estas curvas permitem a interação da instabilidade distorcional com o escoamento do material, representando a reserva de resistência pós-crítica no modo distorcional. Entretanto, a interação do modo local com o modo distorcional é ignorada, exceto quando esta ocorre na alma.

Assim, para o cálculo da instabilidade distorcional com a filosofia de instabilidade de barras, tem-se:

$$
\begin{array}{ll}
M_{\text {máx }}=M_{y}\left(1-\frac{M_{y}}{4 \cdot M_{d e}}\right) & M_{d e} \geq \frac{M_{y}}{2} \\
M_{\text {máx }}=M_{y}\left(0,055\left(\sqrt{\frac{M_{y}}{M_{d e}}}-3,6\right)^{2}+0,237\right) & M_{d e} \leq \frac{M_{y}}{2}
\end{array}
$$

O cálculo da instabilidade distorcional com a filosofia de instabilidade de chapas pode ser expresso pela curva de resistência 5. Logo, tem-se:

$$
\begin{array}{lll}
M_{\text {máx }} & =M_{y} & M_{d e}>2,2 M_{y} \\
M_{\text {máx }}=M_{y} \sqrt{\frac{M_{d e}}{M_{y}}}\left(1-0,22 \sqrt{\frac{M_{d e}}{M_{y}}}\right) & M_{d e} \leq 2,2 M_{y} \\
\lambda_{d}=\sqrt{\frac{M_{y}}{M_{d e}}} &
\end{array}
$$

Onde:

$M_{\text {máx }}$ Momento de instabilidade distorcional máxima;

$M_{d e} \quad$ Momento distorcional de instabilidade elástica;

My Momento de cálculo para o início de escoamento.

Alternativamente, Hancock et al (1997) apud Rogers, C.A. \& Schuster, R.M. (1997) alteraram a curva 5 para melhor representar o comportamento 
pós-crítico em função de evidências experimentais e abranger outro modo distorcional de instabilidade na flexão, instabildade distorcional mesa/alma.

Assim,

$M_{\text {máx }}=M_{y}$

$M_{d e}>3,18 M_{y}$

$M_{\text {máx }}=M_{y}\left(\frac{M_{d e}}{M_{y}}\right)^{0,6} \cdot\left(1-0,25\left(\frac{M_{d e}}{M_{y}}\right)^{0,6}\right) \quad M_{d e} \leq 3,18 M_{y}$

$\lambda_{d}=\sqrt{\frac{M_{y}}{M_{d e}}}$

Onde:

$M_{\text {máx }}$ Momento de instabilidade distorcional máxima;

$M_{d e} \quad$ Momento distorcional de instabilidade elástica;

My Momento de cálculo para o início de escoamento.

A instabilidade distorcional mesa/alma apresenta comportamento rotacional do conjunto mesa/enrijecedor sobre a junção alma/mesa, característica comum do modo distorcional. Entretanto, ocorre posteriormente movimento lateral do conjunto comprimido com deslocamento da junção alma/mesa, incluindo flexão transversal da alma próximo do estado limite (ruína).

Segundo Rogers, C.A. \& Schuster, R.M. (1997), testes experimentais de perfis $U$ enrijecidos com aços de elevada resistência, esbeltez de alma próxima de 200 e mesa de largura estreita podem ocorrer a ruína por instabilidade distorcional mesa/alma. Entretanto, poucos casos foram encontrados de fato. Os autores realizaram estudo experimental e analisaram diversos resultados coletados de pesquisadores. Deste estudo, Rogers, C.A. \& Schuster, R.M. (1997) concluíram que a curva 6 de Hancock apresenta resultados satisfatórios para os casos de perfis submetidos à flexão com comprimento de meia-onda senoidal reduzido. 


\subsection{Simplificação do Modelo Distorcional de Hancock para Perfis Submetidos à Flexão}

Segundo Ellifritt et al (1998), o modelo analítico de Hancock (1997) utilizado no cálculo da instabilidade distorcional de perfis do tipo $U$ enrijecido e $Z$ enrijecido na flexão é um procedimento de cálculo extenso e as propriedades geométricas utilizadas no desenvolvimento não se encontra disponível normatizações comuns. Desta forma, o autor desenvolveu um procedimento prático e expedito de se analisar o problema da instabilidade distorcional na flexão considerando-se as propriedades da seção total, a espessura da chapa e a tensão de escoamento do material. Observa-se que no modelo de Hancock são consideradas as propriedades do elemento mesa/enrijecedor isolado para o cálculo da tensão de instabilidade distorcional elástica.

O autor realizou um estudo baseado no modelo de Hancock (1997) do cálculo de aproximadamente 200 seções de perfis susceptíveis ao modo distorcional na flexão para os perfis do tipo $U$ enrijecido e $Z$ enrijecido. Neste procedimento o autor determinou o momento resistente ao modo distorcional avaliando a influência da variabilidade do método de Hancock. Deste procedimento, Ellifrit associou a capacidade de momento resistente destes perfis às variáveis: espessura de chapa, momento de escoamento e dimensões nominais do perfil. Deste modo, de forma simplificada pode-se analisar a influência do modo distorcional no dimensionamento do perfil.

Assim, para os perfis do tipo $U$ enrijecido e $Z$ enrijecido tem-se $o$ parâmetro abscisso:

$$
X=\left(\frac{B}{t}\right)^{1,1} \cdot\left(\frac{D}{d}\right)^{0,4} \cdot \frac{F_{y}}{50}
$$

Onde:
$B$ Largura nominal da mesa;
$t \quad$ Espessura da chapa do perfil;
$D \quad$ Altura nominal da alma do perfil;
d Comprimento nominal do enrijecedor. 
Os parâmetros ordenados ajustados são:

Para o perfil do tipo $U$ enrijecido:

$$
\frac{D_{M n}}{M_{y}}=-8 \cdot 10^{-9} \cdot X^{3}+10^{-5} \cdot X^{2}-0,0048 \cdot X+1,268
$$

Para o perfil do tipo $Z$ enrijecido:

$$
\frac{D_{M n}}{M_{y}}=-3 \cdot 10^{-8} \cdot X^{3}+2 \cdot 10^{-5} \cdot X^{2}-0,0063 \cdot X+1,2747
$$

Onde:

$D_{M n} \quad$ Momento nominal distorcional;

$M_{y} \quad$ Momento de início de escoamento.

Sendo:

$M_{y}=W_{x} \cdot F_{y}$

Segundo Ellifritt et al (1998) a simplificação do modelo de Hancock apresenta-se como um indicativo satisfatório para a análise da instabilidade distorcional de perfis submetidos a flexão. A NBR 14762 apresenta no anexo D um procedimento auxiliar para a análise da influência da instabilidade distorcional no dimensionamento de perfis submetidos à flexão e à compressão.

\subsection{Influência de Travamentos nos Modos de Instabilidade Estrutural}

A instabilidade distorcional nos perfis formados a frio do tipo $U$ enrijecidos e $Z$ enrijecidos submetidos à flexão pode ser pronunciada na presença de pontos de travamentos. Os travamentos impedem deslocamentos da seção transversal e, normalmente, devido à excentricidade de carregamentos em relação ao centro de torção, surgem tensões normais provenientes do empenamento da seção. Desta maneira, 
tensões adicionais podem ser acrescentadas nestes pontos e o comportamento estrutural poderá ser modificado.

O estado total de tensões pode ser definido pelas parcelas conforme pode ser visto na figura 28 .

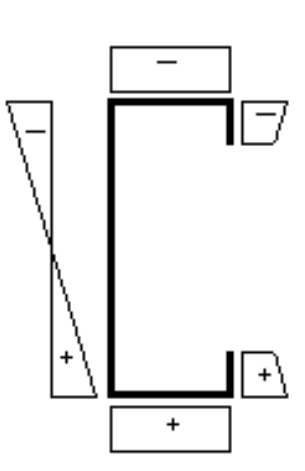

(a)

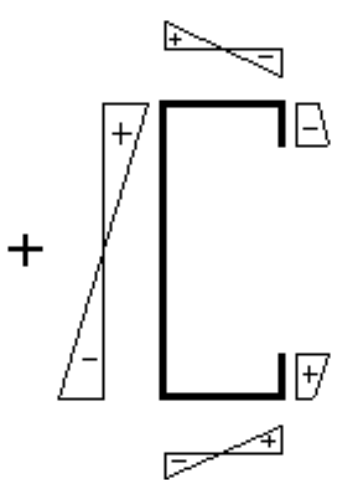

(b)

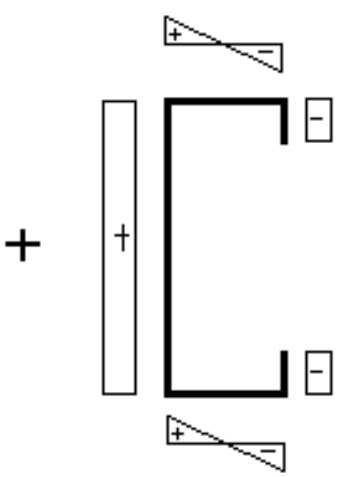

(c)

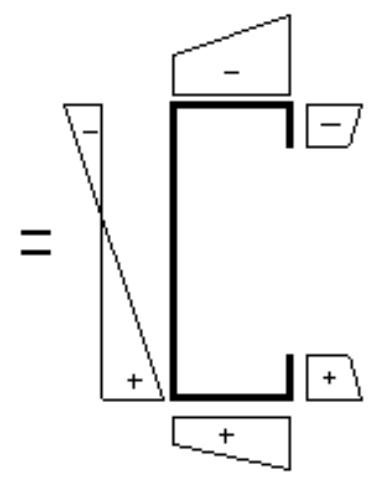

(d)

Figura 28 Parcelas da distribuição total de tensões.

Conforme podemos ver na figura 28 , o estado total de tensões é composta das tensões normais ocorridas na flexão simples do eixo de maior inércia (figura 28.a), das tensões normais devido ao empenamento da seção (figura 28.b) e das tensões da flexão simples em relação ao eixo de menor inércia (figura 28.c). Observa-se que as tensões normais ocorridas na flexão simples em relação ao eixo de menor inércia são desprezíveis. No estado total de tensões (figura 28.d) o fenômeno distorcional pode ocorrer devido ao ponto de aplicação da carga e/ou pontos de travamentos e/ou pontos de carga concentrados.

Segundo Ellifritt et al (1994) perfis submetidos à flexão simples na presença de pontos de travamentos podem ter modo de instabilidade distinguidos em duas formas:

$\checkmark$ Escoamento da interseção mesa/alma. Ocorrendo translação lateral da mesa comprimida e empenamento da seção transversal. $O$ empenamento eleva as tensões normais devido a flexão simples no eixo de maior inércia; 
$\checkmark$ Escoamento e/ou instabilidade distorcional do conjunto mesa/enrijecedor no ponto do travamento. A restrição ao empenamento produz acréscimos de tensões no enrijecedor de borda. Para este caso não existe prescrição nas principais normatizações.

O número de travamentos e a localização dos mesmos têm significante influência no estado de tensões em casos de perfis submetidos à torção combinada a flexão. Segundo Ellifritt et al (1994), para os casos de perfis submetidos somente à flexão simples em relação ao eixo de maior inércia, o estado de tensão é independente do número de travamentos e localização. Por outro lado, existindo a tripla combinação com a flexão nos dois eixos de inércia principais e a torção, o estado de tensão total é função da configuração dos travamentos. Neste caso, a relação entre tensões de empenamento e tensões da flexão exerce influência no modo de instabilidade do perfil. Observa-se que para vãos muito longos (comprimento destravados) o momento fletor é significativa em relação ao momento torçor e deste modo, a presença de travamentos não produz influência no comportamento estrutural. Entretanto, para vão muito curto a influência do momento torçor torna-se significativa em relação ao momento fletor e efeitos do empenamento da seção transversal podem alterar o comportamento estrutural.

Os ensaios experimentais realizados em perfis formados a frio do tipo U enrijecido e $Z$ enrijecido por Ellifritt et al (1994) indicaram resultados não conservativos para vigas de comprimento destravados da ordem de 1 a $2 \mathrm{~m}$. Este fato está diretamente ligado aos casos de vigas com vãos curtos ou vigas com múltiplos travamentos. $O$ autor ainda afirma que ensaios experimentais e resultados analíticos indicaram que as tensões e o modo de instabilidade é função do número de travamentos e localização, não apenas do comprimento destravado. 


\subsection{Modelo de Peköz \& Soroushian para Perfis Conectados a Painéis Metálicos}

Peköz e Soroushian propuseram o modelo de cálculo aplicado a perfis do tipo $\mathrm{Z}$ e $\mathrm{U}$, podendo ser enrijecidos, conectados a painéis metálicos e submetidos a carregamentos transversais quaisquer paralelo ao plano inicial da alma. Como hipótese de cálculo considera-se que os apoios de extremidade impedem apenas rotações em torno do eixo transversal. 0 objetivo do modelo compreende na determinação da tensão normal máxima no perfil, não se desprezando as imperfeições iniciais devidas às tensões de cisalhamento nas mesas.

O perfil, sob ação do carregamento, basicamente possui comportamento composto por dois estágios: deslocamento vertical e rotação da seção transversal, conforme Figura 29.
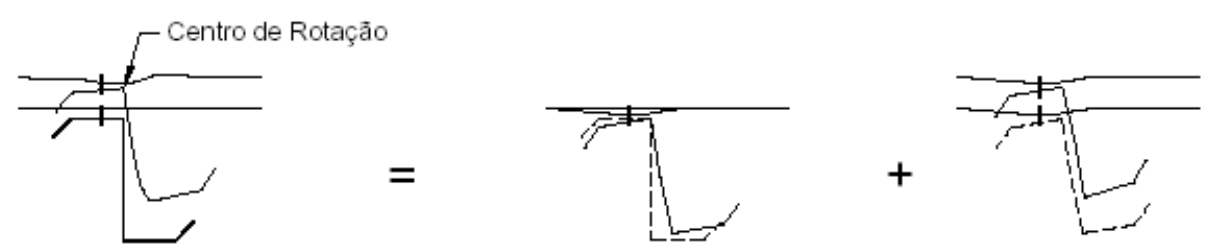

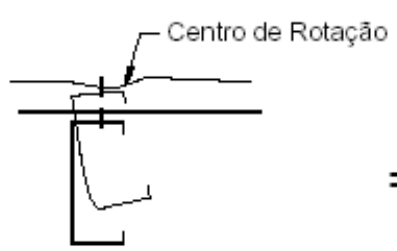

(Estágio Final)

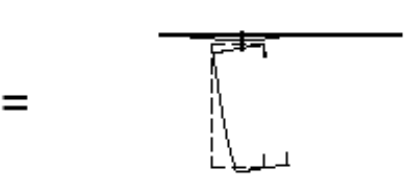

(Rotaçäo)

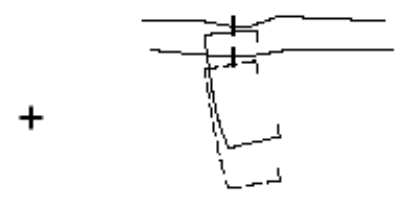

(Deslocamento Vertical)

Figura 29 Comportamento dos perfis sob efeito de sucção. Fonte, Javaroni (1999).

O deslocamento vertical do perfil deve ser verificado pela teoria clássica da resistência dos materiais (flexão simples), com o momento de inércia calculado para seção deformada. 
O segundo estágio compreende na composição de deslocamentos laterais e o giro do perfil, sendo analisado através de modelo analítico aproximado.

As equações foram desenvolvidas assumindo-se como restrição ao giro no plano da mesa. A tensão normal máxima atuante no perfil será obtida pela superposição das tensões normais oriundas da flexão no plano da alma com as tensões normais oriundas do deslocamento lateral e giro:

$$
\sigma=\frac{M_{x}}{W_{x}}+\frac{M_{y}}{W_{y}}
$$

Onde:

$\mathrm{M}_{\mathrm{x}} \quad$ Momento fletor devido à flexão simples, em torno do eixo $\mathrm{x}$;

$W_{x} \quad$ Módulo de resistência elástico da seção transversal da barra em relação ao eixo x;

$W_{y}$ Momento fletor na seção idealizada, em torno do eixo paralelo à alma, passando pelo centro de gravidade da seção.

O momento fletor $M_{y}$ é obtido a partir de uma força lateral idealizada, resultante das tensões de cisalhamento na mesa devidas à ação vertical. Seja a seção transversal idealizada como um perfil $Z_{90}{ }^{1}$, conforme a Figura 30 .

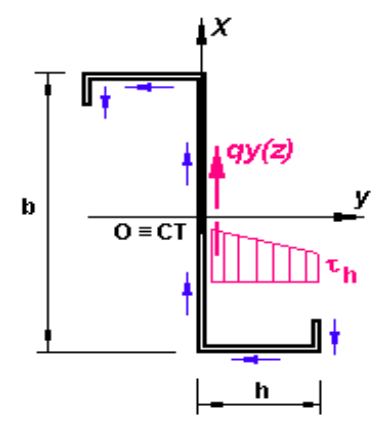

Figura 30 Seção transversal do perfil $Z_{90}$. Fonte: Fruchtengarten, 1995. 
Segundo Peköz \& Soroushian apud Fruchtengarten (1995), para perfis que possuem mesas com bordas enrijecidas, pode-se desprezar as tensões de cisalhamento nas bordas, embora as mesmas sejam consideradas no momento estático da mesa inferior. A força horizontal distribuída ao longo do comprimento do perfil na seção idealizada pode ser expressa por:

$$
q_{x}(z)=-\frac{d H_{x}(z)}{d z}=q_{y}(z) \cdot\left(\frac{W_{x i} \cdot b}{2 \cdot I_{x}^{0}}+\alpha\right)
$$

Onde:

$q_{y}(z)$ Força distribuída na direção vertical;

$H x(z)$ Resultante das tensões de cisalhamento na mesa;

$W_{x i} \quad$ Momento estático da aba inferior em relação ao eixo x;

$I_{x}^{\circ} \quad$ Momento de inércia da seção deformada em relação ao eixo horizontal;

$\alpha \quad$ Razão entre a distância do centro de rotação até a junção da alma com a mesa e a altura da alma (0 para seções tipo Z).

Em qualquer seção da barra idealizada, a força normal pode ser obtida por:

$N(z)=\frac{M_{x}}{I_{x}} \cdot y \cdot A_{c}=\frac{M_{x}}{I_{x}} \cdot M_{s}$

Sendo:

Ms Momento estático da seção idealizada em relação ao eixo x.

A força de compressão distribuída ao longo da barra por unidade de comprimento é obtida como:

$$
p(z)=\frac{d N(z)}{d z}=V_{y} \cdot \frac{M_{s}}{I_{x}}
$$


A suposição dos efeitos permite a análise da viga como sendo uma barra flexo-comprimida, Figura 31.

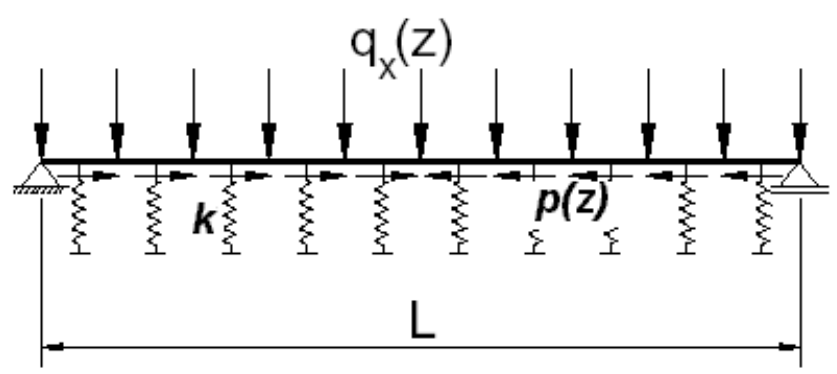

Figura 31 Idealização de uma barra flexo-comprimida.

Devido à simetria, a expressão da energia potencial total pode ser expressa por:

$V=2 \cdot\left[\int_{0}^{\frac{L}{2}} \frac{E l_{y}^{0}}{2}\left(u^{\prime \prime}-u_{0}^{\prime \prime}\right)^{2} d z+\int_{0}^{\frac{L}{2}} \frac{K \cdot\left(u-u_{0}\right)^{2}}{2} d z-\int_{0}^{\frac{L}{2}} q_{x}(z) \cdot\left(u-u_{0}\right) d z-\int_{0}^{\frac{L}{2}} \frac{1}{2} p(z) \cdot\left(u^{\prime 2}-u_{0}^{\prime 2}\right) d z\right]$

Sendo:

u Configuração final da mesa;

$u_{0} \quad$ Imperfeição inicial.

As funções podem ser expressas por meio das seguintes séries:

$$
\begin{aligned}
& u=\sum_{n=1,3,5 \ldots} a_{n} \cdot \operatorname{sen} \frac{n \pi x}{L} \\
& u_{0}=\sum_{n=1,3,5 \ldots} a_{0 n} \cdot \operatorname{sen} \frac{n \pi x}{L}
\end{aligned}
$$

No deslocamento lateral total da mesa $u$ está incluído a imperfeição inicial. Como resultado do deslocamento lateral e giro, o momento de inércia com respeito ao eixo central perpendicular à posição inicial da alma deve ser reduzido, conforme os autores: 
ly é o momento de inércia da seção idealizada em relação ao eixo central paralelo à alma e $K$ é o coeficiente do apoio elástico.

O valor do coeficiente do apoio elástico pode ser obtido a partir da equação (4.26), desprezando-se a redução no momento fletor, tem-se:

$$
q_{x}(z)=q_{y}(z) \cdot\left(\frac{b^{2} \cdot t \cdot h}{4 \cdot I_{x}}+\alpha\right)
$$

O valor correspondente de $q_{x}(\mathrm{z})$ deve ser determinado assumindo-se um valor de $q_{y}(z)$ como sendo o de falha da barra. A partir de um gráfico força lateral contra deslocamento lateral o valor de $K$ é determinado para aquele valor de $q_{y}(z)$.

O momento fletor na seção idealizada será dado por:

$$
M_{y}=E I_{y}^{0} \cdot\left(u^{\prime \prime}-u_{0}^{\prime \prime}\right)=\frac{\pi^{2} E I_{y}^{0}}{L^{2}} \cdot \sum_{n=1,3,5} n^{2}\left(a_{n}-a_{0 n}\right) \cdot \operatorname{sen} \frac{n \pi x}{L}
$$

Para o caso em particular, viga submetida ao carregamento uniformemente distribuída, a amplitude dos deslocamentos pode se determinada através do método de Ritz. Pode-se obter:

$$
\begin{aligned}
& a=\frac{c \cdot\left(\frac{h b^{2} t}{4 I_{x}}+\alpha\right)+a_{0}}{1-0,9 \cdot \frac{h b t}{4 I_{x}} c} \\
& c=\frac{1,27 \cdot q_{y}(z)}{\frac{\pi^{4} E b^{3} t}{12 \cdot L^{4}}}+K
\end{aligned}
$$

Assim, a expressão para o cálculo da máxima tensão normal para seção tipo $Z$ ou seção tipo U é dada pela equação (4.28). 


$$
\sigma_{\text {máx }}=\frac{M_{x}}{I_{x}} \cdot \frac{h}{2}+\frac{\pi^{2} E b}{2 L^{2}} \cdot\left(a-a_{0}\right)
$$

A tensão normal máxima deve ser limitada à tensão limite de escoamento do material ou à tensão crítica corresponde a instabilidade local para os elementos de chapa comprimidos.

Neste modelo de cálculo não se expõe o valor de uma carga crítica, e sim, a verificação da tensão máxima, de tração ou de compressão, a qual deve ser limitada aos valores característicos do material.

\subsection{Método de LaBoube}

O método de Laboube $(1991,1992)$ se destina ao cálculo de terças conectadas a painéis metálicos. Trata-se de um método empírico baseadose em resultados experimentais, não possuindo um modelo matemático formal de cálculo.

A finalidade do método está na determinação da resistência nominal à flexão em perfis cuja mesa tracionada encontra-se fixada às telhas de cobertura. LaBoube correlacionou os momentos fletores últimos observados em ensaios com o momento fletor de início de escoamento da seção transversal, propondo alguns valores para a relação abaixo:

$$
M_{n}=R \cdot M_{y}
$$

Onde:

$M n \quad$ Resistência nominal ao momento fletor;

$R \quad$ Fator de redução.

$M_{y}=W_{e f} \cdot f_{y}$

Wef Módulo de resistência efetivo, elástico;

$f_{y} \quad$ Tensão limite de escoamento do aço. 
$\mathrm{O}$ fator $\mathrm{R}$ é um fator empírico, com valor dado pela razão entre o momento fletor último observado em ensaio e o momento fletor que causa o escoamento inicial da seção transversal $\left(M_{y}\right)$. Os valores de R, obtido para os perfis do tipo $U$ enrijecido e tipo $Z$ enrijecido são, respectivamente, 0,40 e 0,50 para vigas simplesmente apoiadas e 0,60 e 0,70 para vigas contínuas.

Esse procedimento proposto por LaBoube foi adotado pelo AISI (1996, 1991) e continua sendo mantido na atualização de 2001. 


\subsection{Método de Resistência Direta}

Neste método têm-se proposto curvas para prever a resistência dos elementos diretamente com a utilização das propriedades da seção transversal do elemento. Desta maneira, o cálculo da resistência do perfil representa o comportamento mais próximo do real, permitindo a interação entre as partes componentes do perfil na determinação das tensões para os modos de instabilidade local e distorcional.

Os MRD podem ser aplicados através conceitos de generalização de vigas (GBT), Método das Faixas Finitas, Métodos dos Elementos Finitos e entre outros.

O Método de Resistência Direta (MRD) é o método mais atual para a análise de instabilidade de perfis formados a frio e a tendência das principais normas é que este método substitua os métodos analíticos.

A análise de perfis pelo MRD, via método das faixas finitas, consiste no emprego de uma simplificação do método dos elementos finitos para a solução numérica de um problema de auto-valores/auto-vetores. Outros tipos de soluções numéricas permitem a resolução do problema, entretanto, o método das faixas finitas para a análise de instabilidade de perfis possui a vantagem de ser rápido, prático e de gerar bons resultados.

Nesta análise numérica, são apenas indicadas as características geométricas da seção transversal e as propriedades do material. Deste modo, definindo-se o comprimento e os pontos intermediários na extensão, o programa executa varredura no perfil analisando as tensões e os modos de instabilidade ocorridos.

A curva de instabilidade é uma representação dos auto-vetores para os três modos de instabilidade: local, distorcional e global. Conforme pode ser visto na Figura 32. 


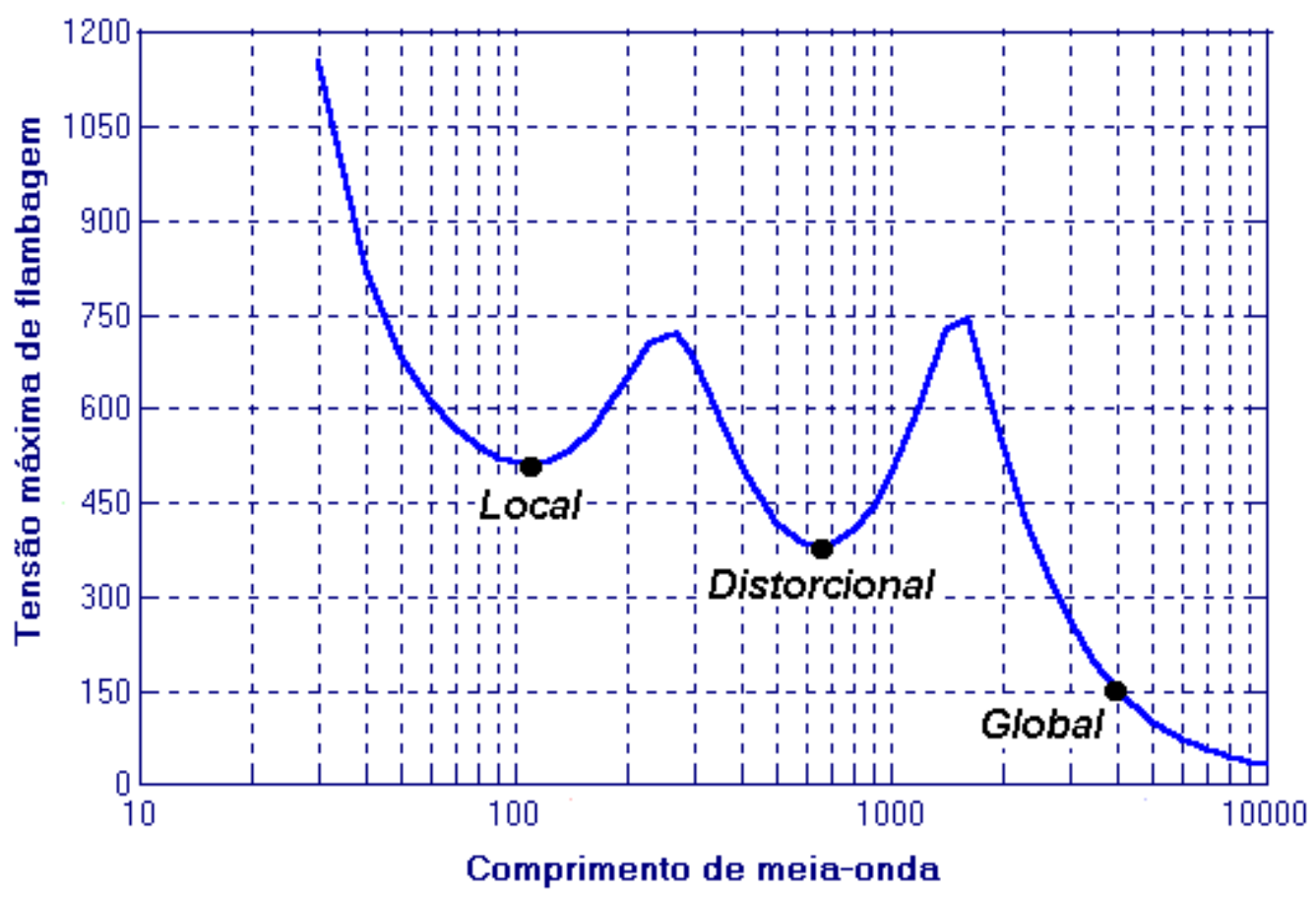

Figura 32 Curva típica de análise de instabilidade via MFF.

Na curva da Figura 32, a caracterização dos modos de instabilidade é representado pelos pontos de mínimo.

As determinações dos modos de instabilidade requerem considerações de comprimento de meia onda senoidal e os tipos de instabilidade. $\mathrm{Na}$ análise, o perfil é carregado com uma tensão distribuída de referência para encontrar um determinado valor de momento crítico.

O ponto de mínimo para a instabilidade local ocorre para comprimentos de meia onda menor ou igual às dimensões características do elemento sob tensão de compressão. Os comprimentos de meia onda senoidal dos outros tipos de instabilidade são muitas vezes maiores em relação ao modo local. Esta condição de comprimento de meia onda é inversamente proporcional a capacidade de resistência pós-crítica, pois quanto menores esses comprimentos maiores serão as resistências pós-críticas. No modo distorcional, o ponto de mínimo ocorre para comprimentos de meia onda intermediários entre a instabilidade local e global.

As principais limitações do MRD são de origem geométrica dos perfis e do material. Conforme a característica do perfil analisado, o AISI determina o 
grau do coeficiente de segurança para o emprego do método de dimensionamento utilizado na estrutura: método do estados limite ou tensões admissíveis.

A título de exemplo, o AISI determina para vigas não perfuradas do tipo $U$ enrijecido as seguintes limitações, conforme Tabela 4:

Tabela 4: Limitações para o dimensionamento de perfis $U$ enrijecido pelo MRD. Fonte AISI, 2002.

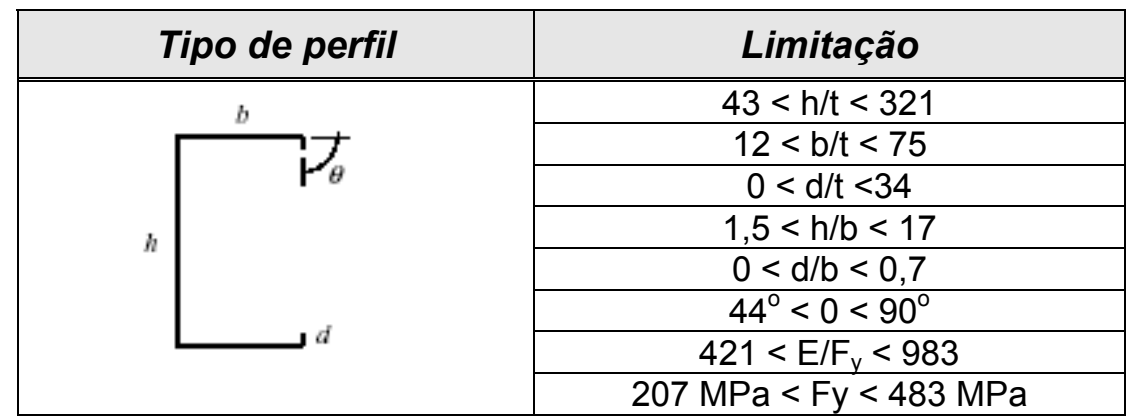

\subsection{Método das Faixas Finitas}

O método das faixas finitas (MFF) foi desenvolvido originalmente por Y.K. Cheung (1976), segundo Schafer (2002). O uso do método foi empregado para análise de perfis laminados por Cheung. Hancock estendeu este estudo aos perfis formados a frio elaborando algumas modificações na matriz de rigidez derivada de Cheung.

A teoria e a metodologia básica empregada no MFF é uma simplificação do método dos elementos finitos (MEF). A diferença entre esses dois métodos está na discretização do perfil (Figura 33). A denominação do MFF é devido ao emprego de elementos de faixas (tiras) usados para modelar na direção longitudinal. Cada faixa é assumida para ser livre para deformações no seu plano (deslocamentos de membrana) e também fora do seu plano (deslocamentos devido à flexão) em semi-ondas senoidais simples. Os extremos da seção são livres para deformação longitudinal, mas são restritas no plano x e y, conforme Figura 34 e Figura 35. 


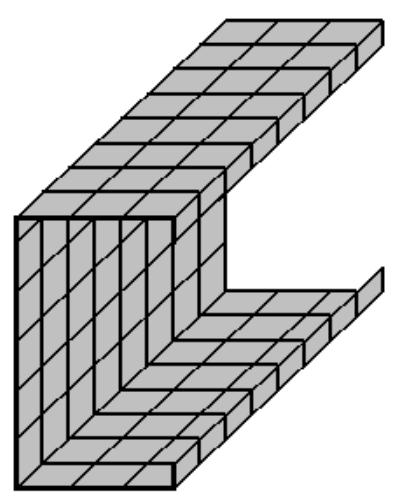

Elementos

Finitos

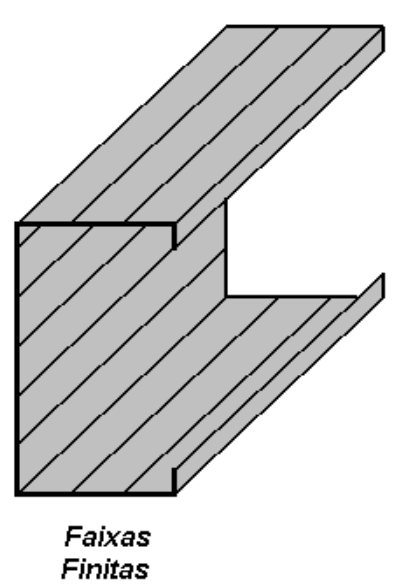

Finitas

Figura 33 Diferença de discretização entre MEF e MFF, Schafer (1998).

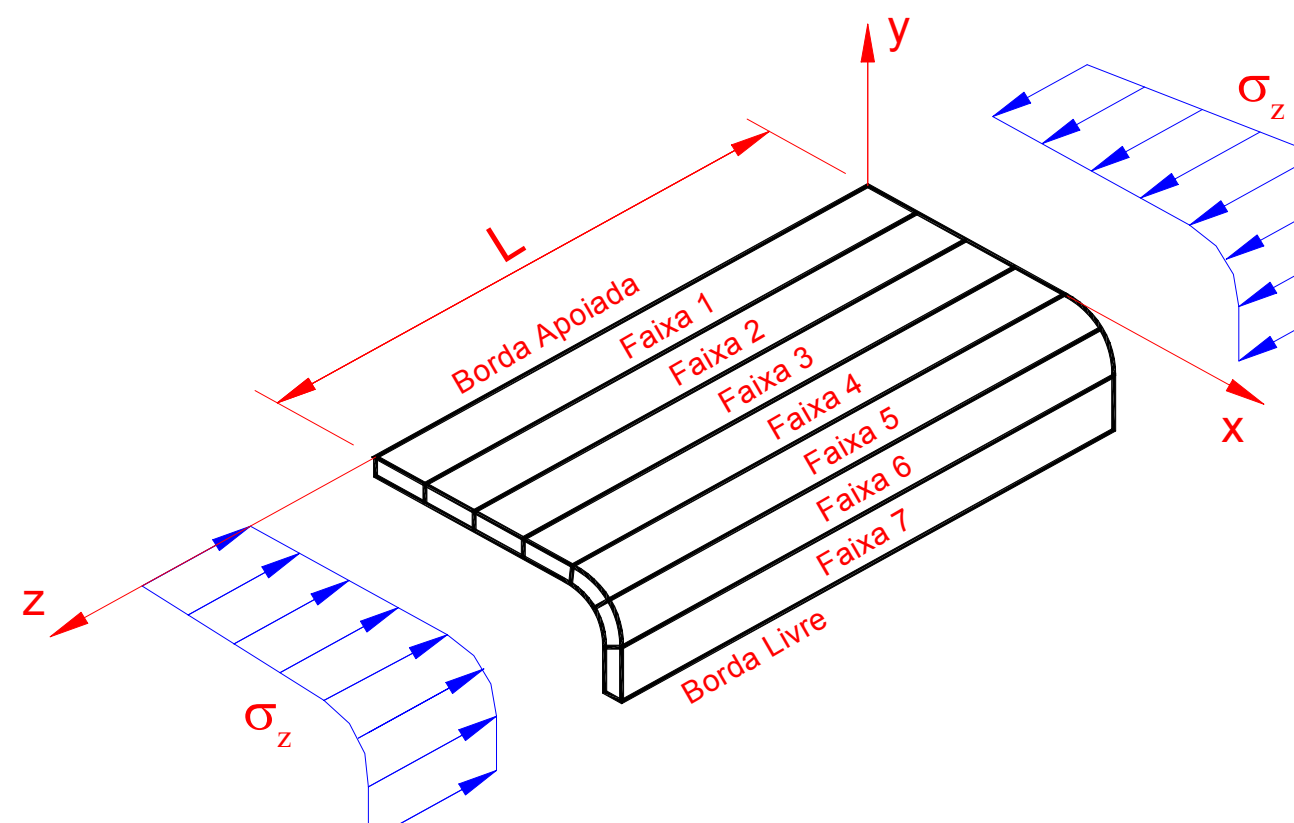

Observação:

- Sem deslocamentos na direção x e y

- Liberdade de deslocamentos na direção z

Figura 34 Discretização parcial de perfil formado a frio via MFF. Fonte: Hancock, 2001. 


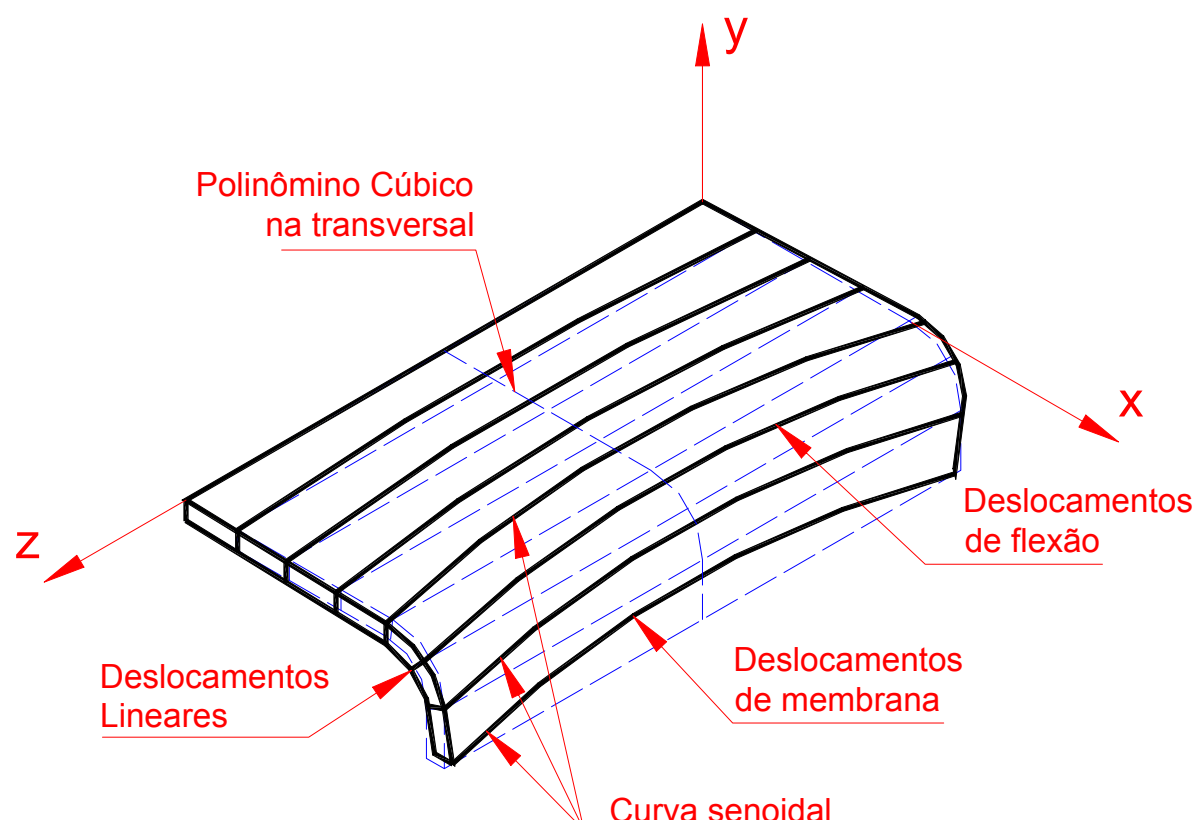

Figura 35 Deslocamentos dos elementos da discretização via MFF. Fonte: Hancock, 2001.

As principais desvantagens do MFF são:

$\checkmark$ Representação das condições de contorno: o modelo assume nas extremidades dos elementos apoio simples. Ao longo do comprimento não se pode representar variações das vinculações. Quando surgirem tais limitações na discretização, a melhor saída é a opção pelo MEF.

$\checkmark$ A seção transversal não pode variar ao longo do seu comprimento.

O elemento utilizado no MFF é o elemento de placa simples com número de nós e graus de liberdade representados na Figura 36. 


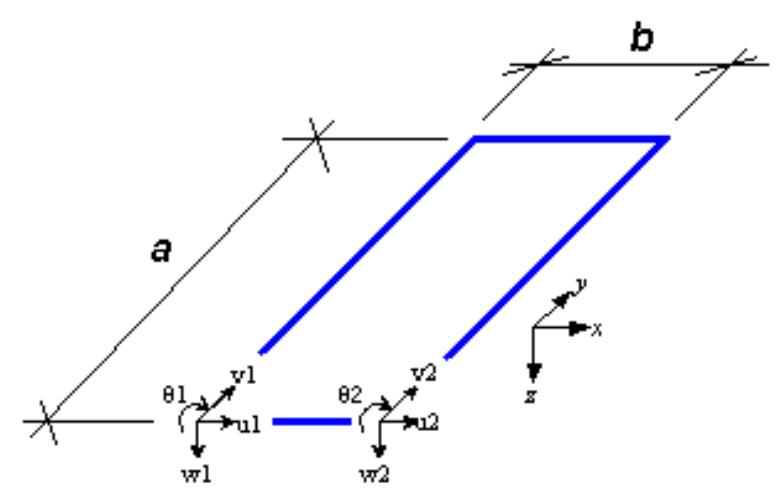

Figura 36 Elemento de placa para MFF. Fonte: Schafer, 1998.

As vantagens e precisões do MFF dependem da escolha do tipo de função de forma para o campo de deslocamento longitudinal. A solução do MFF emprega um polinômio cúbico na direção transversal e uma função harmônica senoidal da direção longitudinal, conforme Figura 35. A direção longitudinal possui a forma de meia onda senoidal para ter a consistência com as condições de contorno nas extremidades apoiadas. O cálculo dos auto-valores (tensões de instabilidade) e auto-vetores (modos de instabilidade) são dependentes das matrizes globais de rigidez inicial $[\mathrm{K}] \mathrm{e}$ rigidez geométrica $\left[K_{g}\right]$.

A matriz global é função do comprimento a do elemento. Conseqüentemente, a tensão de instabilidade elástica e o correspondente modo de instabilidade também são funções do comprimento do elemento. Por isso, o problema de instabilidade pode ser resolvido para vários comprimentos do perfil demonstrando a cada ponto a tensão e o modo de instabilidade ocorrido.

\subsection{Curvas de Instabilidade para MRD}

A primeira curva para o MRD foi desenvolvida por Hancock (1994) onde foi proposta uma curva para análise de instabilidade distorcional. $\mathrm{O}$ objetivo da curva foi obter a resistência última do perfil à flexão e a compressão em função da tensão (força) crítica de instabilidade elástica do material. 
Peköz \& Schafer (1998) desenvolveram uma curva para o cálculo direto de perfis na instabilidade local e propuseram alteração na curva de Hancock para o cálculo distorcional. Estas propostas foram elaboradas através da análise de dados experimentais de diversos pesquisadores.

O AISI (2002) em seu manual para o cálculo de resistência direta de perfis formados a frio está propondo curvas para normatização. Este trabalho vem sendo coordenado por Schafer. Observa-se que as especificações atuais do AISI não explicitam a permissão para o uso de análise de perfis formados a frio via MRD. A norma Australiana AS/NZS permite o uso deste método.

Para valores acima do limite de proporcionalidade $\left(f_{y} / 2\right)$, a tensão crítica deve ser corrigida através da equação da parábola, regime não elástico.

\subsubsection{Instabilidade Local}

O conceito de falha para chapa segue o seguinte modo: para esbeltez local $\left(\lambda_{\mathrm{L}}\right)$ menor igual ao valor adimensional 0,776 tem-se o momento limite do perfil o momento de escoamento. Acima deste valor de esbeltez local, o momento limite é caracterizado pelo momento efetivo de cálculo.

Assim, a curva para a instabilidade local apresenta-se:

$$
\begin{array}{ll}
M_{n L}=M_{y} & \text { para } \lambda_{L} \leq 0,776 \\
M_{n L}=\left(1-0,15\left(\frac{M_{c r L}}{M_{y}}\right)^{0,4}\right)\left(\frac{M_{c r L}}{M_{y}}\right)^{0,4} M_{y} & \text { para } \lambda_{L}>0,776
\end{array}
$$

Onde:

$$
\lambda_{\mathrm{L}}=\sqrt{\frac{\mathrm{M}_{\mathrm{y}}}{\mathrm{M}_{\mathrm{crL}}}}
$$

$\mathrm{M}_{\mathrm{nL}} \quad$ Momento nominal devido à instabilidade local;

$\mathrm{M}_{\mathrm{y}} \quad$ Momento de escoamento;

$\mathrm{M}_{\mathrm{crL}} \quad$ Momento crítico da instabilidade elástica local. 
O expoente 0,4 em lugar de 0,5 da equação de Winter (1947) reflete a maior capacidade de reserva local pós-crítica da seção completa quando comparado com elementos isolados da seção.

\subsubsection{Instabilidade Distorcional}

Hancock (1994) apresentou pela primeira vez uma curva para o cálculo da resistência direta de perfis submetidos à flexão conforme equações abaixo:

$$
\begin{array}{ll}
M_{n D}=M_{y} & \text { para } \lambda_{d} \leq 0,561 \\
M_{n D}=\left(1-0,25\left(\frac{M_{c r D}}{M_{y}}\right)^{0,6}\right)\left(\frac{M_{c r D}}{M_{y}}\right)^{0,6} M_{y} & \text { para } \lambda_{d}>0,561
\end{array}
$$

Onde:

$\lambda_{d}=\sqrt{\frac{M_{y}}{M_{c r D}}}$

$\mathrm{M}_{\mathrm{nD}} \quad$ Momento nominal devido à instabilidade distorcional;

$\mathrm{M}_{\mathrm{y}} \quad$ Momento de escoamento;

$\mathrm{M}_{\mathrm{crD}} \quad$ Momento crítico da instabilidade elástica distorcional.

Hancock utilizou o expoente 0,6 ao invés de 0,4 usado no cálculo da resistência direta devido a instabilidade local refletindo a baixa reserva póscritica na distorção. No gráfico da figura 15, são apresentadas as curvas comparativas para o cálculo da instabilidade distorcional. A curva para elementos isolados se refere à curva da NBR14762 e é a representação gráfica das equações (4.31) e (4.32).

Peköz e Schafer propuseram uma curva de cálculo para o modo distorcional intermediária entre o modo local e o modo distorcional de Hancock, sendo:

$$
M_{n D}=M_{y} \quad \text { para } \lambda_{d} \leq 0,673
$$




$$
M_{n D}=\left(1-0,22\left(\frac{M_{c r D}}{M_{y}}\right)^{0,5}\right)\left(\frac{M_{c r D}}{M_{y}}\right)^{0,5} M_{y} \quad \text { para } \lambda_{d}>0,673
$$

Onde:

$$
\lambda_{d}=\sqrt{\frac{M_{y}}{M_{c r D}}}
$$

Hancock, através de sugestões de Peköz \& Schafer, alterou 0 coeficiente de 0,25 para 0,22 e o expoente de 0,6 para 0,5 por considerações a favor da instabilidade distorcional, porém, mantendo-se o limite inicial de $\lambda_{d}$. Assim, a modificação da curva de Hancock apresenta-se:

$$
\begin{array}{ll}
M_{n D}=M_{y} & \text { para } \lambda_{d} \leq 0,561 \\
M_{n D}=\left(1-0,22 \cdot\left(\frac{M_{c r D}}{M_{y}}\right)^{0,5}\right) \cdot\left(\frac{M_{c r D}}{M_{y}}\right)^{0,5} M_{y} & \text { para }_{\lambda_{d}}>0,561
\end{array}
$$

Peköz e Schafer justificam que o valor de $\lambda_{d}$ maior em relação a Hancock é devido a uma maior reserva pós-critica da seção transversal dos perfis em comparação ao modelo de elementos isolado de distorcional de Hancock. A conclusão deste fato está relacionada à análise de diversos resultados experimentais. Na verdade, nota-se um conservadorismo da curva de Peköz \& Schafer mantendo-se o limite de $\lambda_{d}$ igual ao do método das larguras efetivas, procedimento do AISI. Porém, através de estudos, Hancock (2002) comprova uma maior adequação de sua curva proposta, abrangendo uma maior gama de perfis aos casos de instabilidade distorcional.

Como pode ser visto na figura 37 , as curvas do MRD geram valores de resistência maiores em comparação ao modelo de cálculo analítico (elementos isolados de Hancock). Para esbeltez moderada, entre os valores de 0,7 e 1,2 não se tem diferenças significativas nos valores de resistência para as curvas de Hancock. 


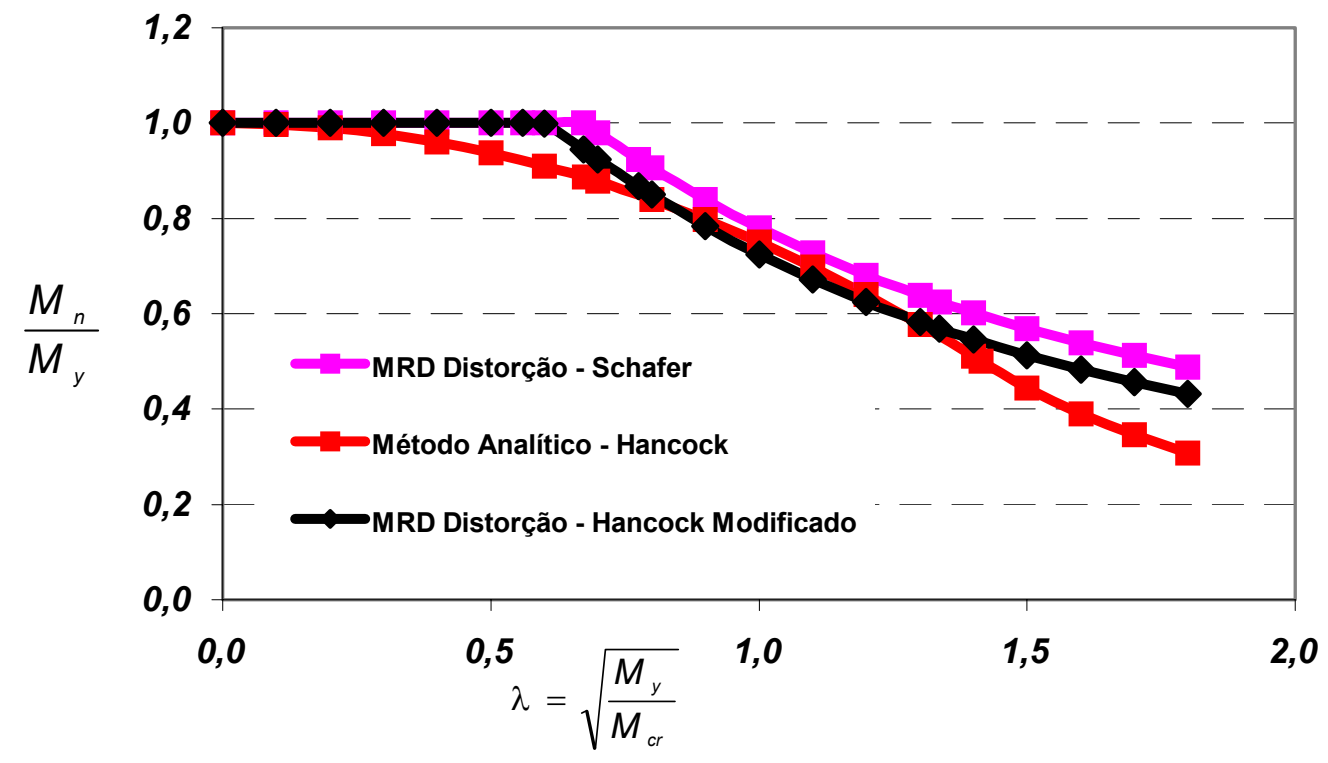

Figura 37 Curvas comparativas de instabilidade distorcional

\subsubsection{Instabilidade Global}

A curva de análise é a clássica curva de estabilidade elástica global. A determinação do momento de instabilidade inelástico $\left(M_{n e}\right)$ é fundamental para a análise da interação da instabilidade global com os outros modos de instabilidade. Assim, para a instabilidade global tem-se:

$$
\begin{array}{cc}
M_{\text {cre }} \leq 0.56 M_{y} & M_{n e}=M_{\text {cre }} \\
2.78 M_{y} \geq M_{c r e} \geq 0.56 M_{y} & M_{n e}=\frac{10}{9} M_{y}\left(1-\frac{10 M_{y}}{36 M_{c r e}}\right) \\
M_{c r e} \geq 2.78 M_{y} & M_{n e}=M_{y}
\end{array}
$$

Onde:

$M_{\text {cre }}$ Momento crítico de instabilidade elástica global.

$\mathrm{M}_{\mathrm{y}}=\mathrm{M}_{\mathrm{S}} \cdot \mathrm{F}_{\mathrm{y}}$

$\mathrm{M}_{\mathrm{s}} \quad$ Momento estático. 
Abaixo são traçadas as curvas do MRD, sem interação, no gráfico da Figura 38.

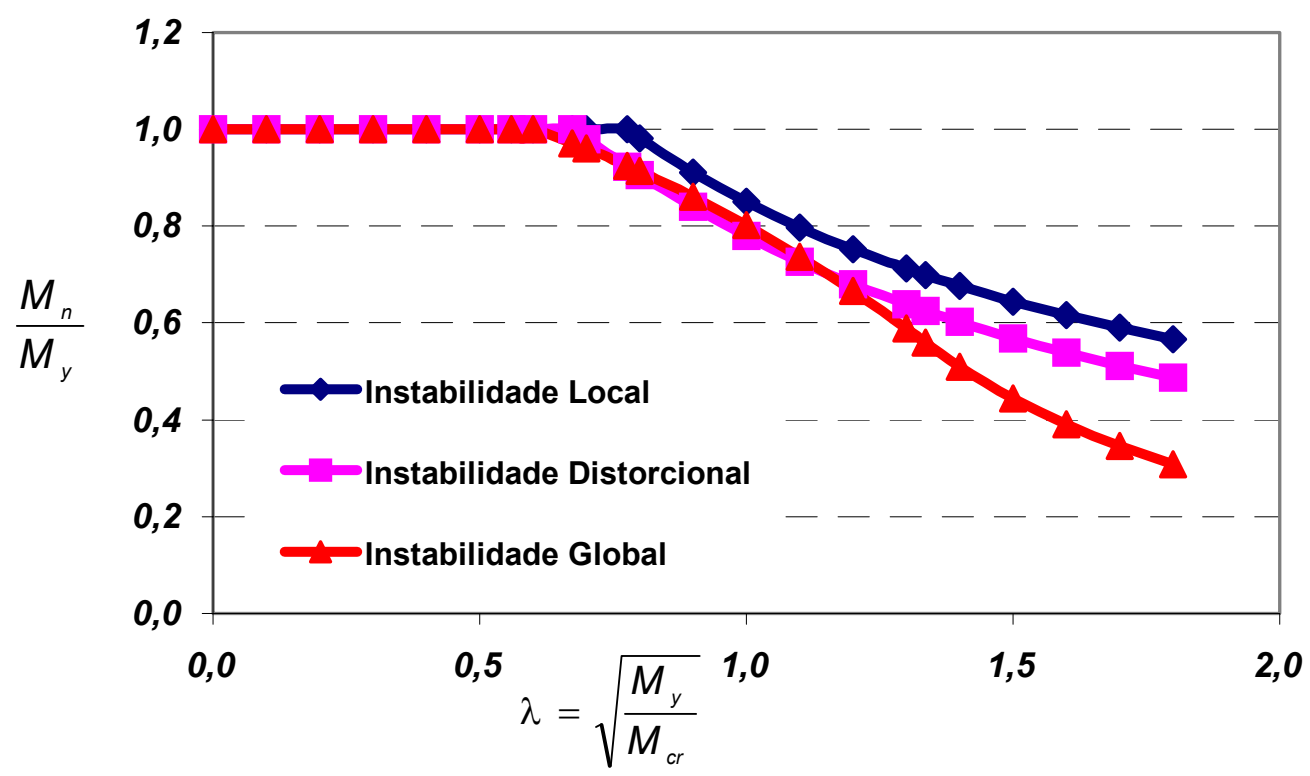

Figura 38 Gráficos das curvas do MRD sem interação.

No gráfico da Figura 38, as curvas de resistência de vigas para instabilidade pelo MRD são apresentadas como função da esbeltez. Para vigas não esbeltas (totalmente efetivas, compactas e localmente estáveis) $M_{c r} \gg M_{y}$ a seção transversal é estável e a capacidade é igual ao momento de escoamento, $M_{y}$ da viga. A capacidade de resistência inelástica não é considerada no MRD.

As vigas moderadamente esbeltas comportam-se inelasticamente com $\mathrm{M}_{\mathrm{n}}<\mathrm{M}_{\mathrm{cr}}$. Vigas esbeltas comportam-se elasticamente, entretanto, $\mathrm{o}$ comportamento elástico em viga delgada implica em capacidade de resistência pós-crítica com $\mathrm{M}_{\mathrm{n}}>\mathrm{M}_{\mathrm{cr}}$.

$\mathrm{Na}$ prática, as vigas de aço formado a frio existem nas três faixas: totalmente efetiva com $M_{n}=M_{y}$; inelástica com $M_{n}<M_{c r}$ e $M_{n}<M_{y}$; póscrítica $M_{n}>M_{c r}$ e $M_{n}<M_{y}$.

Ainda, se a esbeltez local e distorcional forem iguais, o modo distorcional possui menor capacidade pós-crítica em comparação ao primeiro. 
A resistência nominal do perfil será o menor valor entre os momentos $M_{n L}, M_{n D}$ e $M_{n e}$.

\subsubsection{Interação entre os Modos de Instabilidade}

O MRD permite a interação entre a instabilidade local e a instabilidade global através de aproximações de cálculo. O procedimento baseia-se na substituição do $\mathrm{M}_{\mathrm{y}}$ (momento de escoamento) nas equações de instabilidade local pelo $M_{n e}$. O momento limite $\left(M_{n L}\right)$ resulta da interação da instabilidade local com a global da viga pela limitação de $M_{n e}$ ao invés de $M_{y}$.

Para a interação entre a instabilidade local e global tem-se:

$$
\begin{array}{ll}
M_{n L}=M_{n e} & \text { para } \lambda_{L} \leq 0,776 \\
M_{n L}=\left(1-0,15\left(\frac{M_{c r L}}{M_{n e}}\right)^{0,4}\right)\left(\frac{M_{c r L}}{M_{n e}}\right)^{0,4} M_{n e} & \text { para } \lambda_{L}>0,776
\end{array}
$$

Onde:

$$
\lambda_{\mathrm{L}}=\sqrt{\frac{f_{y}}{f_{c r L}}}
$$

O MRD também permite a interação entre a instabilidade distorcional com a instabilidade global substituindo-se o momento de escoamento $M_{y}$ por $M_{n e}$ nas equações de instabilidade distorcional do MRD.

Assim, para a interação entre a instabilidade distorcional de Hancock e a instabilidade global tem-se:

$$
\begin{array}{ll}
M_{n D}=M_{n e} & \text { para } \lambda_{L} \leq 0,561 \\
M_{n D}=\left(1-0,22\left(\frac{M_{c r D}}{M_{n e}}\right)^{0,5}\right)\left(\frac{M_{c r D}}{M_{n e}}\right)^{0,5} M_{n e} & \text { para } \lambda_{L}>0,561
\end{array}
$$

Onde:

$$
\lambda_{\mathrm{L}}=\sqrt{\frac{\mathrm{M}_{\mathrm{y}}}{\mathrm{M}_{\mathrm{crD}}}}
$$


A resistência nominal do perfil será o menor valor entre os momentos $\mathrm{M}_{\mathrm{nL}}$ e $\mathrm{M}_{\mathrm{nD}}$.

\subsection{Aspectos Normativos}

\subsubsection{Perfis fletidos Isolados}

A instabilidade distorcional de perfis formados a frio submetidos à flexão e à compressão foi primeiramente inserida em norma através da AS/NZS 4600/1996 (Australian/New Zealand Standard). A AS/NZS 4600/1996 utiliza-se dos modelos de Lau \& Hancock $(1987$; 1997) para a determinação das tensões de instabilidade elástica e curvas de resistência aferida por ensaios experimentais. A AS/NZS 4600/1996 permite ainda que seja utilizado aço de elevada resistência mecânica e, também, na determinação da tensão elástica distorcional seja empregado programa de análise de estabilidade via faixas finitas.

Em relação às principais normas específicas mundiais pode-se dizer que não existe tamanha abordagem quanto à AS/NZS 4600/1996. No AISI não existe tratamento deste assunto justificando-se o fato pela incorporação do problema à eficiência dos enrijecedores de borda. Hancock et al (1994) observa que tal procedimento é não conservador quando aplicado a aços de elevada resistência mecânica. O Eurocode - parte 1.3 cita o problema de instabilidade distorcional, porém não indica um procedimento de cálculo para a análise.

A norma brasileira "Dimensionamento de estruturas de aço constituídas por perfis formados a frio", NBR 14.672, ABNT (2001), em seus itens 7.7.3, 7.8.1.3 e anexo D, adota as expressões da AS/NZS 4600/1996 para o cálculo da tensão crítica de instabilidade por distorção. Observa-se que, para valores acima do limite de proporcionalidade $\left(f_{y} / 2\right)$, a tensão crítica deve ser corrigida através da equação da parábola, regime não elástico. No caso, a norma já trás esta correção nas equações para o cálculo da tensão distorcional. 


\subsubsection{Perfis fletidos conectados a painel}

Os procedimentos da norma AS/NZS 4600/1996 e AISI seguem o método empírico de cálculo de perfis conectados a painel de LaBoube, utilizando-se de fatores de redução $R$ para a determinação da resistência do perfil. Este procedimento tem a vantagem de ser prático. A NBR 14762 segue a prescrição do AISI e o procedimento esta incorporado em seu anexo $\mathrm{F}$, como caráter informativo.

O Eurocode 3 baseia-se no modelo de cálculo de Peköz \& Soroushian. Este procedimento tem como dificuldade a determinação da rigidez rotacional oferecida ao painel e a variação desta rigidez. Esta variação esta ligada ao fato da locação dos parafusos na mesa, diâmetro dos parafusos, quantidade de parafusos, etc. Tomà \& Wittemann (1994) apud Javaroni (1999) compararam os resultados de ensaios e os resultados obtidos através deste procedimento para situações de carregamento gravitacional e carregamento de sucção. A comparação mostrou que o procedimento do Eurocode é conservador. 


\section{PROGRAMA EXPERIMENTAL}

\subsection{Introdução}

O objetivo deste capítulo é apresentar, discutir e comparar os resultados obtidos nos ensaios experimentais realizados em perfis do tipo $U$ enrijecido submetidos à flexão. O foco principal destes ensaios foi a análise do comportamento estrutural quanto a instabilidade distorcional. Deste modo, a intenção deste programa experimental foi investigar o comportamento destes perfis, sob a ação de cargas transversais, comparando dos resultados obtidos nos ensaios com as principais curvas de resistência à instabilidade distorcional na flexão e ao método das faixas finitas.

Os ensaios experimentais foram realizados no Laboratório de Estruturas do Departamento de Engenharia de Civil da Unesp, campus de Bauru.

\subsection{Propriedades Geométricas dos Perfis}

O perfil utilizado nos ensaios foi o perfil formado a frio com seção transversal do tipo $U$ enrijecido. A seção transversal do tipo $U$ enrijecido possui dimensões nominais com a seguinte nomenclatura: altura de alma (h), largura de mesa (b), altura de enrijecedor (d) e espessura de chapa (t), conforme figura 39. 


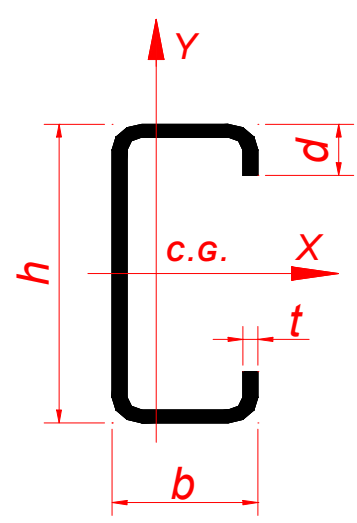

Figura 39 Dimensões nominais do perfil U enrijecido.

As propriedades geométricas das seções transversais para os vários perfis utilizados estão apresentadas na tabela 5. Estas propriedades estão referidas às dimensões nominais da seção transversal e aos eixos indicados na figura 39.

Tabela 5: Propriedades geométricas das seções transversais.

\begin{tabular}{|c|c|c|c|c|c|c|c|c|c|c|c|}
\hline Perfil (") & $\underset{\left(\mathrm{cm}^{2}\right)}{\mathrm{A}}$ & $\begin{array}{c}I_{x} \\
\left(\mathrm{~cm}^{4}\right)\end{array}$ & $\begin{array}{l}\mathrm{W}_{\mathrm{x}} \\
\left(\mathrm{cm}^{3}\right)\end{array}$ & $\begin{array}{c}r_{x} \\
(\mathrm{~cm})\end{array}$ & $\begin{array}{l}\mathrm{W}_{\mathrm{y}_{3}} \\
\left(\mathrm{~cm}^{3}\right)\end{array}$ & $\begin{array}{c}r_{y} \\
(\mathrm{~cm})\end{array}$ & $\begin{array}{c}\mathrm{I}_{\mathrm{t}} \\
\left(\mathrm{cm}^{4}\right)\end{array}$ & $\begin{array}{c}r_{o} \\
(\mathrm{~cm})\end{array}$ & $\begin{array}{c}\mathrm{C}_{\mathrm{w}} \\
\left(\mathrm{cm}^{6}\right)\end{array}$ & $\begin{array}{c}x \\
(\mathrm{~cm})\end{array}$ & $\begin{array}{c}x_{0} \\
(\mathrm{~cm})\end{array}$ \\
\hline Ue $250 \times 85 \times 25 \times 2,65$ & 11,99 & $1.128,3$ & 90,70 & 9,70 & 114,2 & 3,09 & 0,281 & 11,88 & 14.69 & 2,43 & 6,12 \\
\hline Ue $250 \times 85 \times 25 \times 2,25$ & 10,24 & 967,0 & 77,60 & 9,73 & 98,9 & 3,11 & 0,173 & 11,92 & 12.73 & 2,43 & 6,15 \\
\hline Ue $300 \times 85 \times 25 \times 2,65$ & 13,32 & $1.736,7$ & 115,8 & 11,42 & 120,5 & 3,01 & 0,312 & 13,10 & 21.89 & 2,20 & 5,66 \\
\hline Ue $300 \times 85 \times 25 \times 2,25$ & 11,37 & $1.491,1$ & 99,4 & 11,45 & 104,4 & 3,03 & 0,192 & 13,14 & 18.94 & 2,20 & 5,69 \\
\hline Ue $350 \times 85 \times 25 \times 3,00$ & 16,51 & $2.817,5$ & 161,0 & 13,06 & 139,7 & 2,91 & 0,495 & 14,38 & 34.37 & 2,01 & 5,25 \\
\hline Ue $350 \times 85 \times 25 \times 2,65$ & 14,64 & $2.511,5$ & 143,5 & 13,10 & 125,6 & 2,93 & 0,343 & 14,42 & 30.85 & 2,01 & 5,27 \\
\hline Ue $350 \times 85 \times 25 \times 2,25$ & 12,49 & $2.154,3$ & 123,1 & 13,13 & 108,8 & 2,95 & 0,211 & 14,47 & 26.67 & 2,01 & 5,30 \\
\hline Ue $400 \times 85 \times 25 \times 2,25$ & 13,62 & $2.973,6$ & 148,7 & 14,78 & 112,6 & 2,88 & 0,230 & 15,85 & 35.98 & 1,86 & 4,97 \\
\hline
\end{tabular}

Conforme pode ser visto na tabela 5, a altura de alma (h) e a espessura de chapa $(t)$ dos perfis foram variáveis. A largura de mesa $(b)$ e a altura de enrijecedor $(d)$ foram mantidas constantes com 85 e 25 mm, respectivamente. As espessuras de chapa (t) dos perfis foram de 2.25, 2.65 e $3.00 \mathrm{~mm}$. A altura de alma (h) dos perfis variou entre 250 a $400 \mathrm{~mm}$, com acréscimos de $50 \mathrm{~mm}$. 
Observa-se que os enrijecedores de borda foram formados por viradas de mesa simples a $90^{\circ}$. Não se investigou nenhuma influência do trabalho a frio nos ensaios.

Os perfis foram fabricados pela conformação por prensagem em comprimento igual a 6 metros. $O$ processo de prensagem foi escolhido dado o seu grande emprego na conformação de perfis em nossa região.

Foi efetuado o controle dimensional dos perfis e todas as dimensões respeitaram as tolerâncias exigidas pela NBR6355/2002 (Perfis estruturais de aço formados a frio - Padronização em revisão). Não foram avaliadas as imperfeições geométricas iniciais dos perfis.

\subsection{Propriedades mecânicas do aço}

O aço empregado na confecção dos perfis foi o USI-300, nome comercial fabricado pela empresa USIMINAS. Este tipo de aço classifica-se na faixa de resistência média com limite de escoamento na faixa de 300 a $350 \mathrm{MPa}$. Segundo a Usiminas, este aço estrutural foi desenvolvido para utilização na construção civil em geral e possui como características principais: boa soldabilidade, conformabilidade, tenacidade e resistência à corrosão atmosférica.

Em análise experimental, para efeito de cálculo os valores reais das propriedades mecânicas do aço em relação à tensão de início de escoamento e à tensão limite de ruptura são de fundamental importância. Deste modo, os limites de resistência reais do aço foram obtidos do ensaio de tração para serem utilizados nas verificações de cálculo. $\mathrm{Na}$ determinação das propriedades mecânicas do aço foram realizados ensaios à tração em 16 (dezesseis) corpos-de-prova. Foram confeccionados corposde-prova a partir de chapas com espessura de 2.25 e $2.65 \mathrm{~mm}$, cujas dimensões nominais estão indicadas na figura 40 . 


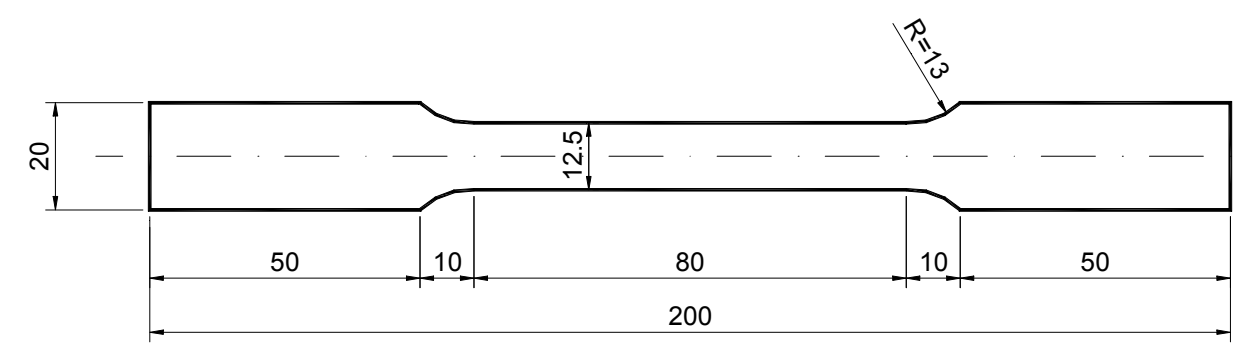

Figura 40 Dimensões nominais do corpo-de-prova para ensaio à tração.

Os corpos-de-prova foram retirados aleatoriamente das extremidades de alguns perfis e de posições diversas na seção, conforme ilustrado na figura 41. Observa-se que foram retirados, para cada extremidade do perfil, 2 corpos-de-prova da alma e 1 das mesas.

$\mathrm{Na}$ extração dos corpos-de-prova evitaram-se regiões próximas as dobras da seção de modo a minimizar a influência do trabalho a frio nas propriedades mecânicas do aço.

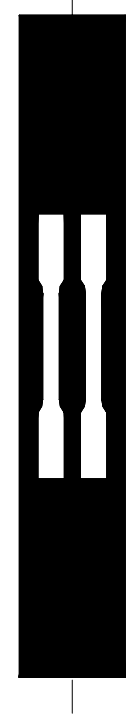

a) $\Delta \operatorname{lma}$

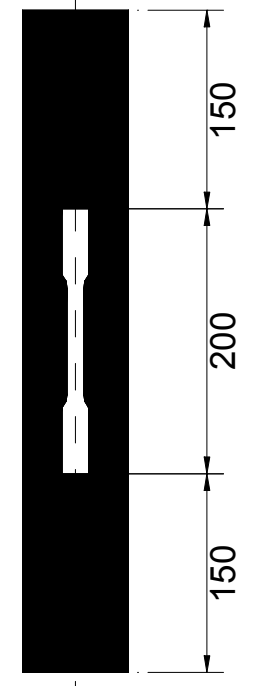

h) Mocac

Figura 41 Localização dos pontos de extração de corpo-de-prova nos perfis ensaiados.

Os ensaios à tração foram realizados no Laboratório de Ensaio de Materiais da Faculdade de Ciências Agrárias da Unesp, Campus de Botucatu. 
Na tabela 6 apresentam-se os resultados obtidos dos ensaios à tração. Os procedimentos utilizados foram os preconizados pela norma ASTM 37095 da American Society for Testing and Materials (ASTM).

Os alongamentos dos corpos-de-prova foram medidos sobre a base de $50 \mathrm{~mm}$. O valor do módulo de elasticidade (E) admitido foi igual a 205.000 $\mathrm{MPa}$, valor este normalizado para o aço. Isto se deve ao fato de que a utilização de "clip-gage" na determinação do módulo de elasticidade não ter produzido resultados confiáveis. O mesmo desliza sobre o corpo-de-prova, resultando em valores imprecisos para o módulo de elasticidade $(E)$.

Conforme se pode verificar na tabela 6 , a relação entre a resistência à ruptura e a resistência ao escoamento $f_{u} / f_{y}$ e os alongamentos dos corposde-prova ensaiados sob a base de $50 \mathrm{~mm}$ foram superiores aos valores recomendados pela NBR 14762 (item 4.1), respectivamente 1,08 e 10\%.

Tabela 6: Características mecânicas obtidas nos ensaios à tração.

\begin{tabular}{|c|c|c|c|c|c|}
\hline CP & $\underset{\left(\mathrm{mm}^{2}\right)}{\mathrm{A}}$ & $\begin{array}{c}\mathbf{f}_{\mathrm{v}} \\
(\mathrm{MPa})\end{array}$ & $\begin{array}{c}\mathbf{f}_{\mathrm{u}} \\
(\mathrm{MPa})\end{array}$ & Along (\%) & $\mathbf{f}_{\mathrm{u}} / \mathbf{f}_{\mathrm{y}}$ \\
\hline $1-A$ & 32,96 & 320,00 & 425,92 & 28 & 1,33 \\
\hline $1-B$ & 33,23 & 340,00 & 438,43 & 28 & 1,29 \\
\hline $2-A$ & 34,84 & 340,00 & 436,85 & 26 & 1,28 \\
\hline $2-B$ & 34,44 & 350,00 & 434,11 & 28 & 1,24 \\
\hline $3-A$ & 28,73 & 336,00 & 453,22 & 28 & 1,35 \\
\hline $3-B$ & 28,50 & 333,33 & 450,18 & 30 & 1,35 \\
\hline $3-C$ & 28,96 & 336,00 & 451,03 & 30 & 1,34 \\
\hline $3-D$ & 28,96 & 336,00 & 451,03 & 28 & 1,34 \\
\hline 4 & 28,39 & 340,50 & 453,04 & 28 & 1,33 \\
\hline $4-B$ & 28,73 & 334,00 & 443,12 & 32 & 1,33 \\
\hline $4-C$ & 28,39 & 339,70 & 450,93 & 30 & 1,33 \\
\hline 4-D & 28,73 & 332,81 & 438,60 & 30 & 1,32 \\
\hline $5-A$ & 28,61 & 342,30 & 4447,33 & 26 & 1,31 \\
\hline $5-B$ & 28,61 & 371,20 & 457,82 & 26 & 1,23 \\
\hline $5-C$ & 28,5 & 351,31 & 453,33 & 24 & 1,29 \\
\hline $5-D$ & 28,50 & 332,72 & 442,11 & 28 & 1,33 \\
\hline \multicolumn{2}{|c|}{ Média } & 340,39 & 447,52 & 28,00 & 1,32 \\
\hline \multicolumn{2}{|c|}{ Desvio Padrão } & 12,72 & 9,13 & 2,37 & 0,03 \\
\hline
\end{tabular}


O valor de $f_{y}$ pode ser calculado através da expressão abaixo, onde o valor 1,645 corresponde ao quantil de $5 \%, \overline{f_{y}}$ o valor médio das tensões de escoamento e $s$ o desvio padrão, tem-se:

$$
f_{y}=\overline{f_{y}}-1,645 s=340,39-1,645.12,72=319,47 \mathrm{MPa}
$$

Entretanto, será utilizado o valor médio de limite ao escoamento de 340 $\mathrm{MPa}$ para a realização das verificações de cálculo, tendo em vista a necessidade de comparação dos resultados com os teóricos.

\subsection{Metodologia Empregada}

Descreve-se aqui a metodologia empregada nos ensaios de flexão e os modelos a serem ensaiados. Contrariamente ao que se verifica nos países da América do Norte e Europa, no Brasil os programas de ensaios com os perfis de aço formados a frio ainda são modestos e a necessidade em se dispor de resultados experimentais sobre os mesmos levou à realização deste programa experimental.

Alguns ensaios pilotos foram realizados para se verificar os procedimentos, aferição dos instrumentos de medição, equipamentos e resultados iniciais. O panorama geral dos ensaios pilotos demonstrou grande valia para execução dos ensaios principais.

Como objetivo procurou-se obter resultados experimentais referentes aos modos de estabilidade característicos para os perfis, especialmente para o modo de instabilidade por distorção. Foi investigado o comportamento desses perfis sob a ação de forças transversais e a verificação de resultados teóricos em comparação com os obtidos nesses ensaios.

Os vãos, carregamentos e travamentos laterais foram escolhidos prevendo-se somente a ocorrência da instabilidade por distorção. Fato este, como se verá mais adiante, não totalmente obtido.

Os perfis foram submetidos a uma única situação de carregamento, conforme se ilustra na figura 42 . Os pontos travados lateralmente, indicados por um $\mathrm{X}$ na figura 42.a, tanto os dos apoios quanto os intermediários, foram 
obtidos através do ensaio dos perfis aos pares, possibilitando a ligação entre os mesmos, através do dispositivo indicado na figura 42 .b e na figura 43 .

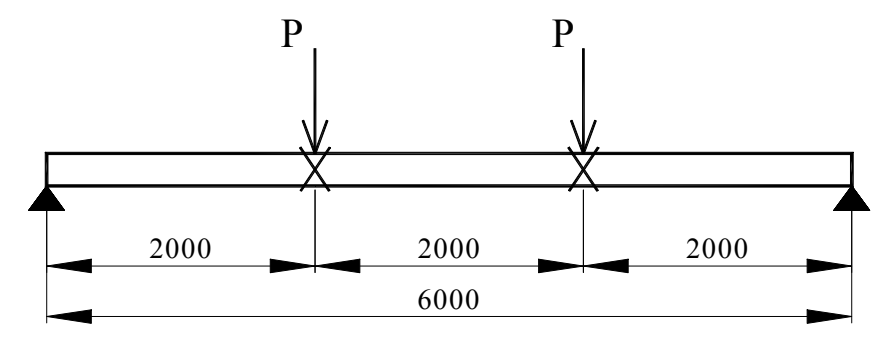

(a) Esquema estático estrutural do ensaio.

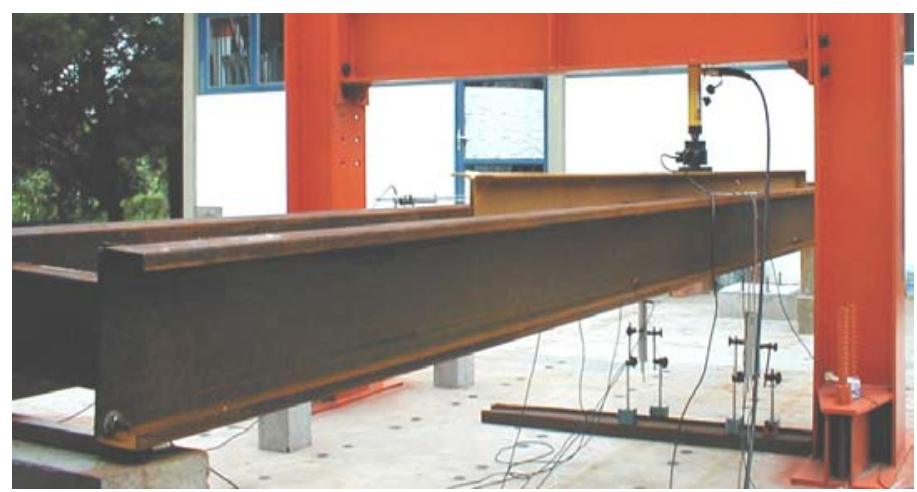

(b) Vista lateral do ensaio.

Figura 42 Esquema de carregamento para os ensaios à flexão.

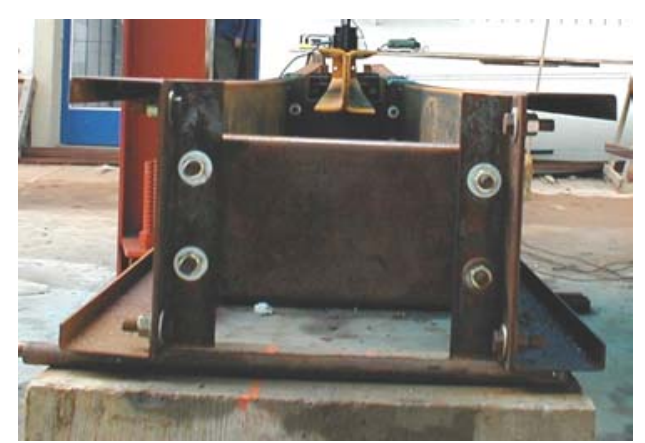

Figura 43 Detalhe do travamento lateral entre perfis.

Conforme pode ser visto na figura 43, o dispositivo distanciador/fixador do conjunto permite o travamento no ponto $e$ a transferência do carregamento. Nota-se ainda que esses dispositivos promovem liberdade às mesas dos perfis. A fixação entre dispositivos e perfis, formando o conjunto de ensaio, foi realizada através de parafusos e arruelas comuns. 
As forças foram aplicadas através de atuador hidráulico acionado manualmente. Para a aferição da intensidade da força foi utilizada célula de carga devidamente calibrada, com capacidade para $100 \mathrm{kN}$.

Como pode ser visto na figura 42.b, o carregamento aplicado pelo atuador hidráulico foi transferido para a viga de transição. Além da função de distanciar/fixar, os dispositivos centrais atuaram na transferência do carregamento à alma dos perfis proporcionando o esquema apresentado na figura 42.a. A viga de transição e os dispositivos distanciadores/fixadores foram dimensionados para que não houvesse problemas de instabilidade local, de modo que não ocorressem interrupções durante a execução dos ensaios. Entretanto, alguns problemas de instabilidade nos dispositivos ocorreram nos ensaios pilotos, mas foram sanados posteriormente.

Em cada montagem de conjunto de perfis para ensaio foi realizado o alinhamento do mesmo. O objetivo deste alinhamento foi de garantir o esquema de carregamento planejado através da simetria longitudinal e transversal do conjunto ensaiado. $O$ alinhamento longitudinal foi verificado através da viga mantendo-se metade do comprimento para cada lado. A simetria transversal do conjunto de ensaio foi controlada através do posicionamento centrado da viga de transição. O ponto de aplicação de carregamento foi adotado como centro de referência.

Foram medidos os deslocamentos verticais e os deslocamentos horizontais ao longo da seção transversal no meio do vão, como se ilustra na figura 44. Os transdutores de deslocamentos de números 7 e 8 e os de números 11 e 12 têm por finalidade verificar o afastamento ou aproximação das mesas dos perfis, auxiliando na identificação da instabilidade por distorção, bem como as medidas dos deslocamentos verticais dos perfis. Os transdutores de número 9 e 10 e os de número 13 e 14 , mediram os deslocamentos horizontais das seções transversais e permitiram o cálculo do giro da seção transversal. 


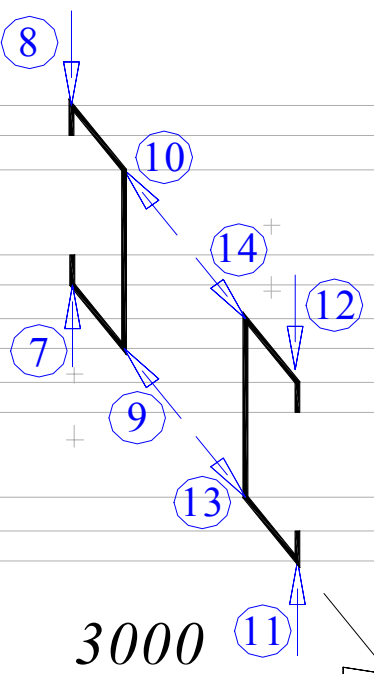

Figura 44 Posição dos transdutores de deslocamentos para medida dos deslocamentos na seção transversal do meio do vão.

As deformações ocorridas foram medidas através de extensômetros elétricos de resistência. Os extensômetros foram posicionados nas mesas superiores dos perfis e na seção transversal do meio do vão, segundo disposição ilustrada na figura 45.

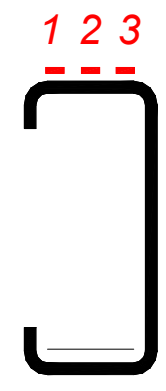

Perfil A

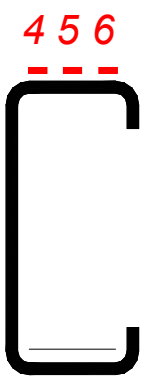

Perfil B

Figura 45 Instrumentação da seção transversal no meio do vão.

As leituras dos dados de força aplicada, de deslocamentos e de deformações ocorridas foram obtidas automaticamente por meio do sistema de aquisição de dados System 5000 da Measurements Group, Inc. O sistema possui 20 canais disponíveis para uso simultâneo. Nos ensaios foram utilizados 6 canais para os extensômetros elétricos de resistência, 8 
canais para os transdutores de deslocamentos lineares e 1 canal para a célula de carga. A numeração apresentada nas figura 44 e figura 45 correspondem aos números dos canais utilizados no sistema para aquisição de dados, sendo que, a célula de carga recebeu o número 15.

\subsection{Modelos Ensaiados}

Os ensaios foram realizados em 24 conjuntos, correspondendo a um total de 48 perfis, conforme apresentado na tabela 7. Os perfis foram simplesmente apoiados em blocos rígidos de concreto sobre os quais foram posicionados barras de aço com formato em meia-cana, conforme figura 46 . Deste modo, permitindo-se assumir a hipótese de viga simplesmente apoiada.

Tabela 7: Perfis para os ensaios de flexão.

\begin{tabular}{|c|c|c|c|}
\hline Perfil & $\begin{array}{c}\text { Comprimento } \\
(\mathrm{m})\end{array}$ & $\begin{array}{l}\text { Número de } \\
\text { Prototipos }\end{array}$ & Total Ensaios \\
\hline Ue $250 \times 85 \times 25 \times 2,65$ & 6,00 & 3 & 6 \\
\hline Ue $250 \times 85 \times 25 \times 2,25$ & 6,00 & 3 & 6 \\
\hline Ue $300 \times 85 \times 25 \times 2,65$ & 6,00 & 3 & 6 \\
\hline Ue $300 \times 85 \times 25 \times 2,25$ & 6,00 & 3 & 6 \\
\hline Ue $350 \times 85 \times 25 \times 3,00$ & 6,00 & 3 & 6 \\
\hline Ue $350 \times 85 \times 25 \times 2,65$ & 6,00 & 3 & 6 \\
\hline Ue $350 \times 85 \times 25 \times 2,25$ & 6,00 & 3 & 6 \\
\hline Ue $400 \times 85 \times 25 \times 2,25$ & 6,00 & 3 & 6 \\
\hline \multicolumn{3}{|l|}{ TOTAL } & 48 \\
\hline
\end{tabular}

Todos os deslocamentos horizontais indicados foram medidos com o auxílio de fios longos, presos aos pontos indicados na figura 47 e ligados aos transdutores de deslocamento. Assim, a influência do deslocamento vertical do conjunto pode ser minimizada. 


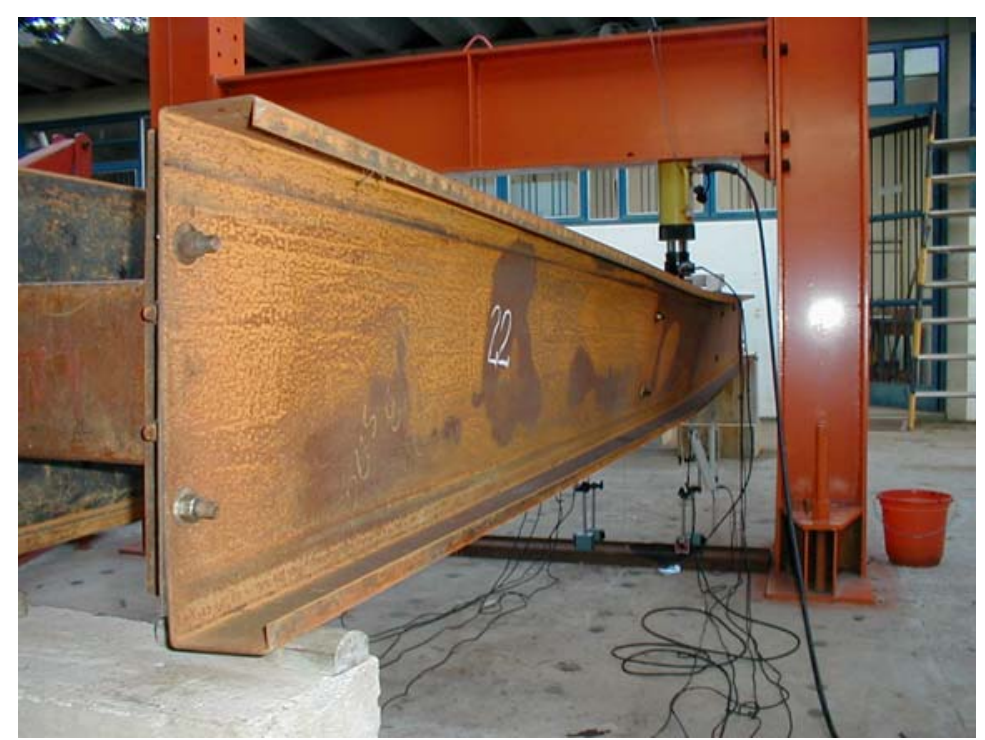

Figura 46 Vista do apoio idealizado em barra de aço com formato em meia-cana para a viga sobre o bloco de concreto.

A aplicação de forças fez-se através do incremento de carga de valor aproximadamente igual a $10 \%$ da força última prevista. A cada acréscimo foi realizada leitura dos deslocamentos e deformações ocorridas. Previamente, foi executado escorvamento dos conjuntos para teste e aferição dos instrumentos de medição. Para a escorva adotou-se o valor igual a $10 \%$ da força última prevista. Deste modo, teve-se o posterior início dos ensaios propriamente dito.

Na figura 47 ilustra-se o pórtico de reação com um conjunto de perfis sendo ensaiado.

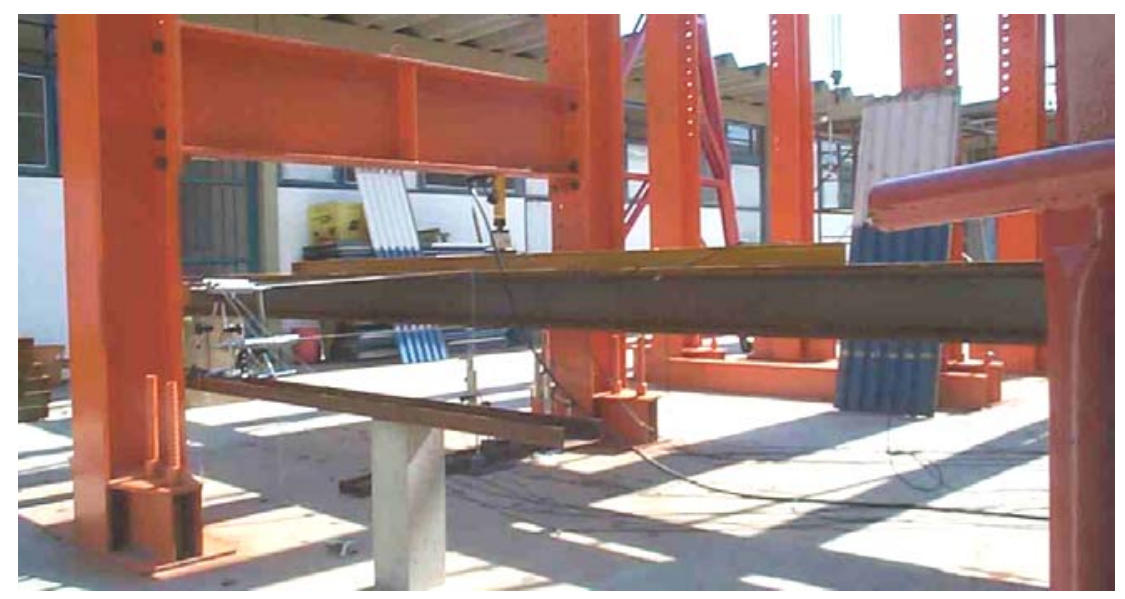

Figura 47 Vista lateral do campo de ensaio experimental.

Na figura 48 pode-se ver os pontos travados lateralmente e a aplicação da força no conjunto. 


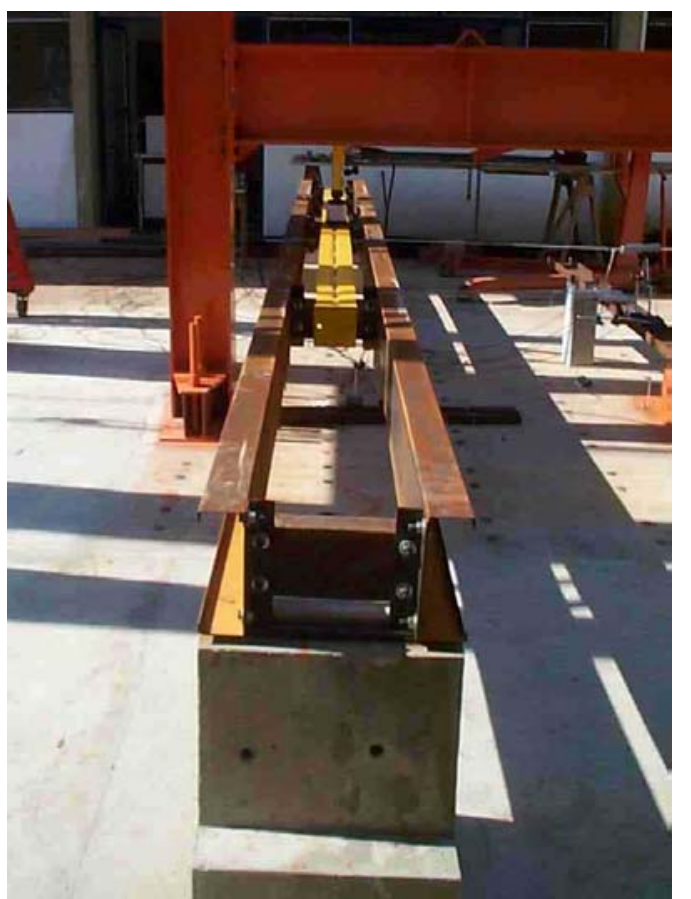

Figura 48 Vista longitudinal do ensaio evidenciando o equipamento hidráulico para aplicação de força e dispositivos de travamentos para união dos perfis. 


\subsection{Apresentação e Análise dos Resultados}

Os resultados experimentais obtidos estão apresentados na tabela 8 . Apresentam-se na tabela 8 as numerações dos conjuntos, os tipos de perfis, as cargas últimas, os valores médios da carga última e os momentos fletores últimos experimentais. Os ensaios experimentais foram divididos em 24 conjuntos de perfis unidos costa-à-costa. Desta forma, foram ensaiados 48 perfis formados a frio. Os 24 ensaios representam 8 séries de perfis com características de seção transversal diferente. Assim, trabalhou-se a variação de alguns elementos para a verificação do comportamento em relação ao modo distorcional.

Adotou-se como força última àquela para a qual verificou-se a ruína total ou parcial do conjunto ensaiado. Assim, quando da ocorrência do estado limite de instabilidade por distorção da seção transversal, o perfil perde a sua posição original e não mais pode ser carregado. Desta forma, caracterizando a sua ruína e, como conseqüência, o valor de ( $\left.\mathrm{P}_{\text {último}}\right)$.

Tratando-se os resultados experimentais obtidos em relação aos estados limites últimos, verificou-se que os conjuntos obtiveram modos de instabilidade distorcional. $\mathrm{O}$ modo de instabilidade distorcional da seção transversal apresentou-se em duas formas distintas. No primeiro caso (prédeterminado), a instabilidade distorcional ocorreu no centro do vão e com comprimento de flambagem longitudinal satisfatório. No segundo caso, a instabilidade distorcional pronunciou-se nas regiões de aplicação de força (travamentos centrais) apresentado os comprimentos de instabilidade inferiores aos pré-calculados. Foram nítidas as influências das tensões localizadas nestas regiões.

As similaridades dos resultados obtida nos conjuntos das séries indicaram satisfatória condução dos ensaios realizados e o comportamento constante do material sob as condições dos ensaios. 
Tabela 8: Resultados obtidos nos ensaios à flexão.

\begin{tabular}{|c|c|c|c|c|c|}
\hline Série & Conjunto & Perfil & $\begin{array}{l}\text { Carga última } \\
(\mathrm{kN})\end{array}$ & $\begin{array}{c}\text { Valor Médio } \\
\text { (kN) }\end{array}$ & $\begin{array}{l}M_{\text {último }} \\
\text { (kN.m) }\end{array}$ \\
\hline \multirow{3}{*}{1} & 1 & $\mathrm{U}_{\mathrm{e}} 250 \times 85 \times 25 \times 2,25$ & 8,85 & \multirow{3}{*}{12,29} & \multirow{3}{*}{24,58} \\
\hline & 2 & $U_{e} 250 \times 85 \times 25 \times 2,25$ & 13,18 & & \\
\hline & 3 & $\mathrm{U}_{\mathrm{e}} 250 \times 85 \times 25 \times 2,25$ & 11,40 & & \\
\hline \multirow{3}{*}{2} & 4 & $U_{e} 250 \times 85 \times 25 \times 2,65$ & 13,45 & \multirow{3}{*}{14,12} & \multirow{3}{*}{28,24} \\
\hline & 5 & $U_{e} 250 \times 85 \times 25 \times 2,65$ & 13,65 & & \\
\hline & 6 & $U_{e} 250 \times 85 \times 25 \times 2,65$ & 15,25 & & \\
\hline \multirow{3}{*}{3} & 7 & $U_{e} 300 \times 85 \times 25 \times 2,25$ & 19,32 & \multirow{3}{*}{15,88} & \multirow{3}{*}{31,76} \\
\hline & 8 & $U_{e} 300 \times 85 \times 25 \times 2,25$ & 15,88 & & \\
\hline & 9 & $U_{e} 300 \times 85 \times 25 \times 2,25$ & 15,88 & & \\
\hline \multirow{3}{*}{4} & 10 & $U_{e} 300 \times 85 \times 25 \times 2,65$ & Perdido & \multirow{3}{*}{17,23} & \multirow{3}{*}{34,46} \\
\hline & 11 & $U_{e} 300 \times 85 \times 25 \times 2,65$ & 17,38 & & \\
\hline & 12 & $U_{e} 300 \times 85 \times 25 \times 2,65$ & 17,08 & & \\
\hline \multirow{3}{*}{5} & 13 & $\mathrm{U}_{\mathrm{e}} 350 \times 85 \times 25 \times 2,65$ & 16,28 & \multirow{3}{*}{16,53} & \multirow{3}{*}{33,06} \\
\hline & 14 & $U_{e} 350 \times 85 \times 25 \times 2,65$ & Perdido & & \\
\hline & 15 & $\mathrm{U}_{\mathrm{e}} 350 \times 85 \times 25 \times 2,65$ & 16,78 & & \\
\hline \multirow{3}{*}{6} & 16 & $U_{e} 350 \times 85 \times 25 \times 3,04$ & 23,15 & \multirow{3}{*}{23,26} & \multirow{3}{*}{46,52} \\
\hline & 17 & $U_{e} 350 \times 85 \times 25 \times 3,04$ & 23,40 & & \\
\hline & 18 & $U_{e} 350 \times 85 \times 25 \times 3,04$ & 23,23 & & \\
\hline \multirow{3}{*}{7} & 19 & $\mathrm{U}_{\mathrm{e}} 350 \times 85 \times 25 \times 2,25$ & 16,73 & \multirow{3}{*}{17,16} & \multirow{3}{*}{34,32} \\
\hline & 20 & $U_{e} 350 \times 85 \times 25 \times 2,25$ & 18,28 & & \\
\hline & 21 & $U_{e} 350 \times 85 \times 25 \times 2,25$ & 16,48 & & \\
\hline \multirow{3}{*}{8} & 22 & $U_{e} 400 \times 85 \times 25 \times 2,25$ & 17,90 & \multirow{3}{*}{18,42} & \multirow{3}{*}{36,84} \\
\hline & 23 & $U_{e} 400 \times 85 \times 25 \times 2,25$ & 18,60 & & \\
\hline & 24 & $U_{e} 400 \times 85 \times 25 \times 2,25$ & 18,77 & & \\
\hline
\end{tabular}

Como pode ser observado na tabela 8, existiram resultados discrepantes dentro de algumas séries ou com perda total dos dados de ensaios. Esta discrepância pode ser observada nos conjuntos 1 e 7 da tabela 8. Comparando-se os resultados discrepantes na mesma série, verificamos que não existe consistência com os demais valores. Em razão disso, estes foram ignorados para efeito do cálculo médio da carga última dentro da série.

Analisando-se os resultados apresentados na tabela 8 podemos observar que as resistências médias entre as séries 1 e 2 houve o incremento de $14,9 \%$ com o aumento da espessura de chapa de 2,25 para 2,65 mm. Para os casos das séries 3 e 4 podemos observar que não 
obtivemos diferenças significativas nas resistências médias entre os perfis. $\mathrm{O}$ aumento de altura de alma da série 1 para a série 3 gerou o aumento de resistência a instabilidade distorcional de $29,2 \%$. Neste caso, podemos verificar que a modificação da altura de alma em relação à mudança de espessura do perfil promoveu efeito significativo na resistência a instabilidade distorcional. Entretanto, para as seguintes séries com a alteração da altura do perfil (séries 5,6 e 7 ) não houve diferenças significativas de resistência à instabilidade distorcional. Na série 6 , o perfil com espessura de chapa igual a 3,0 mm obteve maior resistência média no conjunto total do ensaio.

Analisando-se as alterações geométricas impostas às séries verifica-se que a influência do aumento da espessura de chapa isolado promoveu significativo ganho de resistência aos perfis. Este fato pode ser observado nas séries 5,6 e 7 . O aumento de $2,25 \mathrm{~mm}$ para $3,0 \mathrm{~mm}$ gerou $40,7 \%$ de incremento de resistência. A influência do aumento isolado da altura de alma dos perfis pode ser verificado através das séries 1, 3, 7 e 8. Como pode ser visto na tabela 8 , o aumento de altura de alma melhorou a resistência à instabilidade distorcional. Comparando-se as séries extremas, 1 e 8 , verificamos o aumento de resistência à instabilidade distorcional de $50 \%$.

O posicionamento do modo de instabilidade/ruína ocorrido foi observado em duas localidades distintas. Os dois modos de instabilidade ocorreram nas regiões dos travamentos centrais e no meio do vão da viga. $A$ figura 49.a ilustra o modo de instabilidade devido a instabilidade por distorção da seção transversal no meio do vão e a figura 49.b ilustra a instabilidade ocorrida na região de aplicação do carregamento. 


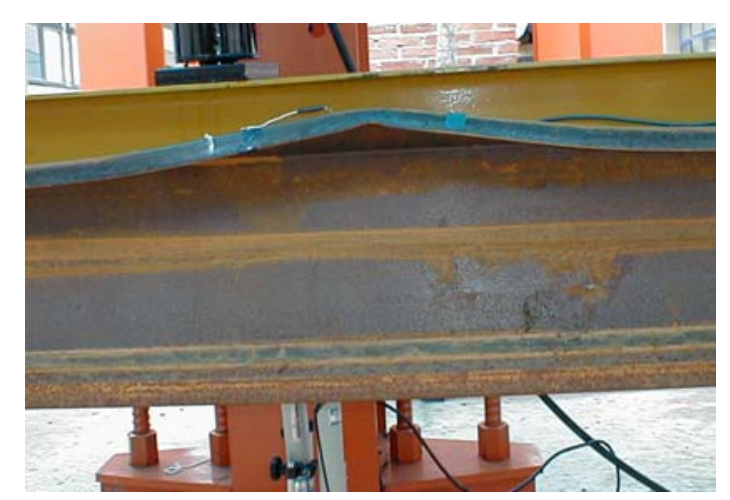

a) Instabilidade distorcional ocorrida no meio do vão da viga.

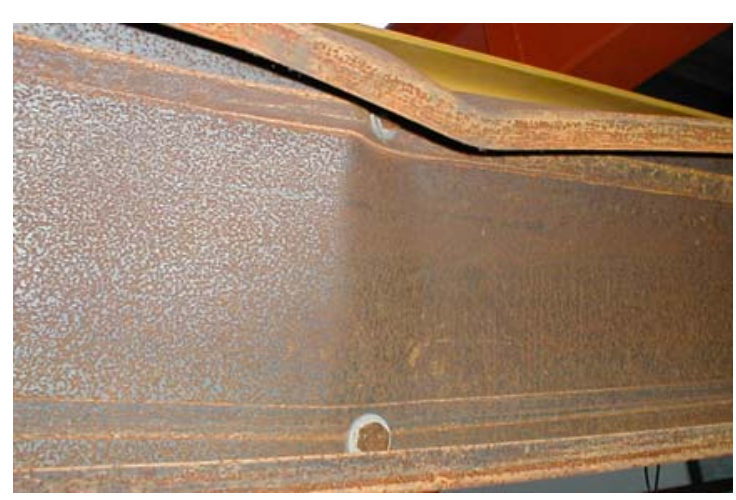

b) Instabilidade distorcional ocorrida no travamento central da viga.

Figura 49 Modos de instabilidade característicos ocorridos nos ensaios.

Os principais resultados obtidos nos ensaios estão apresentados sobre a forma de gráficos, relacionando força aplicada contra deformações e força aplicada contra deslocamentos. Nos anexos de I a IV encontram-se todos os gráficos elaborados para a análise experimental.

$\mathrm{Na}$ figura 50 apresenta-se o gráfico correspondente às deformações ocorridas no ensaio do conjunto 11. Este conjunto obteve instabilidade distorcional na região do travamento central do perfil, como indicado na figura 49.b. Os pontos 1, 2 e 3 correspondem ao perfil $A$ e os demais ao perfil $B$, como indicado na figura 45.

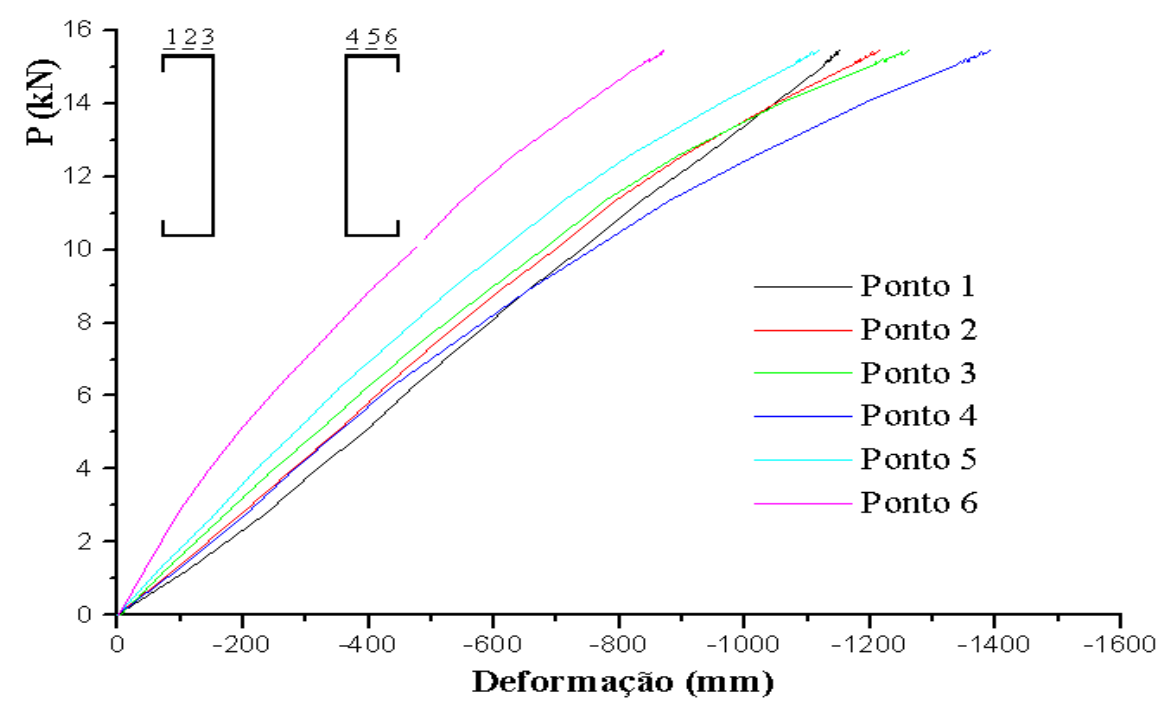

Figura 50 Gráfico: força x deformação do conjunto 11. Perfil: Ue $350 \times 85 \times 25 \times 2,65$. 
Neste ensaio a ruína ocorreu na região de aplicação do carregamento no perfil B. Pode-se observar melhor distribuição das tensões ao longo da mesa comprimida para o perfil A. Para o perfil $B$, verifica-se que as tensões distribuem-se de modo menos uniforme, com variação maior. Observa-se o efeito da instabilidade distorcional na leitura dos extensômetros através da comparação entre os dois perfis. Para o perfil A, (pontos 1, 2 e 3) a tensão praticamente permaneceu inalterada no decorrer do ensaio. Este perfil apresentou tensões regulares na mesa comprimida tendo o comportamento de viga como um caso na flexão simples. Entretanto, para o perfil B (pontos 4, 5 e 6), observa-se que o ponto 4 possui maiores deformações em relação ao ponto 5 e este sucessivamente em relação ao ponto 6 . Como o ponto 6 está mais próximo da borda, durante a ocorrência do giro da seção transversal o fenômeno distorcional existe redução das tensões de compressão em decorrência das tensões de tração longitudinal na mesa comprimida.

$\mathrm{Na}$ figura 51 pode-se observar os deslocamentos verticais ocorridos. Nota-se praticamente os mesmos deslocamentos para as mesas superiores e inferiores dos perfis até aproximadamente a força $P=10 \mathrm{kN}$. A partir deste nível de força os deslocamentos das mesas do perfil $B$ passam a ser diferentes, mantendo-se iguais ao do perfil A. Nota-se também a correspondência linear entre força e deslocamento até aquele valor da força indicando que a seção instrumentada pouco sofreu alteração da forma.

$\mathrm{Na}$ figura 52 e 53 apresentam-se os giros das seções transversais do meio do vão. Na afigura 52 apresenta o giro da alma e na figura 53 o giro da mesa comprimida. Pode-se notar que o mesmo acontece já a partir do início da aplicação do carregamento. Entretanto, o giro ocorrido nos elementos da seção instrumentada foi desprezível (aproximadamente $1^{\circ}$ ). Na figura 54 podemos observar o modo de instabilidade distorcional ocorrido no travamento central. 


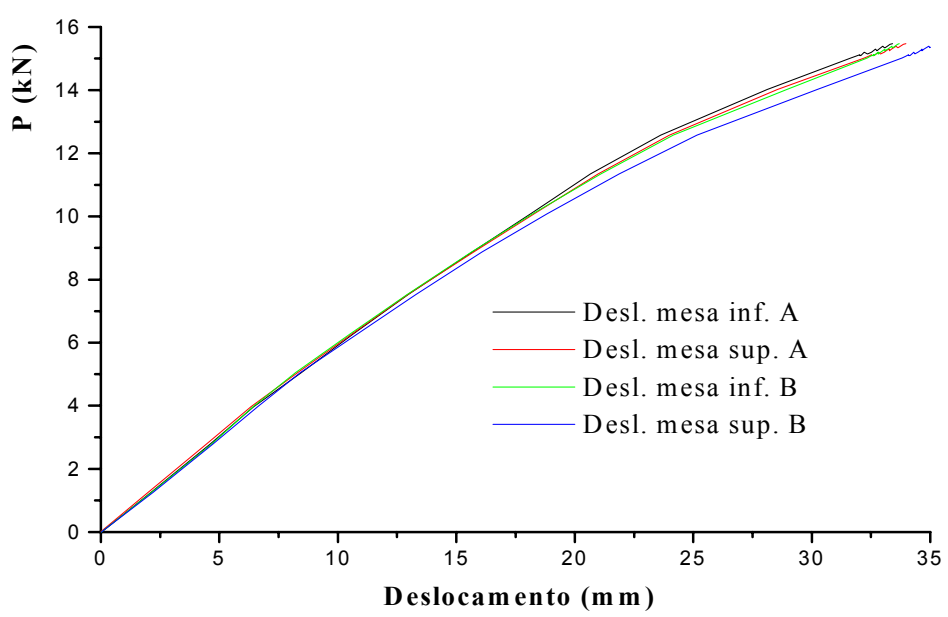

Figura 51 Gráfico força $x$ deslocamento do conjunto 11. Perfil: Ue $350 \times 85 \times 25 \times 2,65$.

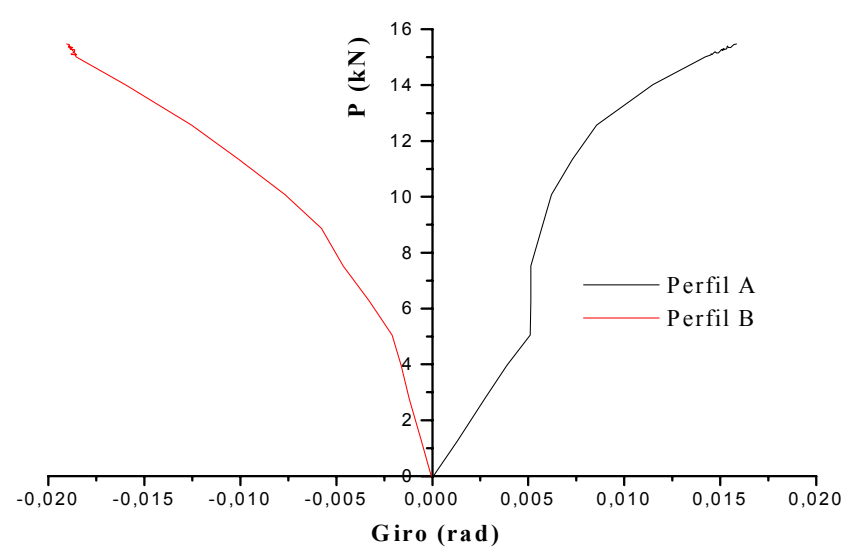

Figura 52 Giro dos perfis do conjunto $11-$ Ue $350 \times 85 \times 25 \times 2,65$.

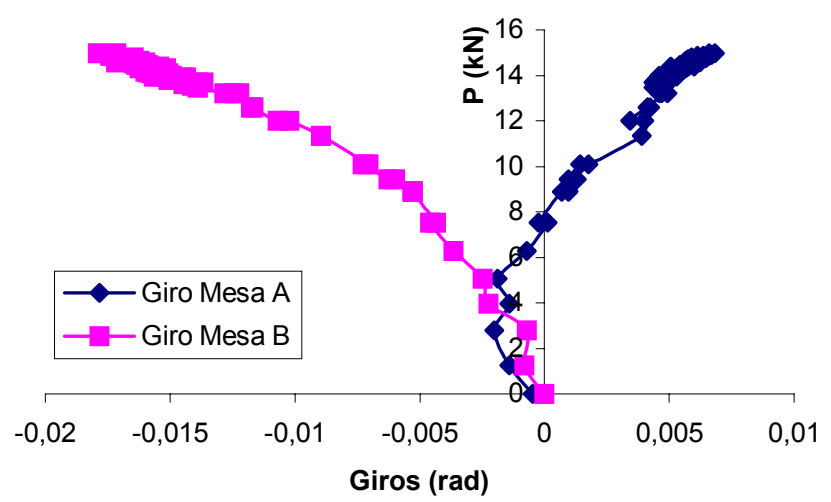

Figura 53 Gráfico Giro das mesas dos perfis Ue $300 \times 85 \times 25 \times 2,65$ conjunto 11. 


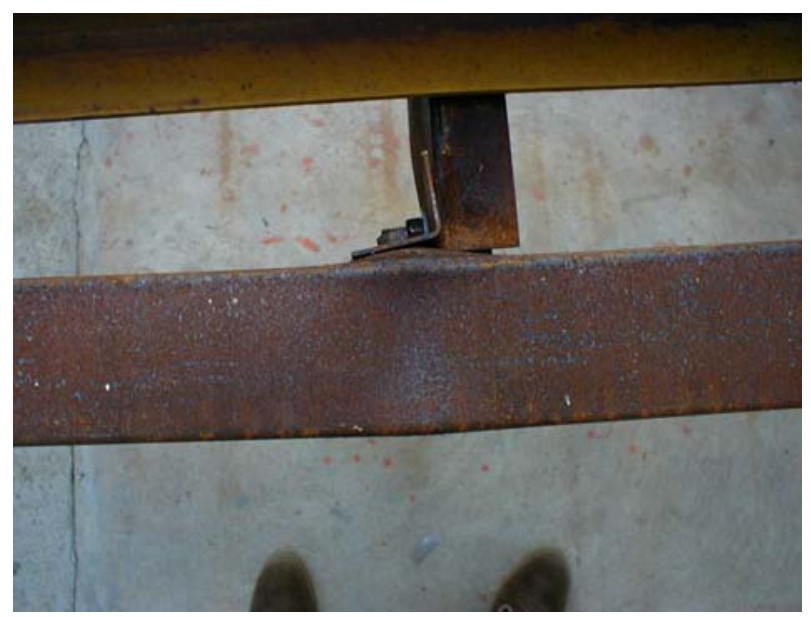

Figura 54 Detalhe em vista superior do modo de instabilidade distorcional ocorrido no travamento central no ensaio do conjunto 11 - Perfil Ue $350 \times 85 \times 25 \times 2,65$.

$\mathrm{Na}$ figura 55 têm-se as deformações ocorridas nas mesas comprimidas dos perfis do conjunto 23. Neste conjunto, a ruína se caracterizou por distorção da seção transversal no meio do vão e foi evidenciada no perfil B.

Comparativamente aos perfis que apresentaram ruína no ponto de aplicação do carregamento, pode-se observar que a distorção no meio do vão caracteriza-se por uma distribuição de tensões ao longo da mesa comprimida bastante irregular, como se observa pelas deformações ocorridas nos pontos 4,5 e 6 da figura 55 .

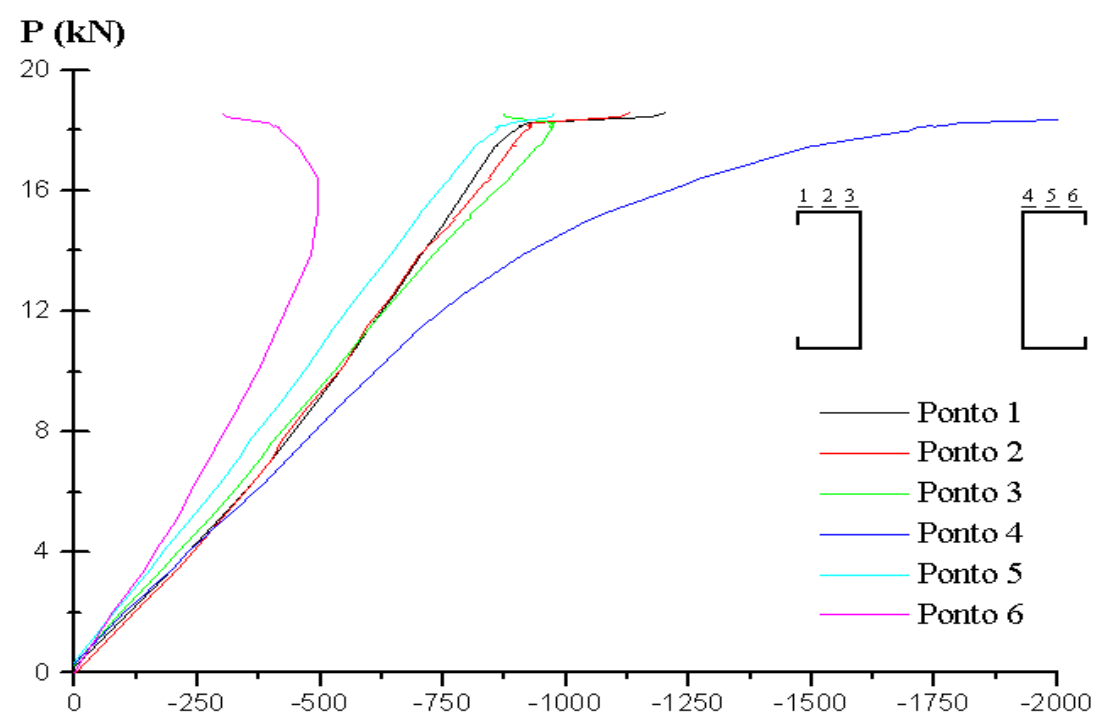


Figura 55 Gráfico força x deformação para o conjunto 23. Perfil Ue $400 \times 85 \times 25 \times 2,25$.

Para os perfis que não apresentaram a distorção, pode-se observar que a distribuição das tensões de compressão na mesa permanece praticamente uniforme. Isto indica que a instabilidade local da mesa não deve ter interagido com o modo distorcional.

$\mathrm{Na}$ figura 56 pode-se observar os deslocamentos verticais sofridos pelas seções transversais dos perfis. Os deslocamentos praticamente mantêm-se iguais para cada perfil, salientando-se que, os deslocamentos superiores tiveram suas medidas prejudicadas pela perda de curso dos transdutores de deslocamentos.

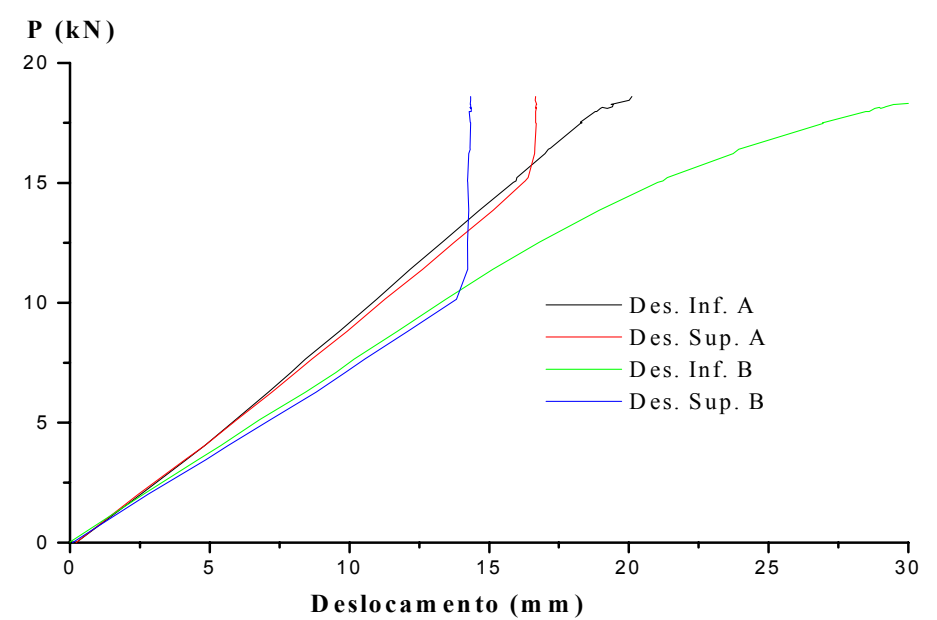

Figura 56 Gráfico força $x$ deslocamento para o conjunto 23. Perfil Ue $400 \times 85 \times 25 \times 2,25$.

No gráfico da figura 57 podemos observar os giros das mesas dos perfis. Verifica-se que os mesmos sofreram o giro de aproximadamente $12,5^{\circ}$ do conjunto mesa/enrijecedor, conforme figura y. 


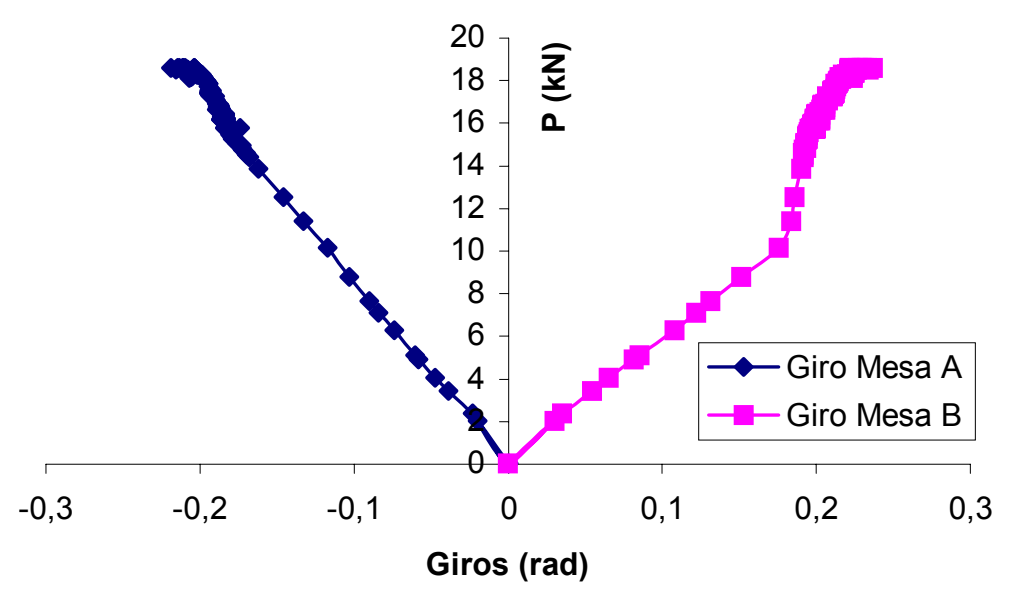

Figura 57 Gráfico Giro das mesas dos perfis Ue $400 \times 85 \times 25 \times 2,25$ conjunto 23.

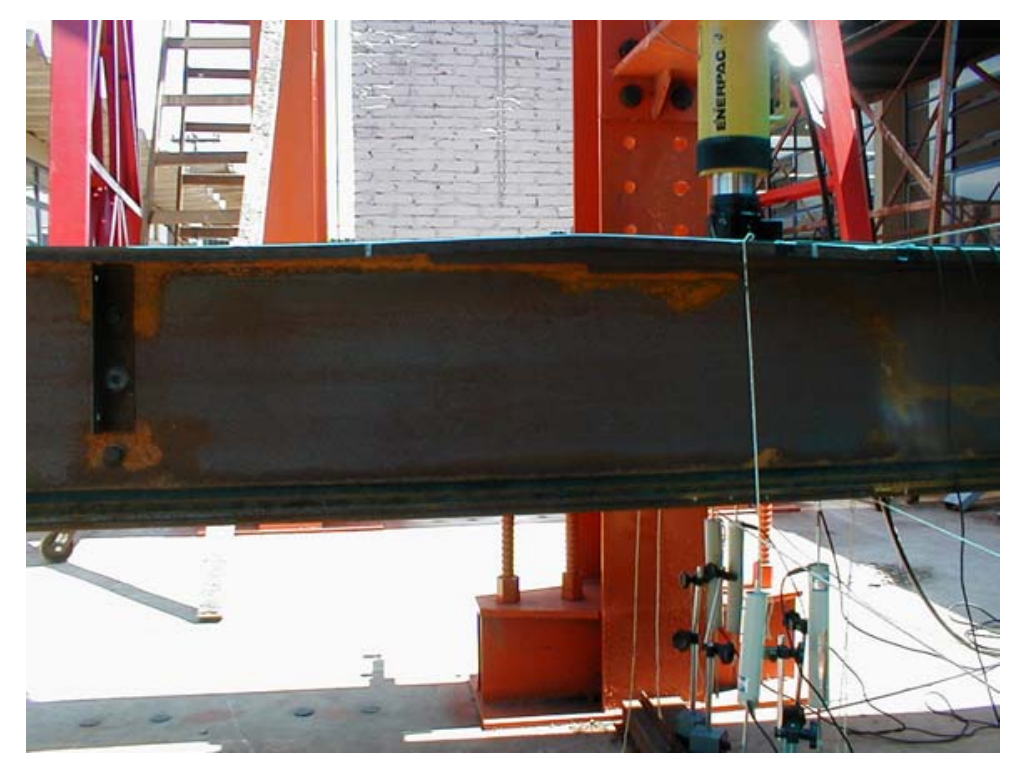

Figura 58 Detalhe em vista frontal do modo de instabilidade distorcional ocorrido no vão central no ensaio do conjunto 23 - Perfil Ue $400 \times 85 \times 25 \times 2,25$.

Estes gráficos anteriormente apresentados são representativos dos ensaios desenvolvidos.

Os modos de instabilidades ocorridos nos pontos de aplicação do carregamento, pontos estes travados lateralmente, podem ser explicados pelo fato de que, nos pontos lateralmente travados, a rotação é impedida e 
tensões adicionais são introduzidas pelas forças impostas por esses travamentos. Assim, a flambagem por distorção da seção transversal ocorre devido ao aumento da tensão de compressão no enrijecedor. A figura 59 ilustra esse acréscimo de tensões.

Este fato indica que os travamentos laterais, em número e locação, podem alterar o comportamento do perfil, inclusive alterando o modo de falha previsto. Este fato também foi constatado por Kavanagh; Ellifrit (1994) e Javaroni (1999). Também, em vista dessas novas distribuições de tensões, as seções podem ser totalmente efetivas, podendo ficar o cálculo da resistência do perfil em função das propriedades da seção bruta.

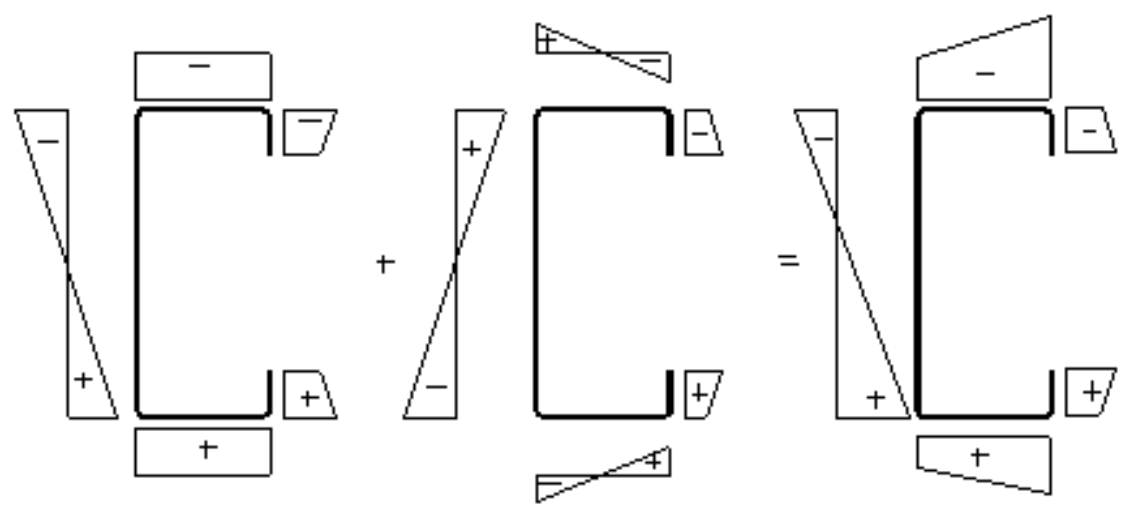

Figura 59 Distribuição de tensões combinada devido ao efeito da presença de travamentos.

Os resultados experimentais que foram obtidos nos ensaios dos diferentes perfis estão comparados com os valores teóricos encontrados em alguns modelos matemáticos propostos por seus autores.

Para os perfis ensaiados neste projeto, a norma brasileira dá como modo de instabilidade o distorcional, coincidindo com o modo obtido experimentalmente. Os resultados de força última obtida nos ensaios estão resumidos e comparados com aqueles obtidos em acordo com a NBR 14762 na tabela 9 .

Tabela 9: Valores últimos observados em ensaio.

\begin{tabular}{c|c|c|c|c|c}
\hline Perfil & $\begin{array}{c}\text { Vão } \\
(\mathbf{m})\end{array}$ & $\begin{array}{c}\text { Esquema } \\
\text { Carregamento }\end{array}$ & $\begin{array}{c}\mathbf{P}_{\text {último }} \\
(\mathbf{k N})\end{array}$ & $\begin{array}{c}\mathbf{P}_{\text {NBR }} \\
(\mathbf{k N})\end{array}$ & $\mathbf{P}_{\text {último }} / \mathbf{P}_{\text {NBR }}$ \\
\hline$U_{\mathrm{e}} 250 \times 85 \times 25 \times 2,25$ & 6,0 & $1^{*}$ & 12,29 & 10,37 & 1,19 \\
\hline
\end{tabular}




\begin{tabular}{c|c|c|c|c|c}
\hline$U_{\mathrm{e}} 250 \times 85 \times 25 \times 2,65$ & 6,0 & $1^{*}$ & 14,12 & 12,58 & 1,12 \\
\hline$U_{\mathrm{e}} 300 \times 85 \times 25 \times 2,25$ & 6,0 & $1^{*}$ & 15,88 & 12,80 & 1,24 \\
\hline$U_{\mathrm{e}} 300 \times 85 \times 25 \times 2,65$ & 6,0 & $1^{*}$ & 17,23 & 15,73 & 1,09 \\
\hline $\mathrm{U}_{\mathrm{e}} 350 \times 85 \times 25 \times 2,25$ & 6,0 & $1^{*}$ & 17,16 & 15,25 & 1,12 \\
\hline $\mathrm{U}_{\mathrm{e}} 350 \times 85 \times 25 \times 2,65$ & 6,0 & $1^{*}$ & 16,53 & 18,91 & 0,87 \\
\hline$U_{\mathrm{e}} 350 \times 85 \times 25 \times 3,00$ & 6,0 & $1^{*}$ & 23,26 & 22,05 & 1,05 \\
\hline$U_{\mathrm{e}} 400 \times 85 \times 25 \times 2,25$ & 6,0 & $1^{*}$ & 18,42 & 17,52 & 1,05 \\
\hline
\end{tabular}

*Esquema de carregamento 1 com forças aplicadas a cada 1/3 do vão.

Pode-se notar que os resultados obtidos de acordo com a norma brasileira, NBR 14.762, têm boa correlação com os experimentais, ficando, em geral, a favor da segurança. O modo de instabilidade distorcional pode ser crítico, dependendo das características geométricas da seção transversal da barra. Para fins de projeto, a norma brasileira fornece, em seu anexo $D$, relações para $\left(b_{w} / t\right)$ e $\left(D / b_{w}\right)$ a partir das quais pode-se dispensar a verificação da instabilidade por distorção para barras comprimidas e para barras fletidas.

As exceções observadas nos modos de instabilidade teórico e experimental podem ser justificadas analisando-se as deformações ocorridas na mesa comprimida, conseqüentemente, o desenvolvimento das tensões normais nesse elemento, ao longo do histórico de carregamento. A ocorrência da flambagem lateral com torção está condicionada a deslocamento horizontal e giro em torno do centro de torção da seção transversal. Assim, na seção transversal surgem tensões que se superpõe às tensões normais da flexão e com isso, a tensão de compressão na mesa deixa de ser uniforme, conseqüentemente, o coeficiente de flambagem utilizado no cálculo da largura efetiva $(k=0,43)$ passa a ter novo valor, sendo superior ao adotado.

A NBR 14762 permite o cálculo do comprimento de meia-onda de flambagem para a instabilidade distorcional. Deste modo, nos ensaios pôdese medir diretamente os comprimentos nos perfis. Como podemos ver na figura 60 , os pontos de inflexão definem o comprimento de instabilidade distorcional. 


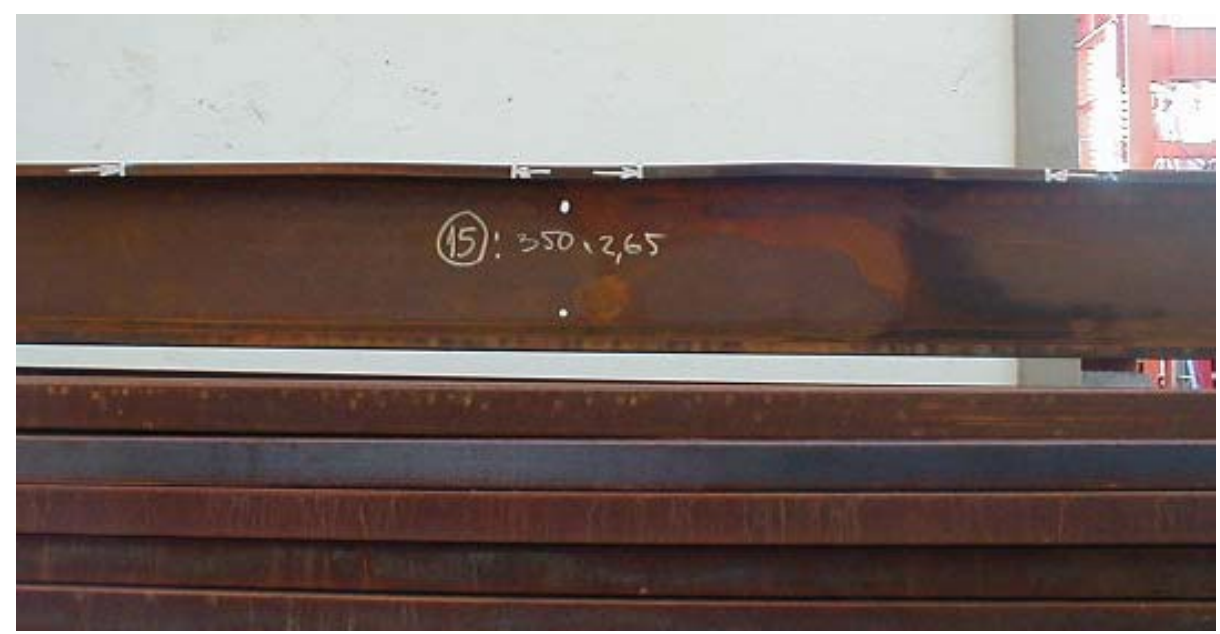

Figura 60 Comprimento de meia-onda entre os pontos de inflexão do perfil tipo Ue $350 \times 85 \times 25 \times 2,65$ - conjunto 15.

Na tabela 10 estão apresentados os comprimentos calculados e os medidos nos perfis ensaiados. Como para os valores das forças últimas, aqui também pode ser observada uma boa correlação entre os valores calculados e os medidos nos ensaios. Em três conjuntos não foi possível realizar uma medida confiável para o valor desse comprimento tendo-se em vista as dificuldades de identificação dos pontos de inflexão.

Tabela 10: Comprimentos de meia onda previstos e observados, em $\mathrm{mm}$.

\begin{tabular}{|c|c|c|}
\hline Perfil & $\mathrm{L}_{d}$ previsto & $\mathrm{L}_{d}$ medido \\
\hline$U_{e} 250 \times 85 \times 25 \times 2,25$ & 753,7 & 704 \\
\hline$U_{e} 250 \times 85 \times 25 \times 2,65$ & 676,3 & 655 \\
\hline$U_{e} 300 \times 85 \times 25 \times 2,25$ & 769,9 & ${ }^{*}$ \\
\hline$U_{e} 300 \times 85 \times 25 \times 2,65$ & 707,8 & * \\
\hline$U_{e} 350 \times 85 \times 25 \times 2,25$ & 800,2 & 830 \\
\hline$U_{e} 350 \times 85 \times 25 \times 2,65$ & 735,6 & 735 \\
\hline$U_{e} 350 \times 85 \times 25 \times 3,00$ & 686,2 & ${ }^{*}$ \\
\hline$U_{e} 400 \times 85 \times 25 \times 2,25$ & 827,4 & 820 \\
\hline
\end{tabular}

A curva de resistência à instabildade distorcional da NBR 14762 foi comparada na tabela 11 com seguintes curvas de resistência apresentadas na revisão bibliográfica. 
Observa-se que a tensão de instabilidade distorcional foi determinada pelo modelo de Lau \& Hancock (1997) e utilizada na determinação dos momentos máximos à instabilidade distorcional para as respectivas curvas apresentadas na tabela 11. Os perfis permaneceram numa faixa de esbeltez distorcional entre 0,849 a 1,108. Esta faixa de esbeltez apresenta-se no trecho de instabilidade distorcional inelástico.

Como podemos verificar na tabela 11 , o ensaio da série 5 apresentou resistência experimental à instabilidade distorcional inferior aos demais casos estudados. Possíveis falhas nos procedimentos experimentais podem ser a causa deste fato. A comprovação através de novos ensaios para esta série se faz necessário a fim de que se possa examinar melhor este caso.

Observando-se a curva 4 em comparação à curva da NBR 14762 verificamos que os resultados são iguais em razão da esbeltez apresentada ser inferior à 1,414. Existem diferenças de resistência a instabilidade distorcional apenas acima deste limite (instabilidade distorcional elástica).

Comparando-se os resultados obtidos com a curva 5 (filosofia de chapa) em relação à curva 4 (filosofia de barra) verificamos que a curva 5 apresentou em média resistência à instabilidade distorcional 5\% superior. Comparando-se os resultados teóricos da curva 5 em relação aos resultados experimentais verificamos que a curva 5 apresentou em média resistência à instabilidade distorcional $4,1 \%$ inferior. Este fato revela que a curva 5 apresenta maior economia no dimensionamento de perfis quanto ao estado limite último caracterizado pela instabilidade distorcional. Entretanto, além do caso geral ocorrido na série 5 , verificamos que os resultados obtidos pelas séries 6 e 8 apresentaram-se próximos dos experimentais. Assim, observase que a curva 6 demonstra maiores diferenças em relação aos resultados experimentais ( $8 \%$ inferiores em média). As curvas 5 e 6 
Tabela 11:Comparação entre as curvas de resistência à instabilidade distorcional.

\begin{tabular}{|c|c|c|c|c|c|c|c|c|c|}
\hline Série & Perfil & $\begin{array}{c}\sigma_{\text {Dist }} \\
\left(k N / m^{2}\right)\end{array}$ & $\lambda_{\text {Dist }}$ & $\begin{array}{c}M_{\text {Dist }} \\
\text { (kN.mm) } \\
\text { NBR 14762 }\end{array}$ & $\begin{array}{c}M_{\text {Dist }} \\
\text { (kN.mm) } \\
\text { Curva } 4\end{array}$ & $\begin{array}{c}M_{\text {Dist }} \\
\text { (kN.mm) } \\
\text { Curva 5 }\end{array}$ & $\begin{array}{c}M_{\text {Dist }} \\
\text { (kN.mm) } \\
\text { Curva } 6\end{array}$ & $\begin{array}{c}\mathbf{M}_{\text {Dist }} \\
\text { (kN.mm) } \\
\text { Simplificação } \\
\text { Ellifritt }\end{array}$ & $\begin{array}{c}\mathbf{M}_{\text {Dist }} \\
(\mathbf{k N} \cdot \mathbf{m m}) \\
\text { Experimental }\end{array}$ \\
\hline 1 & Ue $250 \times 85 \times 25 \times 2,25$ & 0,391 & 0,932 & 20691,9 & 20691,9 & 21666,0 & 20938,2 & 33396,2 & 24580,0 \\
\hline 2 & Ue $250 \times 85 \times 25 \times 2,65$ & 0,472 & 0,849 & 25234,0 & 25234,0 & 26860,9 & 26064,0 & 38914,4 & 28240,0 \\
\hline 3 & Ue $300 \times 85 \times 25 \times 2,25$ & 0,351 & 0,984 & 25655,0 & 25655,0 & 26707,7 & 25713,1 & 42763,8 & 31760,0 \\
\hline 4 & Ue $300 \times 85 \times 25 \times 2,65$ & 0,423 & 0,896 & 31537,7 & 31537,7 & 33222,3 & 32173,6 & 49881,0 & 34460,0 \\
\hline 5 & Ue $350 \times 85 \times 25 \times 2,65$ & 0,378 & 0,948 & 37914,1 & 37914,1 & 39612,5 & 38240,3 & 61798,3 & 33060,0 \\
\hline 6 & Ue $350 \times 85 \times 25 \times 3,00$ & 0,437 & 0,882 & 44226,4 & 44226,4 & 46725,0 & 45282,3 & 69405,7 & 46520,0 \\
\hline 7 & Ue $350 \times 85 \times 25 \times 2,25$ & 0,313 & 1,042 & 30547,1 & 30547,1 & 31742,4 & 30412,7 & 52937,5 & 34320,0 \\
\hline 8 & Ue $400 \times 85 \times 25 \times 2,25$ & 0,277 & 1,108 & 35074,5 & 35074,5 & 36606,5 & 34855,5 & 63915,5 & 36840,0 \\
\hline
\end{tabular}

Observações: A curva 4 na tabela 11 representa a curva de Hancock (1997) para a instabilidade distorcional com filosofia de instabilidade de barra. A curva 5 na tabela 11 representa a curva de Hancock (1997) para a instabilidade distorcional com filosofia de instabilidade de chapa. A curva 6 na tabela 11 representa a curva de Hancock (1997) para a instabilidade distorcional com filosofia de instabilidade de chapa e melhor representação do comportamento pós-crítico. A simplificação de Ellifritt (1998) é um apoio para o cálculo expedito da resistência à instabilidade distorcional. 
apresentaram resultados satisfatórios e o emprego dependerá do risco assumido no cálculo.

A simplificação de Ellifritt (1998) não apresentou resultados satisfatórios comparando-se às curvas de resistência estudadas e aos resultados experimentais.

Observando-se os resultados obtidos pela curva de resistência à instabilidade distorcional da NBR 14762, verifica-se que existe o conservadorismo em relação aos resultados experimentais $(9,1 \%$ em média). No geral, as curvas com filosofia de barra (NBR 14762 e curva 4) apresentaram resultados conservadores em relação às curvas com filosofia de chapa, comparado aos resultados experimentais.

\subsubsection{Análise de Instabilidade via Método das faixas finitas}

O método das faixas finitas é um dos métodos de análise para os diferentes modos de instabilidade aos quais os perfis de aço formados a frio estão sujeitos. Nesta análise, foi empregado o programa CU-FSM (Cornell University - Finite Strip Method), desenvolvido por Schafer, professor da Universidade Johns Hopkins, EUA.

$\mathrm{Na}$ modelagem da seção transversal dos perfis foi adotada a mesma discretização utilizando-se 37 nós em 36 elementos. Observa-se que foram testadas discretizações com um número reduzido de elementos, porém não se verificaram diferenças significativas nos resultados das análises. Chodraui (2003) também verificou este fato em análises de perfis submetidos à flexão e a compressão.

Deste número de elementos, a discretização do perfil seguiu a seguinte forma:

$$
\begin{aligned}
& \checkmark \quad 4 \text { para enrijecedores; } \\
& \checkmark \quad 4 \text { por dobra; } \\
& \checkmark \quad 4 \text { por mesa; } \\
& \checkmark \quad 4 \text { para a alma. }
\end{aligned}
$$


Devido às limitações do programa, analisou-se o perfil de forma isolada representado-se o vão central do conjunto. As vinculações das extremidades foram assumidas com bi-apoiadas.

$\mathrm{Na}$ figura 61 ilustra-se o resultado obtido através do programa para um perfil Ue $250 \times 85 \times 25 \times 2,25$, com distribuição linear de tensões, com valores de $100 \mathrm{~N} / \mathrm{mm}^{2}$ para a tração e $100 \mathrm{kN} / \mathrm{cm}^{2}$ para compressão.

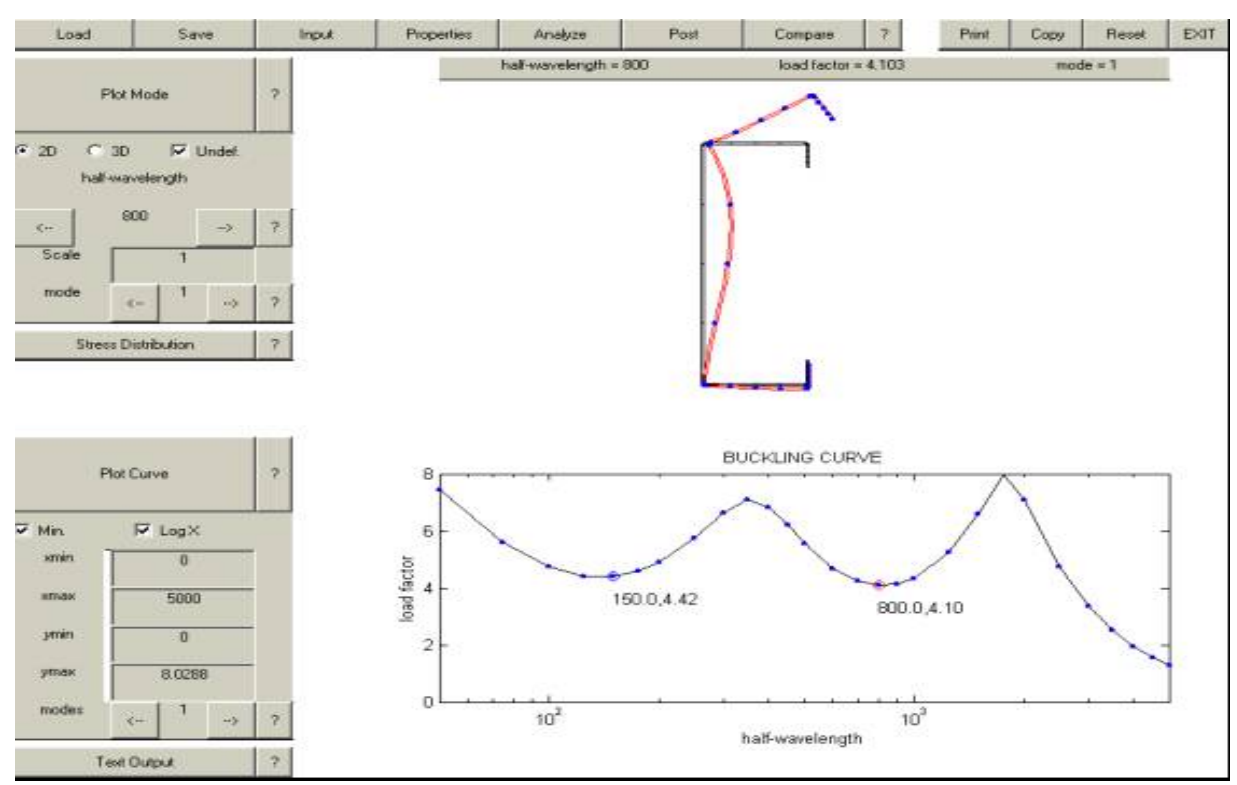

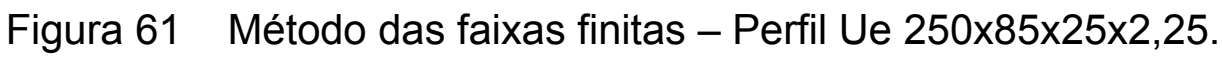

Pode-se notar que o programa fornece os pontos de mínimo para cada modo de flambagem, onde o primeiro corresponde a flambagem local, o segundo ao modo distorcional e o terceiro modo global. Para esses pontos de mínimo, o programa fornece o valor do comprimento de meia-onda e o fator de carga correspondente. Esse fator de carga, multiplicado pelo valor de tensão inicialmente atribuído, $100 \mathrm{~N} / \mathrm{mm}^{2}$ no caso, fornece a tensão crítica para o modo correspondente. Ressaltando-se que esse valor referese ao cálculo em regime elástico, portanto, para valores superiores a $\mathrm{f}_{\mathrm{y}} / 2$, a tensão crítica obtida será corrigida pela equação da parábola.

Para cada comprimento de meia-onda analisado, o programa também desenha o modo de flambagem correspondente. Neste caso, pode-se 
observar que o modo apresentado pelo programa computacional é aquele ocorrido no ensaio, conforme ilustra a figura 62 .
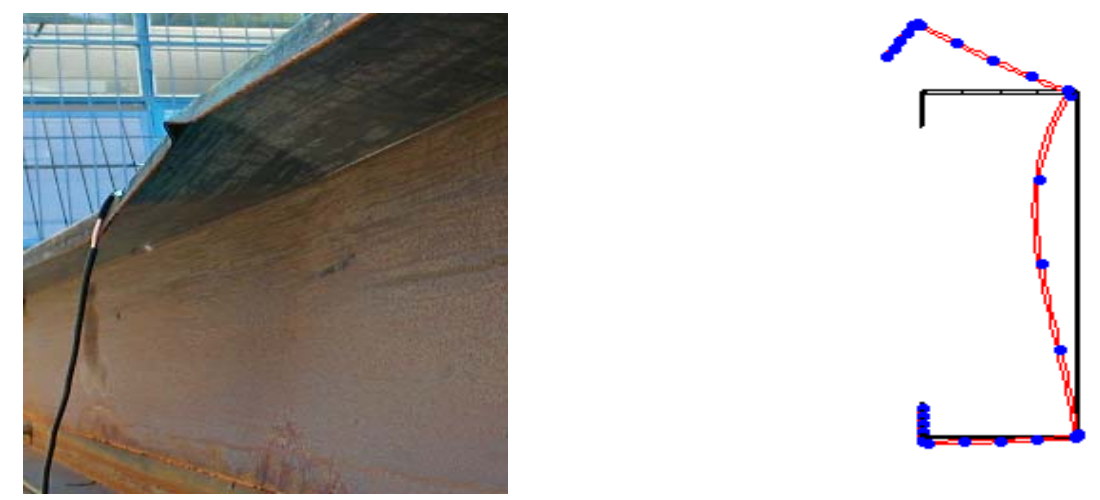

Figura 62 Modo de instabilidade do perfil ensaiado em comparação aos resultados numéricos via faixas finitas.

$\mathrm{O}$ anexo $\mathrm{V}$ apresenta as análises restantes através do método das faixas finitas. Dos resultados obtidos pelo programa pode-se verificar as correspondentes tensões críticas apresentadas na tabela 12.

Tabela 12:Resultados obtidos com o programa CU-SFM.

\begin{tabular}{|c|c|c|c|}
\hline Perfil & $\begin{array}{l}\text { Tensão } \\
\text { Crítica } \\
\left(\mathbf{k N} / \mathrm{cm}^{2}\right)\end{array}$ & $\begin{array}{l}\text { Modo de } \\
\text { falha }\end{array}$ & $\begin{array}{c}\text { Comprimento } \\
\text { de meia onda } \\
(\mathrm{mm})\end{array}$ \\
\hline Ue $250 \times 85 \times 25 \times 2,25$ & 41,0 & Distorção & 800 \\
\hline Ue $250 \times 85 \times 25 \times 2,65$ & 49,7 & Distorção & 800 \\
\hline Ue $300 \times 85 \times 25 \times 2,25$ & $32,3(35,8)$ & Local (Distorção) & $175(850)$ \\
\hline Ue $300 \times 85 \times 25 \times 2,65$ & 43,4 & Distorção & 800 \\
\hline Ue $350 \times 85 \times 25 \times 2,25$ & $24,4(30,9)$ & Local (Distorção) & $200(900)$ \\
\hline Ue $350 \times 85 \times 25 \times 2,65$ & $33,7(37,4)$ & Local (Distorção) & $200(800)$ \\
\hline Ue $350 \times 85 \times 25 \times 3,00$ & 44,3 & Distorção & 700 \\
\hline Ue $400 \times 85 \times 25 \times 2,25$ & 18,8 & Local & 200 \\
\hline
\end{tabular}

Como os valores das tensões críticas foram superiores a fy/2, efetuaram-se correções, pela expressão da parábola, e os respectivos valores são apresentados nas tabela 13 . Na tabela 13 , Púltimo refere-se a carga última de ensaio. 
Tabela 13:Resultados finais pelo método das faixas finitas.

\begin{tabular}{|c|c|c|c|c|}
\hline Perfil & $\begin{array}{c}\text { Tensão Crítica } \\
\text { Corrigida }\left(\mathrm{kN} / \mathrm{cm}^{2}\right)\end{array}$ & $\begin{array}{c}P_{\text {último }} \\
(\mathbf{k N})\end{array}$ & $\begin{array}{l}P_{\text {Cu-FSM }} \\
(\mathbf{k N})\end{array}$ & $\mathbf{P}_{\text {último }} / \mathbf{P}_{\text {CU-FSM }}$ \\
\hline Ue $250 \times 85 \times 25 \times 2,25$ & 26,9 & 12,29 & 10,44 & 1,177 \\
\hline Ue $250 \times 85 \times 25 \times 2,65$ & 28,2 & 14,12 & 12,72 & 1,110 \\
\hline Ue $300 \times 85 \times 25 \times 2,25$ & $25,0(25,9)$ & 15,88 & $12,43(12,87)$ & $1,280(1,230)$ \\
\hline Ue $300 \times 85 \times 25 \times 2,65$ & 27,3 & 17,23 & 15,81 & 1,090 \\
\hline Ue $350 \times 85 \times 25 \times 2,25$ & $22,2(24,6)$ & 17,16 & $13,66(15,14)$ & $1,256(1,133)$ \\
\hline Ue $350 \times 85 \times 25 \times 2,65$ & $25,4(26,3)$ & 16,53 & $18,22(18,87)$ & $0,907(0,876)$ \\
\hline Ue $350 \times 85 \times 25 \times 3,00$ & 27,5 & 23,26 & 22,14 & 1,051 \\
\hline Ue $400 \times 85 \times 25 \times 2,25$ & $18,6(22,8)$ & 18,42 & $13,83(16,95)$ & $1,332(1,087)$ \\
\hline
\end{tabular}

Nota: Os valores entre parênteses são relacionados com o modo de instabilidade por distorção.

Comparando-se os resultados da análise de instabilidade através do método das faixas finitas apresentados na tabela $13 \mathrm{com}$ os resultados da norma brasileira apresentados na tabela 11, verifica-se maior conservadorismo da NBR14762.

O perfis que apresentaram modo de instabilidade crítico diferente do distorcional, de acordo com o programa computacional, tiveram as tensões críticas para cada modo próximas, excetuando-se o perfil Ue $400 \times 85 \times 25 \times 2,25$.

A instabilidade local somente foi evidenciada na alma do perfil Ue $400 \times 85 \times 25 \times 2,25$, perfil A do conjunto 23 , conforme figura 63 . Os pontos de inflexão foram marcados com giz azul.

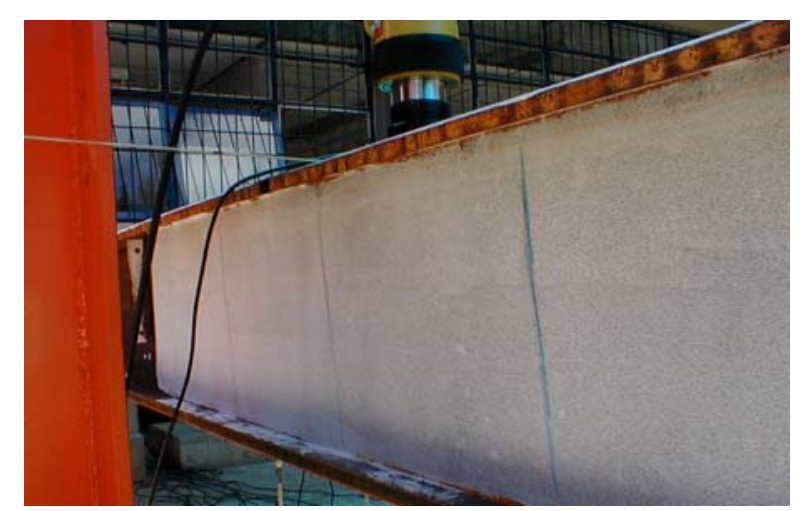

Figura 63 Instabilidade local da alma no conjunto 23, perfil A - Perfil Ue $400 \times 85 \times 25 \times 2,25$. 
A instabilidade local da alma ocorreu para uma carga $P=15 \mathrm{kN}$, com boa aproximação da fornecida pelo programa computacional. Para o outro perfil, instabilidade local não foi notada e com o acréscimo do carregamento, esse outro perfil teve como modo de instabilidade a flambagem por distorção, conforme se apresenta na figura 64. Para os demais perfis onde não se teve modo distorcional como crítico, deve-se lembrar que a interferência dos travamentos laterais altera a distribuição das tensões de compressão na mesa superior do perfil, fazendo com que a distribuição não seja mais uniforme. Assim, a flambagem desse elemento não mais ocorre como um elemento uniformemente comprimido, justificando a não ocorrência da instabilidade local da mesa.

Figura 64 Flambagem local da alma para o conjunto 23, perfil B - Perfil Ue

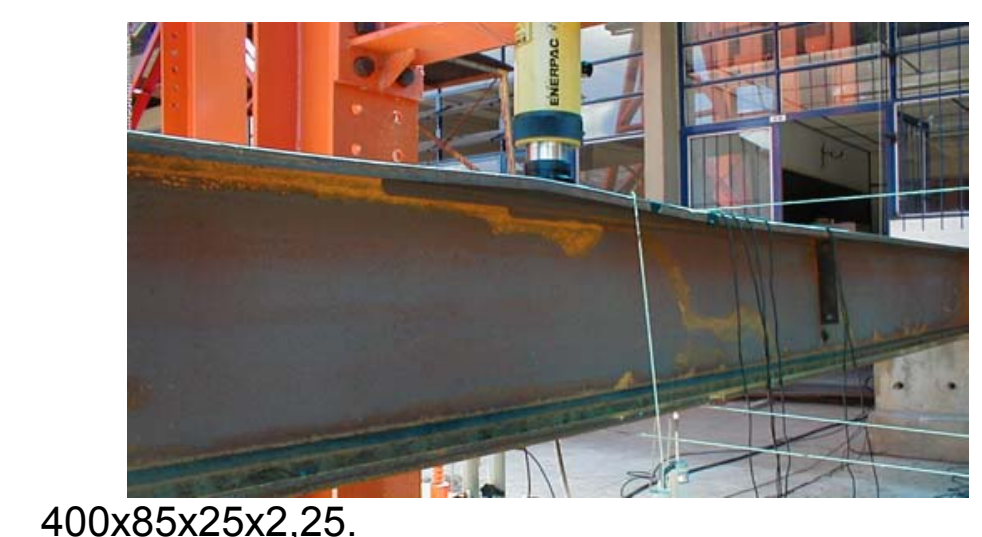




\section{CONCLUSÕES}

Os ensaios de flexão para perfis formados a frio realizados no laboratório de estruturas da FEB/Unesp demonstraram que os resultados preliminares estão condizentes com a curva teórica da NBR14762. O modo de instabilidade distorcional foi preponderante em todas as séries de perfis desta $1^{\text {a }}$ etapa de ensaios. De modo geral, os resultados tiveram boa correlação com a norma brasileira permanecendo sempre a favor da segurança. Agregando-se os resultados dos ensaios realizados no campo experimental de Bauru aos realizados por Javaroni (1999), verifica-se que a nova norma brasileira para o dimensionamento de perfis formados a frio submetidos à flexão possui excelente confiabilidade. Entretanto, foi verificado que a curva de resistência à instabilidade distorcional da NBR 14762 possui resultados conservativos em relação aos resultados experimentais. Foram comparadas curvas de resistência de cálculo baseadas no conceito de instabilidade de chapa e foram verificados melhores desempenhos em relação às curvas de cálculo baseadas no conceito de instabilidade de barra.

O modelo de Hancock mostrou-se eficiente para a determinação da tensão de instabilidade distorcional. Deste modo, verificou-se que o fenômeno da instabilidade distorcional, em comparação com os modos de instabilidade local ou global, foi crítico para as configurações geométricas das seções utilizadas nos ensaios. Assim, foi observado que dependendo das características geométricas, o modo distorcional pode ser crítico na instabilidade de vigas compostas por perfis formados a frio. Constatou-se que os comprimentos de meia-onda senoidal apresentam valores coerentes e próximos aos obtidos pela metodologia proposta pelo prof. Hancock. 
A análise pelo método de resistência direta determinou também 0 modo distorcional como sendo o modo crítico de instabilidade. Porém, as tensões de instabilidade distorcional foram superiores às apresentadas pela NBR14762. Esta diferença indica o conservadorismo da equação analítica de Hancock em relação aos métodos diretos. Este fato pode ser explicado devido à calibração teórica da equação de Hancock a qual foi realizada com análise de instabilidade via faixas finitas.

O método de resistência direta indicou ainda séries de perfis que poderiam apresentar interação do modo distorcional com o modo local de placa. Entretanto, este fato apenas foi verificado na série de perfil com $400 \mathrm{~mm}$ de altura de alma. A presença de pontos de travamento nos conjuntos ensaiados inibiram a ocorrência do modo de instabilidade local de placa e, muitas vezes, alteram o comportamento da distribuição das tensões de compressão no perfil. A instabilidade distorcional ocorrida na presença dos pontos travados também pode ser justificada por este aspecto. $\mathrm{Na}$ rotação impedida do perfil, tensões adicionais também são introduzidas pelas forças impostas por esses travamentos. Assim, a flambagem por distorção da seção transversal ocorrida nestes pontos foi devido ao aumento da tensão de compressão no enrijecedor. Fato constatado por Ellifrit (1994) e Javaroni (1999).

Pelo trabalho experimental realizado nestas séries preliminares ficou apontado que a curva de resistência à instabilidade distorcional da NBR 14762/2001 na flexão (baseada na filosofia de instabilidade de barra) pode ser substituída pela curvas 5 ou 6 propostas por Hancock (baseada na filosofia de instabilidade de chapa). Contudo, este salto de qualidade deverá ser realizado com maiores evidências experimentais para a comprovação do desempenho dimensional.

\subsection{Sugestões para Trabalhos Futuros}

Os perfis ensaiados neste programa experimental, em relação ao modo distorcional, permaneceram numa faixa concentrada de esbeltez distorcional 
reduzido ( $\left.\lambda_{\text {dist }}\right)$ entre 0,85 a 1,10 e com comprimentos de meia-onda entre 700 a $800 \mathrm{~mm}$, conforme as figuras 60 e 65.

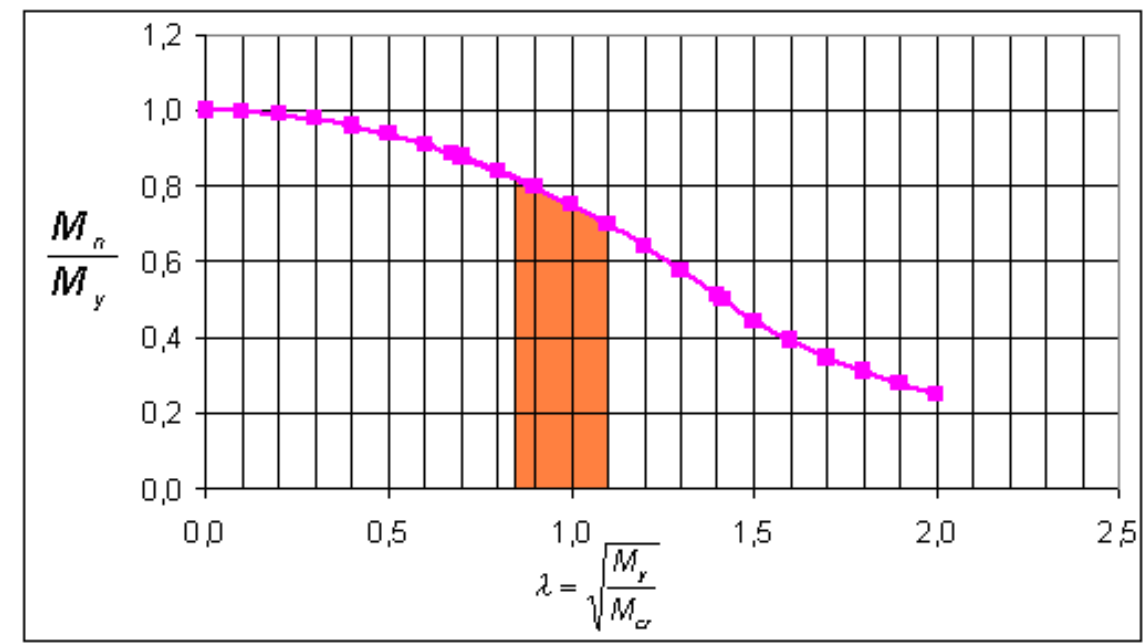

Figura 65 Faixa de esbeltez dos perfis do programa experimental.

Observando a faixa de esbeltez na curva de instabilidade distorcional da NBR14762 na figura 65, pode-se verificar que os valores dispõem-se numa faixa estreita da curva. Por isso, a ampliação desta faixa através de perfis com características geométricas que possam gerar tal ampliação se faz necessário em futuros ensaios experimentais.

Os trabalhos experimentais futuros também poderão evidenciar a influencia dos vínculos de aplicação de carregamento na resistência do perfil. Deste modo verificando profundamente a influência dos vínculos de apoio no efeito do empenamento das seções transversais.

Neste desenvolvimento experimental, foi empregado atuador hidráulico de acionamento manual para aplicação do carregamento. Este tipo de equipamento aplica a carga ponto a ponto e, com isso, não se pode afirmar com certa precisão o ponto correto de origem dos fenômenos de instabilidade. Faz-se necessário a utilização de atuador servo-hidráulico. A finalidade de se utilizar o atuador servo-hidráulico deve-se a maior capacidade na identificação dos fenômenos de instabilidade através do controle de deslocamento dos cilindros atuantes 


\section{BIBLIOGRAFIA}

ABU-SENA, A. B. B.; CHAPMAN, J. C.; DAVIDSON, P. C. (2001). Interaction between critical torsional flexural and lip buckling in channel sections. Journal of Construction Steel Research, v.57, p.925-944.

AMERICAN IRON AND STEEL INSTITUTE. (1996) Cold formed steel design manual. AISI, Washington.

AMERICAN IRON AND STEEL INSTITUTE. (2002) Draft: Design manual for direct strength method of cold formed steel design. AISI, Washington.

ASSOCIAÇÃO BRASILEIRA DE NORMAS TÉCNICAS (2001). Dimensionamento de estruturas de aço constituídas por perfis formados a frio. NBR 14.762. ABNT, Rio de Janeiro. 54p.

BAMBACH, M.R.; MERRICK, J.T.; HANCOCK G.J. (1998) Channel and Zsections with return lips. Fourteenth International Specialty Conference on Cold-Formed Steel Structures, p.21-38, St. Louis, Missouri, USA. Proceedings.

BATISTA, E. M. Et al. (2000). Estudos dos modos de instabilidade local de placa e distorcional em perfis de chapa dobrada de aço. In: JORNADAS SUDAMERICANAS DE INGENIERIA ESTRUCTURAL, Punta Del Este, Uruquay, nov 2000;

BATISTA, E. M. Et al. (2002). Análise da estabilidade de perfis de paredes finas: faixas finitas e MEF. II Congresso Internacional da Construção Metálica - II CICOM, novembro, 2002;

BLEICH, F. (1952). Buckling strength of metal structures. New York: McGraw-Hill. 508p.

CHODRAUI, G. M. B. (2003). Flambagem por distorção da seção transversal em perfis de aço formados a frio submetidos à compressão centrada e à flexão São Carlos, São Paulo. Dissertação de mestrado, Universidade de São Paulo, USP, Escola de Engenharia de São Carlos, EESC. 
DAVIES, J.M. (2000). Recent research advances in cold formed steel structures. Journal of Constructional Steel Research, v.55, p.267288.DESMOND, T.P.; PEKÖZ, T.; WINTER, G. (1981a). Edge stiffeners for thin-walled members. Journal of the Structural Division, ASCE, v.107, n.2, p.219-263, June.

DESMOND, T.P.; PEKÖZ, T.; WINTER, G. (1981b). Intermediate stiffeners for thin-walled members. Journal of the Structural Division, ASCE, v.107, n.ST4, p.627-649, April.

ELLIFRITT, D.S.; GLOVER, R.L.; HREN, J.D. (1998). A simplified model for distortional buckling of channels Zees in flexure. Fourteenth International Specialty Conference on Cold-Formed Steel Structures, p.39-52, St. Louis, Missouri, USA. Proceedings.

EUROCODE 3 (1993) Design of Steel Structures, Part 1.3: Cold-Formed Thin Gauge Members and Sheeting.

FRUCHTENGARTEN, J. (1995). Sobre a instabilidade de perfis de seção aberta. São Paulo. Tese de Doutoramento. Escola Politécnica da Universidade de São Paulo.

HAUSSLER, R. W. (1964) Strength of elastically stabilized beams. Journal of the Structural Division, ASCE, v.90, n.ST3, p.219-263, June.

HANCOCK, G. J.; MURRAY, T.M.; ELLIFRITT, D.S (2001). Cold-formed Steel Structures to the AISI Specification. Marcell-Dekker, New York, NY.

HANCOCK, G. J. (1997) Design for distortional buckling of flexural members. Thin-Walled Structures, v.27, n.1, p.3-12.

HANCOCK, G. J. (1985). Distortional buckling of steel storage rack columns. Journal of Structural Engineering, ASCE, v.111, n.12, p.2770-2783, May.

HANCOCK, G. J.; KWON, Y.B.; BERNARD, E.S. (1994) Strength design curves for thin-walled sectinos undergoing distortional buckling. Journal of Constructional Steel Research, v.31, p.169-186.

JAVARONI, C. E. (1993). Perfis de aço formados a frio por dobramento de chapa fina - fundamentos teóricos para o dimensionamento de barras. 
São Carlos, São Paulo. Dissertação de mestrado, Universidade de São Paulo, USP, Escola de Engenharia de São Carlos, EESC.

JAVARONI, C. E. (1999). Perfis de aço formados a frio submetidos à flexão: análise teórico-experimental. São Carlos, São Paulo. Tese de Doutorado, Universidade de São Paulo, USP, Escola de Engenharia de São Carlos, EESC.

JONHSTON, N.; HANCOCK, G. (1994). Calibration of the AISI R-factor design approach for purlins using Australian test data. Engineering Structures, v.16, n.5, p.342-347.

JÖNSSON, J. (1999). Distortional theory of thin-walled beams. Thin-Walled Structures. v.33, p.269-303.

KAVANAGH, K. T.; ELLIFRITT, D. S. (1994). Design strengths of cold formed channels in bending and torsion. Journal of Structural Engineering, ASCE, v.120, n.5, p.1599-1607, May.

KWON, Y.B.; HANCOCK, G. J. (1992). Strength tests of cold-formed sections undergoing local and distortional buckling. Journal of Structural Engineering, ASCE, v.117, n.2, p.1786-1803, Feb.

LaBOUBE, R. A. (1992). Estimating uplift capacity of light steel roof system. Journal of Structural Engineering, ASCE, v.118, n.3, p.848-852, Mar.

LaBOUBE, R. A. (1991). Uplift capacity of Z-purlins. Journal of Structural Engineering, ASCE, v.117, n.4, p.1159-1166, April.

LEACH, P.; ROBINSON, P. (1993). Behavior of purlins subject to wind uplift (an assessment of EC3: Part 1.3). Structural Engineer, v.71, n.14, p.250-252, July.

LAU, S.C.W.; HANCOCK, G.J. (1987). Distortional buckling formulas for channel columns. Journal of Structural Engineering, ASCE, v.113, n.5, p.1063-1078, May.

PEKÖZ, T. (1983). Diaphragm-braced thin-walled channel and Z-section beams. In: NARAYANAN, R. Beams and beam-columns: stability and strength. Barking, UK: Applied Science. p.161-184. 
PEKÖZ, T.; SOROUSHIAN, D. (1982). Behavior of $C$ and $Z$ purlins under uplift. Sixth International Specialty Conference on Cold-Formed Steel Structures, p.409-429, St. Louis, Missouri, USA. Proceedings.

POLYZOIS, D. (1987). Sag roads as lateral supports for girts and purlins. Journal of Structural Engineering, ASCE, v.113, n.7, p.1521-1531, July. POLYZOIS, D.; BIRKEMOE, P. C. (1985). Z-section girts under negative loading. Journal of Structural Engineering, ASCE, v.111, n.3, p.528544, Mar.

RODRIGUES, F. C. (1993) Estudo teórico-experimental de perfis de chapa dobrada submetidos à compressão. Rio de Janeiro. Tese de Doutorado, Universidade Federal do Rio de Janeiro, COPPE.

ROGERS, C. A.; SCHUSTER, R. M. (1997). Flange/web distortional buckling cold-formed steel sections in bending. Thin-Walled Structures, v.27, n.1, p.13-29.

SCHAFER, B. W. (1998). "CUFSM Users Manual" currently available at www.ce.jhu.edu/bschafer.

SCHAFER, B. W.; PEKÖZ, T. (1998). Direct Strength Prediction of Colformed Steel Members using Numerical Elastic Buckling Solutions. 14 ${ }^{\text {th }}$ International Specialty Conference on Cold-formed Steel Structures. St. Louis, Missouri.

SCHAFER, B. W.; PEKÖZ, T. (1999) Laterally braced cold-formed steel flexural members with edge stiffened flanges. Journal of Structural Engineering, ASCE, v.125, n.2, p.118-127, feb.

TRAHAIR, N.S. (1994). Lateral buckling strengths of unsheeted cold-formed beams. Journal of Structural Engineering, ASCE, v.16, n.5, p.324-331, July.

TIMOSHENKO, S. P.; GERE, J. M. (1961) Theory of elastic stability. 2.ed. New York: McGraw-Hill. 541p.

VASQUEZ, E. G. (1998). Estabilidade e resistencia de perfis de chapa dobrada afetados pelo modo distorcional. Rio de janeiro. Tese de mestrado, Universidade Federal do Rio de Janeiro, COPPE. 
VLASSOV, B. Z. (1962) Pièces longues en voiles minces. Paris: Eyrolles. $655 \mathrm{p}$.

YU, W. W. (2000). Cold formed steel design. New York: Wiley-Interscience. 


\section{ANEXO I- GRÁFICOS: FORÇA X DESLOCAMENTOS}

Estas séries de gráficos representam os deslocamentos das mesas para os perfis ensaiados durante a aplicação do carregamento experimental. Os pontos de deslocamentos seguem conforme a figura X. O deslocamento inferior da mesa A corresponde ao transdutor 7. O deslocamento superior da mesa A corresponde ao transdutor 8. O deslocamento inferior da mesa $\mathrm{B}$ corresponde ao transdutor 11. O deslocamento superior da mesa B corresponde ao transdutor 12 .

8

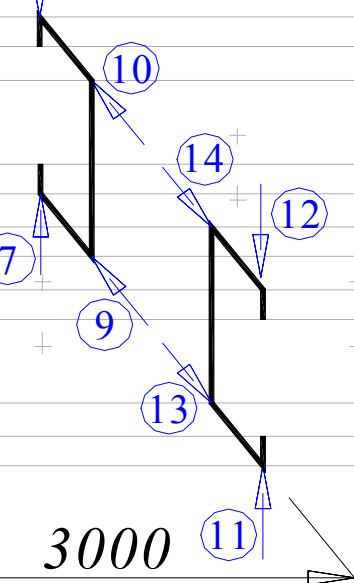

Figura 66 Posição dos transdutores de deslocamentos para medida dos deslocamentos na seção transversal do meio do vão. 


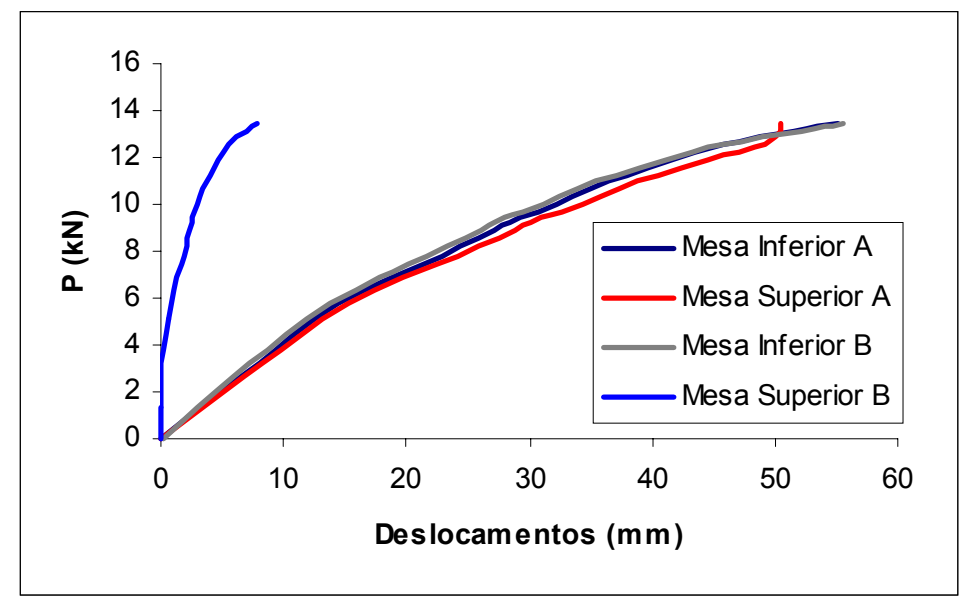

Gráfico Força x Deslocamento do perfil Ue 250x85×25×2,25 - conjunto 1 .

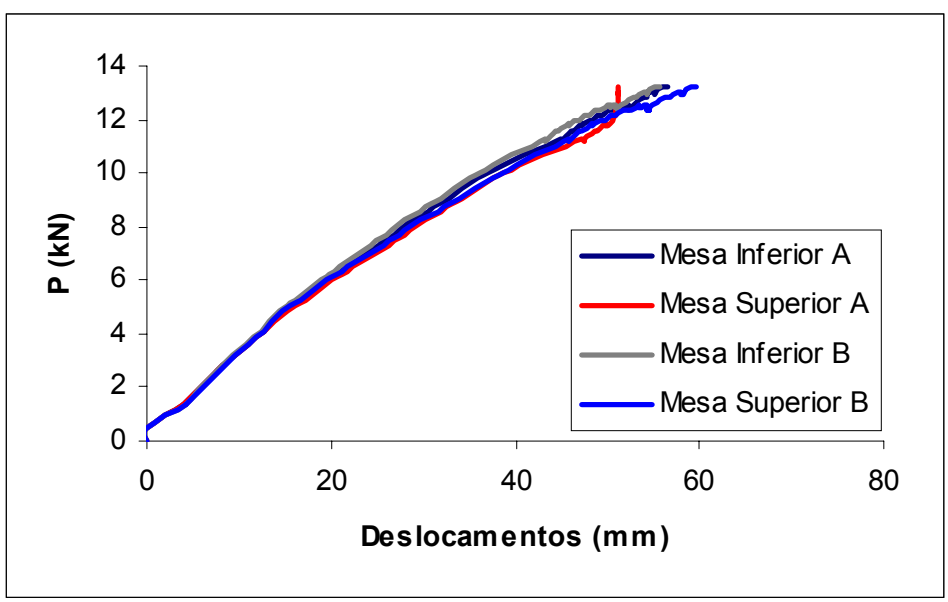

Gráfico Força x Deslocamento do perfil Ue 250x85x25x2,25 - conjunto 2.

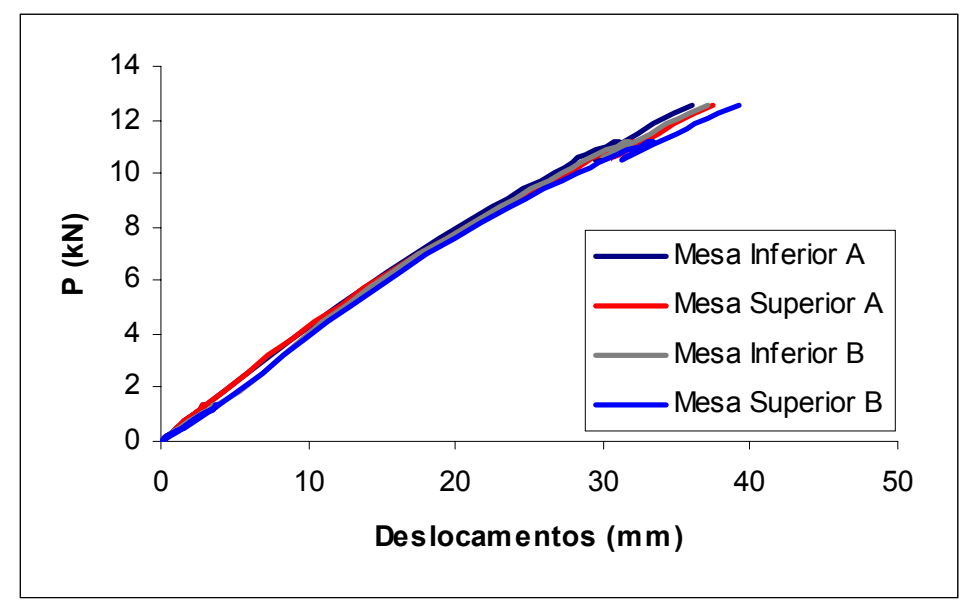

Gráfico Força x Deslocamento do perfil Ue 250x85x25x2,25 - conjunto 3. 


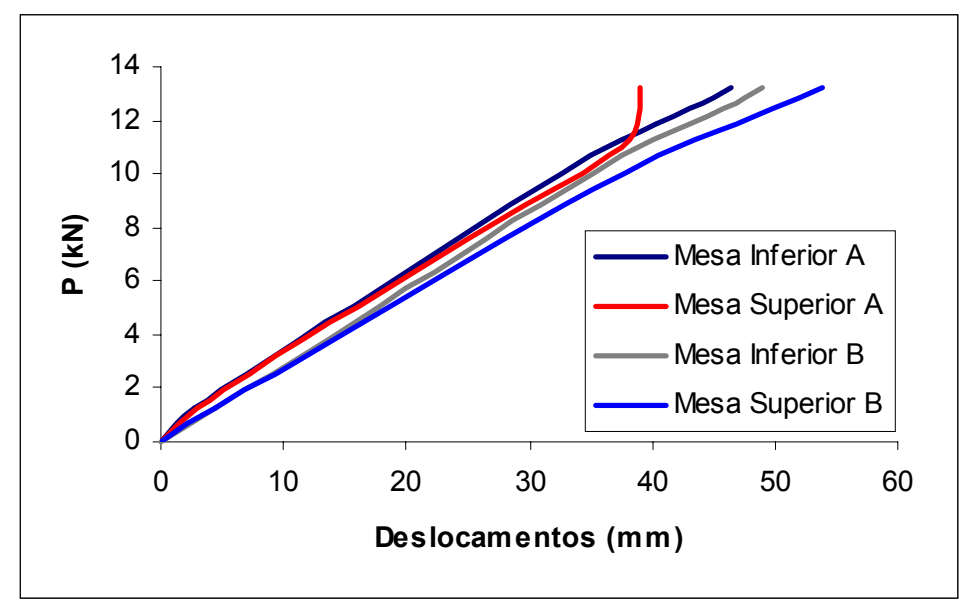

Gráfico Força x Deslocamento do perfil Ue 250x85x25x2,65 - conjunto 5.

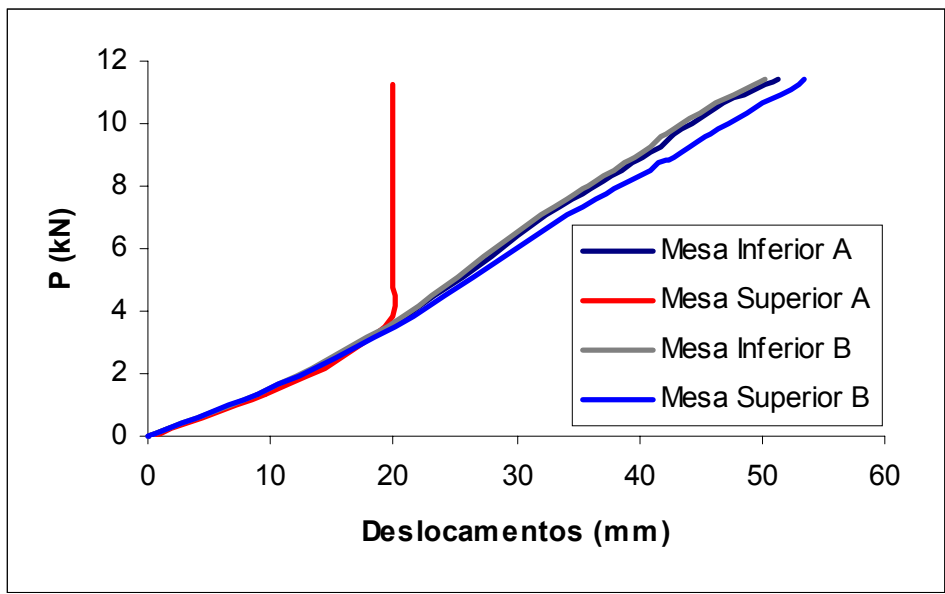

Gráfico Força x Deslocamento do perfil Ue 250x85x25x2,65 - conjunto 6.

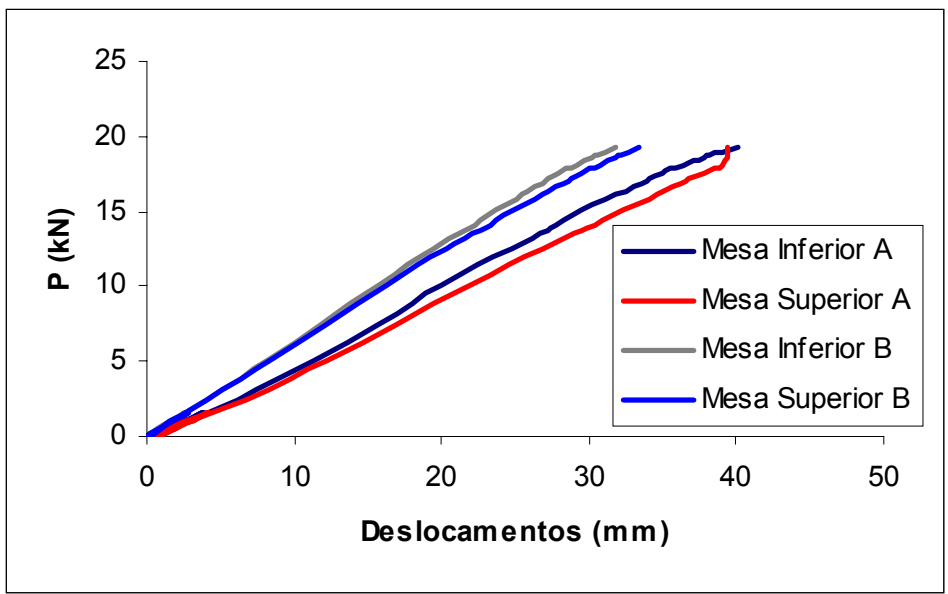

Gráfico Força x Deslocamento do perfil Ue 300x85×25×2,25 - conjunto 7 . 


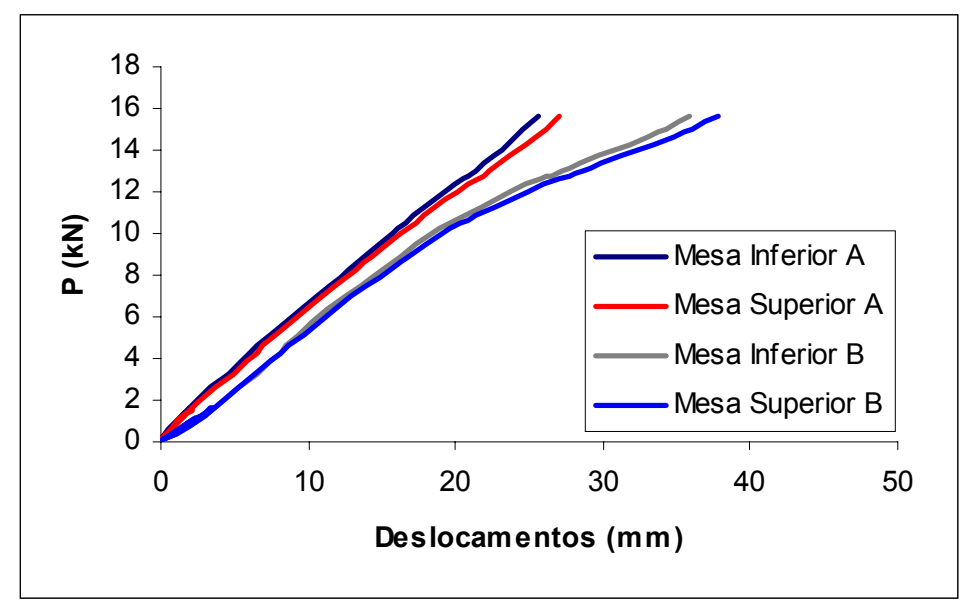

Gráfico Força x Deslocamento do perfil Ue 300x85x25x2,25 - conjunto 8.

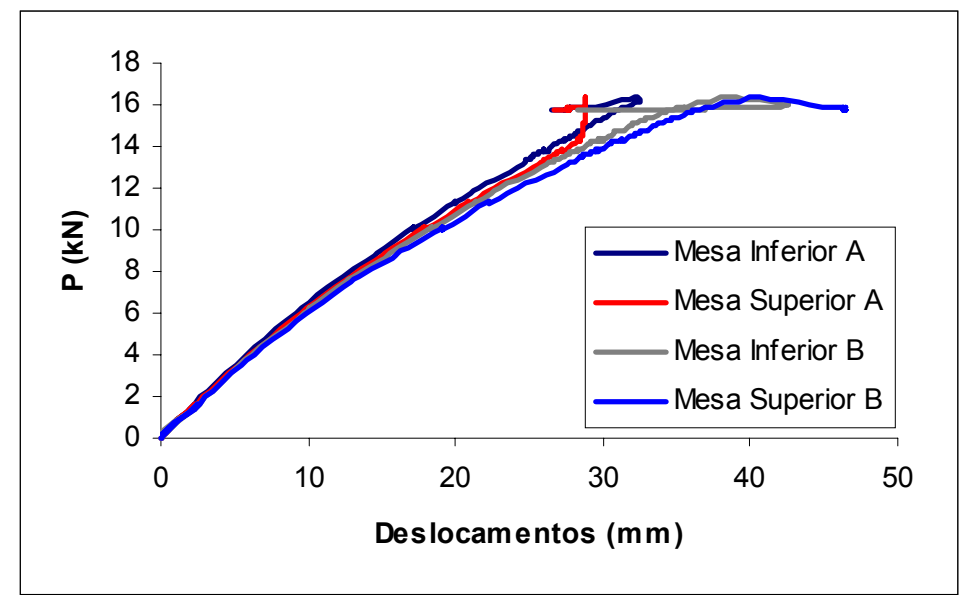

Gráfico Força x Deslocamento do perfil Ue 300x85×25x2,25 - conjunto 9.

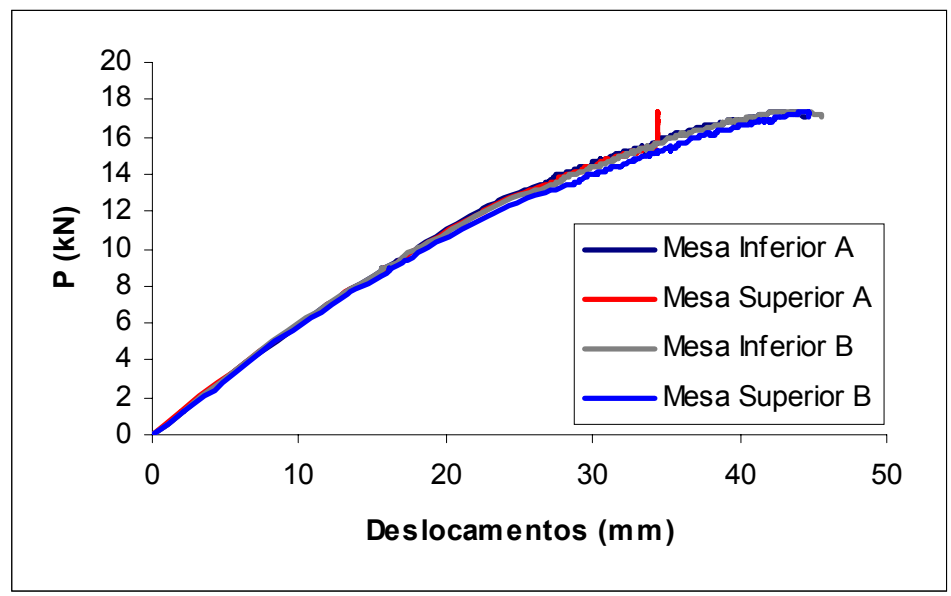

Gráfico Força x Deslocamento do perfil Ue 300x85x25x2,65 - conjunto 11. 


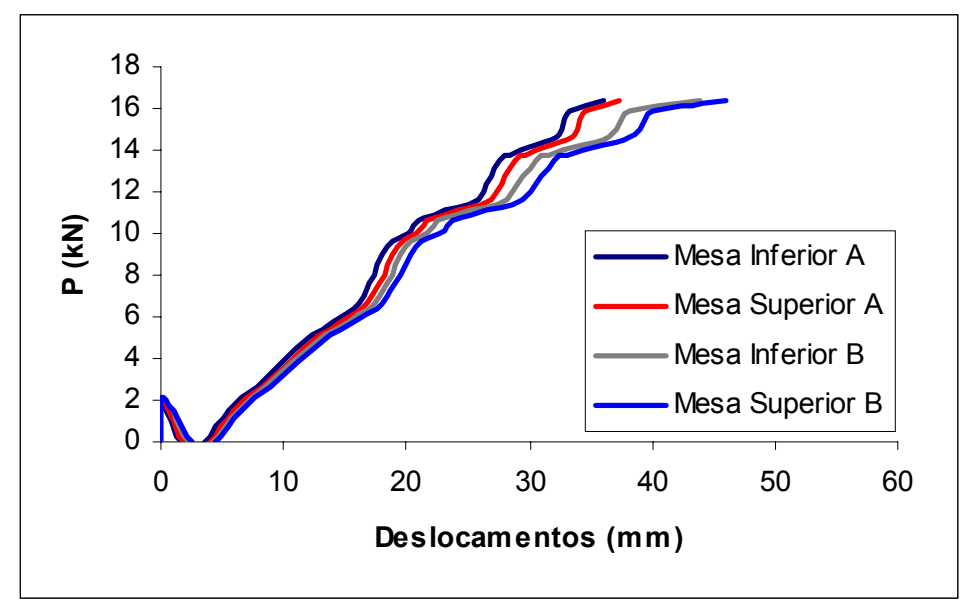

Gráfico Força x Deslocamento do perfil Ue 300x85x25x2,65 - conjunto 12.

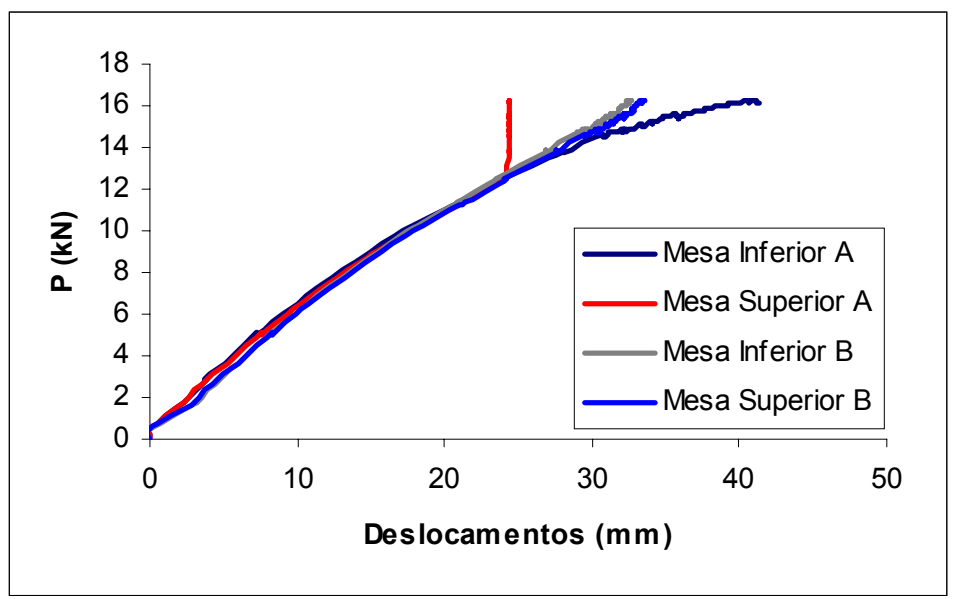

Gráfico Força x Deslocamento do perfil Ue 350x85x25x2,65 - conjunto 13.

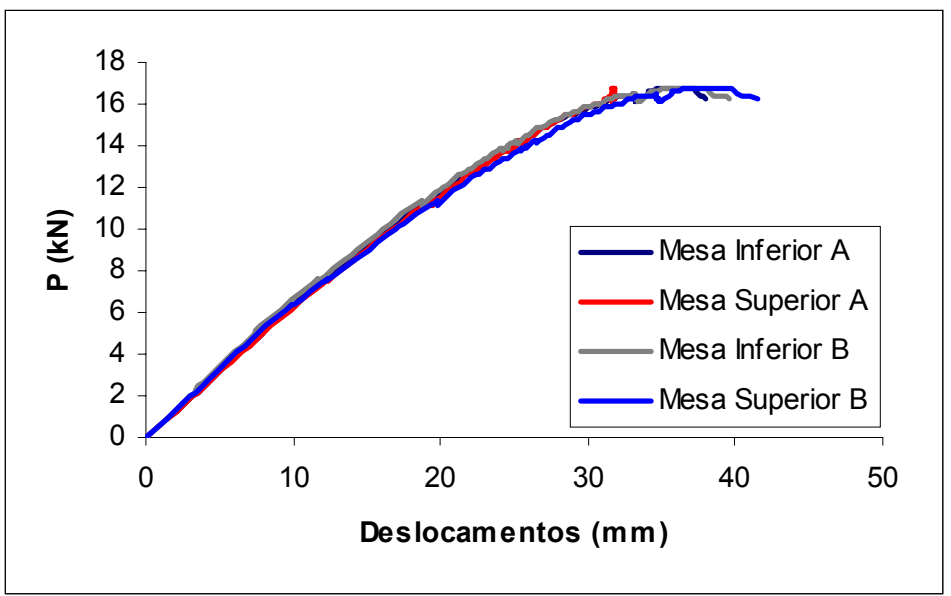

Gráfico Força x Deslocamento do perfil Ue 350x85x25x2,65 - conjunto 15. 


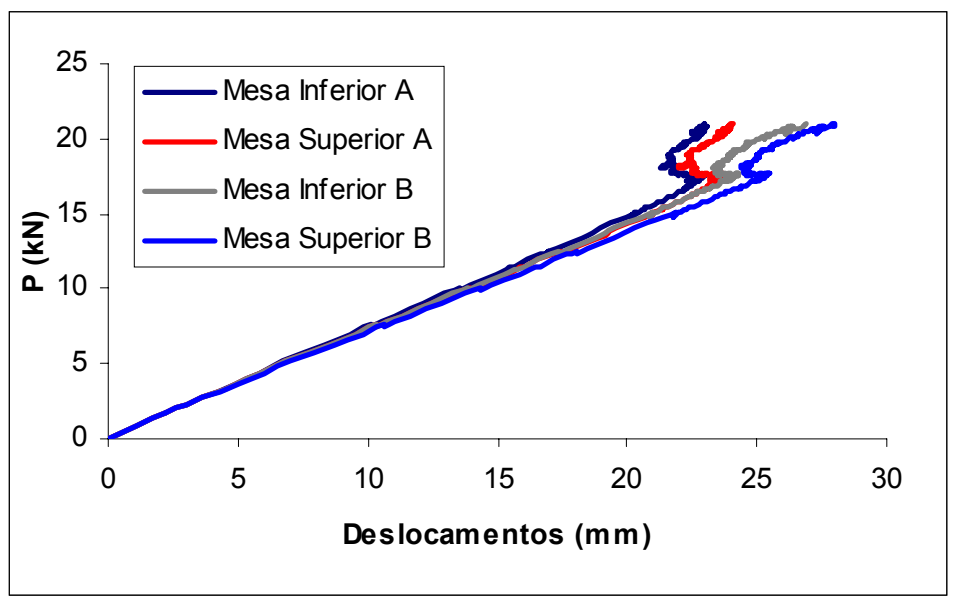

Gráfico Força x Deslocamento do perfil Ue 350x85x25×3,00 - conjunto 16.

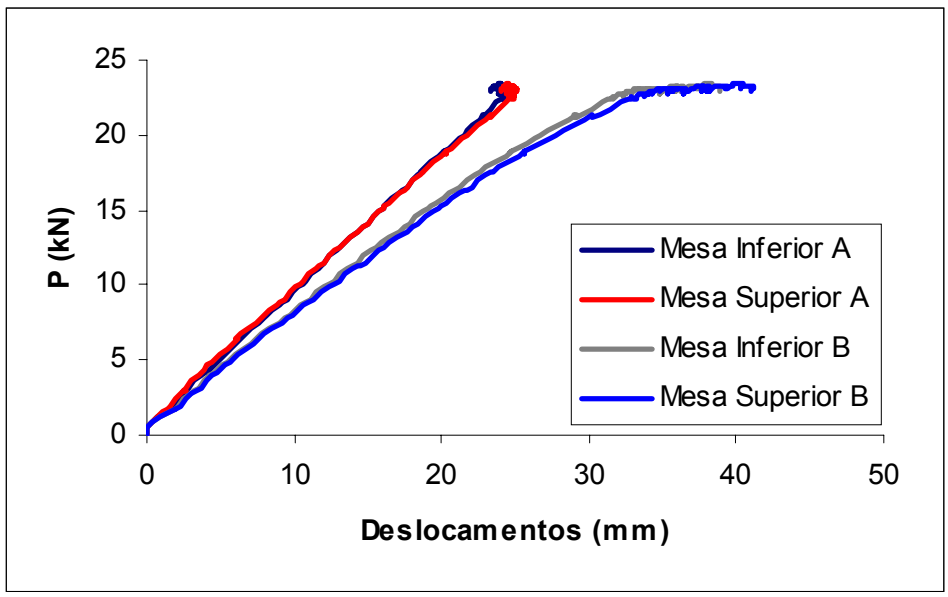

Gráfico Força x Deslocamento do perfil Ue 350x85x25x3,00 - conjunto 17.

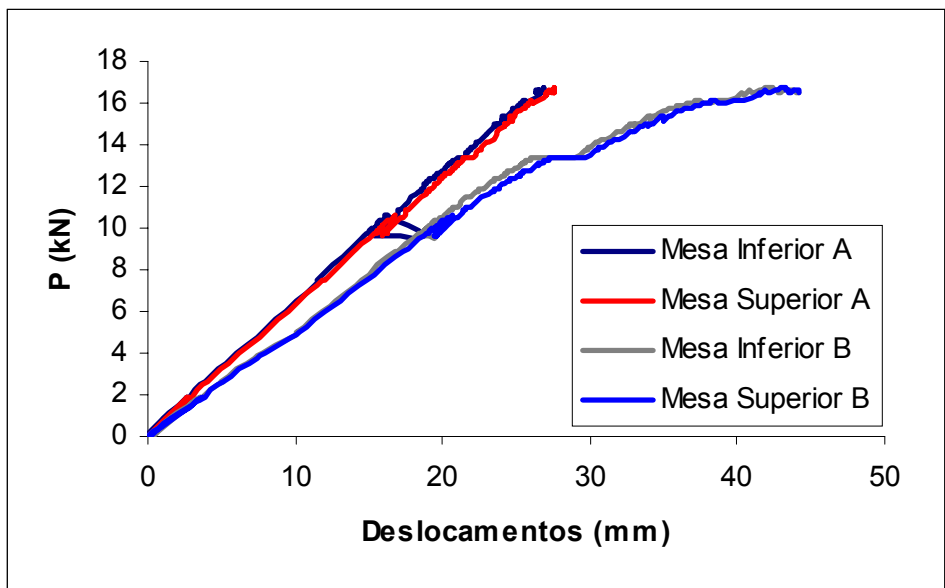

Gráfico Força x Deslocamento do perfil Ue 350x85x25x2,25 - conjunto 19. 


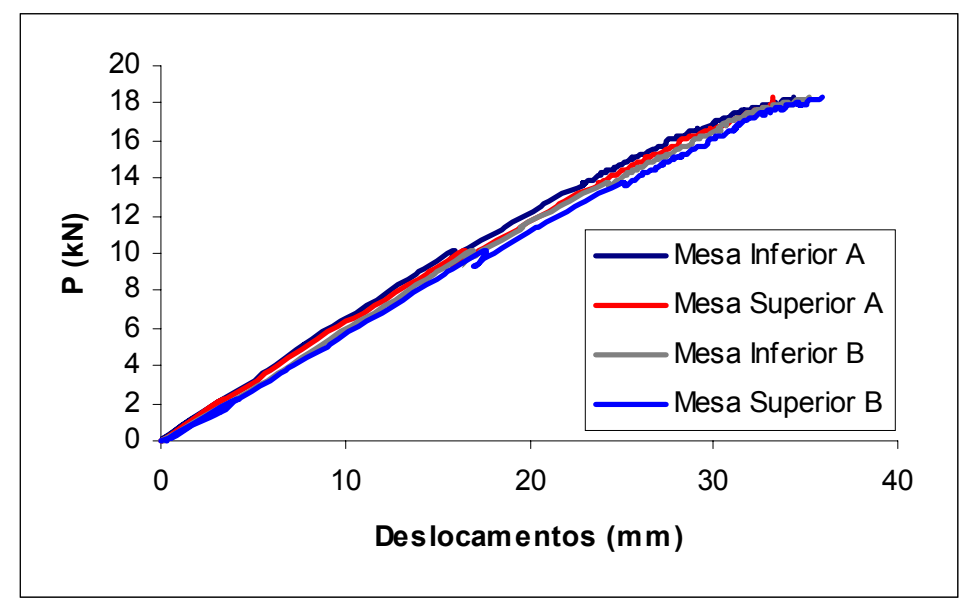

Gráfico Força x Deslocamento do perfil Ue 350x85×25×2,25 - conjunto 20.

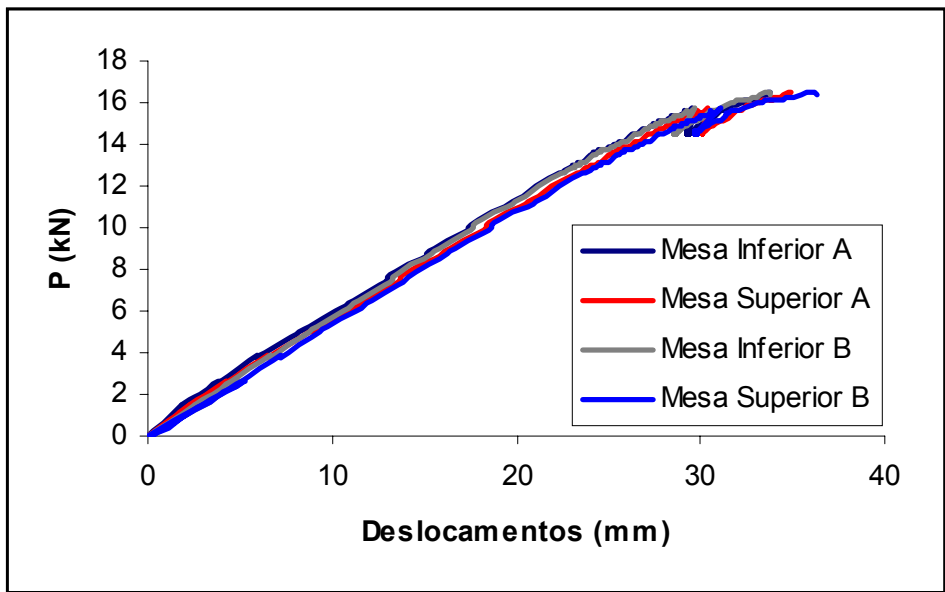

Gráfico Força x Deslocamento do perfil Ue 350x85x25x2,25 - conjunto 21.

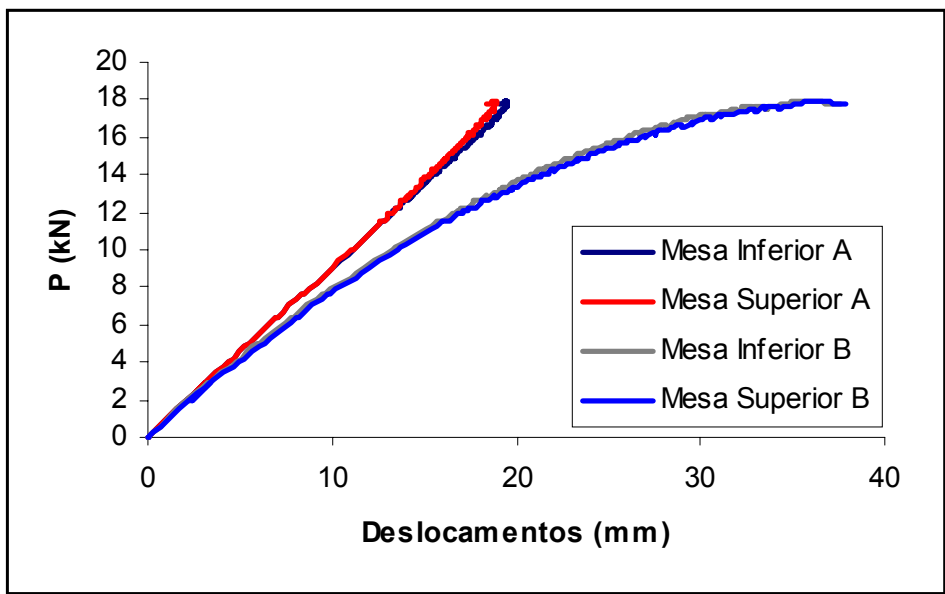

Gráfico Força x Deslocamento do perfil Ue 400x85x25×2,25 - conjunto 22. 


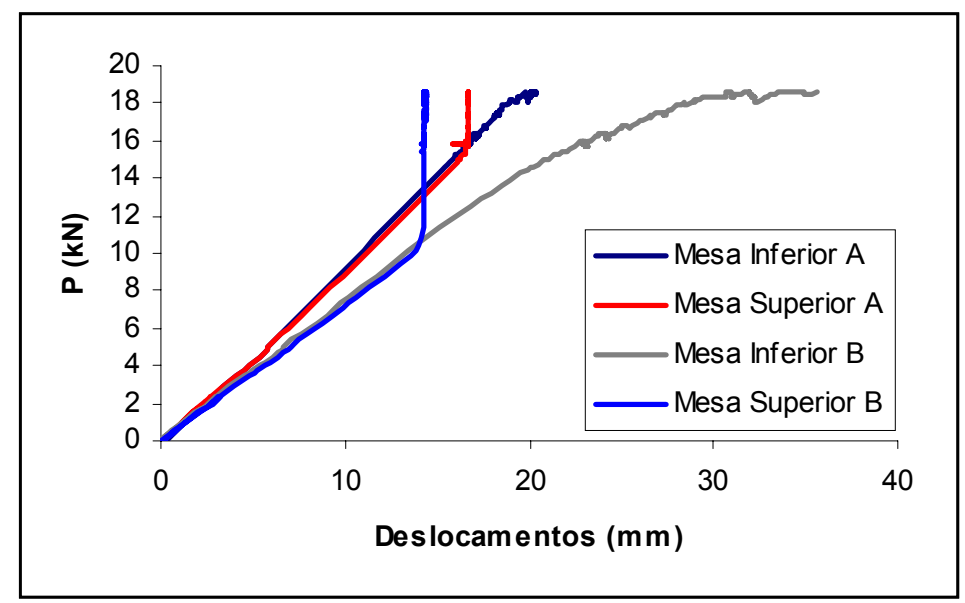

Gráfico Força x Deslocamento do perfil Ue 400x85x25×2,25 - conjunto 23.

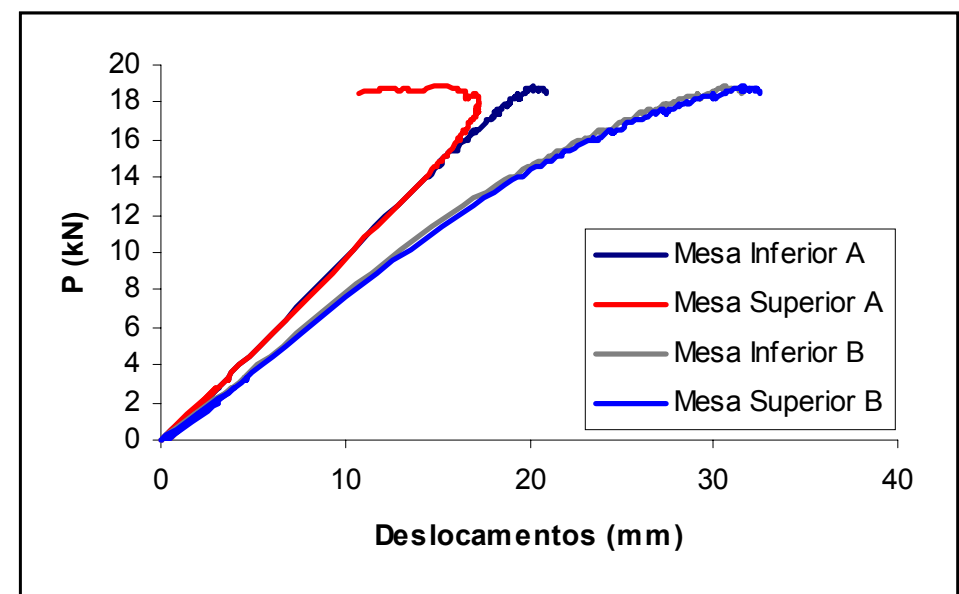

Gráfico Força x Deslocamento do perfil Ue 400x85x25x2,25 - conjunto 24 . 


\section{ANEXO II- GRÁFICOS: GIROS DAS MESAS DOS PERFIS}

Estas séries de gráficos representam os giros das mesas em relação à junção alma-mesa dos perfis ensaiados. 


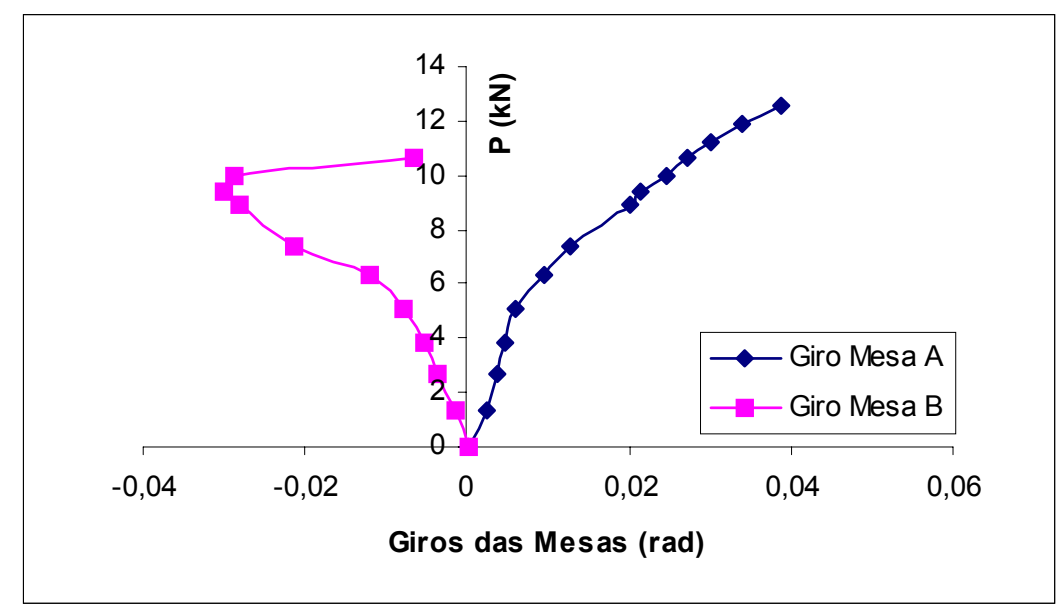

Gráfico Giro das mesas dos perfis Ue 250x85×25×2,25 - conjunto 1.

\section{(Perdido)}

Gráfico Giro dos perfis Ue 250x85x25×2,25 - conjunto 2 .

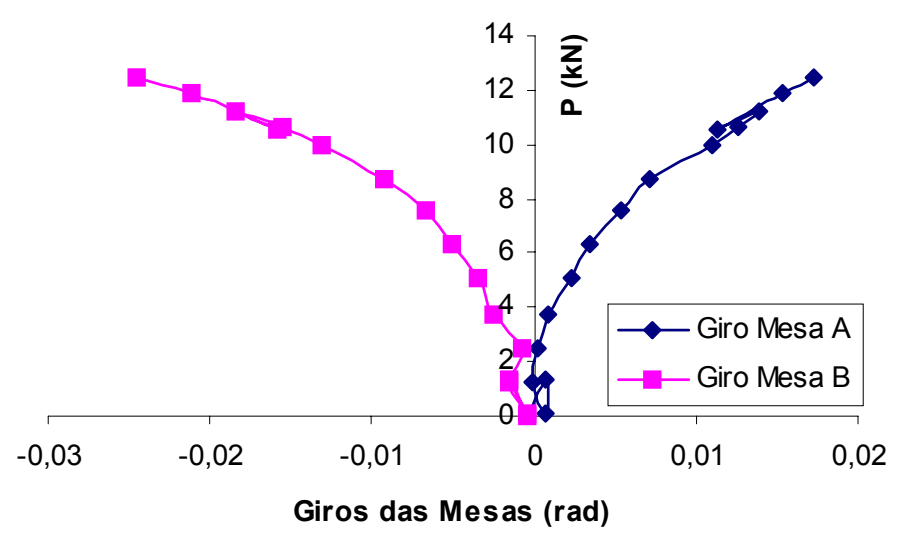

Gráfico Giro das mesas dos perfis Ue 250x85×25×2,25 - conjunto 3. 


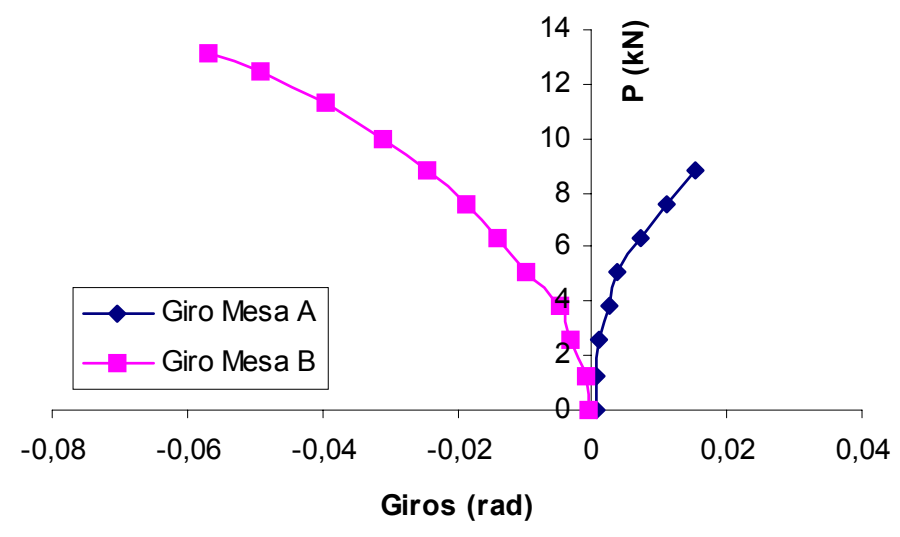

Gráfico Giro dos perfis Ue 250x85x25x2,65 - conjunto 5.

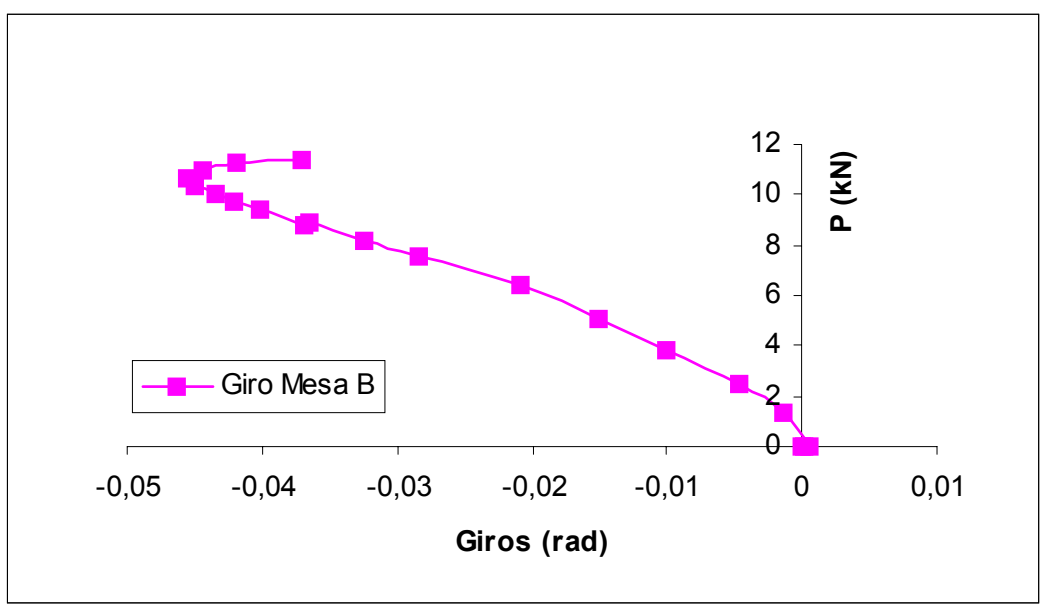

Gráfico Giro dos perfis Ue 250x85x25x2,65 - conjunto 6 .

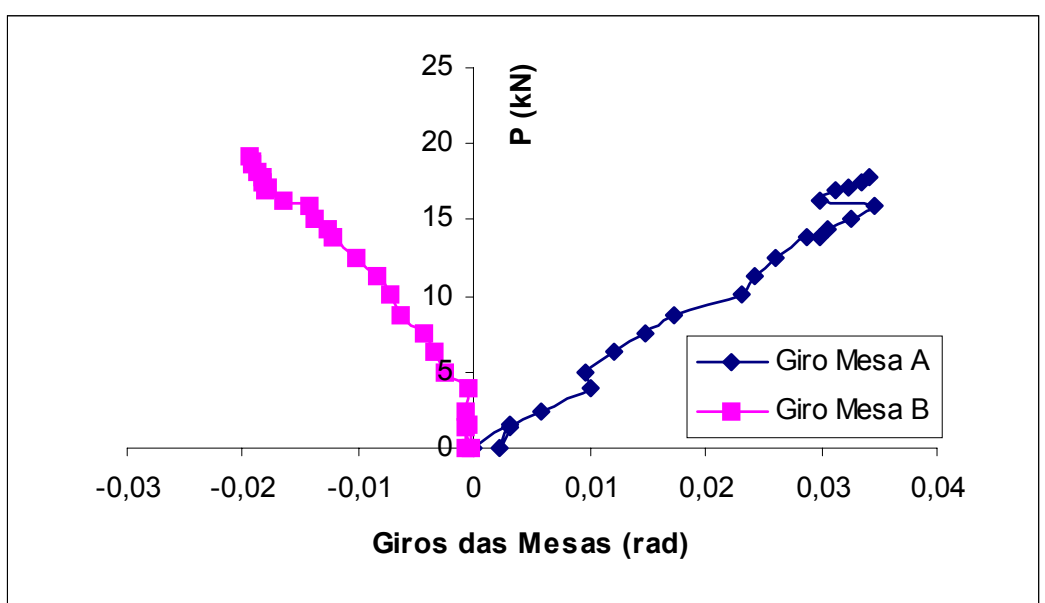

Gráfico Giro dos perfis Ue 300x85x25x2,25 - conjunto 7. 


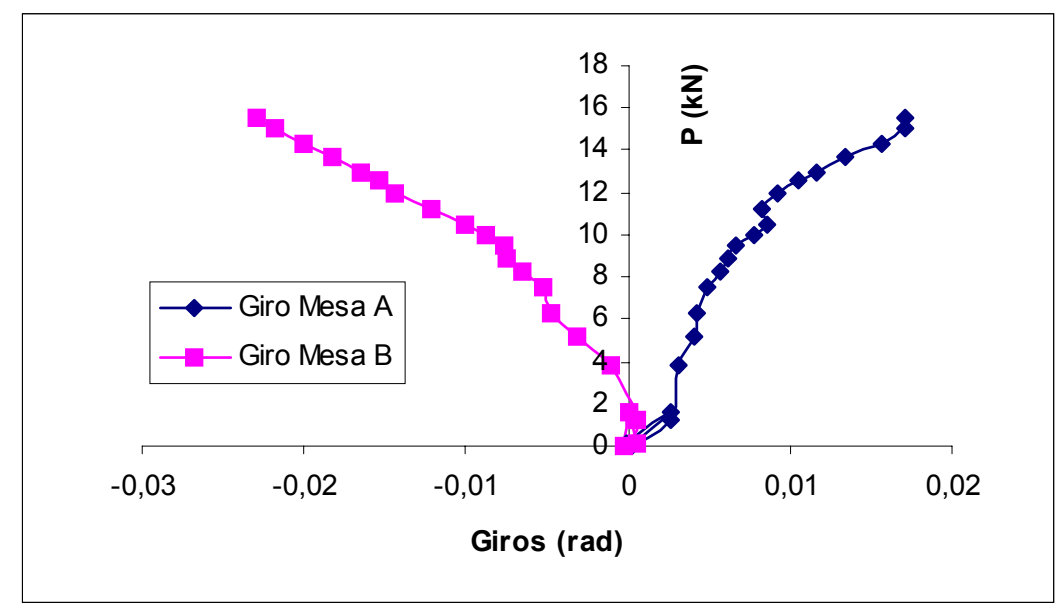

Gráfico Giro dos perfis Ue 300x85x25×2,25 - conjunto 8 .

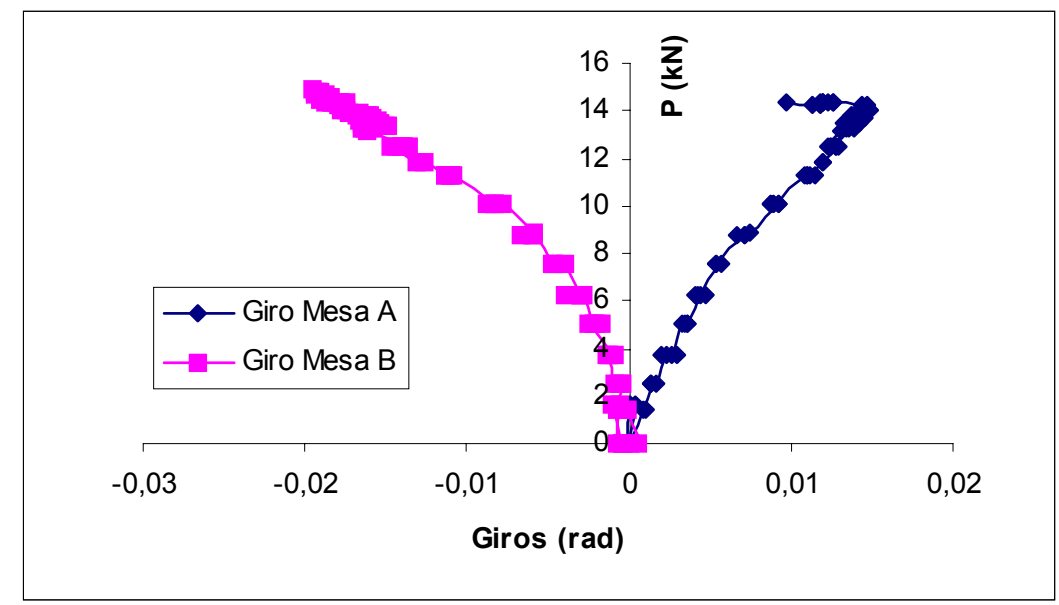

Gráfico Giro dos perfis Ue 300x85x25x2,25 - conjunto 9.

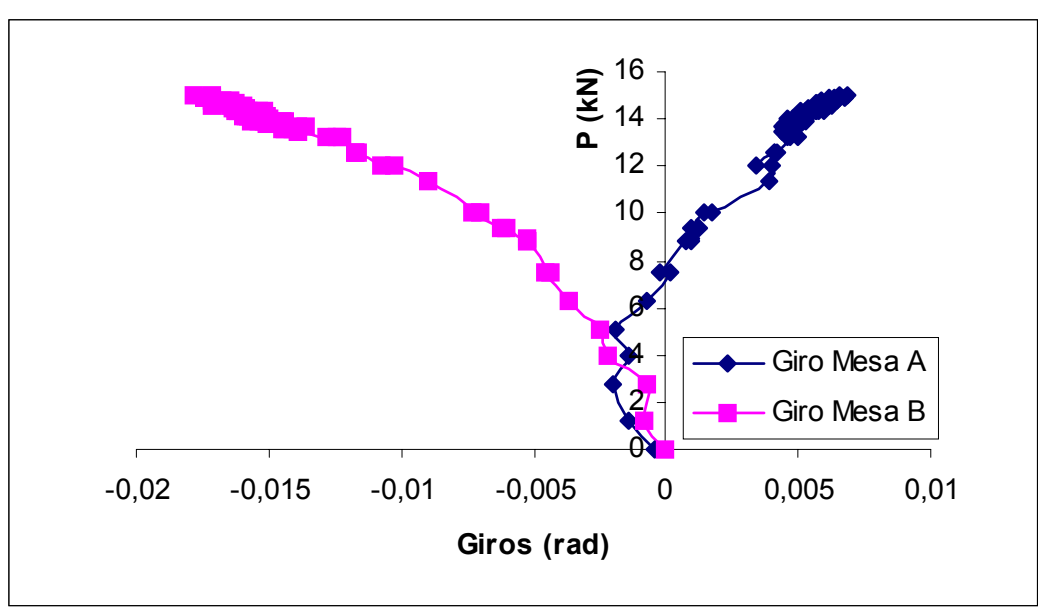

Gráfico Giro dos perfis Ue 300x85×25×2,65 - conjunto 11.

(Perdido) 
Gráfico Giro dos perfis Ue 300x85×25×2,65 - conjunto 12 .

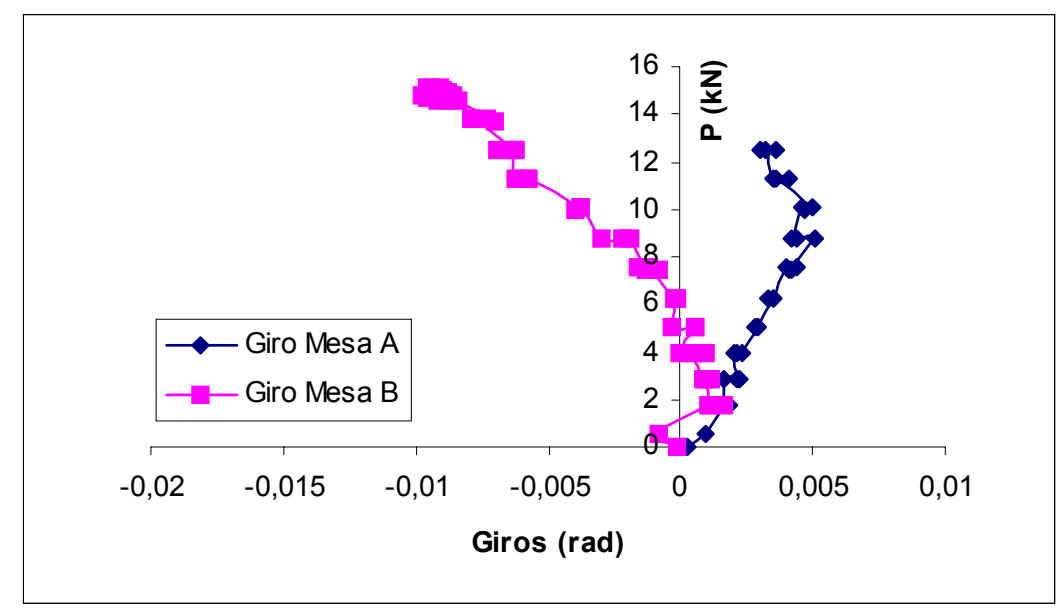

Gráfico Giro dos perfis Ue 350x85×25×2,65 - conjunto 13.

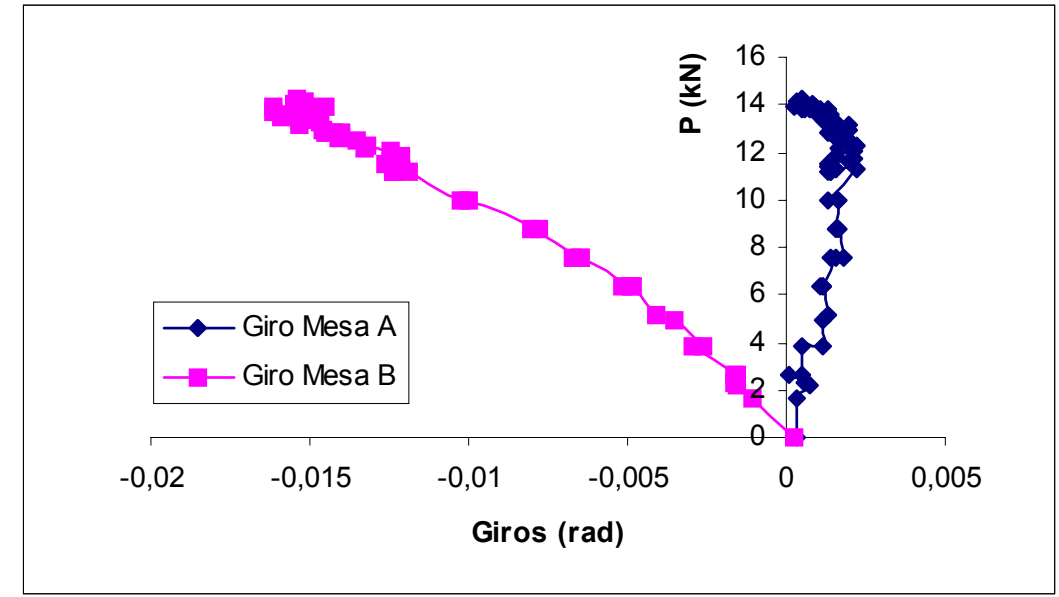

Gráfico Giro dos perfis Ue 350×85×25×2,65 - conjunto 15.

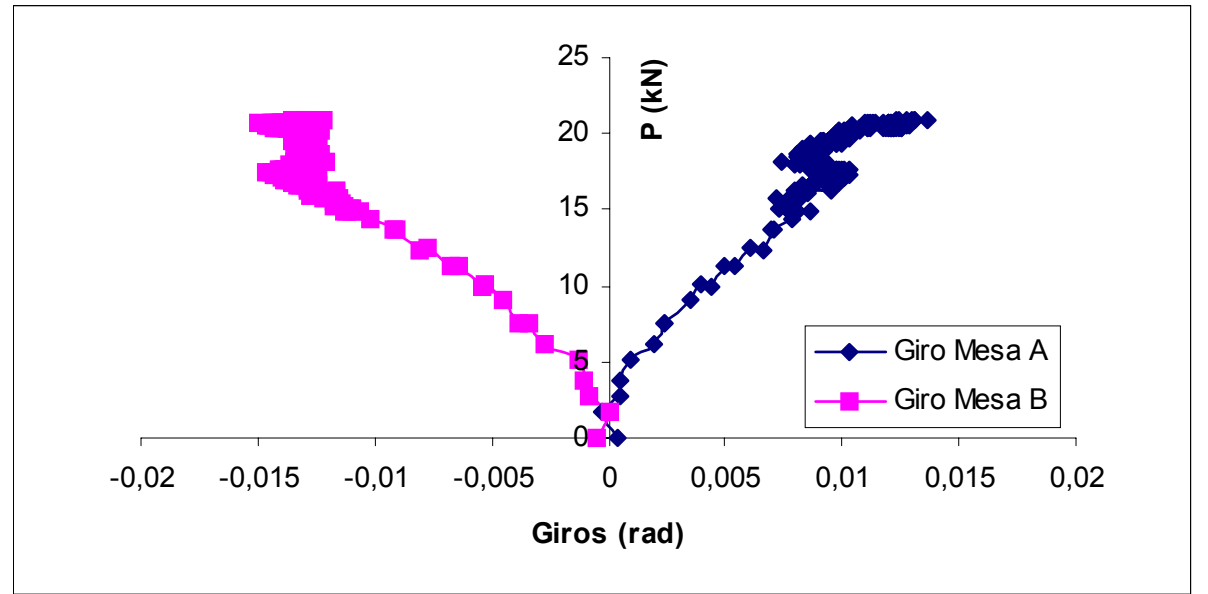

Gráfico Giro dos perfis Ue 350×85×25×3,00 - conjunto 16 . 


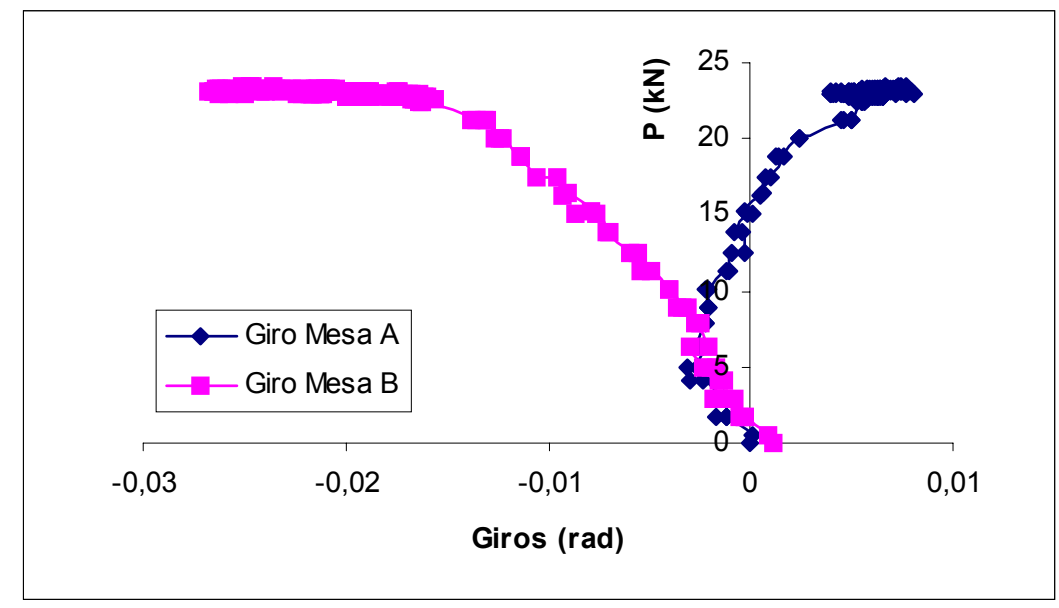

Gráfico Giro dos perfis Ue 350x85×25×3,00 - conjunto 17 .

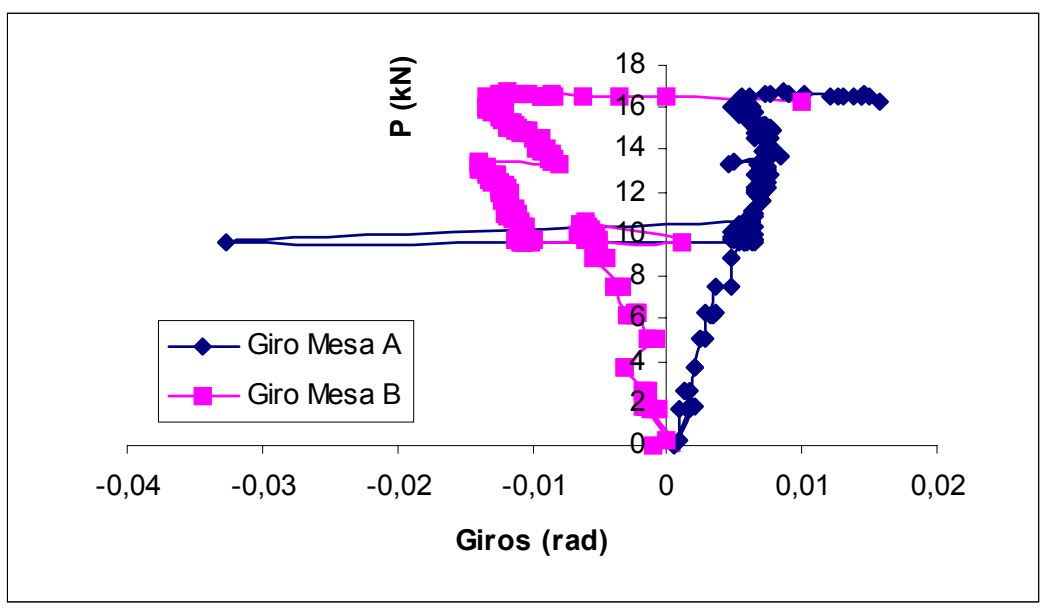

Gráfico Giro dos perfis Ue 350x85×25×2,25 - conjunto 19.

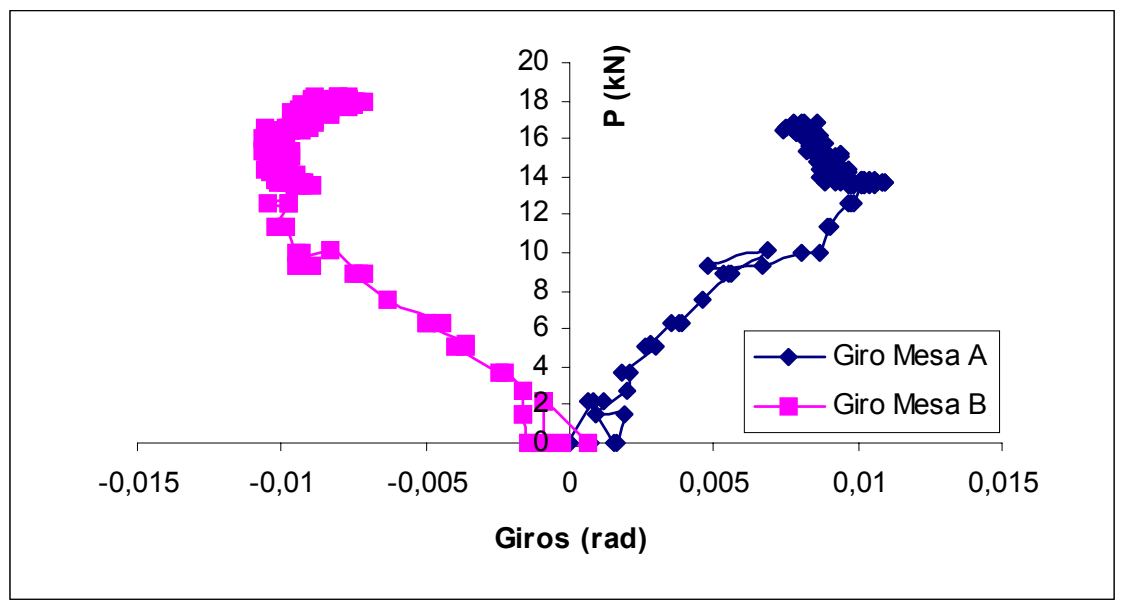

Gráfico Giro dos perfis Ue 350x85×25×2,25 - conjunto 20 . 


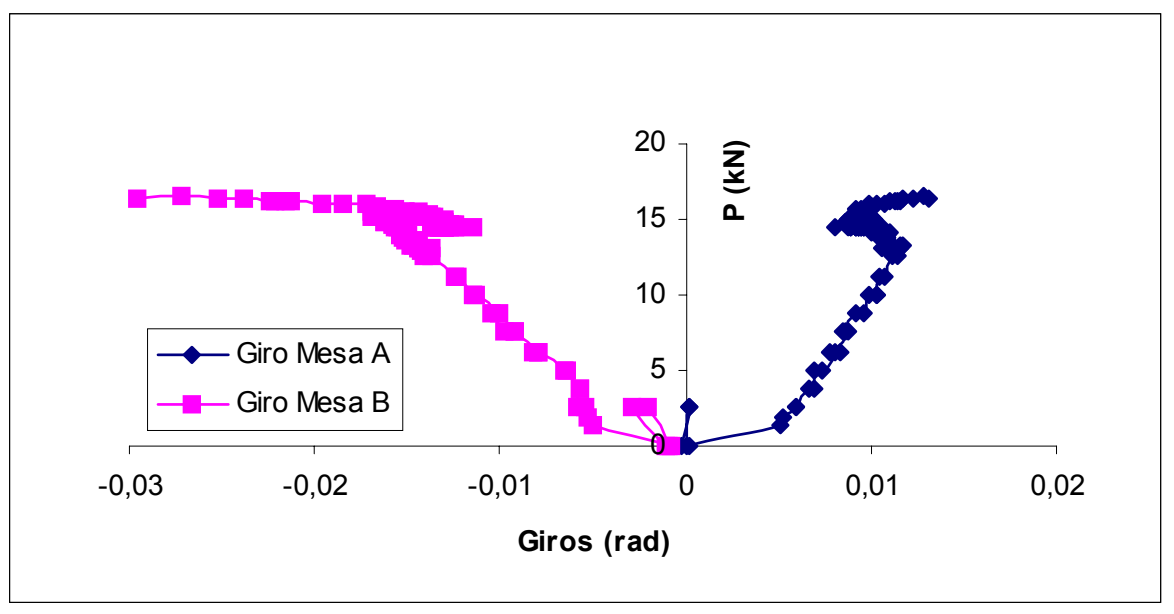

Gráfico Giro dos perfis Ue 350x85x25×2,25 - conjunto 21.

(Perdido)

Gráfico Giro dos perfis Ue 400x85x25x2,25 - conjunto 22.

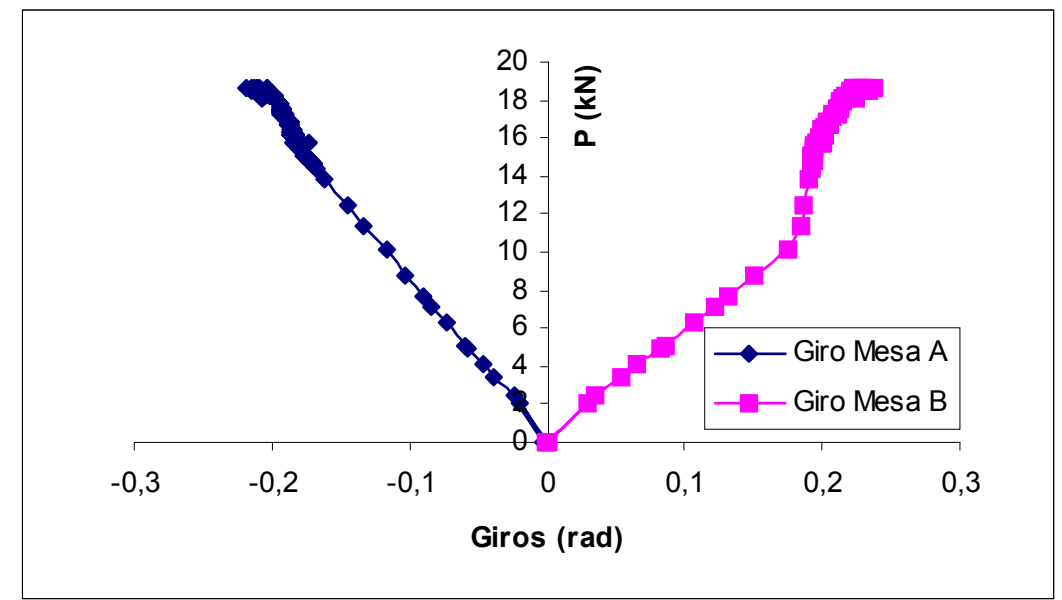

Gráfico Giro dos perfis Ue 400x85×25×2,25 - conjunto 23 .

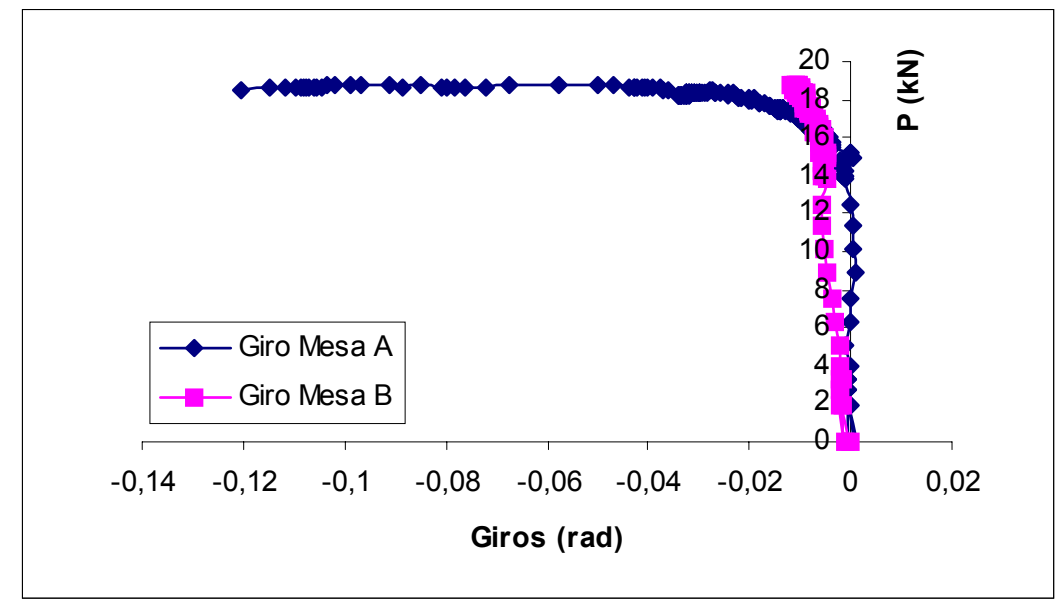

Gráfico Giro dos perfis Ue 400x85×25×2,25 - conjunto 24 . 


\section{ANEXO IIII - GRÁFICOS DE GIRO DOS PERFIS}

Estas séries de gráficos representam os giros das almas dos perfis. 


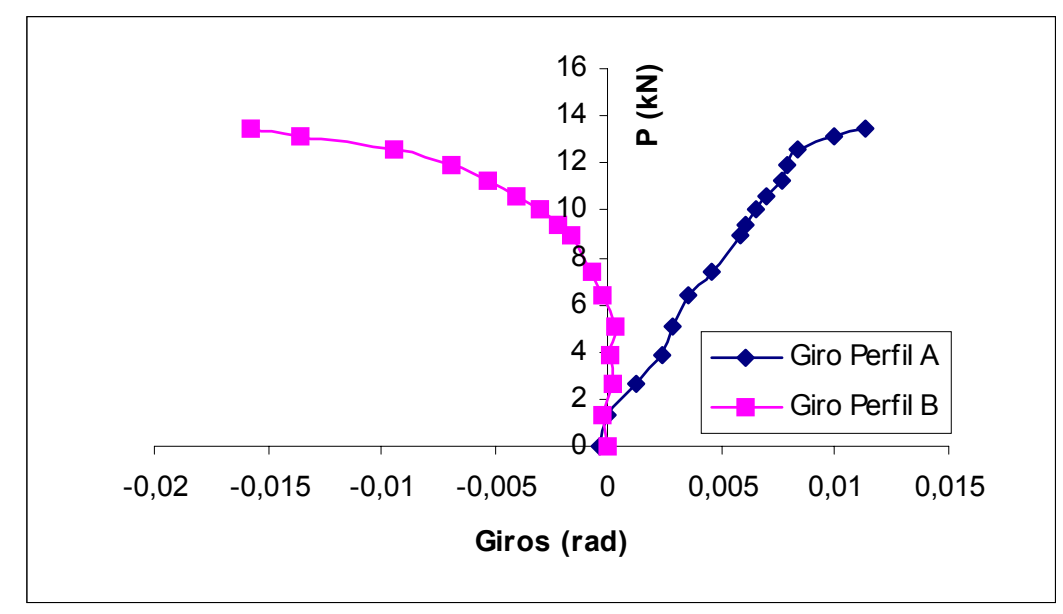

Gráfico Giro dos perfis Ue 250x85x25x2,25 - conjunto 1.

(Perdido)

Gráfico Giro dos perfis Ue 250x85x25x2,25 - conjunto 2.

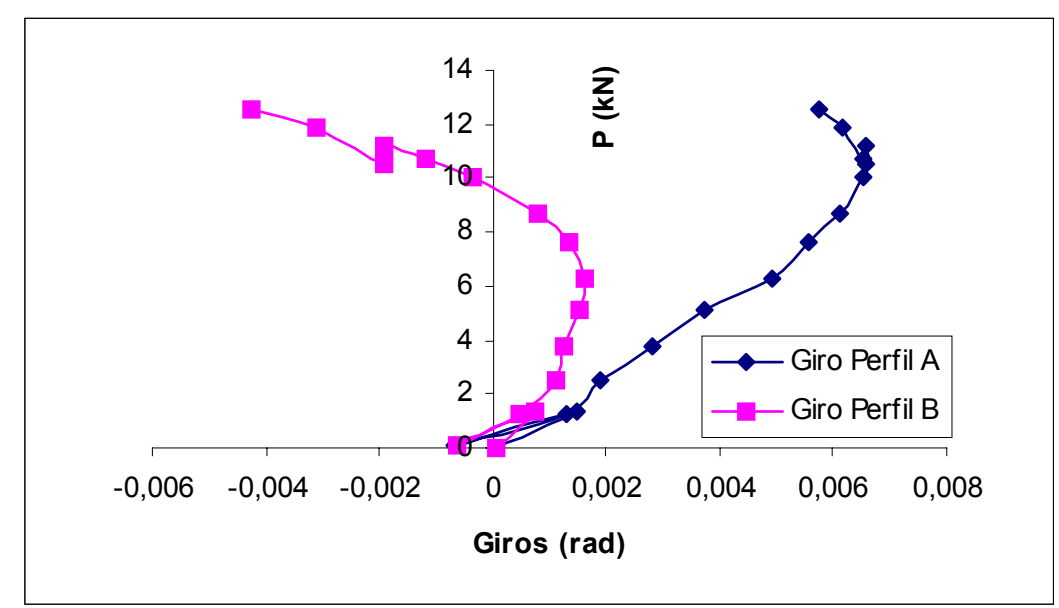

Gráfico Giro dos perfis Ue 250x85x25x2,25 - conjunto 3. 


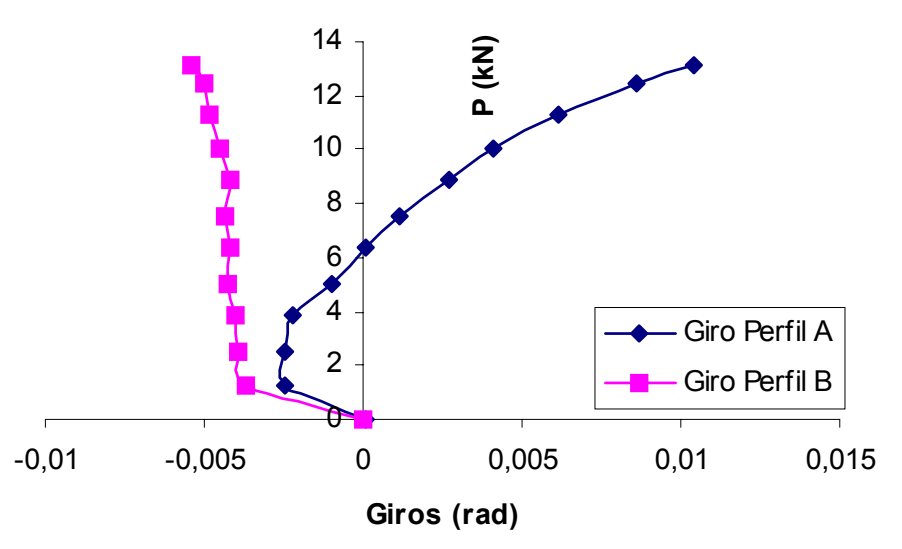

Gráfico Giro dos perfis Ue 250x85x25x2,65 - conjunto 5.

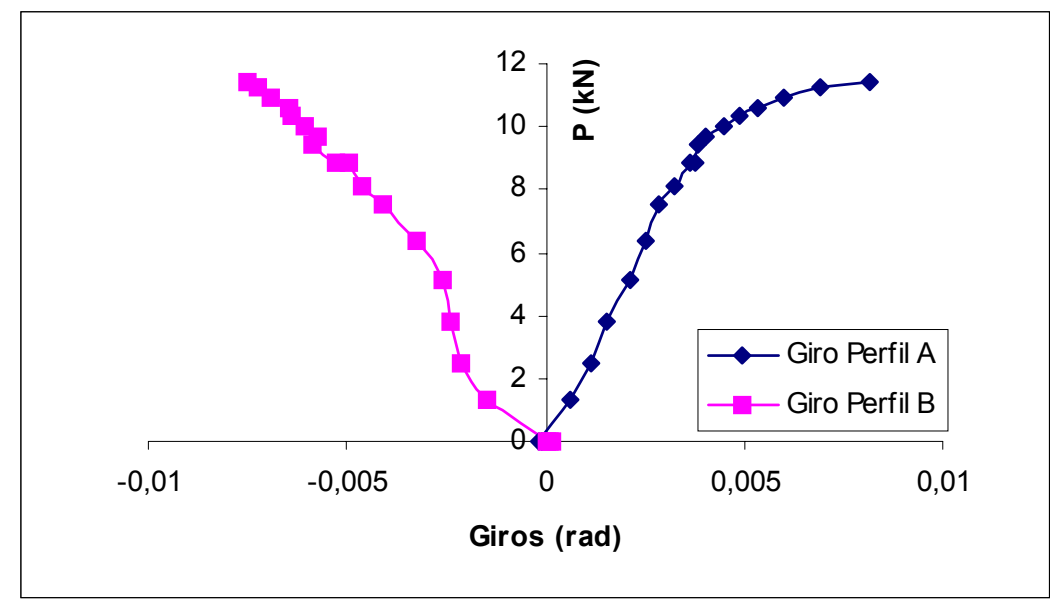

Gráfico Giro dos perfis Ue 250x85x25x2,65 - conjunto 6.

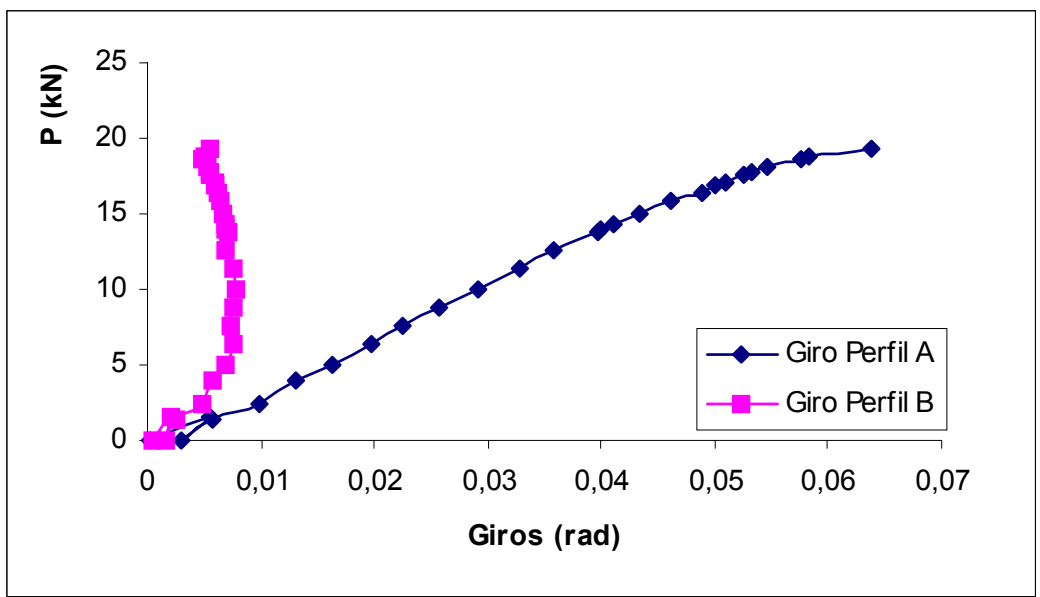

Gráfico Giro dos perfis Ue 300x85x25x2,25 - conjunto 7. 


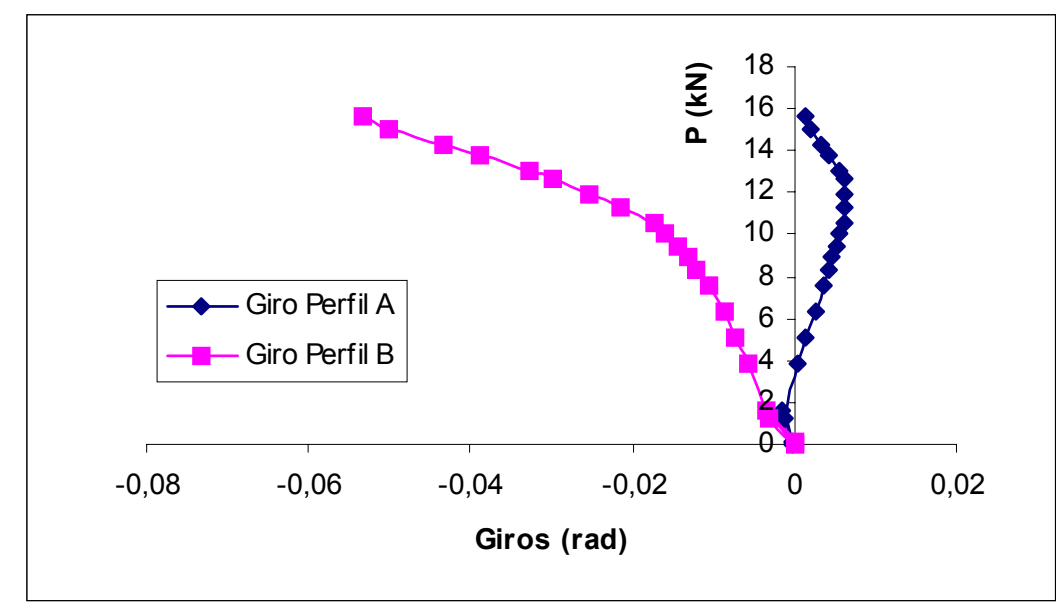

Gráfico Giro dos perfis Ue 300x85x25x2,25 - conjunto 8.

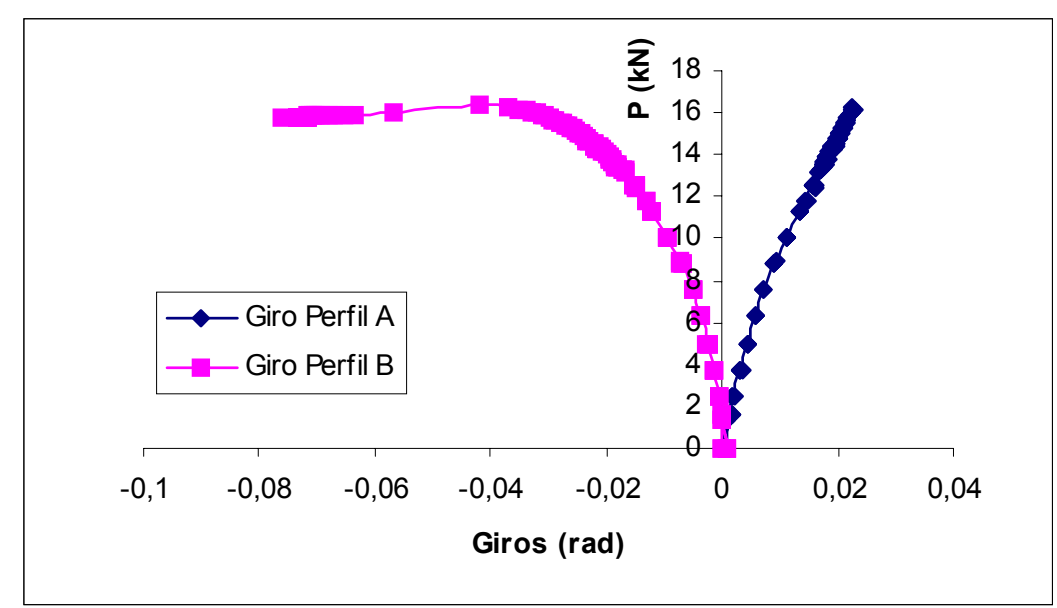

Gráfico Giro dos perfis Ue 300x85x25x2,25 - conjunto 9.

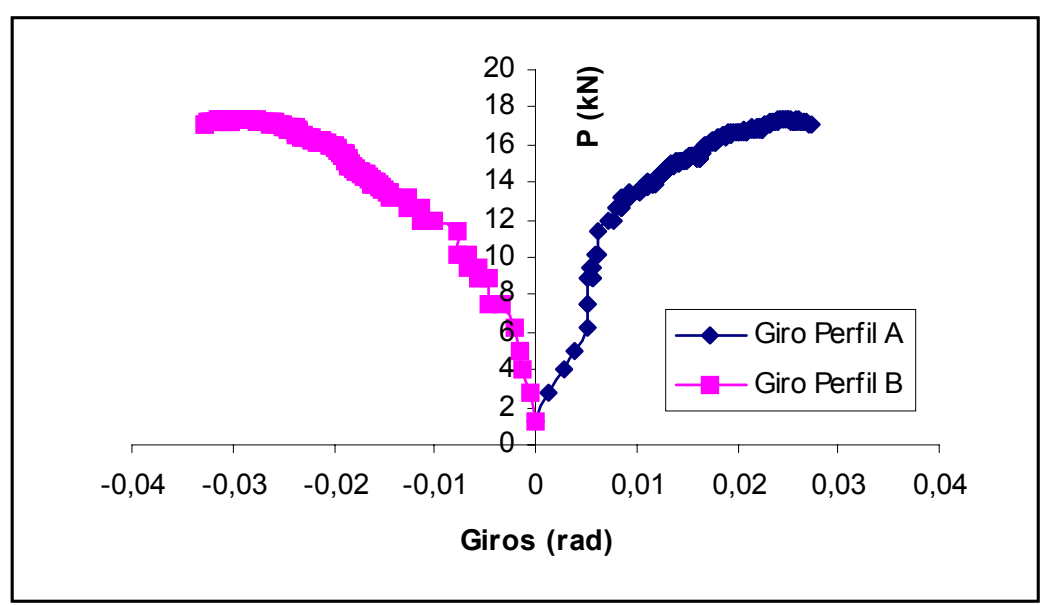

Gráfico Giro dos perfis Ue 300x85x25x2,65 - conjunto 11.

(Perdido) 
Gráfico Giro dos perfis Ue 300×85x25×2,65 - conjunto 12.

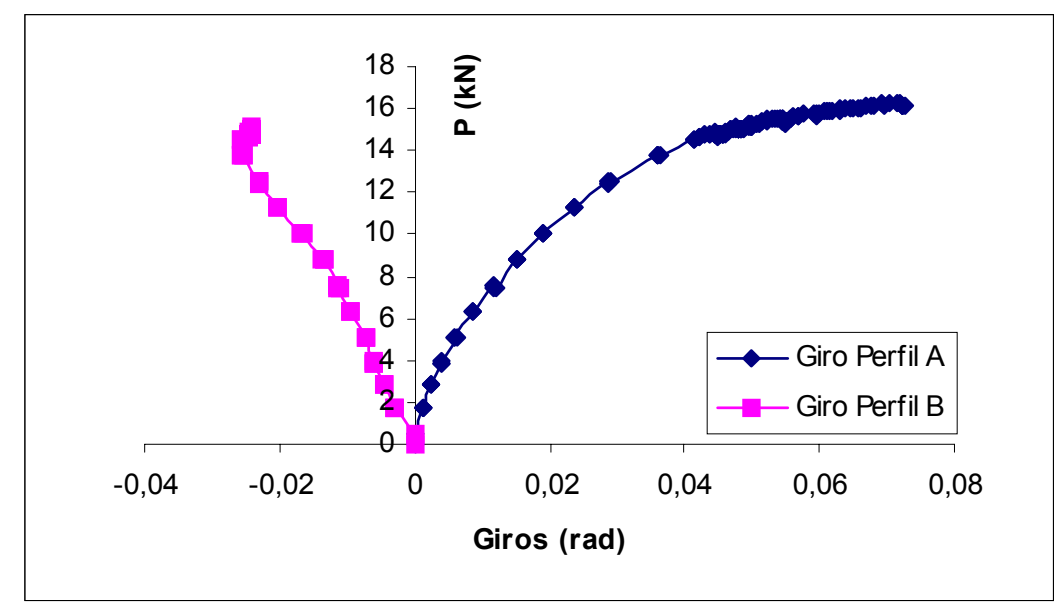

Gráfico Giro dos perfis Ue 350x85x25x2,65 - conjunto 13.

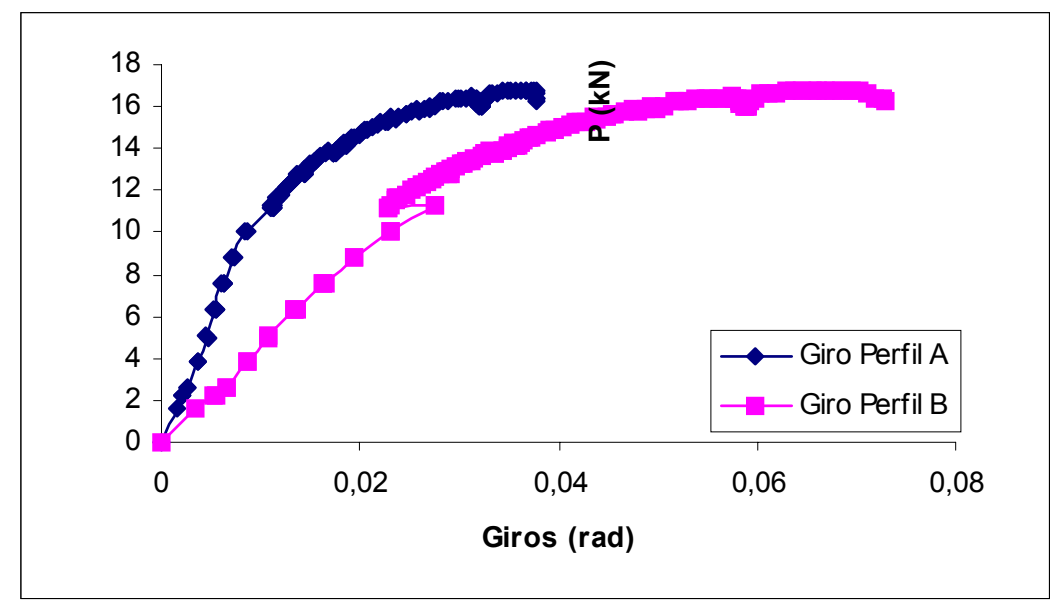

Gráfico Giro dos perfis Ue 350x85×25x2,65 - conjunto 15.

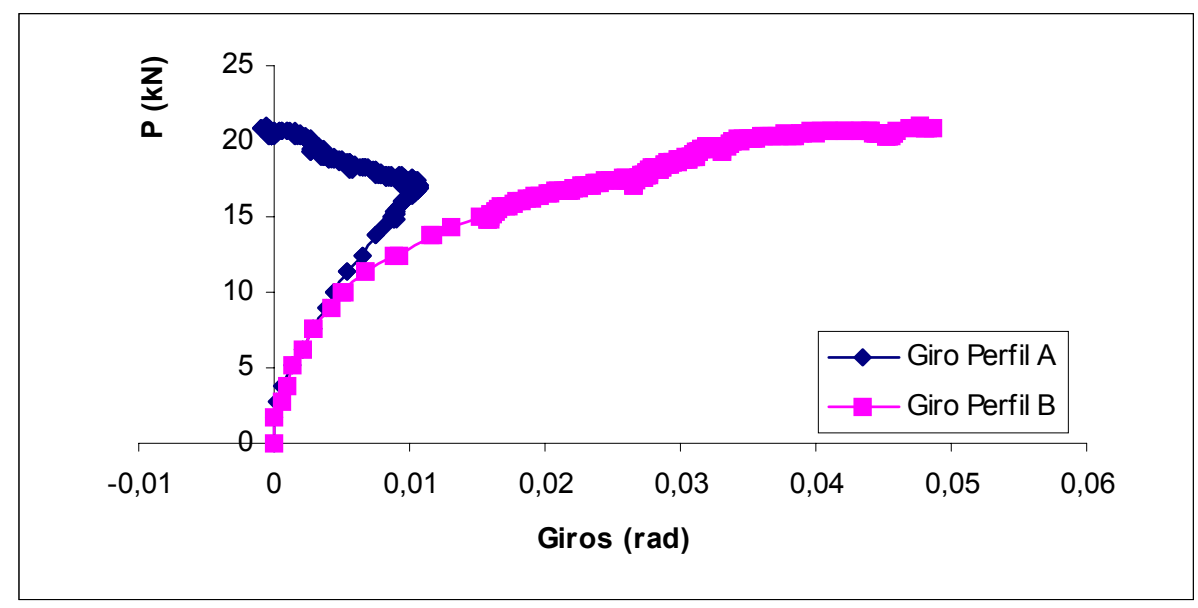

Gráfico Giro dos perfis Ue 350x85x25×3,00 - conjunto 16 . 


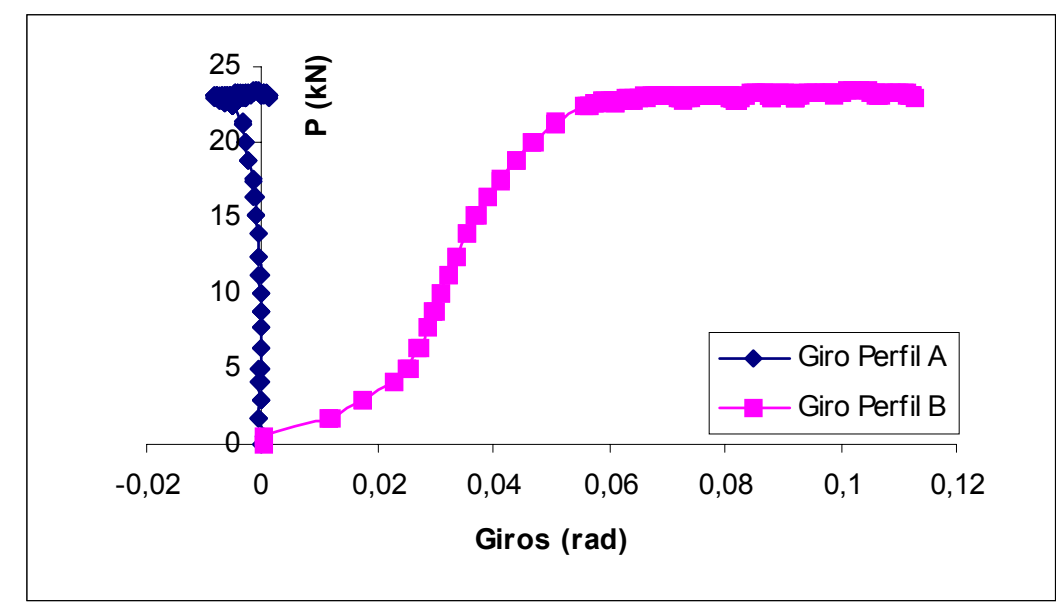

Gráfico Giro dos perfis Ue 350x85x25×3,00 - conjunto 17.

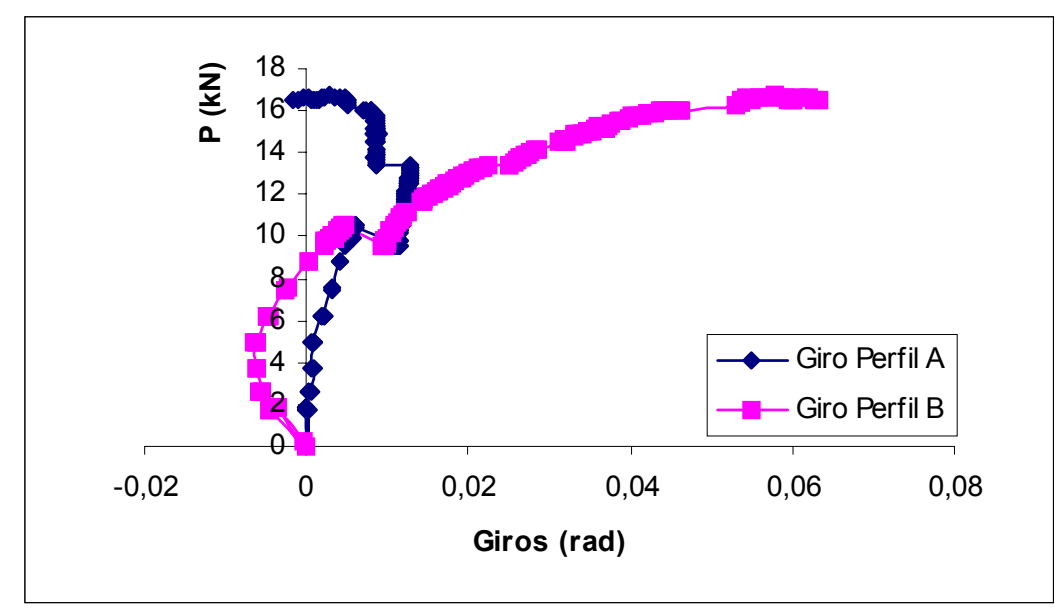

Gráfico Giro dos perfis Ue 350x85x25x2,25 - conjunto 19.

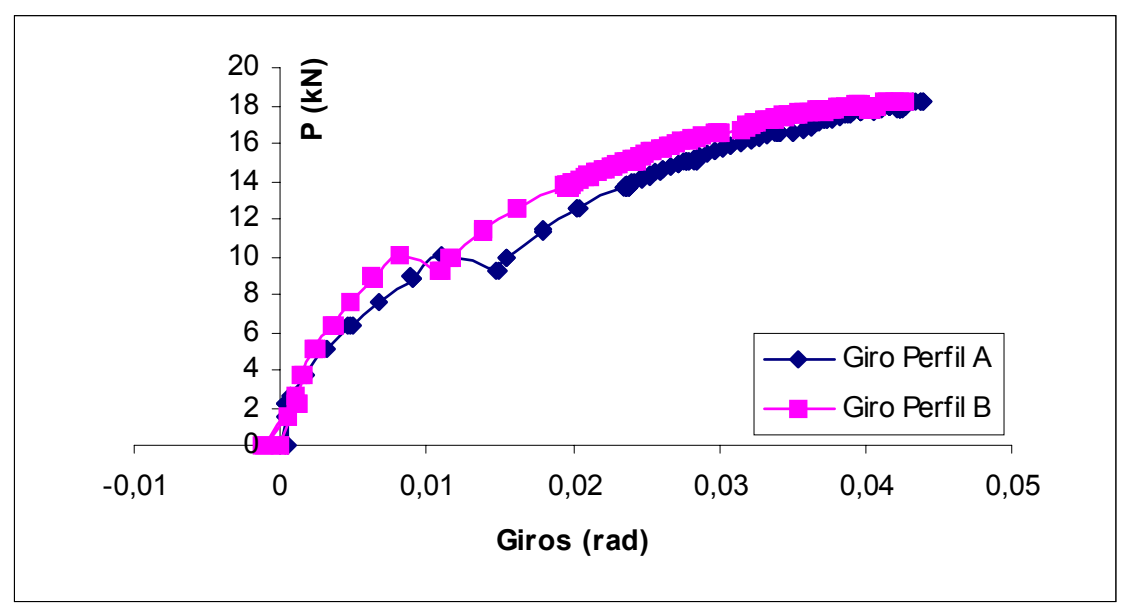

Gráfico Giro dos perfis Ue 350x85x25x2,25 - conjunto 20. 


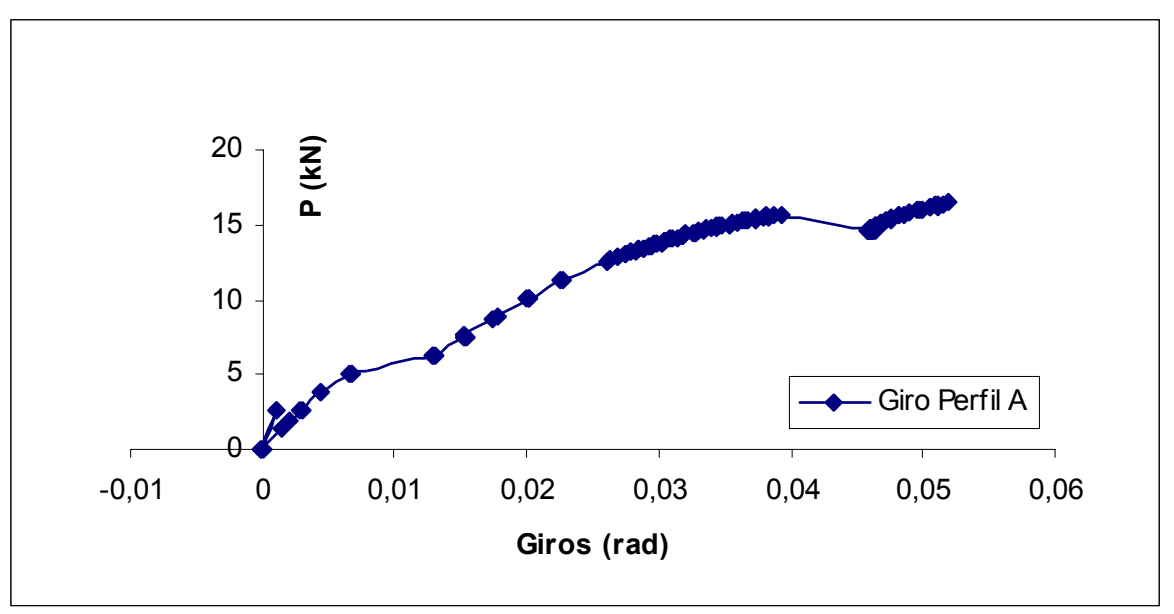

Gráfico Giro dos perfis Ue 350x85x25x2,25 - conjunto 21.

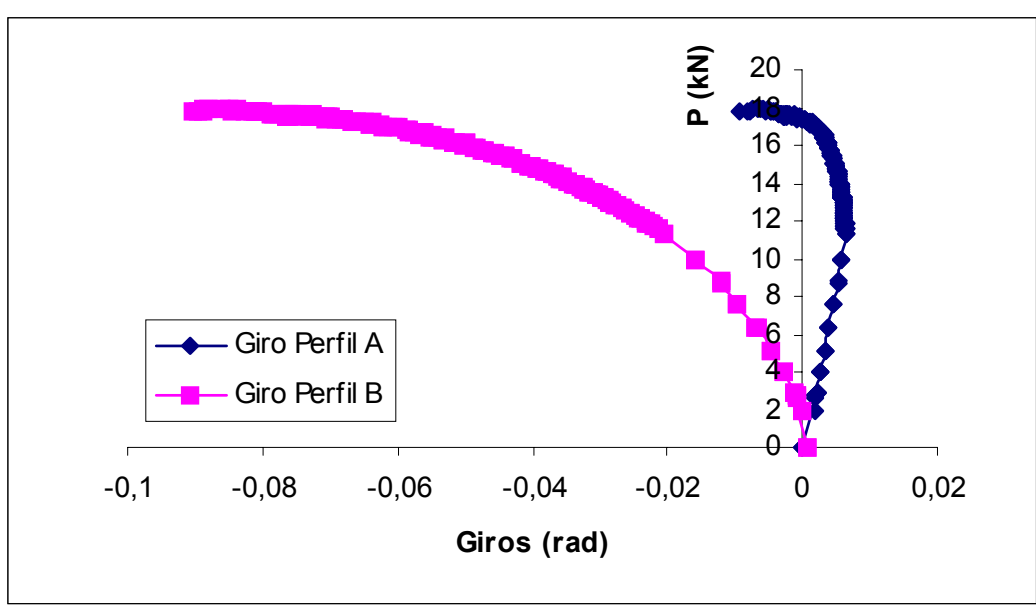

Gráfico Giro dos perfis Ue 400x85x25x2,25 - conjunto 22.

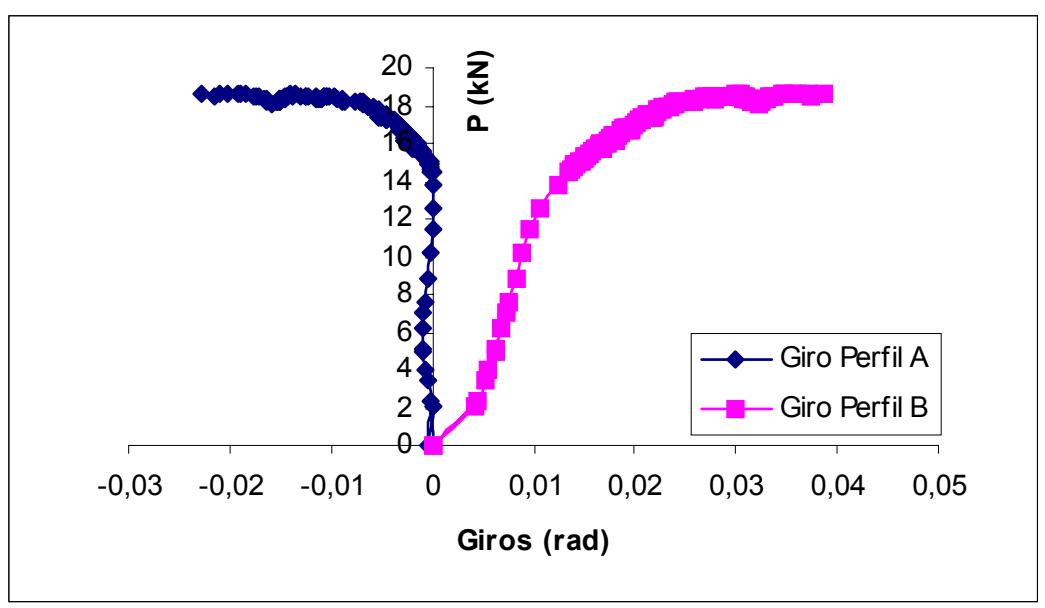

Gráfico Giro dos perfis Ue 400x85x25×2,25 - conjunto 23. 


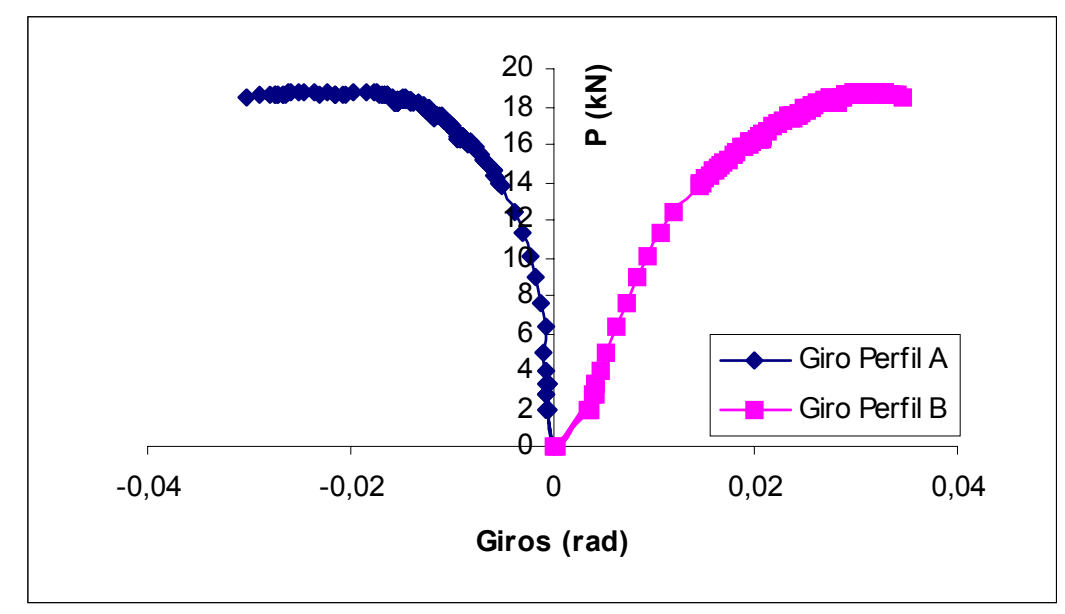

Gráfico Giro dos perfis Ue 400x85x25x2,25 - conjunto 24. 


\section{ANEXO IV - GRÁFICOS FORÇA X DEFORMAÇÃO}

Estes gráficos representam as deformações nos pontos de mensurados dos conjuntos ensaiados, conforme figura $\mathrm{x}$.

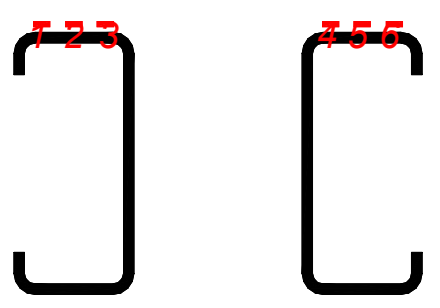

Perfil A Perfil B

Figura 67 Instrumentação da seção transversal no meio do vão. 


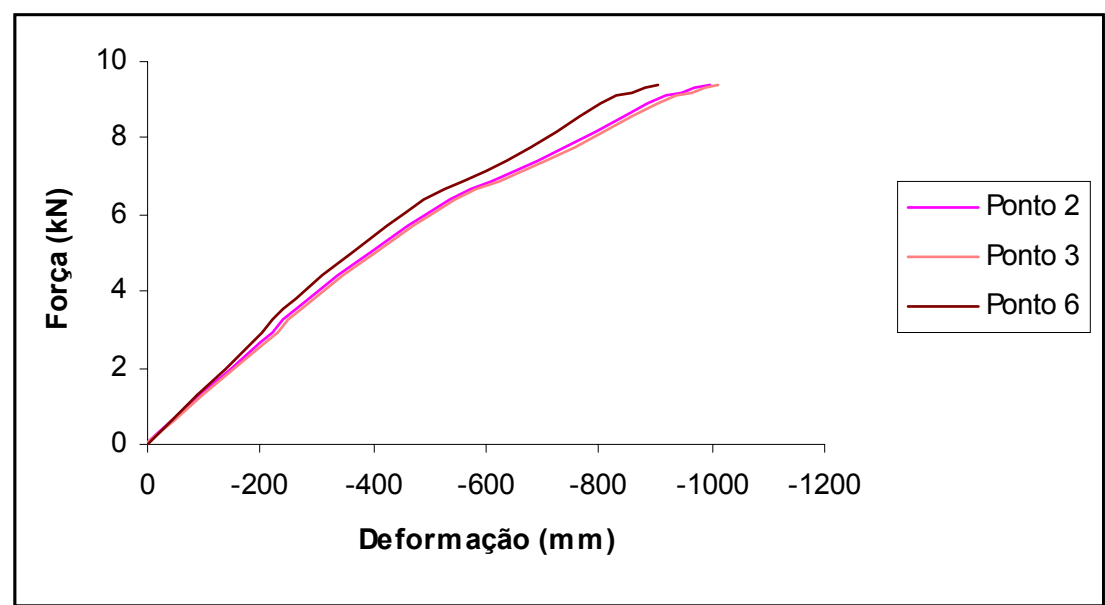

Gráfico Força x Deformação do perfil Ue 250x85x25x2,25 - conjunto 1.

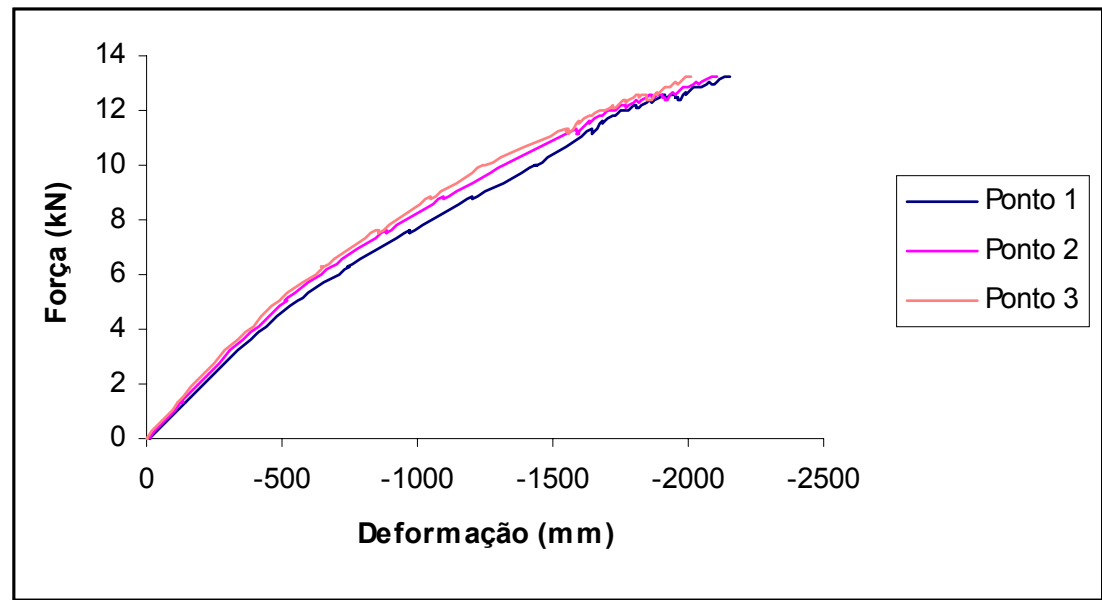

Gráfico Força x Deformação do perfil Ue 250x85x25×2,25 - conjunto 2.

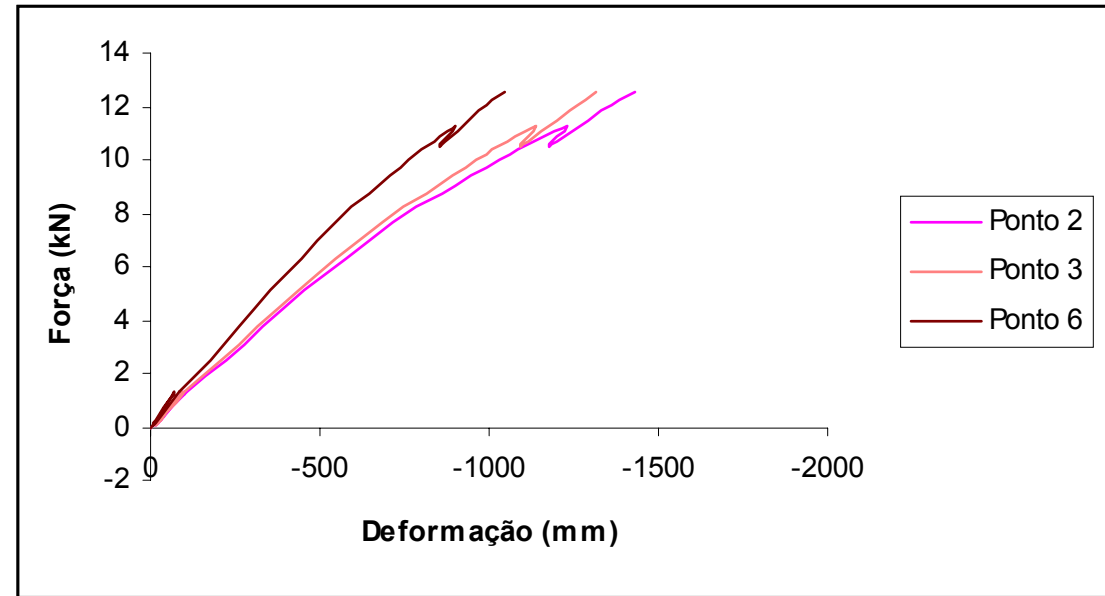

Gráfico Força x Deformação do perfil Ue 250x85x25x2,25 - conjunto 3. 


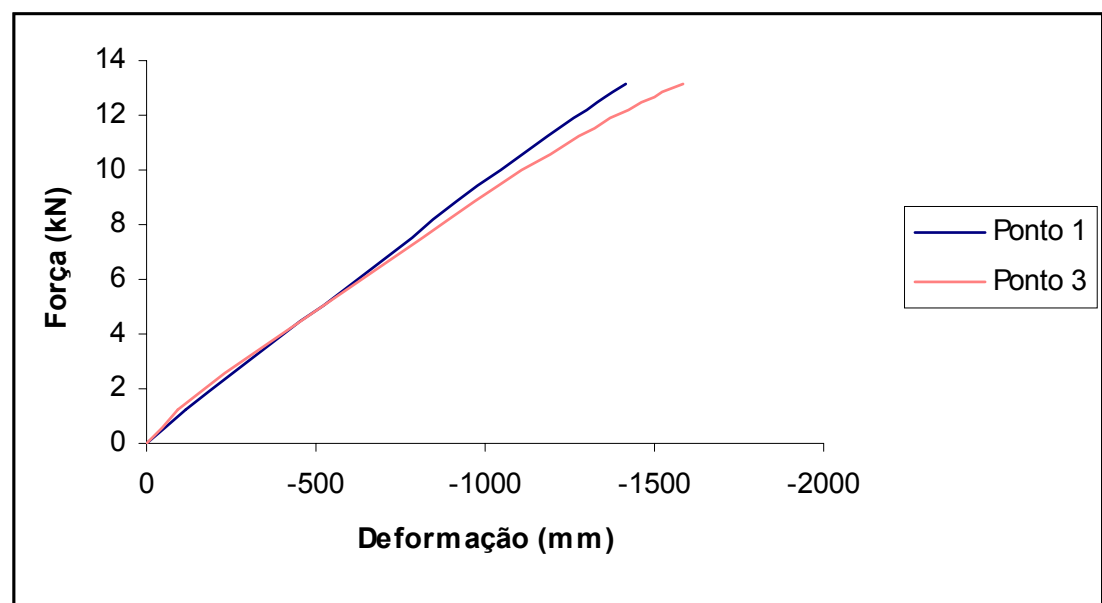

Gráfico Força x Deformação do perfil Ue 250x85x25x2,65 - conjunto 5.

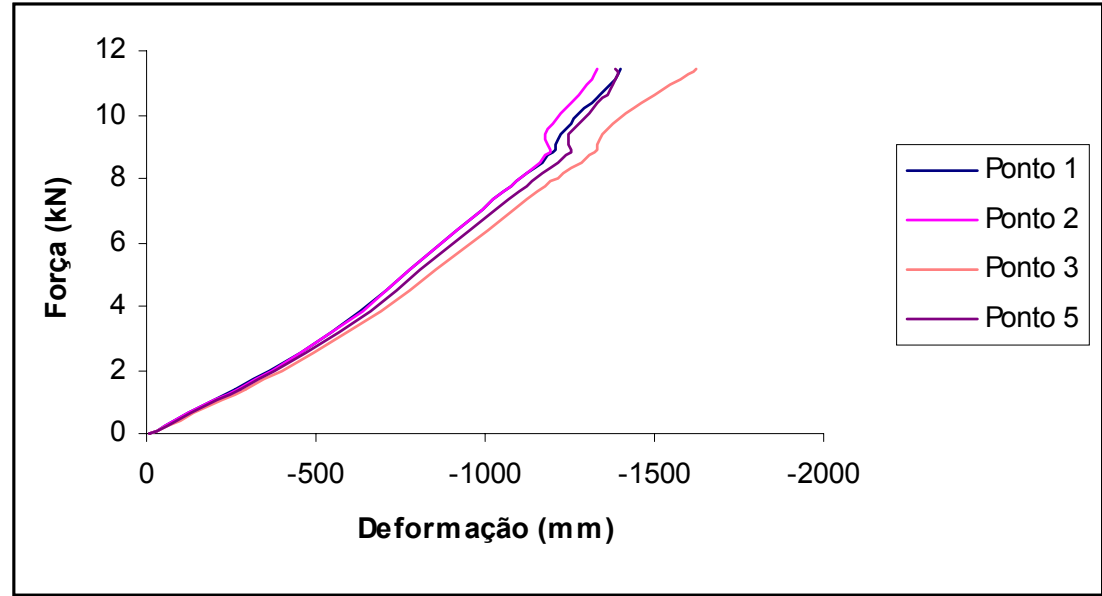

Gráfico Força x Deformação do perfil Ue 250x85×25×2,65 - conjunto 6.

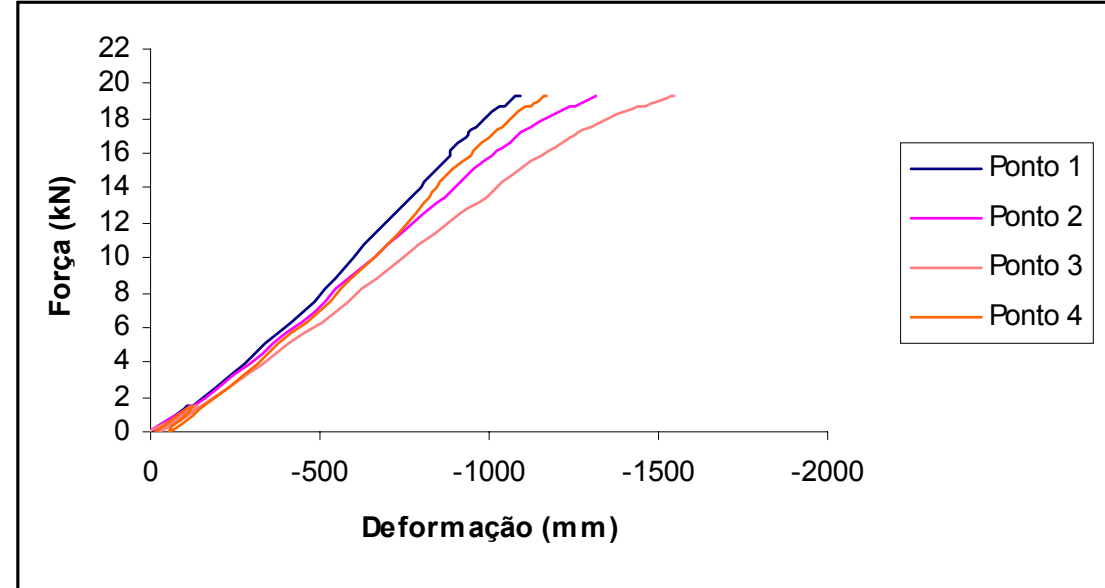

Gráfico Força x Deformação do perfil Ue 300x85x25×2,25 - conjunto 7 . 


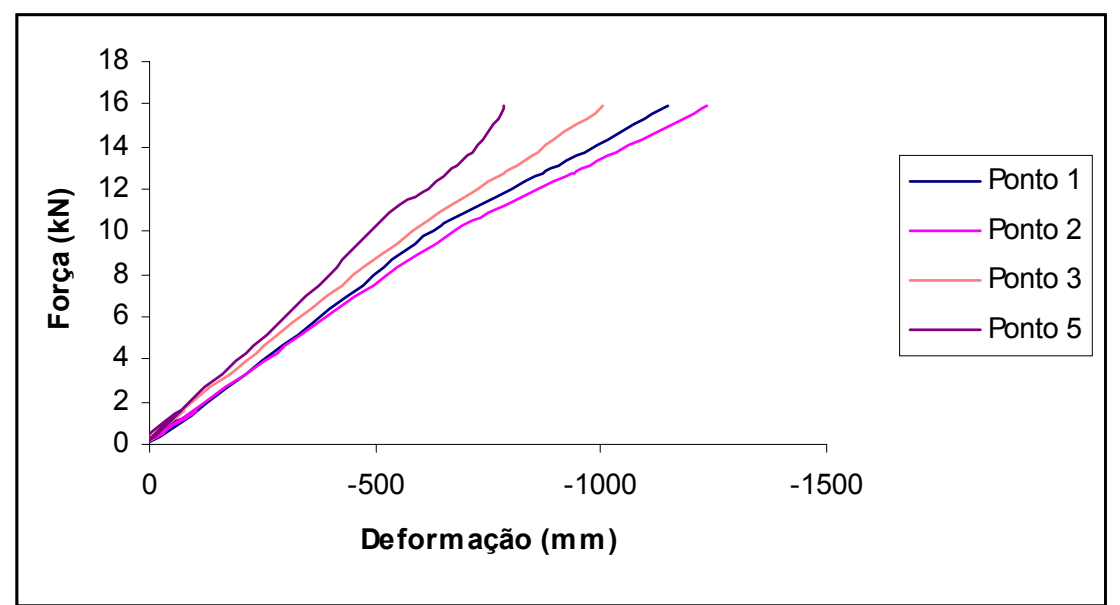

Gráfico Força x Deformação do perfil Ue 300x85x25x2,25 - conjunto 8.

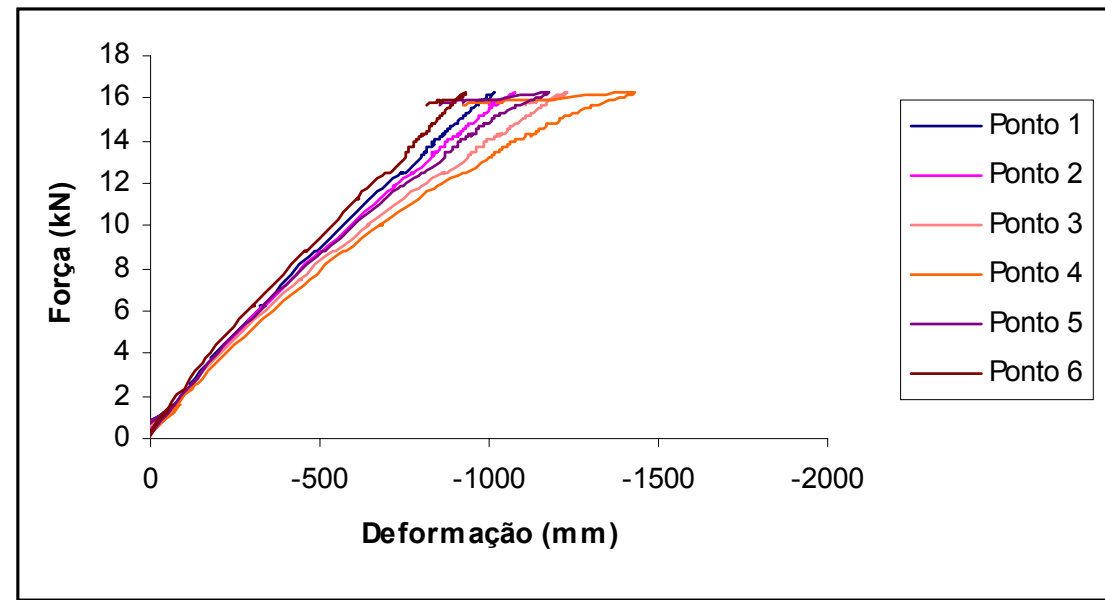

Gráfico Força x Deformação do perfil Ue 300x85x25×2,25 - conjunto 9.

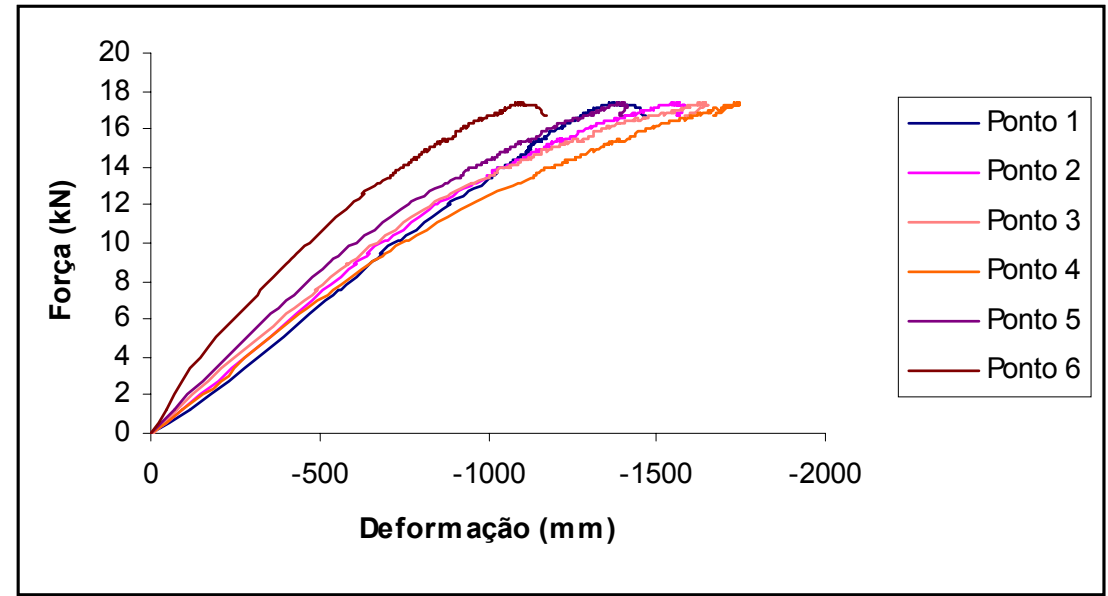

Gráfico Força x Deformação do perfil Ue 300x85x25x2,65 - conjunto 11. 


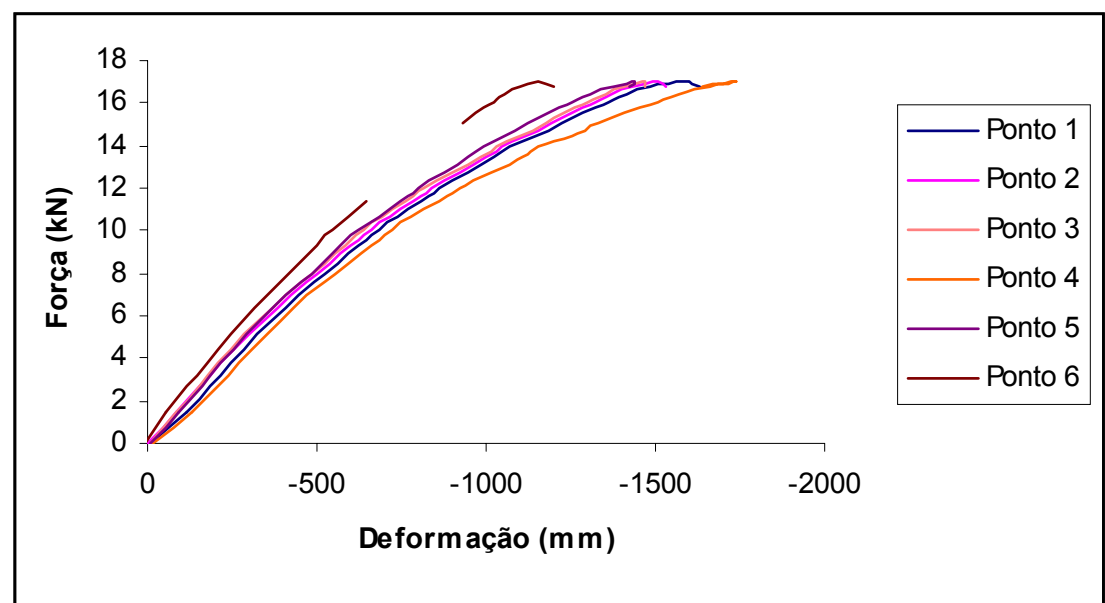

Gráfico Força x Deformação do perfil Ue 300x85x25x2,65 - conjunto 12.

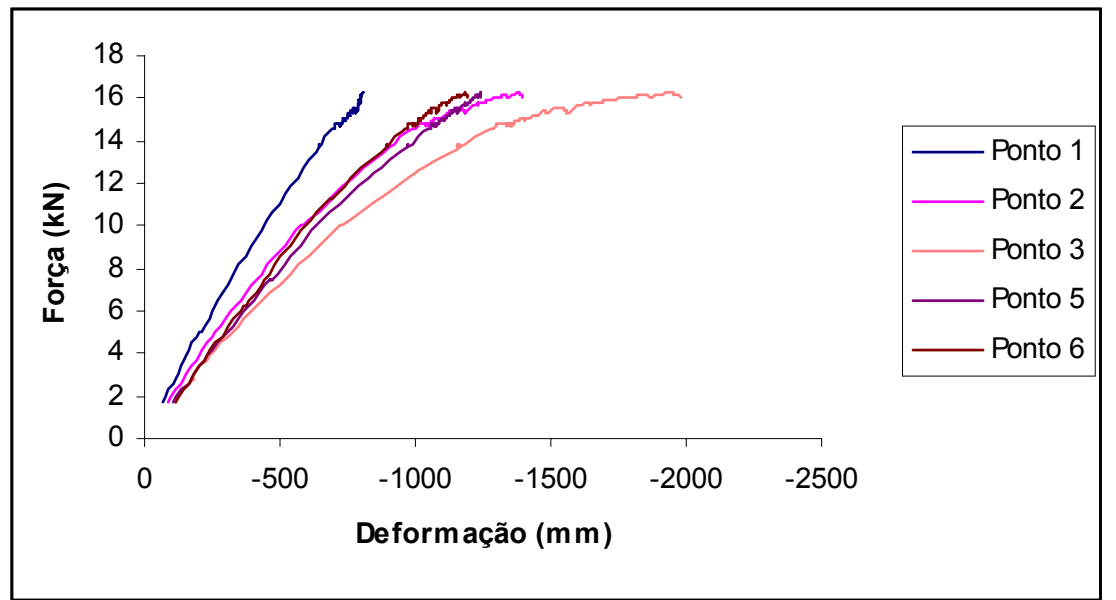

Gráfico Força x Deformação do perfil Ue 350x85x25x2,65 - conjunto 13.

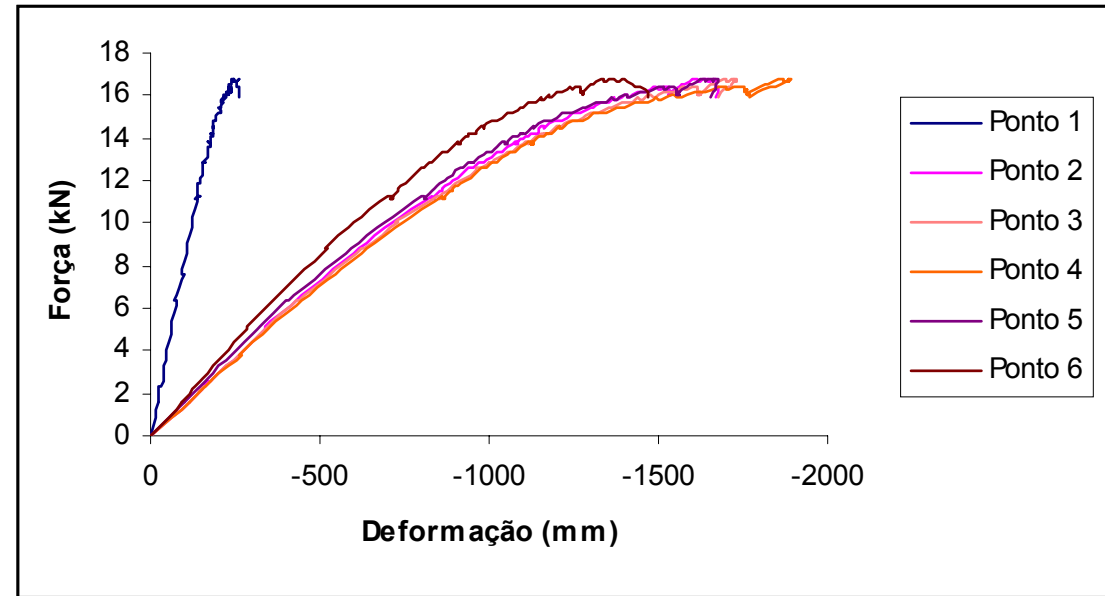

Gráfico Força x Deformação do perfil Ue 350x85x25x2,65 - conjunto 15. 


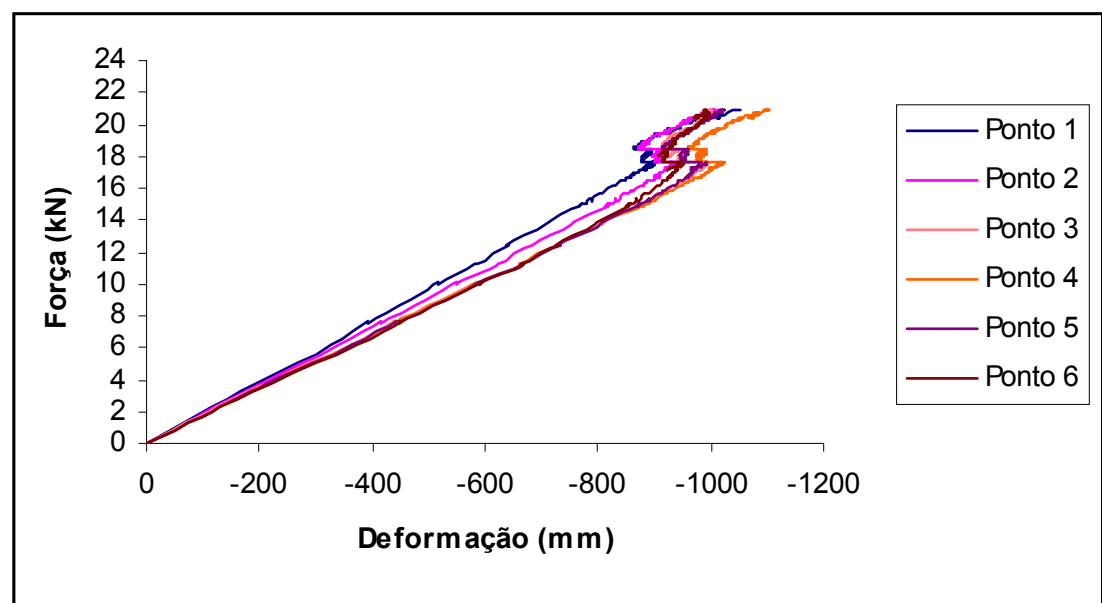

Gráfico Força x Deformação do perfil Ue 350x85x25x3,00 - conjunto 16 .

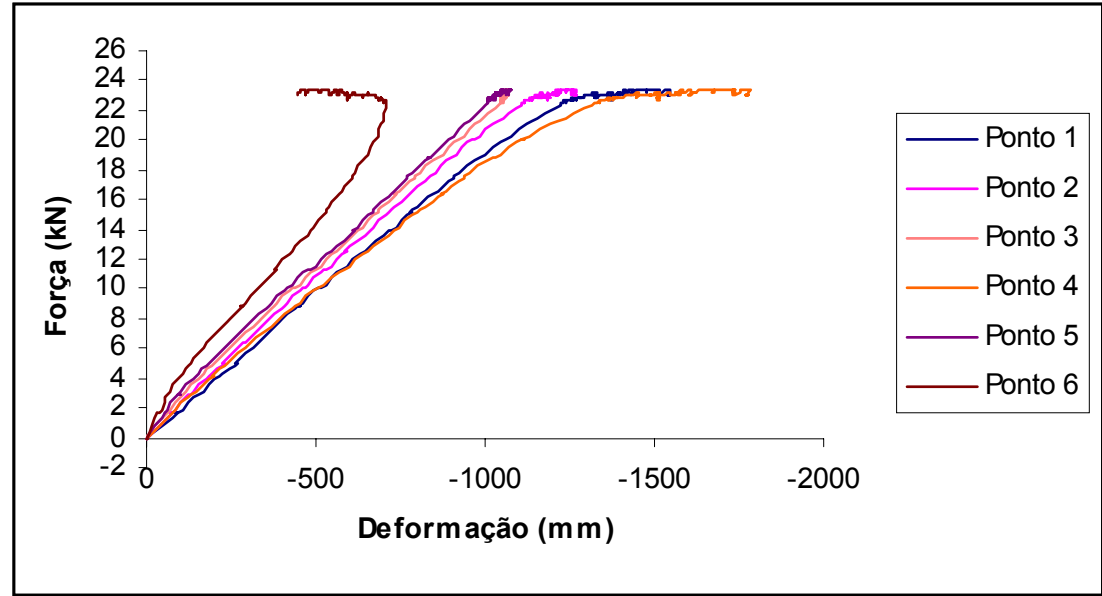

Gráfico Força x Deformação do perfil Ue 350x85x25×3,00 - conjunto 17 .

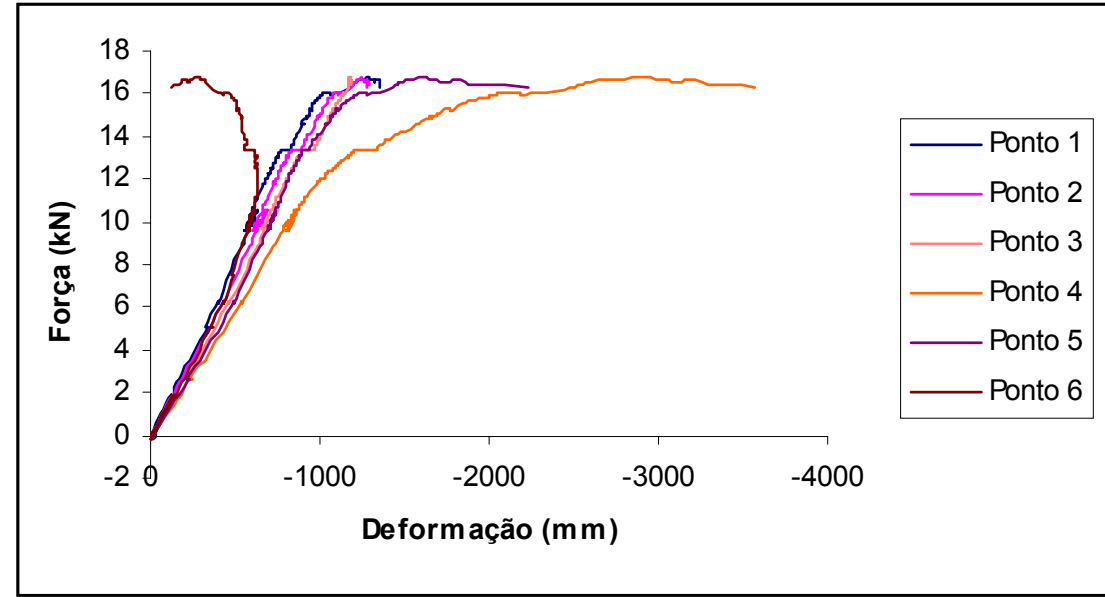

Gráfico Força x Deformação do perfil Ue 350x85x25x2,25 - conjunto 19. 


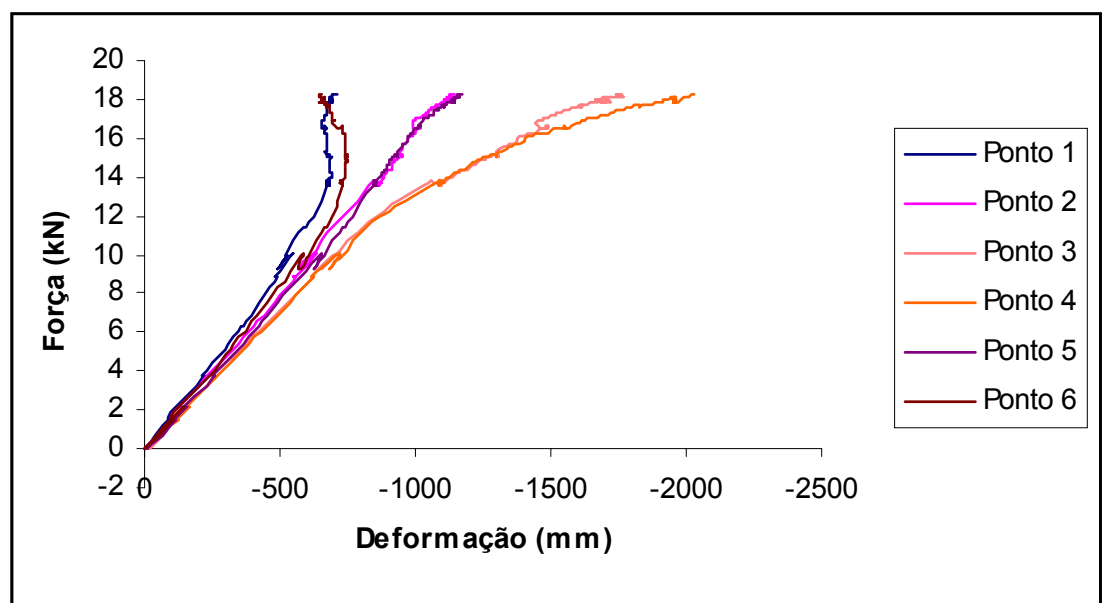

Gráfico Força x Deformação do perfil Ue 350x85x25x2,25 - conjunto 20.

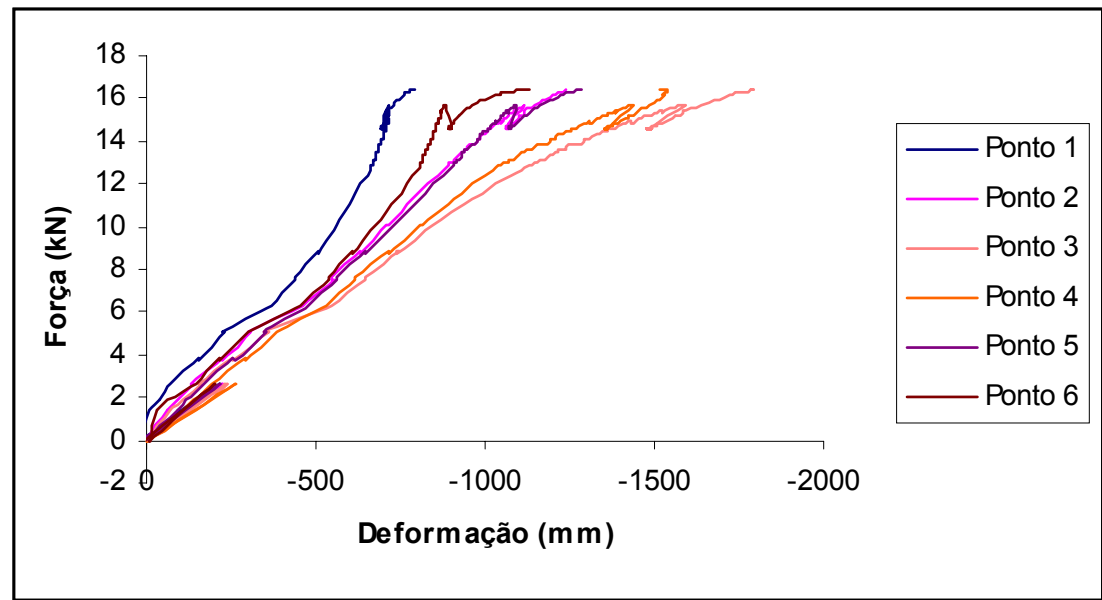

Gráfico Força x Deformação do perfil Ue 350x85x25x2,25 - conjunto 21.

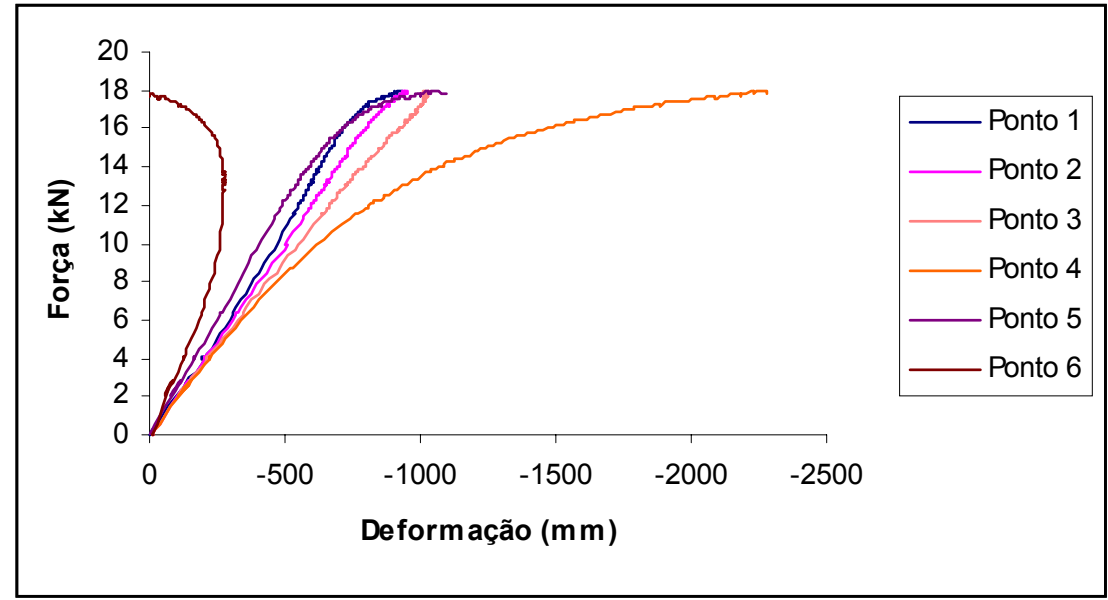

Gráfico Força x Deformação do perfil Ue 400x85x25x2,25 - conjunto 22. 


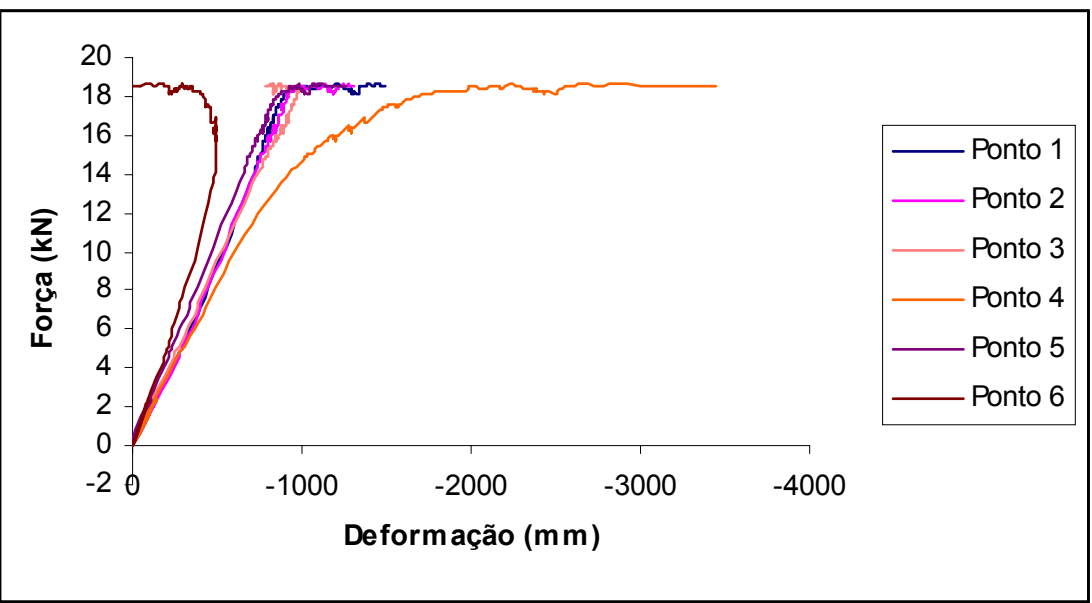

Gráfico Força x Deformação do perfil Ue 400x85x25x2,25 - conjunto 23.

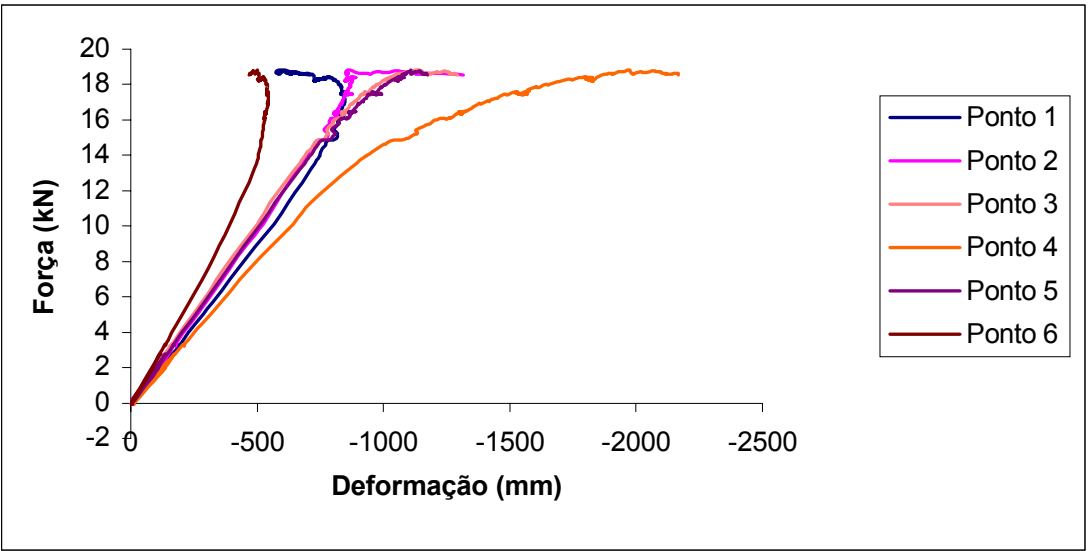

Gráfico Força x Deformação do perfil Ue 400x85x25x2,25 - conjunto 24 . 


\section{ANEXO V = ANÁLASE DE INSTABILIDADE VIA MÉTODO DAS FALXAS FINITAS}

Estas séries representam as análises de instabilidade via faixas finitas do vão central dos conjuntos ensaiados. A análise realizada consiste apenas em instrumento referencial por causa das interferências das tensões de empenamento modificadas em razão dos travamentos centrais dos conjuntos. 

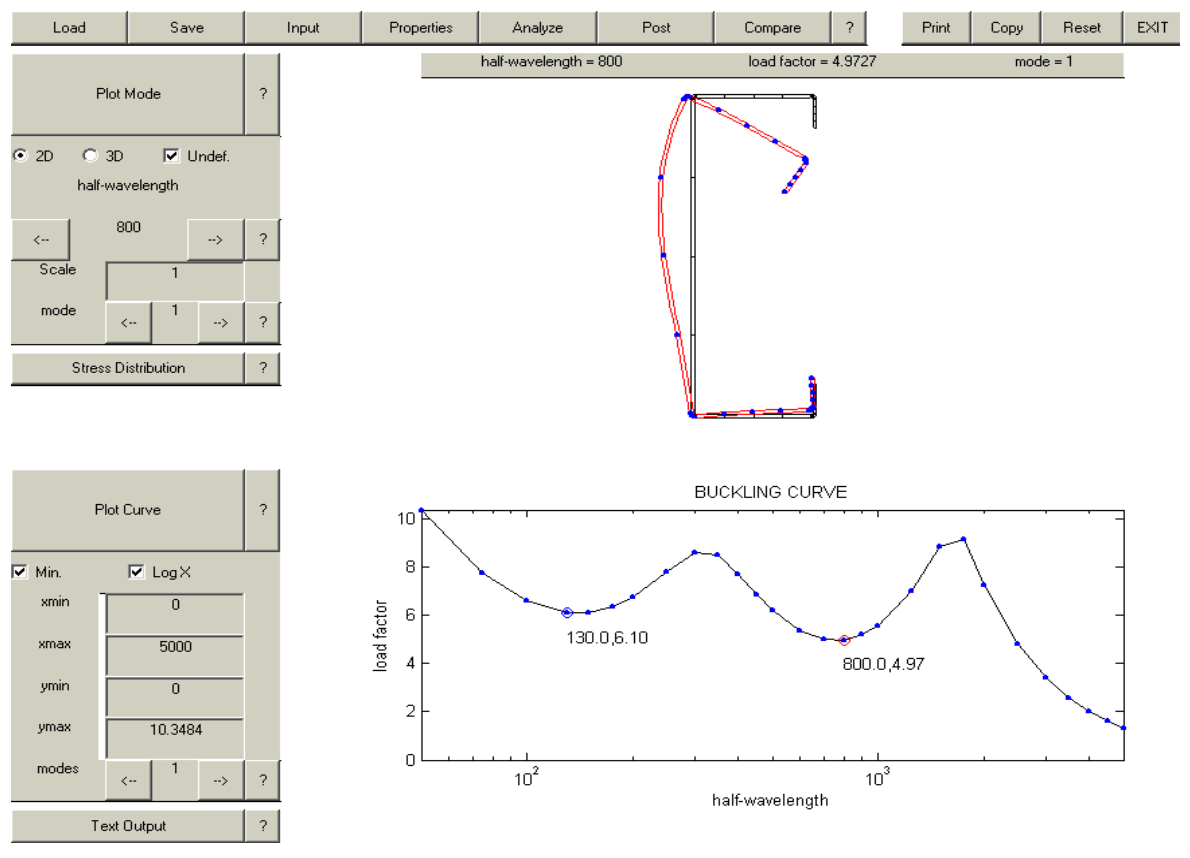

Figura 68 Análise via MFF do perfil Ue $250 \times 85 \times 25 \times 2,65$
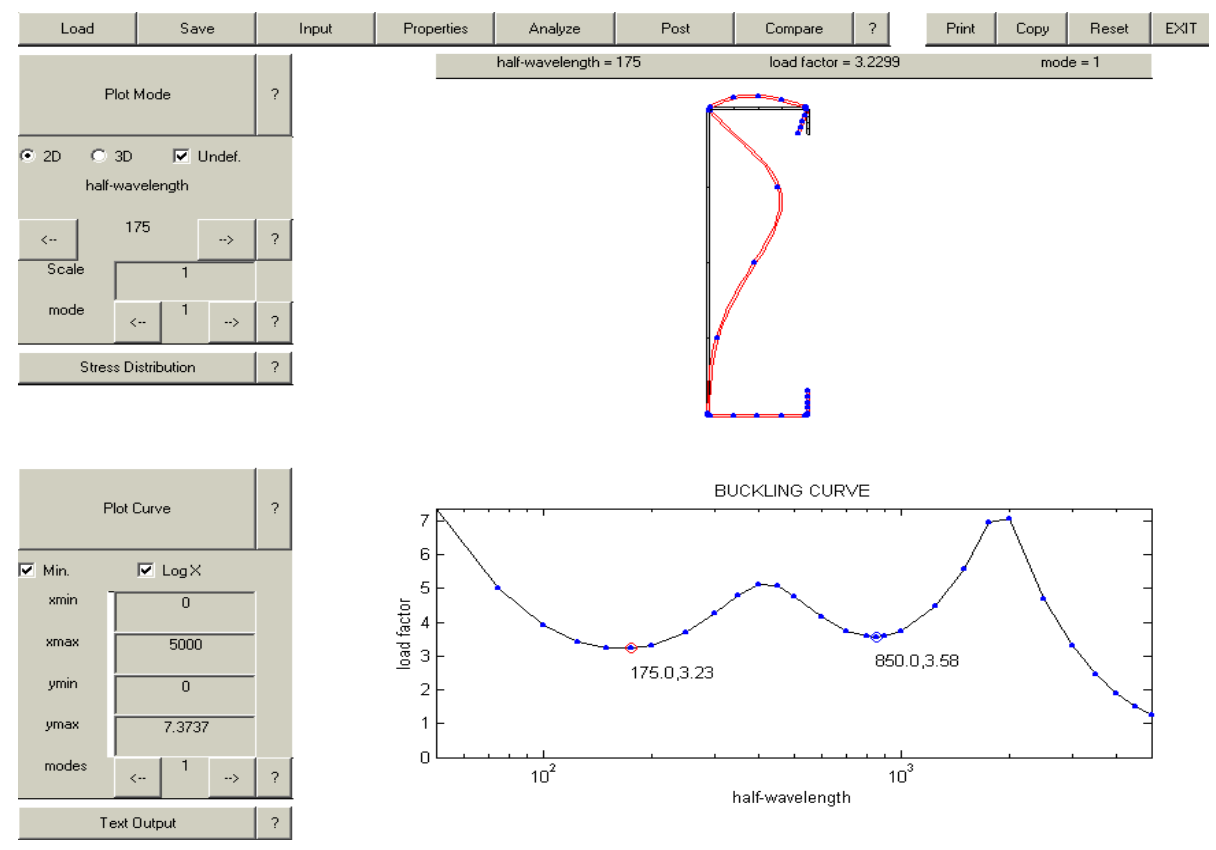

Figura 69 Análise via MFF do perfil Ue $300 \times 85 \times 25 \times 2,25$ 

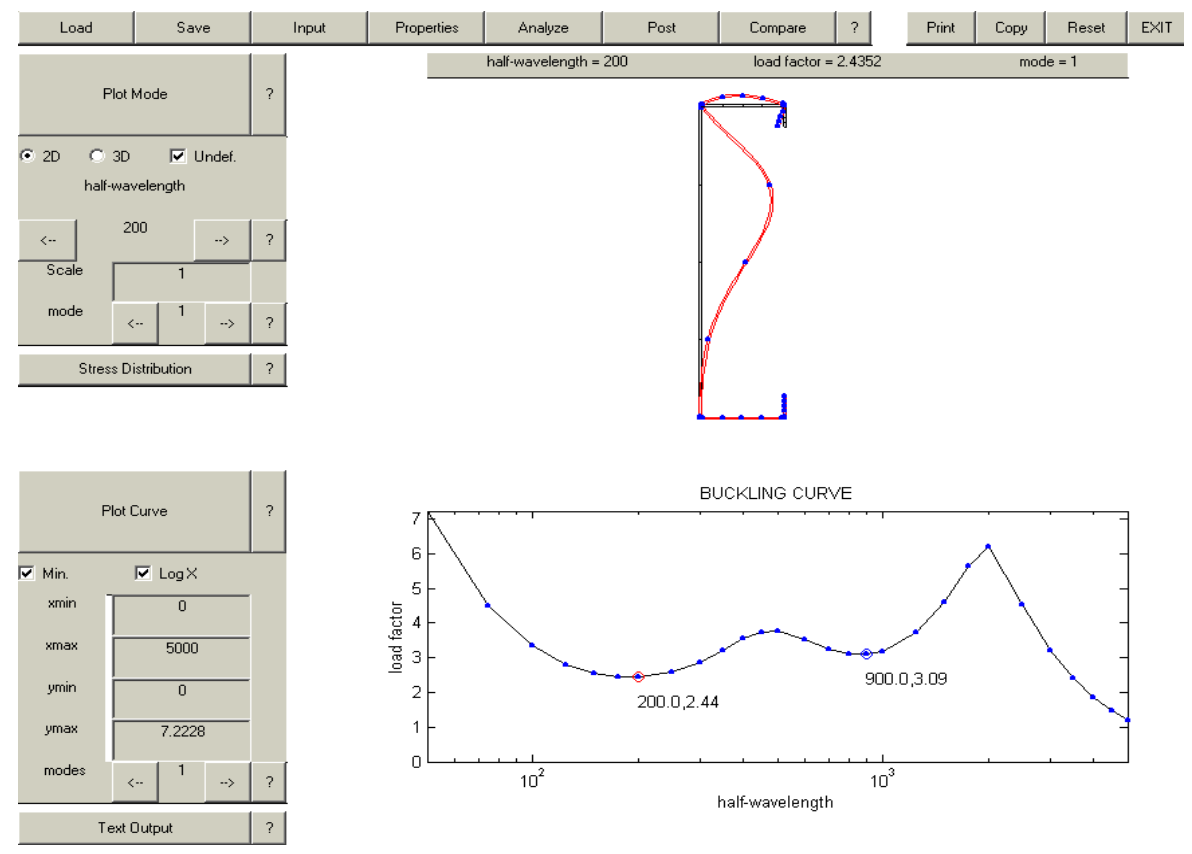

Figura 70 Análise via MFF do perfil Ue 300×85x25×2,65
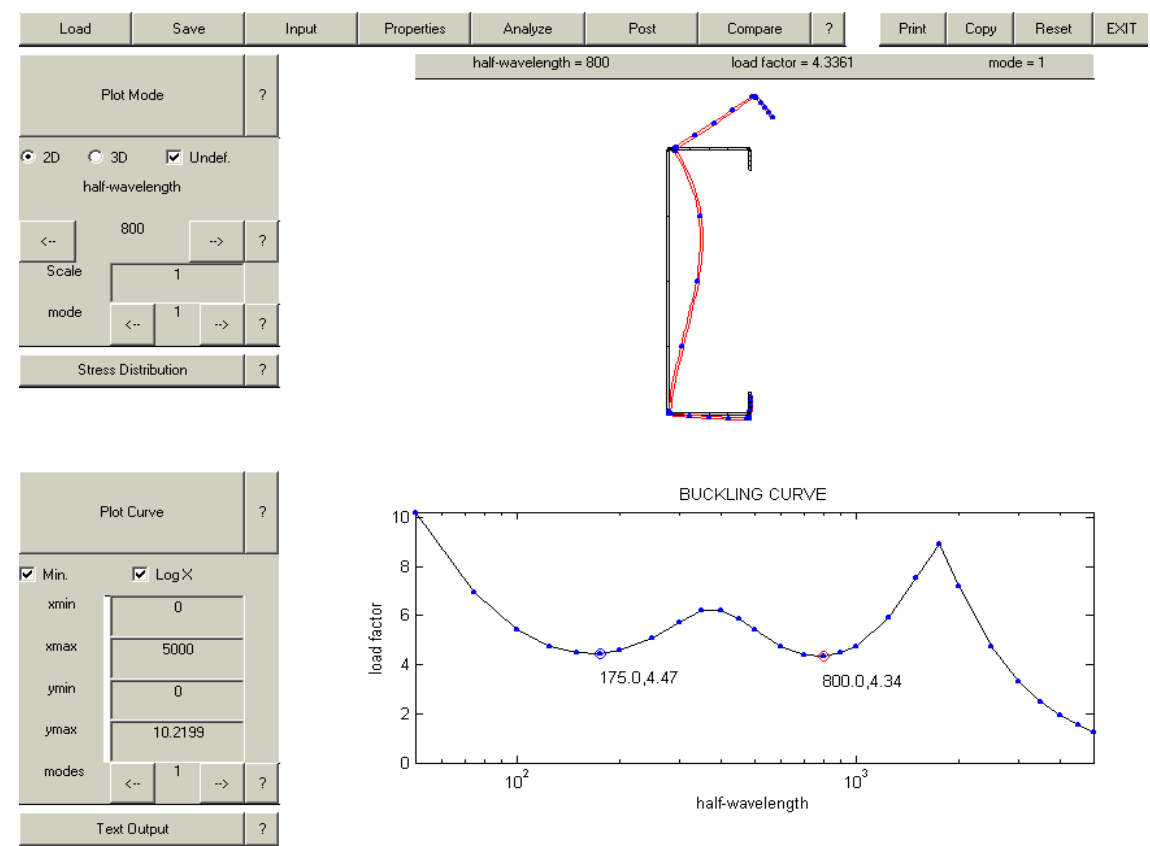

Figura 71 Análise via MFF do perfil Ue $350 \times 85 \times 25 \times 2,25$ 

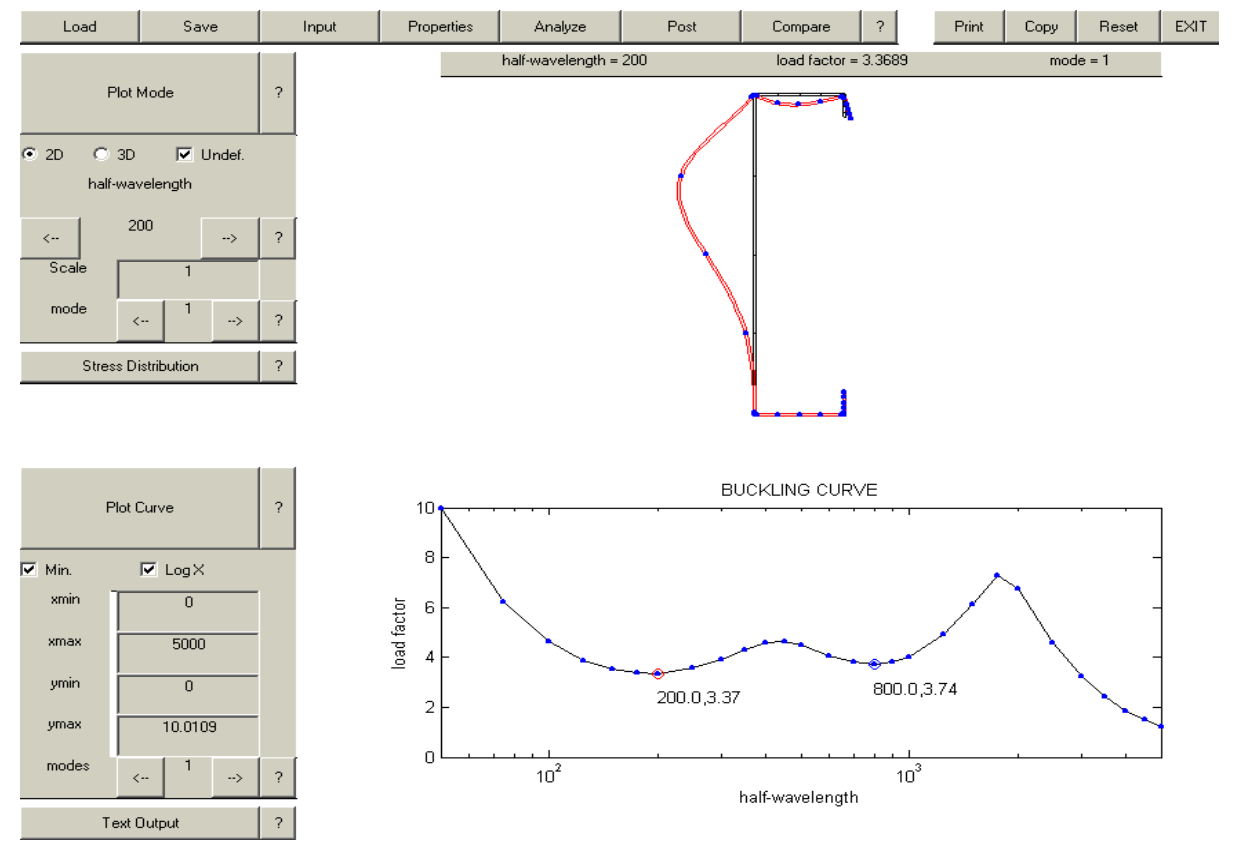

Figura 72 Análise via MFF do perfil Ue $350 \times 85 \times 25 \times 2,65$
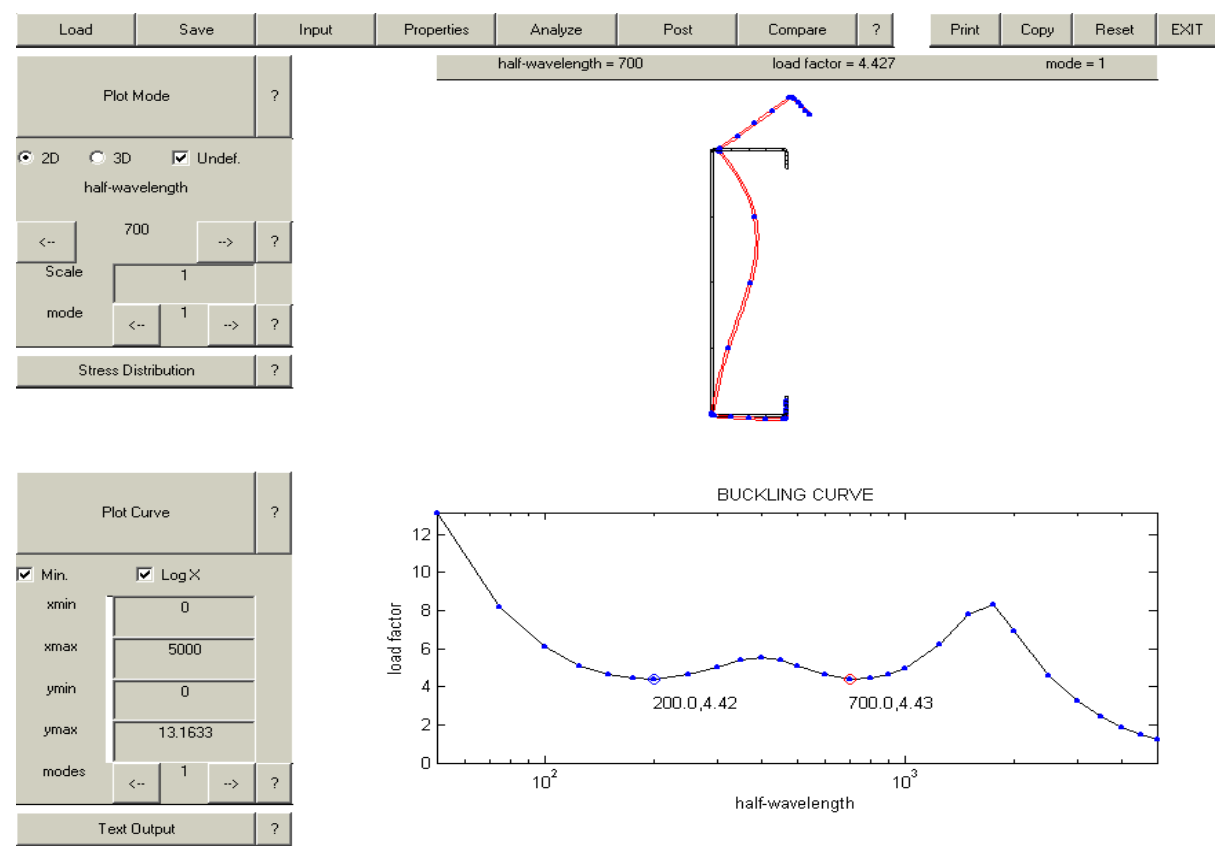

Figura 73 Análise via MFF do perfil Ue 350x85×25×3,00 


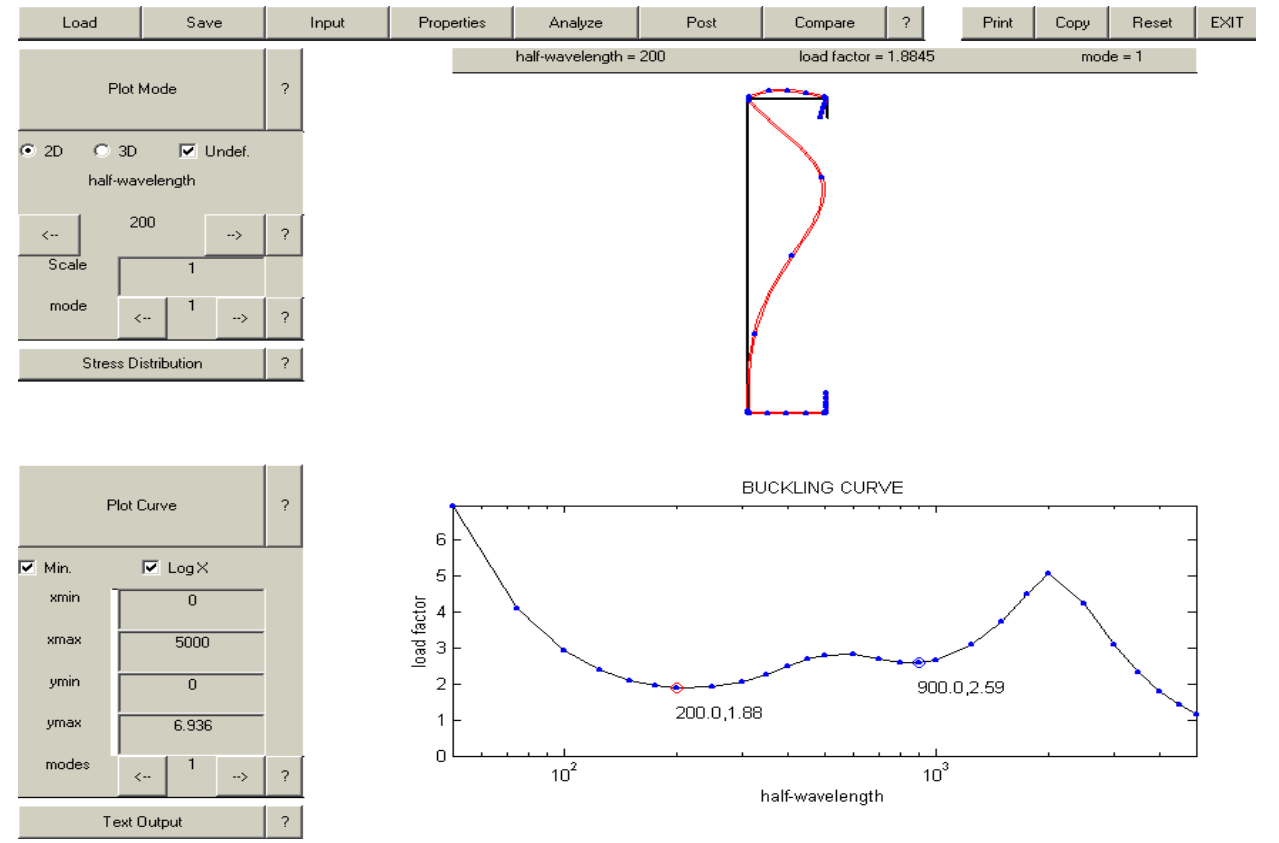

Figura 74 Análise via MFF do perfil Ue 400×85×25×2,25 